UNIVERSIDADE DE SÃO PAULO

FACULDADE DE ECONOMIA, ADMINISTRAÇÃO E CONTABILIDADE DEPARTAMENTO DE ADMINISTRAÇÃO PROGRAMA DE PÓS-GRADUAÇÃO EM ADMINISTRAÇÃO

\begin{abstract}
ESTUDO DOS FATORES INFLUENCIADORES DA INTENÇÃO DE USO DA INFORMAÇÃO DOS SISTEMAS DE BUSINESS INTELLIGENCE EM EMPRESAS BRASILEIRAS
\end{abstract}

Claudinei de Paula Santos

Orientador: Prof. Dr. Cesar Alexandre de Souza

SÃO PAULO 
Prof. Dr. Marco Antonio Zago Reitor da Universidade de São Paulo

Prof. Dr. Reinaldo Guerreiro

Diretor da Faculdade de Economia, Administração e Contabilidade

Prof. Dr. Roberto Sbragia

Chefe do Departamento de Administração

Prof. Dr. Lindolfo Galvão de Albuquerque Coordenador do Programa de Pós-Graduação em Administração 


\section{ESTUDO DOS FATORES INFLUENCIADORES DA INTENÇÃO DE USO DA INFORMAÇÃO DOS SISTEMAS DE BUSINESS INTELLIGENCE EM EMPRESAS BRASILEIRAS}

Tese apresentada ao Departamento de Administração da Faculdade de Economia, Administração e Contabilidade da Universidade de São Paulo como requisito para a obtenção do título de Doutor em Ciências.

Orientador: Prof. Dr. Cesar Alexandre de Souza

\section{Versão Corrigida}

(versão original disponível na Faculdade de Economia, Administração e Contabilidade)

SÃO PAULO

2014 
FICHA CATALOGRÁFICA

Elaborada pela Seção de Processamento Técnico do SBD/FEA/USP

Santos, Claudinei de Paula

Estudo dos fatores influenciadores da intenção de uso da informação dos sistemas de Business Intelligence em empresas brasileiras /

Claudinei de Paula Santos. -- São Paulo, 2014. $196 \mathrm{p}$.

Tese (Doutorado) - Universidade de São Paulo, 2014.

Orientador: Cesar Alexandre de Souza.

1. Sistemas de informação 2. Business intelligence 3. Gestão do conhecimento 4. Qualidade da informação 5. Benefícios esperados 6. Benefícios percebidos I. Universidade de São Paulo. Faculdade de Economia, Administração e Contabilidade. II. Título.

$\mathrm{CDD}-658.4038011$ 


\section{AGRADECIMENTOS}

"Você não pode ensinar nada a um homem; você pode apenas ajudá-lo a encontrar a resposta dentro dele mesmo." (Galileu Galilei)

Meu prezado senhor,

Direi apenas algumas poucas palavras.

A vida fez de mim um homem bem familiarizado com as decepções.

Aos 23 anos, tentei um cargo na política e perdi. Aos 24, abri uma loja que não deu certo. Aos 32, tentei um negócio de advocacia com amigos, mas logo rompemos a sociedade. Ainda naquele ano, tive um grave colapso nervoso e passei um bom tempo no hospital. Com 45 anos, disputei uma cadeira no Senado e não ganhei. Aos 47, concorri à nomeação pelo Partido Republicano para a Eleição Geral e fui derrotado. Aos 49, tentei o Senado e fracassei novamente. Mas, aos 51 anos, finalmente, fui eleito presidente dos Estados Unidos da América.

Por isso, não venha me falar de dificuldades, tropeços ou fracassos. Não me interessa saber se você falhou. O que me interessa é se você soube aceitar o tropeço. Todos os infortúnios que vivi me tornaram um homem mais forte, me ensinaram lições importantes. Aprendi a tolerar os medíocres; afinal, Deus deve amá-los, porque fez vários deles. Aprendi que os princípios mais importantes podem e devem ser inflexíveis. Aprendi que, quando se descobre que uma opinião está errada, é preciso descartá-la. Aprendi que a melhor parte da vida de uma pessoa está nas suas amizades. Aprendi que nunca se deve mudar de cavalo no meio do rio.

Se você está vivendo um momento temporário de fracasso, posso afirmar, com a certeza da minha maturidade, ou dolorida experiência, que você jamais falhará se estiver determinado a não fazê-lo. Por mais que você encontre dificuldades pelo caminho, não 
desista. Pois saiba que o campo da derrota não está povoado de fracassos, mas de homens que tombaram antes de vencer.

Sinceramente,

(ABRAHAM LINCOLN

$16^{\circ}$ presidente norte-americano)

A Deus, pela vida, beleza e perfeição de sua criação; por todo cuidado que tem demonstrado ao longo de minha existência, pelas pessoas que me apresentou e conviveram comigo, algumas por breve instantes, outras por tempos mais longos, todas de grande importância no ensinamento da vida, e pelas oportunidades e caminhos que me permitiu trilhar, garantindo a cada passo a construção de um sonho.

Aos meus pais, José Francisco de P. Santos (in memorian) e Zilá de Souza P. Santos, que dedicaram suas vidas ao bem estar dos filhos, e que desde cedo me ensinaram a importância da educação e do conhecimento, fornecendo os melhores recursos possíveis e oportunidades necessárias para que me tornasse uma pessoa melhor.

Ao meu orientador, Professor Dr. Cesar Alexandre de Souza, a quem devo a oportunidade concedida e a quem aprendi a ouvir e respeitar pela cordialidade, honestidade, compreensão e exemplo de conduta acadêmica, pela empolgação e seriedade com que trata a orientação e pelo vasto conhecimento que possui na área de Tecnologia da Informação e Comunicação.

Aos meus irmãos, Andréa e José Eduardo que não pouparam esforços em fazer com que as coletas de dados fossem realizadas com rapidez e confiabilidade.

À Claudia Mendes, minha namorada, que me apoiou em todas as etapas desse trabalho, retribuindo com dedicação e carinho durante os momentos mais desafiadores.

Aos docentes da FEA, que fazem dessa instituição referência de ensino, sempre comprometidos com a geração e disseminação de conhecimento de qualidade, com os quais pude contar no 
desenvolvimento desse trabalho. Aos funcionários da PPGA e da biblioteca, muito colaborativos em todos os momentos em que os procurei com alguma necessidade.

Aos amigos da USP, que inconscientemente participam e auxiliam no processo de aprendizagem e criação, através de opiniões, conversas de corredor e interação em sala de aula.

E em especial, ao amigo e parceiro Marcelo Taddeo pelas discussões enriquecedoras, pelo compartilhamento de conhecimento e pela descontração nos momentos de convívio, à Iara Nascimento que revisou o trabalho e me inspirou a melhorá-lo, e ao Maurício Borges que contribuiu com sugestões relevantes na elaboração dos modelos.

"Deus nos fez perfeitos e não escolhe os capacitados, capacita os escolhidos." 


\section{RESUMO}

Neste final de século o processo de globalização dos mercados e seu efeito sobre os padrões de conduta econômica, política, social e organizacional, vêm assumindo importância crescente, compondo um cenário no qual a competitividade emerge como uma questão imperativa. Como característica das empresas modernas, tem-se o aumento de padrão de automação onde as tecnologias tem disponibilizado o acesso a uma grande quantidade de dados. Tecnologias de data warehouse (DW) têm servido como repositores desses dados e o avanço nas aplicações de extração, transformação e carregamento (ETL) têm aumentado a velocidade da coleta. Atualmente, muito se tem discutido a respeito desse produto secundário resultante dos processos empresariais, os dados, que tem sido vistos como uma potencial fonte de informação capaz de possibilitar às instituições a garantia de sobrevivência em sua indústria. Nesse contexto, os sistemas de Business Intelligence (SBI), que têm como função prover o tratamento dos dados e entregar informação acionável que pode ser usada para uma específica tomada de decisão, têm recebido o reconhecimento de sua importância por parte dos executivos para a continuidade de suas empresas. Fato esse reforçado pelos resultados de pesquisas realizadas mundialmente pelo Gartner onde por anos seguidos os SBI têm sido relatados pelos executivos como o sonho de consumo das empresas. Aplicações de business intelligence têm dominado a lista de prioridade de tecnologia de muitos CIOs. Apesar desse cenário bastante favorável para os SBI, o Gartner Group aponta um elevado índice na subutilização desses sistemas, o que nos leva a questionar porque um sistema importante e desejado pelas empresas não consegue atender as expectativas dos usuários. Assim surgiu a proposta de estudar nesse trabalho a influência das dimensões fatores críticos de sucesso (FCS) e benefícios esperados (BE) sobre a dimensão intenção de uso (USO) da informação disponibilizada pelos SBI, verificando o efeito das variáveis de cada dimensão sobre o USO. Para isso foi estabelecido um modelo conceitual relacionando as dimensões mencionadas utilizando-se como referência outros trabalhos acadêmicos, suas variáveis e resultados de pesquisa. Foi realizada uma pesquisa quantitativa com a aplicação da técnica estatística Partial Least Square (PLS) com os dados obtidos de usuários de SBI em diferentes áreas da empresa de diferentes setores. Com o uso da técnica PLS, foi possível obter os indicadores para as variáveis das dimensões e estabelecer o modelo estrutural baseado em confiança. 
Palavras-chave: Inteligência de negócios, Business Intelligence, sistemas de informação, benefícios esperados, qualidade de dados, processo decisório, gestão do conhecimento, fatores críticos de sucesso. 


\begin{abstract}
As this century ends, the market globalization process and its effect on patterns of economic, political, social and organizational behaviors become increasingly important, composing a scenario in which competitiveness emerges as an imperative issue. As a trait of modern enterprises, there is an increase in automation standards where technologies provide access to a large amount of data. Technologies of data warehouse (DW) have been serving as repositories of such data and advances in extraction, transformation and loading (ETL) applications have been increasing the speed of data collection. More recently, much has been discussed about this secondary product resulting from business processing: the data that has been seen as a potential source of information able to allow institutions guarantee survival in their industry. In this context, Business Intelligence Systems (BIS), that have as function provide data processing and deliver actionable information, i.e., information that could be used for a specific decision making, have received recognition from executives of its importance to the continuity of their business since for years, has been reported in research conducted worldwide by Gartner as the technology desire of these professionals. Business Intelligence applications have been considered the technology priority investment of many CIOs. Despite of this favorable scenario for Business Intelligence Systems, the Gartner Group indicates a high level of underutilization of these systems which leads us to question why an important and desired business system cannot achieve user's expectations. Thus, this work proposes to study the influence of the dimensions critical success factors (CSF) and expected benefits (BE) on the dimension use (USO) to the information provided by BIS, checking the effect of each dimension on the USO emerged. To do this a conceptual model was established by relating these dimensions using as reference other academic papers, their variables and search results. It was realized a quantitative research with an application of statistical technique Partial Least Square (PLS) with data obtained from users of BIS in different areas of the company from different sectors. Using the PLS technique, it was possible to obtain indicators for the variables and dimensions to establish the structural model based on trust.
\end{abstract}

Keywords: Business Intelligence, information systems, expected benefits, perceived benefits, data quality, decision making, knowledge management, critical success factors. 


\section{SUMÁRIO}

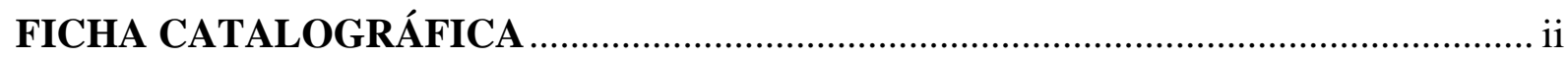

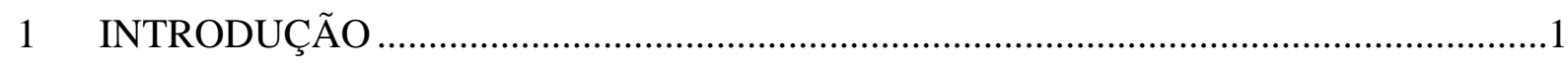

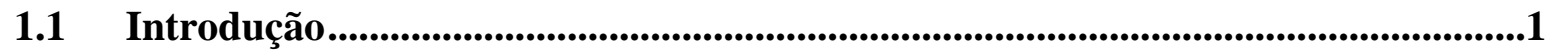

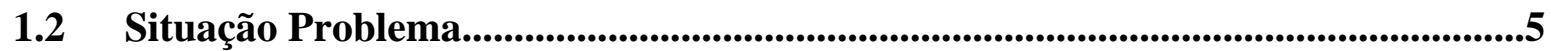

1.3 Objetivos de pesquisa...................................................................................................

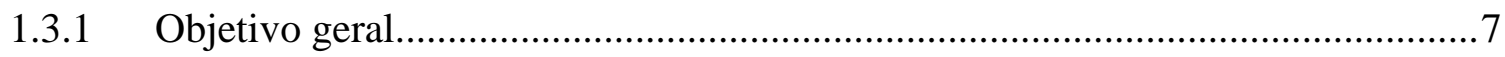

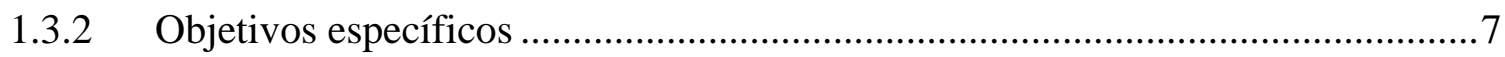

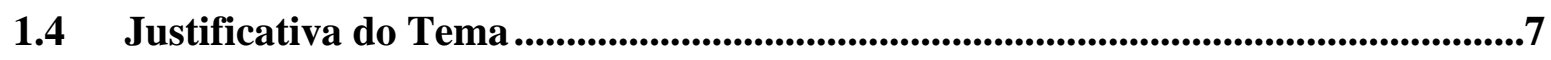

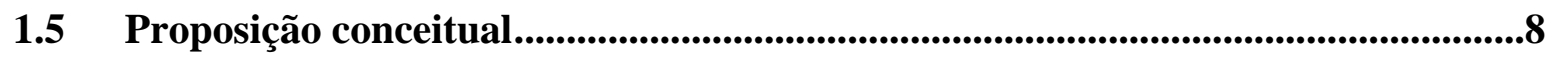

1.6 Descrição dos Capítulos ..............................................................................................10

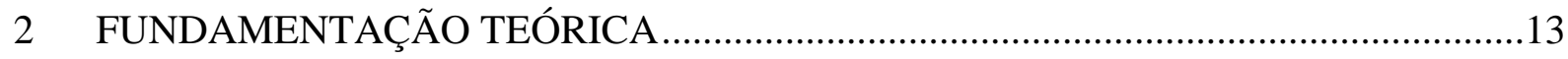

2.1 Relação entre dados, informação, conhecimento e sabedoria ............................14

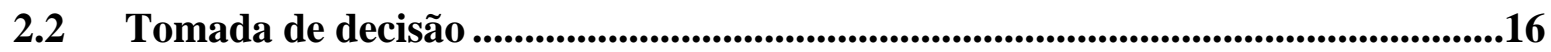

2.2.1 O Processo de Tomada de Decisão ..................................................................... 16

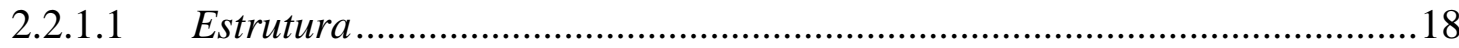

2.2.1.2 Limitações Cognitivas .......................................................................20

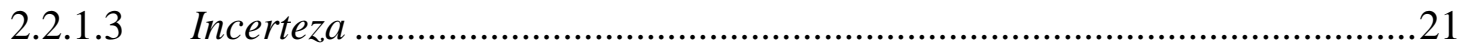

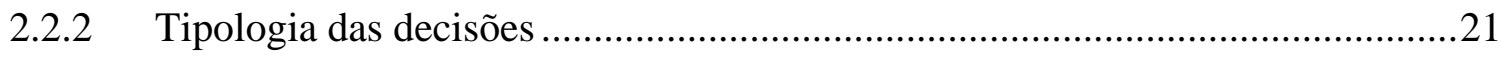

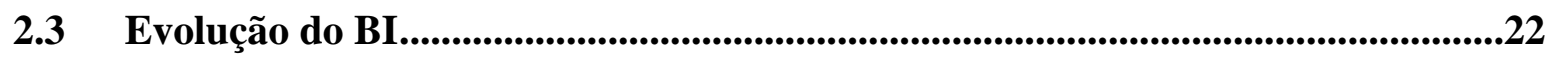

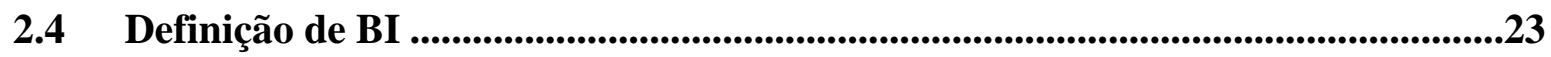

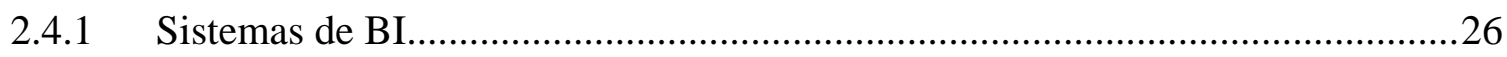

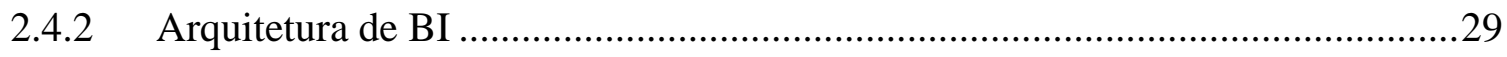

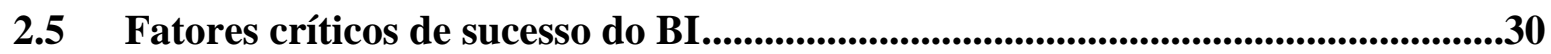

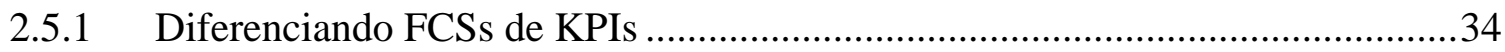




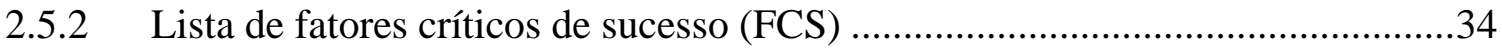

2.5.3 Modelo de classificação de fatores críticos de sucesso (FCS) ............................38

2.6 Gestão do Conhecimento (GC)

2.6.1 Sistema de gestão de conhecimento (SGC) ….................................................4

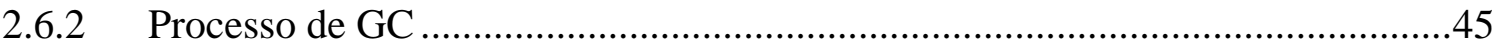

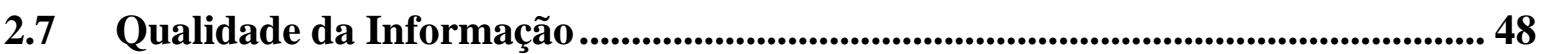

2.7.1 Revisão dos modelos de qualidade da informação ..........................................48

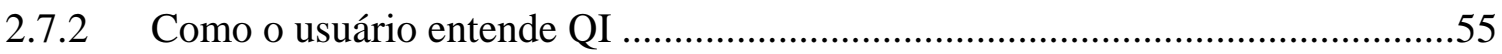

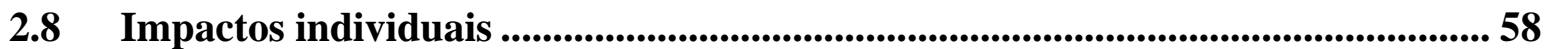

2.9 Benefícios esperados para sistemas de BI ...................................................59

2.10 Valor Percebido / Usabilidade Percebida..................................................................... 74

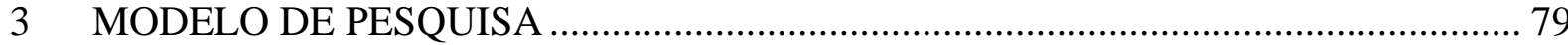

3.1 Suporte conceitual ao problema de pesquisa ........................................................... 79

3.2 Modelo conceitual .......................................................................................................... 80

3.3 Dimensão BE (Benefícios esperados para sistemas de BI) ................................ 82

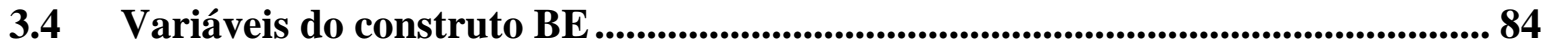

3.5 Variáveis do construto fatores críticos de sucesso (FCS) ...................................... 86

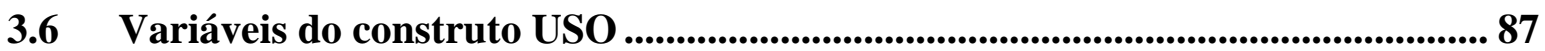

3.7 Modelo de mensuração e estrutural..................................................................... 89

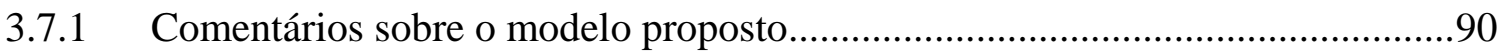

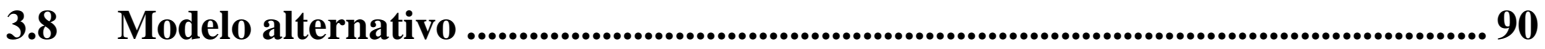

3.9 Outros aspectos presentes no modelo de pesquisa ................................................ 93

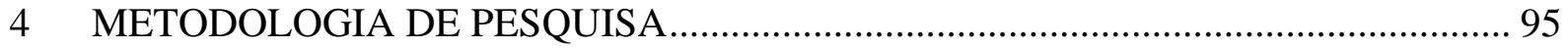

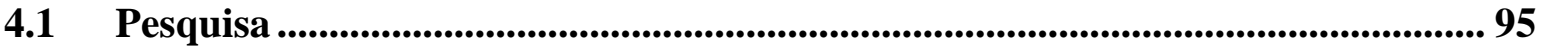

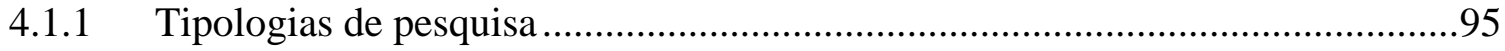

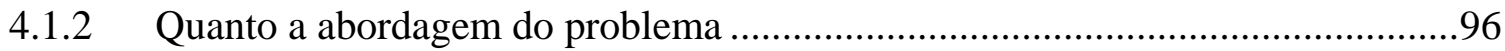

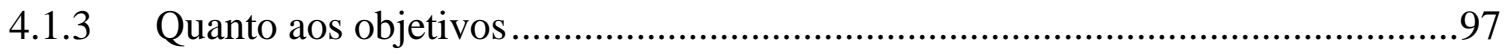


4.1.4 Justificativa das escolhas metodológicas desse trabalho ...................................98

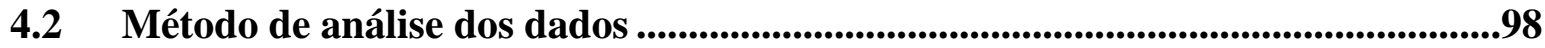

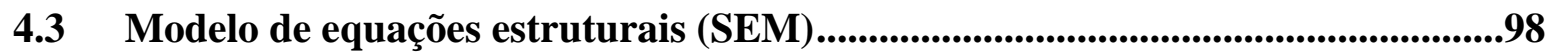

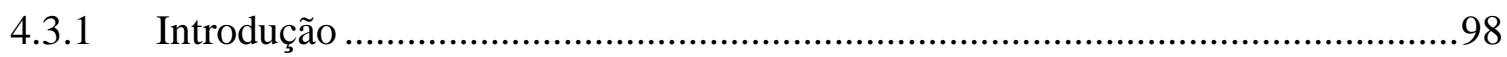

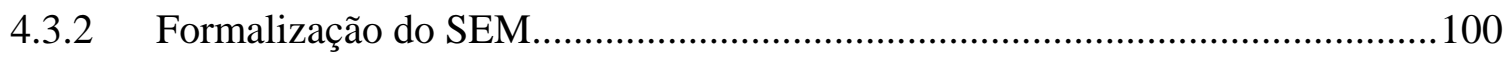

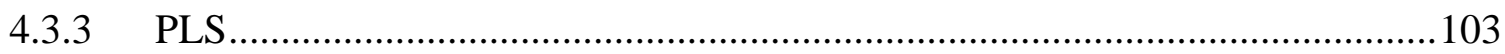

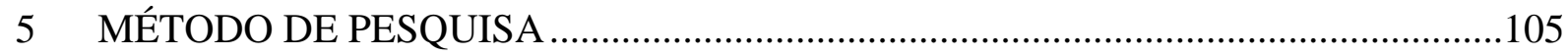

$5.1 \quad$ Tipo de Pesquisa ...................................................................................................................105

5.2 Questionário e coleta de dados .....................................................................................106

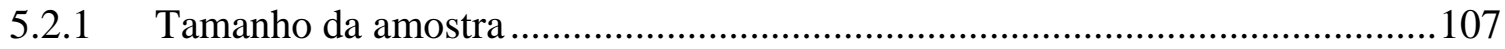

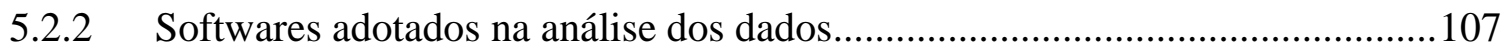

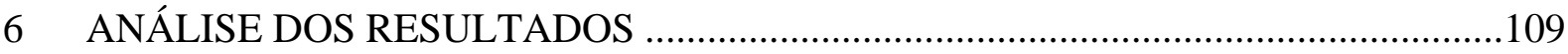

6.1 Tratamento e análise preliminar dos dados......................................................109

6.2 Análise da amostra obtida .....................................................................................109

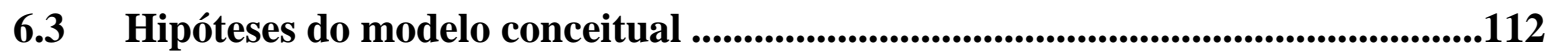

6.4 Interpretação dos resultados ..............................................................................113

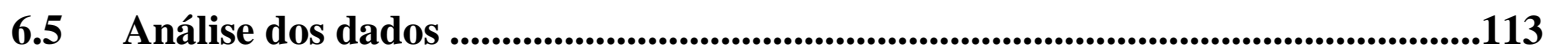

6.5.1 Análise do modelo de equações estruturais inicial .........................................119

6.5.2 Análise de cargas e relevância de variáveis .....................................................120

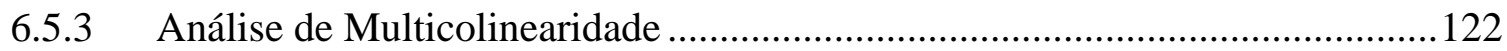

6.5.4 Validade convergente (Cargas, AVEs) ....................................................... 122

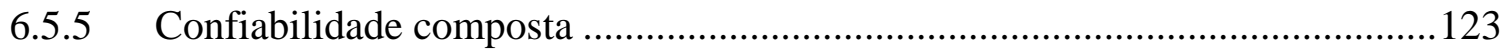

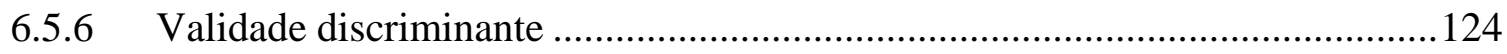

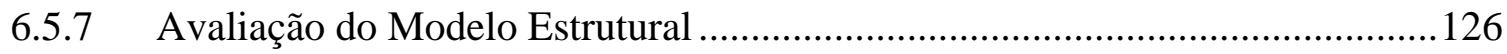

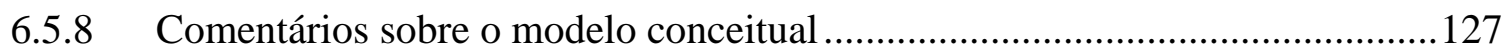

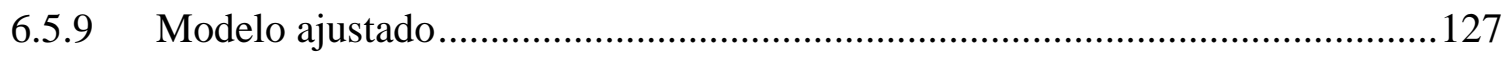

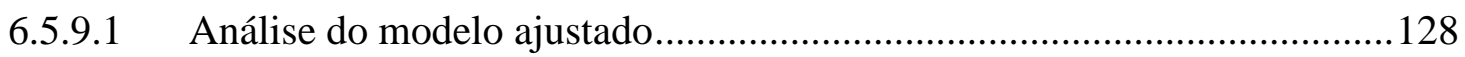




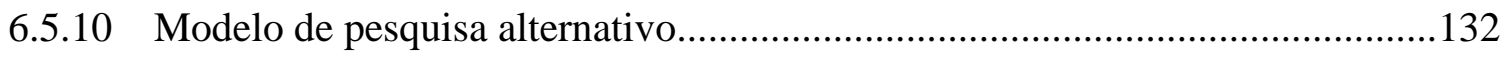

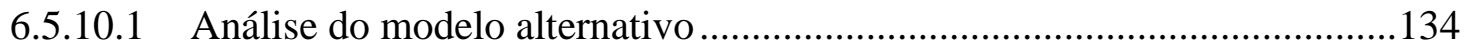

6.5.11 Comentários sobre o modelo alternativo …...................................................137

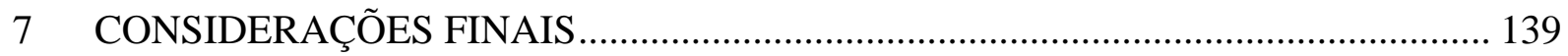

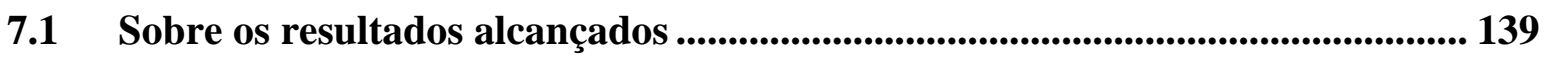

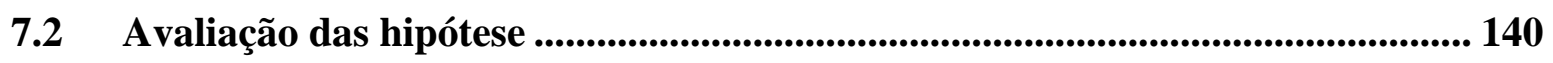

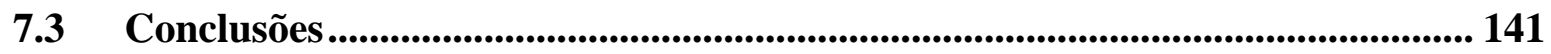

7.4 Limitações e sugestões de pesquisa ............................................................... 143

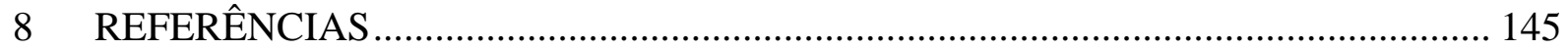

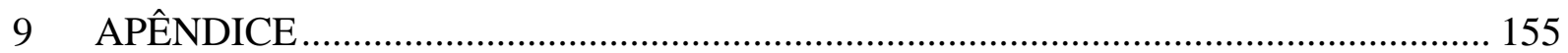

9.1 Apêndice I - Questionário ................................................................................................... 155

9.2 Apêndice II - Cargas fatoriais do modelo conceitual .......................................... 158

9.3 Apêndice III - Análise de Multicolinearidade do modelo conceitual ................ 159

9.4 Apêndice IV - Análise da Validade Discriminante do modelo conceitual ....... 165

9.5 Apêndice V - Análise da Validade Discriminante do modelo ajustado ........... 166

9.6 Apêndice VI - Análise de Multicolinearidade do modelo ajustado................... 167

9.7 Apêndice VII - Scores fatoriais dos indicadores das VL do modelo ajustado. 168

9.8 Apêndice VIII - Scores fatoriais dos indicadores das VL do modelo alternativo 169

9.9 Apêndice IX - Análise da Validade Discriminante do modelo alternativo...... 170

9.10 Apêndice $X$ - Avaliação do modelo alternativo ................................................ 171 


\section{LISTA DE SÍMBOLOS E ACRÔNIMOS}

Acrônimos:

$A C B$ - Análise custo-benefício

$B I$ - Inteligência de Negócio (Business Intelligence)

BICC - Centro de Competência de BI (Business Intelligence Competence Center)

CEO-Chief Executive Officer

CFO - Chief Financial Officer

CIO - Chief Information Officer

CRM - Gestão de relacionamento com o cliente (Customer Relationship Management)

DIKW - Hierarquia dados $(D)$, informação $(I)$, conhecimento $(K)$ e sabedoria $(W)$ disponível

DSS - Sistema de suporte a decisão (Decision Support system)

DW-Data Warehouse

ESS - Sistema de suporte executive (Executive Support System)

ERP - Enterprise Resource Planning

ETL - Extração, transformação e carregamento (Extract, Transform and Load)

FCS - Fator crítico de sucesso

$G C$ - Gestão do Conhecimento (Knowledge Management)

KPI - Indicador chave de desempenho (Key performance indicator)

$M I S$ - Sistema de gerenciamento de informação (Management Information System)

OLAP - Processamento analítico em (Online Analytical Processing)

$R M$ - Gestão de Risco (Risk management)

SBI - Sistemas de Business Intelligence

$S I$ - Sistema de Informação

SIM - Sociedade para gestão da informação

$T I$ - Tecnologia da Informação

TIC - Tecnologia da Informação e Comunicação

$V L$ - Variável latente

$V P$ - Vice presidente 


\section{LISTA DE FIGURAS}

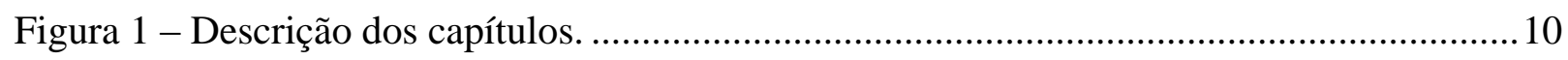

Figura 2 - Estrutura de decisão contínua ....................................................................... 18

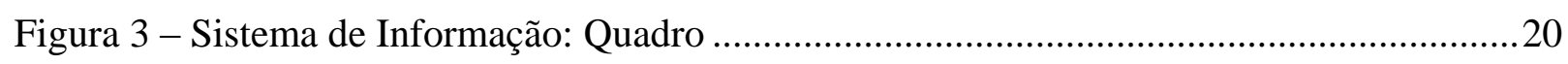

Figura 4 - O papel dos sistemas de BI na tomada de decisão ...............................................27

Figura 5 - Desenvolvimento dos sistemas de gestão de informação .........................................28

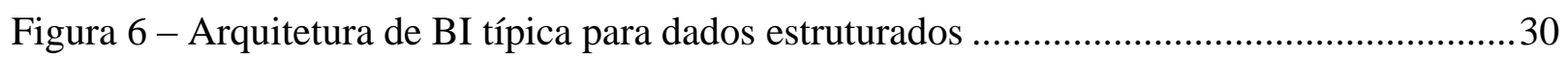

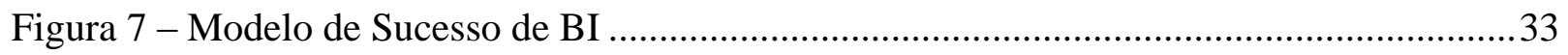

Figura 8 - Agrupamento das perspectivas críticas dos FCS .................................................38

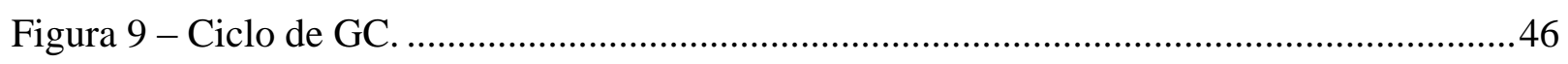

Figura 10 - Modelo que suporta a infraestrutura de GC (Modelo de processo de GC). ...........47

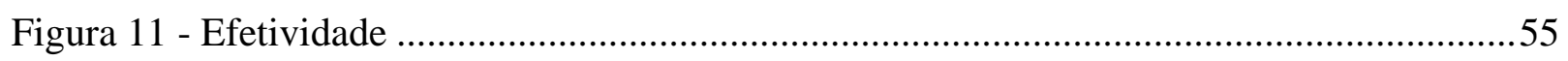

Figura 12 - Dimensões de Wang e Strong ..........................................................................56

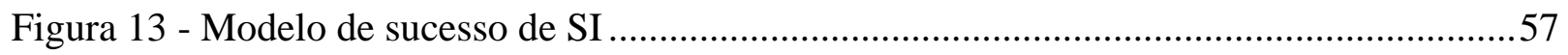

Figura 14 - Natureza dos benefícios estratégico, tático e operacional......................................60

Figura 15 - Representação gráfica das variáveis observadas para a VL Benefícios Esperados. 71

Figura 16 - Modelo estrutural do relacionamento entre usabilidade percebida do website,

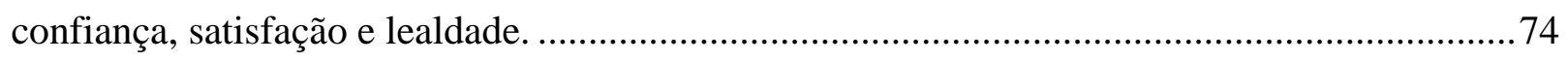

Figura 17 - Modelo de tomada de decisão do consumidor baseado na confiança.....................77

Figura 18 - Modelo Conceitual de Pesquisa........................................................................... 81

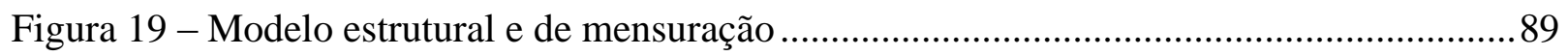

Figura 20 - Modelo estrutural e de mensuração do modelo alternativo ....................................93

Figura 21 - Exemplo de representação gráfica de um modelo SEM...................................... 100

Figura 22 - Composição da amostra em relação aos setores de atuação das empresas............ 110

Figura 23 - Composição da amostra em relação as áreas de negócio de atuação dos respondentes dentro das organizações em que atuam ........................................................ 111

Figura 24 - Composição da amostra em relação aos cargos dos respondentes nas organizações

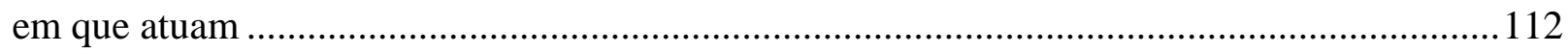

Figura 25 - Modelo estrutural conceitual ......................................................................... 120

Figura 26 - Modelo estrutural conceitual e as respectivas cargas fatoriais ............................ 127

Figura 27 - Modelo estrutural ajustado e as respectivas cargas fatoriais ............................... 128

Figura 28 - Modelo de pesquisa alternativo baseado no modelo de Kim et al. (2008)............ 133 


\section{LISTA DE TABELAS}

Tabela 1 - Principais aplicações e desenvolvimentos de tecnologia, 2003-2011 .4

Tabela 2 - Resumo da variedade de definições de BI ......................................................24

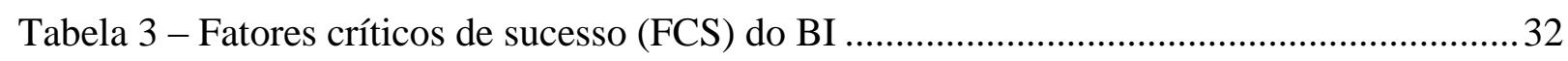

Tabela 4 - Lista de fatores críticos de sucesso da revisão da literatura.................................... 35

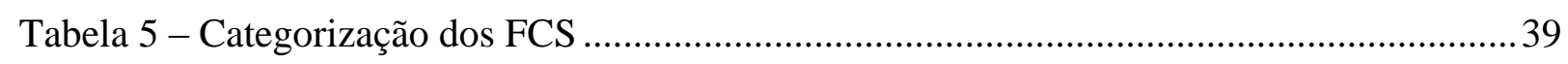

Tabela 6 - Ordem de prioridade dos FCSs da revisão da literatura.......................................... 40

Tabela 7 - Taxonomia de definições de GC.................................................................... 43

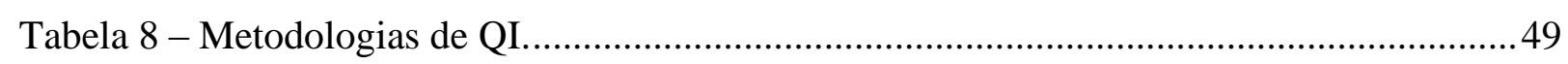

Tabela 9 - Metodologias e dimensões de QI.........................................................................50

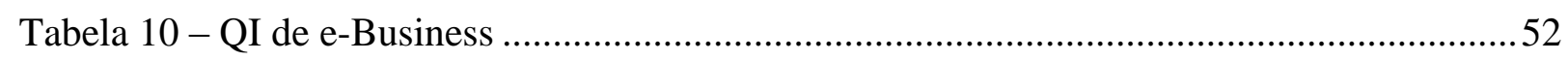

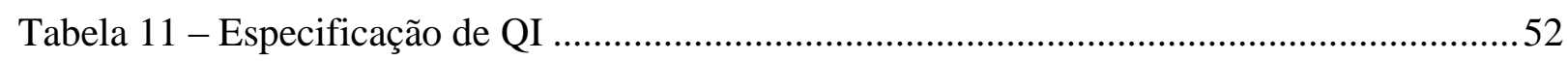

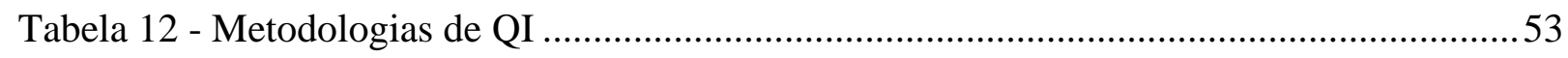

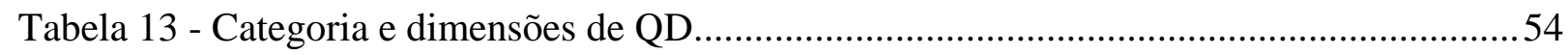

Tabela 14 - Definições dos impactos da TI no trabalho.........................................................5

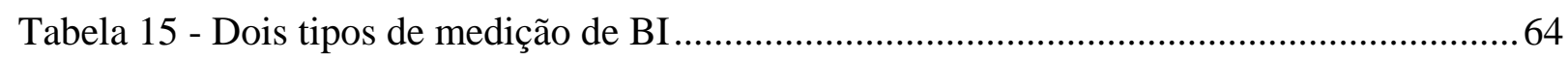

Tabela 16 - Compilação de diferentes pesquisas dos Benefícios esperados do BI.....................65

Tabela 17 - Distribuição dos benefícios esperados do BI......................................................6 67

Tabela 18 - Consolidação dos benefícios esperados mais significativos de acordo ................... 70

Tabela 19 - Aplicações contemporâneas dos sistemas de BI..................................................... 72

Tabela 20 - Dimensões do modelo de tomada de decisão do consumidor baseada em confiança .78

Tabela 21 - Consolidação dos resultados de pesquisa da dimensão BE ................................. 83

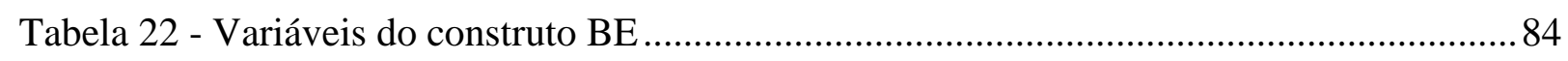

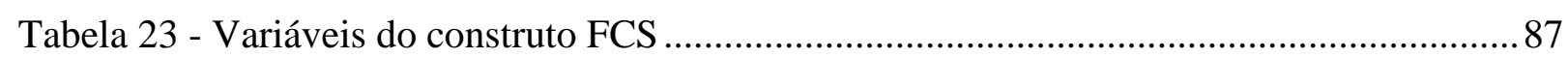

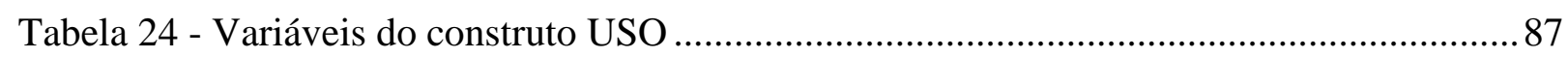

Tabela 25 - Tabela de equivalências .............................................................................. 91

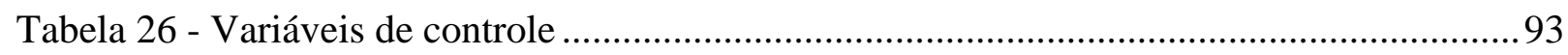

Tabela 27 - Tipologias de delineamento de pesquisas com agrupamento ............................... 95

Tabela 28 - Diferenças entre a SEMPLS e SEMMC ......................................................... 103

Tabela 29 - Caracterização da Amostra Válida................................................................... 110

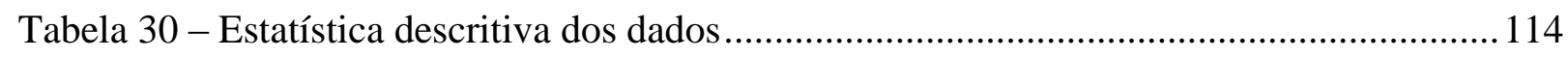

Tabela 31 - Indicadores que atingiram o menor valor de pesquisa ................................... 115 
Tabela 32 - Indicadores com baixa assimetria ................................................................ 115

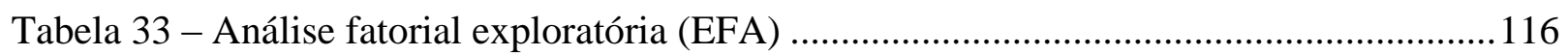

Tabela 34 - Matriz de correlação das VLs do modelo conceitual .......................................... 117

Tabela 35 - Matrizes de correlação dos indicadores das VL e sua distribuição....................... 118

Tabela 36 - Resumo das estatísticas $t$ do indicadores do modelo conceitual .......................... 121

Tabela 37 - AVEs de cada variável do modelo conceitual de pesquisa .................................. 123

Tabela 38 - Confiabilidade Composta da amostra .............................................................. 124

Tabela 39 - Correlação entre as VLs. Na diagonal principal o valor de AVE......................... 125

Tabela 40 - Correlação entre as VLs de segunda ordem..................................................... 125

Tabela 41 - Avaliação do modelo conceitual .................................................................... 126

Tabela 42 - Resumo das estatísticas $t$ do indicadores do modelo ajustado ............................ 129

Tabela 43 - AVEs de cada variável do modelo ajustado...................................................... 130

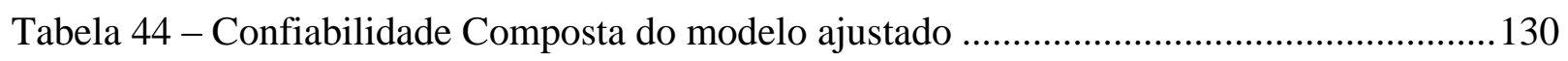

Tabela 45 - Correlação entre as VLs. Na diagonal principal o valor de AVE......................... 131

Tabela 46 - Avaliação do modelo ajustado ........................................................................ 132

Tabela 47 - Estatística t dos indicadores das VL do modelo alternativo de pesquisa .............. 134

Tabela 48 - AVEs de cada variável do modelo alternativo ................................................... 135

Tabela 49 - Confiabilidade Composta do modelo alternativo............................................... 135

Tabela 50 - Correlação entre as VLs. Na diagonal principal o valor de AVE........................ 136 


\section{LISTA DE GRÁFICOS}

Gráfico 1 - Análise dos FCS citados na revisão da literatura............................................... 39

Gráfico 2 - Benefícios esperados das atividades de BI.......................................................67

Gráfico 3 - Principais benefícios esperados das ferramentas de BI e ferramentas de

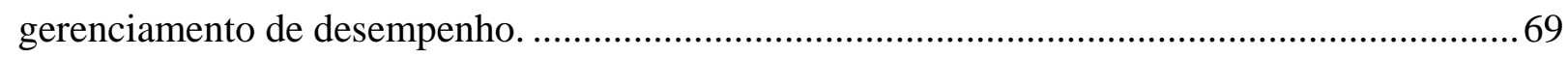




\section{LISTA DE APÊNDICES}

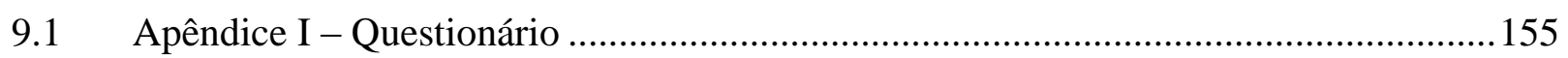

9.2 Apêndice II - Cargas fatoriais do modelo conceitual ............................................... 158

9.3 Apêndice III - Análise de Multicolinearidade do modelo conceitual ......................... 159

9.4 Apêndice IV - Análise da Validade Discriminante do modelo conceitual................... 165

9.5 Apêndice V - Análise da Validade Discriminante do modelo ajustado ....................... 166

9.6 Apêndice VI - Análise de Multicolinearidade do modelo ajustado ............................. 167

9.7 Apêndice VII - Scores fatoriais dos indicadores das VL do modelo ajustado ............. 168

9.8 Apêndice VIII - Scores fatoriais dos indicadores das VL do modelo alternativo ......... 169

9.9 Apêndice IX - Análise da Validade Discriminante do modelo alternativo .................. 170

9.10 Apêndice X - Avaliação do modelo alternativo ....................................................... 171 


\section{INTRODUÇÃO}

\subsection{Introdução}

Em um mercado dinâmico com oportunidades bastante disputadas, as organizações buscam a obtenção de vantagem competitiva para garantir o seu espaço. A competição tem se apresentado como condição predominante no mundo corporativo. $\mathrm{O}$ processo de globalização dos mercados, neste final de século, e seu efeito sobre os padrões de conduta econômica, política, social e organizacional, vêm assumindo importância crescente, compondo um cenário no qual a competitividade emerge como uma questão imperativa (MACHADO DA SILVA E FONSECA, 2010). Em uma época onde o ambiente de negócio muda rapidamente, a necessidade por informação de negócio oportuna e efetiva é reconhecida como essencial para as organizações, não somente para obter sucesso, mas para sobreviver (LÖNNQVIST E PIRTTIMÄKI, 2006).

Muito esforço tem sido feito para o desenvolvimento tecnológico e otimização de processos visando à sobrevivência empresarial nesse ecossistema. Investimentos em sistemas de tecnologia da informação e comunicação elevaram a concorrência a novos patamares, deixando como efeito colateral dessas tecnologias, a geração e o armazenamento de uma vasta quantidade de dados. As empresas modernas apresentam como características o aumento de padrão de automação onde as tecnologias têm disponibilizado o acesso a uma grande quantidade de dados (RANJAN, 2009). Tecnologias de data warehouse (DW) têm servido como repositores desses dados e o avanço nas aplicações de extração, transformação e carregamento (ETL) têm aumentado a velocidade de coleta. Mais importância tem sido dada a esse produto secundário resultante dos processos empresariais, os dados, que têm sido vistos como uma potencial fonte de informação capaz de garantir às instituições a sobrevivência em sua indústria. Tecnologias on-line de processamento analítico (OLAP) têm permitido a disseminação rápida de novos relatórios que analisam dados, transformando o Business Intelligence $(\mathrm{BI})$ na arte de peneirar uma grande quantidade de dados, extraindo informações pertinentes, e tornando essa informação em conhecimento sobre quais ações podem ser tomadas (RANJAN, 2009). 
Pesquisadores como Davenport (2007) apresentam resultados mostrando que empresas preocupadas na realização de estudos analíticos de seus dados apresentaram desempenhos superiores aos concorrentes, mostrando a importância estratégica desse produto secundário. O autor afirma que:

"Em uma época na qual as empresas em vários setores oferecem produtos similares e utilizam tecnologia comparável, os processos de negócios de alto desempenho estão entre os últimos pontos de diferenciação que restaram. ... O que lhe resta como uma base para a competição é executar seu negócio com o máximo de eficiência e eficácia, e tomar as decisões de negócio mais inteligentes possíveis. E os líderes analíticos extraem o máximo possível de valor dos processos de negócio e decisões-chave."

(DAVENPORT, 2007, p. 9)

Tecnologia e otimização de processos além de inovação, sobretudo de modelos de negócio, tem sido práticas comuns adotadas pelas organizações. Em uma época na qual as empresas em vários setores oferecem produtos similares e utilizam tecnologia comparável, os processos de negócios de alto desempenho estão entre os últimos pontos de diferenciação que restaram (DAVENPORT E HARRIS, 2007, p.9). Com o continua necessidade das empresas de se reinventarem para competir e com a acentuada implantação de infraestrutura de tecnologia da informação (TI), o tratamento dos dados e a interpretação das informações tornaram-se um dos focos na busca dessa vantagem competitiva. Um componente crítico para o sucesso da empresa moderna é sua habilidade de obter vantagem de toda informação disponível. Esse desafio se torna mais difícil com o crescimento constante do volume de informação, tanto a interna como a externa, da empresa (CODY et al., 2002).

No dia a dia das corporações, decisões precisam ser tomadas e decisões insatisfatórias podem ser feitas pelos gestores nas organizações durante a administração dos negócios. Essas decisões insatisfatórias podem ser atribuídas à falta de informação ou utilização inapropriada das informações disponíveis. Sob esse prisma, o sistema de business intelligence (SBI) é uma ferramenta que poderia auxiliar os gestores a fazer melhores escolhas por disponibilizar análises, relatórios e projeções garantindo a qualidade de informação (QI) necessária para a tomada de decisão. A adoção de SBI têm sido prioridade nas organizações por poder gerar informação acionável aos gestores e executivos, i.e., informação que pode ser usada para uma específica tomada de decisão pelos decisores. 
Percebe-se a preocupação e o reconhecimento, por parte dos executivos, da importância dos sistemas de business intelligence para a sobrevivência de suas empresas pelo fato de que por anos seguidos, os SBI têm sido relatados nas pesquisas realizadas mundialmente pelo Gartner como o sonho de consumo desses profissionais. As aplicações de BI tem dominado a lista de prioridade de tecnologia de muitos chief information officer (CIO) (YEOH E KORONIOS, 2010). Com o considerável aumento do volume e exigência de informação, os sistemas de BI têm sido apontados como prioridade nas empresas, no entanto, problemas com a implantação desses sistemas tem frustrado as expectativas dos gestores, principalmente com relação à qualidade da informação entregue, levando ao questionamento da real eficiência desses sistemas (GARTNER, 2012).

Pesquisas realizadas pelo Gartner têm demonstrado no decorrer dos anos que BI continua sendo nos Estados Unidos, prioridade dos executivos. A necessidade de criar novos insights está levando a um maior volume de investimentos em BI. A análises e tomada de decisões é a principal área de TI que necessita de investimentos para 59\% dos CIOs ouvidos pelo Gartner e pela Financial Executives Research (FERF). De acordo com o estudo, o segundo segmento é o monitoramento contínuo da performance de negócios (50\%) e, em seguida, a colaboração e gestão de conhecimento (45\%).

“As respostas do estudo 2013 Gartner FEI CFO Technology estão em linha com os resultados de anos anteriores e apontam as aplicações de BI, sistemas analíticos e comerciais como as principais áreas de investimento e foco", afirma João Tapadinhas, diretor de pesquisas da consultoria. Os projetos de gestão da performance corporativa (CPM) são os mais importantes na lista de iniciativa de BI dos CFOs. Os cinco segmentos dessa área mais procurados incluem performance scorecards, orçamentos, planejamento e previsão, consolidação financeira e gestão da lucratividade. ${ }^{1}$

Em 2011, Luftman e Bem-Zvi consolidaram os resultados de nove anos de pesquisa onde fica clara a importância dada pelos executivos à adequada geração de informação estratégica, pois desde 2009, BI é repetidamente a aplicação de maior prioridade nas pesquisas realizadas com organizações baseadas nos Estados Unidos.

I A WBA é uma empresa nacional, especializada no desenvolvimento de softwares corporativos e consultoria de gestão de negócios. 
Na tabela 1 são apresentadas, em diferentes anos, em que posição se encontram cada uma das aplicações e tecnologias mencionadas nas pesquisas.

Tabela 1 - Principais aplicações e desenvolvimentos de tecnologia, 2003-2011

\begin{tabular}{|l|c|c|c|c|c|c|c|c|c|}
\hline $\begin{array}{l}\text { Aplicações e } \\
\text { Desenvolvimento de } \\
\text { Tecnologia }\end{array}$ & 2011 & 2010 & 2009 & 2008 & 2007 & 2006 & 2005 & 2004 & 2003 \\
\hline BI & 1 & 1 & 1 & 2 & 2 & 2 & 3 & 2 & 1 \\
\hline Cloud Computing & 2 & 5 & 17 & & & & & & \\
\hline ERP & 3 & 3 & 3 & 14 & 6 & & 5 & & \\
\hline Aplicações móveis e sem fio & 4 & 9 & 24 & & & & & & \\
\hline CRM & 5 & 9 & 13 & & & & & & \\
\hline SaaS, PaaS & 6 & 9 & 15 & & & & & & \\
\hline Virtualização & 7 & 2 & & & & & & & \\
\hline $\begin{array}{l}\text { Ferramentas colaborativas e } \\
\text { de workflow }\end{array}$ & 8 & 7 & 7 & & & & & & \\
\hline $\begin{array}{l}\text { Integração de aplicação de } \\
\text { negócio / gerenciamento } \\
\text { (EAI/EAM) }\end{array}$ & 9 & 18 & 5 & 12 & 32 & & & & \\
\hline Mineração de dados & 10 & 16 & 23 & & & & & & \\
\hline Segurança & 11 & 26 & & 25 & 8 & 3 & 1 & 1 & \\
\hline $\begin{array}{l}\text { ITIL/IT práticas de } \\
\text { gerenciamento de projeto }\end{array}$ & 11 & 22 & 8 & 3 & 4 & & & & \\
\hline Gestão do conhecimento & 12 & 22 & 24 & 28 & & & & & \\
\hline Virtualização de servidor & 13 & 6 & 2 & 5 & & & & & \\
\hline $\begin{array}{l}\text { Planejamento de } \\
\text { continuidade / recuperação } \\
\text { de desastres }\end{array}$ & 14 & 4 & 6 & 3 & 4 & & & & \\
\hline $\begin{array}{l}\text { Arquitetura orientada ao } \\
\text { serviço (SOA) }\end{array}$ & 15 & & 9 & & & & & & \\
\hline
\end{tabular}

* Células em branco indicam que a pergunta não foi feita durante a pesquisa ou não foi selecionada Fonte: adaptado de Luftman e Bem-Zvi (2011, p.208)

Uma nova pesquisa foi publicada por Luftman et al.(2013) baseada em dados de quatro regiões geográficas, Estados Unidos, Europa, Ásia e América Latina, através de survey da "Sociedade para gestão da Informação" reforçando a condição dos SBI. A pesquisa obteve respostas de 787 organizações (195 no Estados Unidos, 360 na Europa, 55 na Ásia, 41 na Austrália e 136 na América Latina) em 2012. O BI continua na posição de líder entre as cinco tecnologias mais influentes que são: (1) BI, (2) Cloud computing, (3) Enterprise resource planning (ERP), (4) Desenvolvimento de aplicativos (Apps), e (5) Customer relationship management (CRM).

Para o Gartner, mais e mais organizações de negócios estão adotando BI para uma melhor tomada de decisão nos negócios, "Pelo quarto ano consecutivo, aplicações de BI tem sido 
ranqueadas como tecnologias de alta prioridade por mais de 1.500 CIOs ao redor do mundo nos programas de pesquisa do Gartner Executivo de 2009”"2 (GARTNER, 2009).

"A receita de softwares de Inteligência de Negócio, Analíticos e Gestão de Desempenho atingiram $\$ 8,8$ bilhões em 2008, um crescimento de 21,7\% com relação a receita de 2007 que foi de \$7,2 bilhões.”3 (GARTNER, 2009). O Gartner ainda mantém a previsão da taxa de crescimento previamente publicada, i.e., que o mercado de BI apresentará cinco anos de crescimento anual de receita na ordem de 8,6\% de 2006 ate 2011 (GARTNER, 2008). Para Mr. Dan Sommer, analista de pesquisa sênior da Gartner, "Em tempos difíceis, o primeiro passo é aumentar a transparência o que ajuda a identificar os centros de custo, e então um maior ajuste do alinhamento estratégico com 12 execuções. Este é o porque da demanda por BI, Analíticos e Gestão de Desempenho estar relativamente forte mesmo em uma economia dificil." 4

Nesse contexto, o estudo mais aprofundado dos fatores determinantes nos projetos de BI é possivelmente uma grande contribuição no entendimento e elaboração de melhores práticas e procedimentos na gestão desses sistemas.

\subsection{Situação Problema}

Apesar da necessidade e da importância percebidas pelos executivos com relação às soluções de BI, como descrito no item anterior, depois de anos de investimento e implementação, o BI tem falhado em se tornar unanimidade entre os usuários de negócio. O Gartner estima que não mais que $20 \%$ dos usuários de negócio utilizam o BI pro ativamente, ou seja, o BI não tem sido usado para a obtenção de ganho de desempenho.

De acordo com Gonsalves (2009), em uma pesquisa realizada em 2009 nos Estados Unidos pela BIScorecard com 324 profissionais de BI, verificou-se que a taxa de sucesso de

\footnotetext{
2 "For the fourth year in a row, BI applications have been ranked the top technology priority in the 2009 Gartner Executive programs survey of more than 1,500 Chief Information Officers (CIOs) around the world."

3 "Worldwide Business Intelligence, Analytics and Performance Management software revenue reached $\$ 8.8$ billion in 2008, a 21.7 percent increase from 2007 revenue of \$7.2 billion."

4 "In tough times, the first step is to increase transparency which helps identify cost-centers, and then to more tightly align strategy with 12 execution. This is why demand for BI, analytics and performance management is relatively strong even in a bearish economy."
} 
implantação desse sistema se manteve inalterada com relação à semelhante pesquisa realizada em 2007 (BISCORECARD, 2007). A pesquisa também aponta que fatores técnicos como qualidade dos dados, confiabilidade do sistema e acesso a dados relevantes têm prejudicado o uso dos aplicativos de BI. "Na maioria dos casos, as implantações estavam paradas no meio do processo, com pequeno ou moderado sucesso e impacto ao negócio”, Cindi Howson, fundadora da BIScorecard. Identificou-se que $85 \%$ dos projetos de BI possuem patrocinador de nível executivo, um fator crítico de sucesso, e que houve um crescimento acentuado no número de companhias que buscam padronizar suas plataformas de BI além do fato de que as empresas que adotaram uma abordagem estratégica estavam muito provavelmente obtendo algum benefício. Os respondentes apontam que $29 \%$ das implantações de BI foram levemente bem sucedidas, $47 \%$ de sucesso moderado e somente $21 \%$ dos respondentes consideraram seus projetos de BI muito bem sucedidos. De maneira geral, apesar dos projetos de BI terem gerado impacto significante em $70 \%$ das organizações representadas na pesquisa, a questionável qualidade dos dados disponibilizados tem gerado forte impacto sobre o sucesso das implantações, fazendo desse fator um dos mais impactantes no baixo índice de sucesso desses projetos.

Apesar desse cenário de prioridade tecnológica, bastante favorável para os sistemas de BI, os resultados apresentados pelo Gartner apontando um elevado índice de subutilização desses sistemas leva a questionar porque uma tecnologia importante e desejada pelas empresas não consegue atender as expectativas dos usuários.

Assim, a partir dessa problemática, esse trabalho visa compreender quais são os motivos pelos quais as organizações não estão atingindo uso adequado das soluções BI, através do estudo dos fatores apontados pela literatura como os críticos para esse sistema de informação. Nesse estudo avaliamos a influência das dimensões fatores críticos de sucesso (FCS) e benefícios esperados (BE) sobre a dimensão uso (USO) das informações oriundas dos sistemas de BI. Para isso foi estabelecido um modelo conceitual relacionando as dimensões mencionadas utilizando-se como referência outros trabalhos acadêmicos, as dimensões apresentadas e seus resultados de pesquisa.

Os testes e validação do modelo foram feitos através da modelagem de equações estruturais (SEM) sobre os dados obtidos em pesquisa realizada em empresas de diferentes indústrias cujas unidades experimentais serão os indivíduos usuários de BIS de diferentes áreas do negócio em 
uma amostra de 136 respondentes possibilitando a utilização do método PLS sem o comprometimento dos resultados por falta de robustez estatística.

\subsection{Objetivos de pesquisa}

\subsubsection{Objetivo geral}

Especificar e validar um modelo que relacione as influências dos fatores críticos de sucesso (FCS) dos sistemas de BI e seus benefícios esperados (BE) ao uso das informações disponibilizadas aos clientes desses sistemas por meio de revisão bibliográfica e pesquisa quantitativa com usuários de BI em áreas de negócio de empresas brasileiras.

\subsubsection{Objetivos específicos}

a) Conceituar benefícios esperados e fatores críticos de sucesso dos sistemas de BI através de revisão da literatura;

b) Avaliar o uso das informações pelos usuários de sistemas de BI nas áreas de negócio das organizações brasileiras a serem pesquisadas;

c) Avaliar a influência dos FCS e BEs sobre o uso das informações;

d) Melhorar a compreensão dos FCS mais relevantes para a obtenção de uma percepção positiva por parte do usuário a respeito do sistema de BI.

\section{$1.4 \quad$ Justificativa do Tema}

Recentemente as aplicações de BI têm sido prioridade na agenda de muitos CIOs. Entretando, o conceito de BI é relativamente recente e pouco acordo comum existe com relação a uma definição. Revisão acadêmica sobre o assunto resultou na identificação de três principais perspectivas do BI nomeadas como aspectos de gestão, aspectos tecnológicos e aspectos de produto (CHEE et al., 2009). Muitos dos trabalhos realizados sobre o assunto foram feitos por 
fornecedores de BI que enfatizam seus estudos nos aspectos tecnológicos e de produto. Menor atenção tem sido dada nessas pesquisas às questões referentes à gestão da implantação e uso de sistemas de BI. Recentemente temos presenciado inúmeras discussões sobre questões referentes aos sistemas de BI que incluem técnicas OLAP, data mining ou data warehouse, entretanto, pouca atenção tem sido dada às questões de criação e implementação do BI nas organizações (OLSZAK e ZIEMBA, 2007). Dada a grande importância desses sistemas para os tomadores de decisão nas organizações, fato esse suportado pela intenção de investimento apresentada pelos CEOs em pesquisas relacionadas ao tema, e os elevados índices observados nas pesquisas realizadas pelo Gartner de subutilização dos recursos para os quais esses sistemas foram concebidos, o estudo dos aspectos administrativos dessas soluções apontam ser de grande importância à medida que tentam esclarecer os fatores que influenciam no sucesso dessas implantações.

Os resultados desse estudo podem ser relevantes à medida que possibilitam um melhor entendimento dos fatores a serem considerados pelos gestores de projetos de TI durante a implantação e uso de sistemas de BI, melhorando a percepção dos usuários dos benefícios desses sistemas como ferramenta de suporte à decisão em suas atividades diárias.

\subsection{Proposição conceitual}

Diferentemente dos sistemas transacionais, onde a tecnologia está inserida no fluxo de processo da organização, o sistema de BI atua como sistema auxiliar disponibilizando informação de suporte a decisão dos usuários. Nos sistemas transacionais temos processos de decisões programadas e situações rotineiras que nos remetem ao tratamento de informações estruturadas. Nos sistemas de BI encontramos o processo de decisões não programadas com situações novas e semi-estruturadas, que apesar de poder atender as necessidades de informação operacionais, táticas e estratégicas, apresenta forte viés de nível estratégico.

Estudos sobre as estratégias de decisão do consumidor sobre a aquisição de produtos através de plataformas de comércio eletrônico (e-commerce) servem de inspiração para o modelo estrutural final devido à semelhança de procedimento observada com o sistema de BI. Em ambos os caso o processo de uso dos sistemas são influenciados por fatores semelhantes. Usualmente, ambos os sistemas estão na internet ou intranet, e o processo tem inicio com a 
intenção de consumo ou uso dos produtos ou informação. No sistema de BI essa intenção ocorre pela necessidade de informação que otimize o processo decisório do usuário, fato esse reiterado pela posição no ranking de prioridade de investimento. Essa intenção associada à credibilidade das informações e a familiaridade com a tecnologia resulta no uso do sistema. Esse processo de decisão ocorre de maneira semelhante no comércio eletrônico.

Essa pesquisa foi realizada através da coleta de dados de 13 empresas de 8 diferentes indústrias, algumas multinacionais, e todas com unidades no município de São Paulo. Sendo assim, o titulo do trabalho faz menção à empresas brasileiras com intuito de restringir o escopo da pesquisa se referindo à empresas com unidades de negócio no território nacional.

Consideramos nesse estudo do sistema de BI como um sistema que trata de informação semiestruturada com foco no apoio às decisões de nível estratégico na organização. $\mathrm{O}$ modelo estrutural final se baseia no modelo de estratégia de decisão do consumidor baseado na confiança para plataformas de comércio eletrônico, como será descrito e justificado mais adiante.

$\mathrm{O}$ estudo adota método de pesquisa quantitativa, realizando revisão dos conceitos e apresentando proposições relevantes a partir desses. 


\subsection{Descrição dos Capítulos}

Na figura 1 temos a apresentação da descrição dos capítulos.

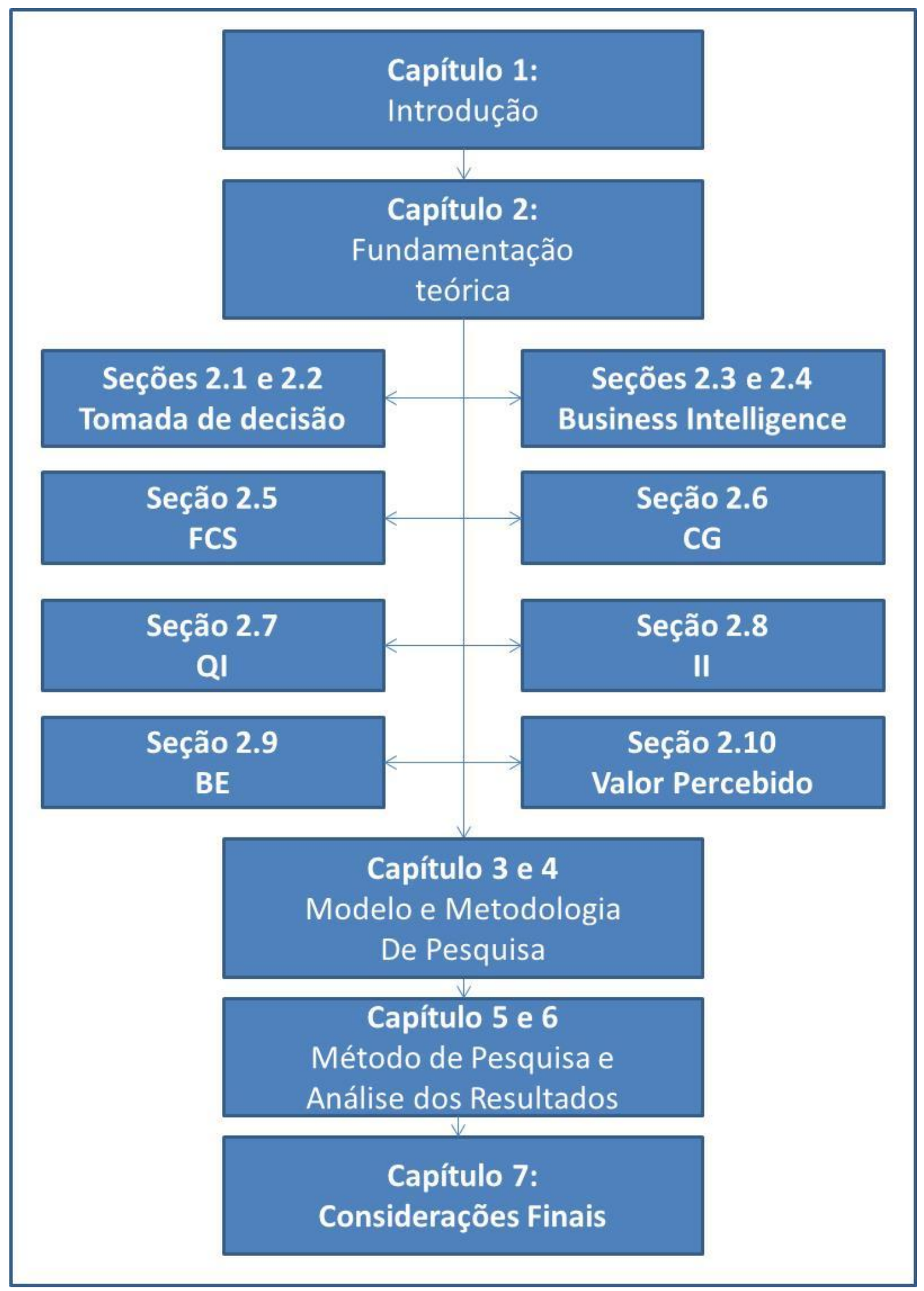

Figura 1 - Descrição dos capítulos.

Fonte: elaborado pelo autor 
No capítulo 2 é apresentada a fundamentação teórica. Inicia-se com a apresentação do processo de tomada de decisão. Seguindo, apresentamos os conceitos de BI, FCS, GC, QI, II, BE e USO.

No capítulo 3, 4, 5 são apresentados os modelos e métodos de pesquisa utilizados, e discutimos a modelagem por equações estruturais, além dos cuidados tomados com a coleta dos dados e do tamanho da amostra utilizada nas simulações.

No capítulo 6, fundamentados na revisão teórica, expomos as hipóteses e discutimos os resultados teóricos e empíricos obtidos. Apresentamos também os resultados obtidos das simulações feitas no modelo através do SEM.

No capítulo 7 apresentamos as considerações finais. 


\section{FUNDAMENTAÇÃO TEÓRICA}

"A dúvida é o princípio da sabedoria." Aristóteles (Filósofo Grego).

Em toda a história, as companhias têm desenvolvido e implementado sistemas para facilitar a coleta, processamento e disseminação da informação (HAWKING E SELLITTO, 2010). A utilização de tecnologias computacionais para dar suporte a esses sistemas de informação tem causado uma revolução em todos os níveis e aspectos dos negócios. As companhias têm reconhecido a importância da tecnologia da informação (TI) para alcançarem seus objetivos estratégicos (MORTON, 1990). Cada vez mais as atividades das companhias têm utilizado TI, das atividades operacionais aos planejamentos estratégicos de longo prazo. Estima-se que até a virada do último século, as empresas americanas tinham dedicado aproximadamente 50\% de suas despesas com TI (CARR, 2003). Na visão de Peter Drucker (1998), o uso dessa TI se destina muito mais a produção de dados do que de informação, informação essa potencialmente relevante para facilitar de maneira efetiva a tomada de decisão dos gestores.

O papel dos sistemas de informação (SI) em suportar os processos centrais do negócio e suas transações tem crescido tanto em número quanto na variedade de implementação de aplicações (HAWKING E SELLITTO, 2010). Os sistemas de business intelligence, que são na essência um SI, têm, portanto, como uma das demandas mais importantes, servir de facilitador aos decisores de negócio na identificação de oportunidades e possibilitar um processo de tomada de decisão mais assertiva, i.e., servir como suporte de informação para que as ações e planejamento estratégicos criem vantagem competitiva às corporações. Por se tratar de um sistema sob o guarda-chuva de TI, é aconselhável que obedeça às diretrizes estabelecidas como boas práticas de gestão para um projeto nessa área. Assim nesse capítulo será inicialmente discutido os conceitos de dados, informação, conhecimento e sabedoria, para depois apresentarse o tema de como se estabelece o processo decisório e suas características; a seguir será feito uma apresentação dos conceitos e definições de BI, incluindo resultados de pesquisa a respeito dos seus fatores críticos de sucesso; e, por fim, devido às dimensões indicadas pelos FCS, a apresentação da teoria de gestão do conhecimento $(\mathrm{GC})$ e as definições de qualidade de 
informação. Também serão definidos os benefícios esperados e risco e credibilidade percebidos pelos usuários para os sistemas de BI e sua relação com FCS, componentes necessários para a elaboração do modelo de pesquisa proposto nesse trabalho.

\subsection{Relação entre dados, informação, conhecimento e sabedoria}

De acordo com Ackoff (1989 apud BELLINGER; CASTRO; MILLS, 2004), o conteúdo da mente humana pode ser classificado em cinco categorias:

1. Dados: símbolos

2. Informação: dados que são processados para serem úteis; fornecem respostas para questões como "quem", "o que", "aonde", e "quando";

3. Conhecimento: aplicação dos dados e informação; responde as questões "como";

4. Entendimento: apreciação do "por que";

5. Sabedoria: entendimento avaliado.

Ackoff (1989 apud BELLINGER; CASTRO; MILLS, 2004) indica que as quarto primeiras se relacionam com o passado, elas tratam do que tem sido ou do que é conhecido. Somente a quinta categoria, sabedoria, trata do futuro, porque incorpora visão e desenho. Com sabedoria, pessoas podem criar o futuro, mais do que somente compreender o presente e passado, no entanto, alcançar sabedoria não é trivial, as pessoas tem que passar através das outras categorias. Na visão de Humberg (1997), dados, informação, conhecimento e sabedoria são frequentemente representados como tendo uma hierarquia, a qual provê uma maneira para se distinguir os significados e retrata o relacionamento entre eles. Aven (2013) trata da conhecida hierarquia dados (D), informação (I), conhecimento (K) e sabedoria (W) disponível, i.e., os vários elementos da DIKW. Os elementos da DIKW e hierarquia constituem o quadro fundamental para analisar o conhecimento em muitos tipos de aplicação, especialemente as aplicações de BI, objeto desse trabalho.

Dados: Davenport e Prusak (1998) definem dados como um conjunto de fatos discretos e objetivos a respeito de determinado evento. Consistem em um texto cru, números, imagens ou sons. No cenário organizacional, os dados são descritos como gravações estruturadas de transações. Os dados por si só tem pouca importância ou significado essencial e são usualmente 
armazenados em algum tipo de sistema tecnológico. Todas as organizações precisam de dados e algumas são fortemente dependentes deles para funcionarem. Como exemplos de dados podemos citar: balanços, estatísticas demográficas ou nomes e endereços de clientes. Aven (2013) apresenta dados como uma representação simbólica de propriedades obseváveis do mundo, símbolos que representam propriedades dos objetos, eventos e seu ambiente. Eles são produtos da observação. Para Bellinger, Castro e Mills (2004), os dados são crus, em estado natural. Eles simplesmente existem e não têm significância além de sua existência. Eles podem existir de qualquer forma, utilizável ou não. Eles não têm significado neles mesmos.

Informação: Para Davenport e Prusak (1998), informações são como dados colocados em perspectiva e contexto significativo. Informação tem relevância e base organizada com certo propósito. Quando os dados são processados e apresentados de maneira a ter significação em uma tomada de decisão específica ou contexto de aprendizagem, então temos informação. Como exemplos de informação: uma lista de nomes e endereços dos clientes de uma organização. Para transformá-la em informação tem que haver um uso particular e estrutura, por exemplo, identificação de um cliente particular de acordo com demografia que tem um padrão particular de compra. Na visão de Aven (2013), a informação é relevante, ou útil, ou expressiva, ou significativa, ou processada. A ideia é que as questões perguntadas se iniciam com "quem", “o que", “aonde", “quando", ou "quantos", e os dados são processados em respostas. Dados por si só não tem valor até que seja transformado numa forma relevante. Consequentemente, a diferença entre dado e informação é funcional, não estrutural. Para Bellinger, Castro e Mills (2004), informação é dado ao qual se é atribuído significado através de conexões relacionais. Esse significado pode ser útil, mas não tem que ser.

Conhecimento: Em Davenport e Prusak (1998), o conhecimento é descrito como a combinação de experiências enquadradas, valores, informação contextual e insight de especialista que provê uma estrutura para avaliar e integrar novas experiências e informação. Isto origina e é aplicada nas mentes dos trabalhadores do conhecimento. Em organizações, isto frequentemente se torna incorporado não somente em documentos ou repositórios, mas também em rotinas organizacionais, processos, práticas e padrões (DAVENPORT E PRUSAK, 1998). Para Bellinger, Castro e Mills (2004), conhecimento é uma coleção apropriada de informação, com a intenção de ser útil. Conhecimento é um processo determinístico. Quando alguém memoriza informação, então ele acumulou conhecimento. É comum a distinção entre conhecimento e know-how (habilidade). Know-how é o que faz possível a transformação da 
informação em instrução, por exemplo, dados da temperatura do quarto pode se tornar informação quando um agente pergunta "qual é a temperatura ?" e, por sua vez, para conhecimento quando o agente sabe como controlar a temperatura (AVEN, 2013, p.31).

Sabedoria: Bellinger, Castro, e Mills (2004) descrevem sabedoria como um processo extrapolativo, não determinístico e não probabilístico. Isso se chama, além de tudo, níveis prévios de consciência, e especificamente sobre tipos especiais de programação humana (moral, códigos éticos, etc.). Ela dá indicação de nos dar entendimento sobre o qual não se tinha entendimento prévio, e nos permite ir além do entendimento por si só. É a essência da sondagem filosófica. Ela apresenta questões que não possuem respostas fáceis, e em alguns casos, para os quais não existe resposta humanamente conhecida. Sabedoria é, portanto o processo pelo qual nós também discernimos, ou julgamos entre certo e errado, bom e mal. Para Aven (2013), sabedoria é a capacidade de colocar em ação o comportamento mais apropriado, tomando em consideração o que é conhecido (conhecimento) e o que faz mais bem (considerações éticas e sociais).

\subsection{Tomada de decisão}

\subsubsection{O Processo de Tomada de Decisão}

Em nossas atividades diárias, frequentemente somos chamados a tomar decisões, em sua grande maioria, rotineiras e pouco complexas. Nas organizações, os gestores lidam com questões que podem ser bastante complexas, como investimentos, opções tecnológicas, recursos humanos e estratégias, com a finalidade de garantir vantagem competitiva para a empresa. Em outras palavras, as decisões realmente importantes são frequentemente difíceis de tomar e requerem tanto uma boa e qualificada rede de informação como um avançado nível de suporte a decisão.

Tereza, Pereira e Lunardi (2007) comentam que os modelos de análise do processo decisório tem evoluído seguindo as mudanças históricas do processo de gestão organizacional, e exemplifica dizendo que no século $\mathrm{XX}$ o pensamento vigente era de que a realidade administrativa deveria ser racional, controlável e uniformizada, como consequência, o processo 
decisório apresentava atributos essencialmente lógicos e centrados no executivo principal ou proprietário, no qual se acreditava deter amplo conhecimento de todas as possibilidades e consequências, não sendo, portanto, necessário explicar os critérios adotados para suas escolhas (WIJNBERG; DEN ENDE; WIT., 2002).

Para Simon $(1960,1965)$, citado pelos autores, ninguém é absolutamente racional em suas decisões, considerando todas as possibilidades, mas se satisfaz com o fato de articular o número de informações que possa alcançar e processar, ou seja, o homem administrativo possui racionalidade limitada, e trabalha com o fato de as organizações serem espaços sociais limitados pela capacidade humana de processar informações (TEREZA; PEREIRA; LUNARDI, 2007, p.155).

Por fim, Tereza, Pereira e Lunardi (2007) vêem o dirigente contemporâneo menos como decisor racional, planejador sistêmico e supervisor de atividades ordenadas, e mais como desbravador de caminhos, encontrando soluções e tomando decisões com base em informações incompletas, coletadas esparsamente em meio a um processo gerencial fragmentado e descontínuo, associado a um aumento na complexidade, hostilidade e imprevisibilidade do ambiente externo às empresas nas últimas décadas.

Nas situações em que a tomada de decisão é exigida, rapidamente realizamos o julgamento antecipado a respeito da complexidade dessa decisão, i.e., avaliamos se a decisão será uma decisão simples ou uma decisão difícil. "[...]nossa habilidade de medir diferentes situações de decisão de maneira muito rápida e classificá-las em fáceis ou difíceis é simplesmente espetacular" (MARAKAS, 1998 p.57).

Marakas (1998) também discute a questão de como identificamos previamente se a decisão a ser tomada será fácil ou difícil quando nós nem mesmo começamos a reunir informações sobre a situação. Para o autor, a questão depende de fatores estruturais, psicológicos, físicos e ambientais. As dificuldades associadas à tomada de decisão pode ser o resultado de inumeráveis combinações de complexidade, incerteza, pressões organizacionais e ambientais, e limitações na capacidade de decisão individual. 
Simon (1960) apud Marakas (1998) apresenta uma proposta de classificação de problemas baseado em uma escala de classificação continua que vai de completamente estruturado para completamente desestruturado. Essa proposta pode ser visualizada na figura 2.

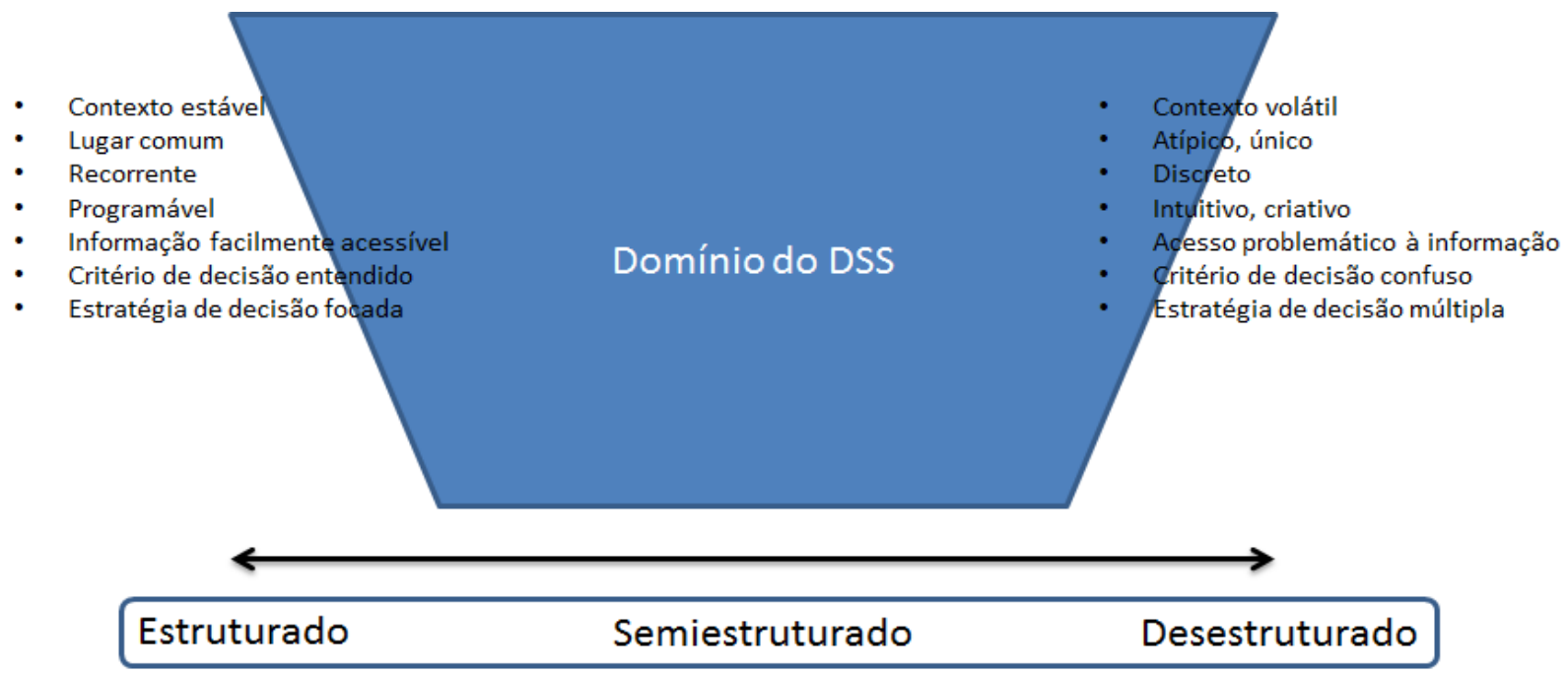

Figura 2 - Estrutura de decisão contínua

Fonte: adaptado de Marakas (1998, p.58)

Para Simon, de acordo com Marakas (1998), o indivíduo entende o grau de complexidade da decisão a ser tomada através de uma relação direta entre a estrutura do problema em questão. Seu modelo, conforme apresentado na figura 2, distingue entre os dois extremos do espectro relacionando-os com a identificação do grau com o qual a decisão é programada, i.e., as decisões podem ser programadas e não programadas. As decisões programadas são do tipo repetitivas e rotineiras, com procedimentos definidos capazes de lidar com a situação todas as vezes que ocorrerem. Já as decisões não programadas são relativas a situações novas e desestruturadas. Nessas não existem métodos definidos de como lidar com o problema porque nunca ocorreu anteriormente ou porque sua estrutura é bastante complexa ou porque é tão importante que merece tratamento personalizado.

Portanto, para Simon, decisões programadas são simples porque temos disponível de imediato todas as partes necessárias para a tomada de decisão, temos quase que uma rotina preestabelecida para fazê-la. Já as decisões não programadas são difíceis porque apresenta uma grande dificuldade na consolidação das informações necessárias para a tomada de decisão e porque também não possui rotina preestabelecida, ela precisa ser construída. 
Gorry e Morton (1971) comentam a necessidade de se entender o processo decisório humano no gerenciamento de SI e que a pesquisa sobre o problema humano de resolução de problemas levou Simon a definir que toda a solução de problema pode ser dividida em três categorias:

- A primeira fase do processo de decisão consiste na procura de ambiente em condição de necessidade por decisão, o que os autores chamariam de atividade de inteligência;

- A segunda fase consiste em inventar, desenvolver, e analisar diferentes possibilidades de ação, que os autores definiram como atividade de desenho;

- A terceira fase é a seleção da possibilidade de ação entre as possibilidades identificadas, chamada por Gorry e Morton como atividade de escolha.

Para Gorry e Morton (1971), essas três fases são claramente discerníveis como o processo de decisão organizacional, e que são muito semelhantes aos estágios em solução de problemas descritos por John Dewey (1925), qual é o problema? Quais são as alternativas e qual é a melhor alternativa?

Portanto, um problema totalmente estruturado é um no qual as três fases, inteligência, desenho e escolha, estão estruturados, i.e., é possível especificar algoritmos ou regras de decisão, que nos permite encontrar o problema, desenhar soluçães alternativas, e escolher a melhor solução; agora os problemas não estruturados são os que nenhuma das três fases está estruturada. Muitos dos problemas de gestão enfrentados pelos executivos no trabalho se enquadram nessa classificação, de atividades desestruturada.

De maneira geral, Gorry e Morton (1971) apresentam em seu trabalho duas maneiras diferentes de observar as atividades dentro das organizações. Uma delas realizando a categorização baseada no propósito da atividade gerencial, ao passo que na classificação de Simon a classificação é baseada na maneira com a qual o gestor lida com os problemas existentes. A combinação dessas duas visões fornece um modelo bastante útil no exame da resolução de problemas das atividades de SI. 
Sistema de Informação

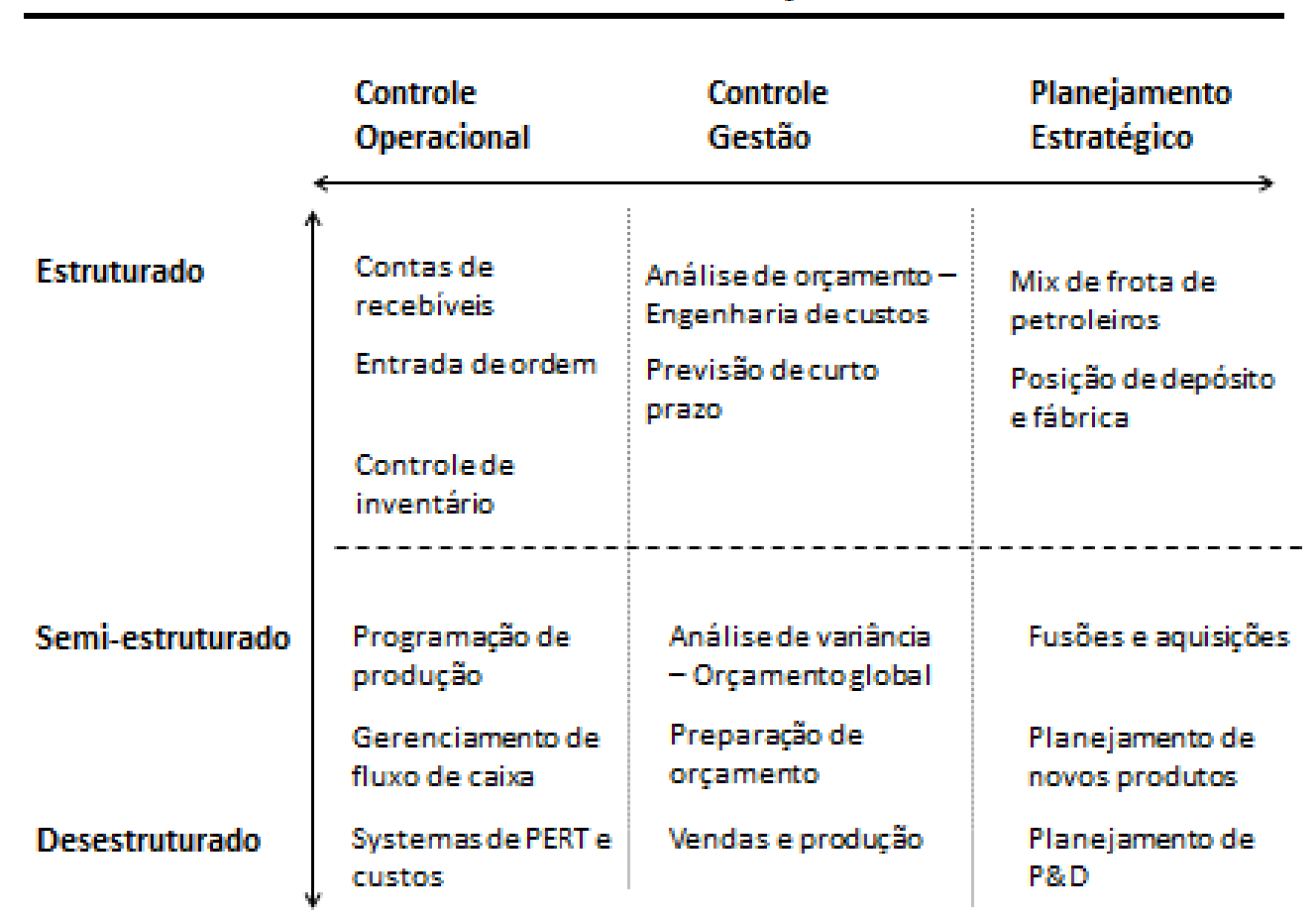

Figura 3 - Sistema de Informação: Quadro Fonte: adaptado de Gorry e Morton (1971, p.53)

Na figura 3 é apresentada a essência dessa combinação. O quadro contém uma classe de decisões definidas como semi-estruturadas, que são decisões com uma ou duas das fases desestruturadas. As decisões acima da linha pontilhada na figura 3 são amplamente estruturadas e os SI que as suportam definidos por Gorry e Morton (1971) como sistemas de decisão estruturada (SDS). As decisões abaixo da linha pontilhada são amplamente desestruturadas e os SIs que as suportam chamados de sistemas de suporte a decisão (DSS). O SDS engloba muito do que se define na literatura por sistemas de gerenciamento de informação.

\subsubsection{Limitações Cognitivas}

Possuímos limitações cognitivas dado que não somos capazes de saber tudo e muitas vezes nem mesmo podemos manipular tudo que temos que saber para lidar com certas situações, e pior, por diversas vezes somos incapazes de acessar informações previamente encontradas e armazenadas em nossa mente consciente, e nas vezes em que temos sucesso em acessá-las, frequentemente a recuperação não é completamente acurada. Enquanto a mente humana é capaz de raciocínio, cálculos computacionais, e armazenamento, nosso entendimento sobre ela 
sugere que nós somos limitados em nossas habilidades de processar e armazenar informação e conhecimento (MARAKAS, 1998, p.59).

Marakas apresenta a pesquisa realizada por Miller (1956) que demonstra os limites cognitivos da mente humana. Através de uma série de experimentos usando uma grande amostra de assuntos humanos, Miller determinou que o campo imediato da consciência da mente humana é limitada a manipulação de algo entre cinco e sete peças distintas de informação, ou seja, em algum momento, nós podemos conscientemente somente manter controle de um número mágico de sete mais ou menos dois itens de conhecimento durante o processo de decisão.

\subsubsection{Incerteza}

Quando olhamos os resultados obtidos de determinada decisão, fica claro e relativamente simples de avaliar o processo decisório com grande certeza. Se pudéssemos prever o resultado de determinada decisão com o mesmo grau de certeza, as decisões seriam fáceis. O fato é que certeza implica na existência do completo e acurado conhecimento sobre o resultado da decisão pendente.

Para Marakas (1998, p.60), a incerteza genuína indica que os resultados de uma decisão a ser tomada não podem ser determinados mesmo dentro dos limites do cenário probabilístico. $\mathrm{Na}$ realidade, nos sempre somos confrontados com certo grau de incerteza nas situações de tomada de decisão e raramente se apresenta a total certeza. Usualmente o tomador de decisão pode atribuir alguma probabilidade subjetiva para o resultado esperado da decisão de maneira que algum grau de certeza é assumido.

\subsubsection{Tipologia das decisões}

Não existem duas decisões completamente iguais. A diversidade de decisões enfrentadas pelo gestor durante sua vida é enorme. De fato, o gestor em um dia típico pode ter uma aparente cadeia ininterrupta de decisões. O tipo de suporte necessário para uma decisão pode ser completamente diferente do suporte requerido para a próxima decisão. Marakas (1998, p.61), portanto sugere um método para reduzir esse vasto numero de possíveis contextos de decisões em um conjunto de categorias mais administrável. Existem diversos métodos de classificação das decisões, entre elas a classificação de acordo com o nível gerencial, como por exemplo, 
decisões de nível operacional, decisões de nível gerencial médio e decisões de gerenciamento sênior. A classificação também poderia ser baseada no foco, decisões estratégicas versus decisões administrativas. Essa discussão sobre a tipologia de decisões e os tipos de informação relevantes que a ela correspondem é de importância para a compreensão dos sistemas de BI, descritos nos itens a seguir, uma vez que esses são tipicamente voltados à tomada de decisão em níveis gerenciais e estratégicos, com as características de sistemas do tipo DSS.

\subsection{Evolução do BI}

Em sua tese, Vodapalli (2009) comenta que muitos na indústria acreditam que o termo business intelligence foi primeira mente cunhado por Howard Dresner da Gartner Research em 1989, onde ele utilizou o termo BI como "uma ampla categoria de softwares e soluções para agregar, consolidar, analisar e prover acesso a dados de maneira a permitir aos usuários das organizações tomarem melhores decisões de negócios” (GIBSON et al, 2004; YEOH, 2008).

Entretanto, de acordo com Yeoh (2008), Imhoff (2009) e Answers.com (2009), o termo foi primeiramente apresentado por H.P.Luhn no IBM Journal intitulado "Um sistema de inteligência de negócio" (LUHN, outubro, 1958). Abaixo segue a definição original apresentada por Luhn em 1958, como também por Yeoh (2008):

"Um negócio é uma coleção de atividades conduzidas com qualquer propósito, seja ela ciência, tecnologia, comércio, indústria, lei, governo, defesa, etc... A habilidade de comunicação serve de conduto para o negócio (no sentido amplo) podendo ser interpretado como um sistema inteligente. A noção de inteligência é também definida aqui, em um sentido mais geral, como a habilidade de perceber as inter-relações de fatos presentes de modo a guiar ações em direção do objetivo desejado. "5 (p.314)

\footnotetext{
5 "Business is a collection of activities carried on for whatever purpose, be it science, technology, commerce, industry, law, government, defense, et cetera. The communication facility serving the conduct of a business (in the broad sense) maybe referred to as an intelligence system. The notion of intelligence is also defined here, in a more general sense, as "the ability to apprehend the interrelationships of presented facts in such a way as to guide action towards a desired goal."
} 
Entretanto, é largamente aceito que Howard Dresner foi quem tornou o termo business intelligence mundialmente conhecido quando propôs BI como um termo guarda-chuva para descrever conceitos e métodos para melhorar a tomada de decisão nos negócios pela utilização de um sistema de suporte baseado em fatos.

\subsection{Definição de BI}

BI, como o nome sugere, corresponde a negócios e é similar a muitos termos nessa área, não apresentando definição padrão como muitos termos científicos. Entretanto, muito da literatura de BI vem da área de negócio da indústria de TI, e de empresas vendedoras (JADIELSKA; DARKE; ZAGARI, 2003; YEOH, 2008).

Para Ranjan (2009), BI tem dois significados diferentes relacionados ao uso do termo inteligência. $O$ primeiro e menos frequente, é o da capacidade de inteligência humana aplicada em atividades de negócio. Inteligência de negócio é um novo campo de investigação da aplicação das faculdades cognitivas humanas e de tecnologias de inteligência artificiais para o suporte a gestão e tomada de decisão em diferentes questões de negócio. A segunda está relacionada à inteligência como o valor da informação pela sua relevância. Trata-se da informação especializada, conhecimento e tecnologias eficientes na gestão das questões de negócio organizacionais e individuais. Portanto, nesse caso, inteligência de negócio é uma categoria ampla de aplicações e tecnologias para reunir, dar acesso e analisar dados com o propósito de auxiliar os usuários da empresa a tomarem as melhores decisões.

Na visão de Stackowiak, Rayman e Greenwald (2007), BI é o processo de captura de uma grande quantidade de dados, analisando e apresentando um conjunto de relatórios de alto nível que transforme a essência dos dados em base para as ações de negócios.

Outros autores enfatizam pontos diferentes em suas conceituações de BI:

Para Davenport e Harris (2007), "BI é um conjunto de tecnologias e processos que usam dados para entender e analisar o desempenho nas organizações”. Já na perspectiva da empresa Platon A/S (2009), o termo BI engloba "o uso de informação para direcionar o insight de negócio. Basicamente trata-se de prover uma melhor fundação para os tomadores de decisão através da geração de informação da forma correta, na qualidade correta, no tempo certo”. Vitt, Luckevich 
e Misner (2002) dizem que o termo BI é "usado por diferente especialistas e empresas vendedoras de softwares para caracterizar um grande número de tecnologias, plataformas de softwares, aplicações específicas, e processos". Portanto fica claro que muitas pessoas têm visto ou expressado BI diferentemente e de contextos variados.

Na tabela 2 são apresentadas definições encontradas de algumas empresas vendedoras de softwares e autores relacionados a BI:

Tabela 2 - Resumo da variedade de definições de BI

\begin{tabular}{|l|l|}
\hline \multicolumn{1}{|c|}{ Empresas Vendedoras/Autores } & \multicolumn{1}{c|}{ Definição de BI } \\
\hline Turban et al (2007) & $\begin{array}{l}\text { Um termo guarda-chuva que engloba } \\
\text { ferramentas, arquiteturas, base de dados, data } \\
\text { warehouses, gestão de desempenho, } \\
\text { metodologias, entre outros, todos dos quais } \\
\text { são integrados em uma plataforma de } \\
\text { software unificada. }\end{array}$ \\
\hline Moss e Atre (2003) & $\begin{array}{l}\text { É uma arquitetura e uma coleção de } \\
\text { operações integradas assim como aplicações } \\
\text { de suporte a decisão e base de dados que } \\
\text { provêm à comunidade de negócio fácil } \\
\text { acesso aos dados do negócio. }\end{array}$ \\
\hline Chang (2006) & $\begin{array}{l}\text { A acurácia, tempestividade, dados críticos, } \\
\text { informação e conhecimento que suportam as } \\
\text { tomadas de decisão estratégicas e } \\
\text { operacionais e a avaliação de risco num } \\
\text { ambiente de negócio incerto e dinâmico. A } \\
\text { fonte de dados, informação e conhecimento } \\
\text { são ambas organizadamente coletadas } \\
\text { internamente assim como externamente } \\
\text { supridas por parceiros, clientes ou terceiros } \\
\text { como resultado de suas próprias escolhas. }\end{array}$ \\
\hline Kulkarni e King (1997) & $\begin{array}{l}\text { O resultado de análises aprofundadas dos } \\
\text { dados de negócio detalhados, incluindo base } \\
\text { de dados e tecnologias de aplicação, assim } \\
\text { como análises práticas. }\end{array}$ \\
\hline Gangadharan e Swami (2004) & $\begin{array}{l}\text { Um produto da análise dos dados de negócio } \\
\text { usando ferramentas de BI. Isso surge como } \\
\text { resultado dessa análise. }\end{array}$ \\
\hline $\begin{array}{l}\text { Os processos, tecnologias, e ferramentas } \\
\text { necessárias para transformar dados em } \\
\text { informação, informação em conhecimento e } \\
\text { conhecimento em planos para direcionar } \\
\text { ações de negócios lucrativas. BI engloba } \\
\text { data warehousing, ferramentas de business }\end{array}$ \\
\hline
\end{tabular}




\begin{tabular}{|c|c|}
\hline & $\begin{array}{lllll}\begin{array}{l}\text { analytics e gestão } \\
\text { conhecimento. }\end{array} & \text { de conteúdo / } \\
\end{array}$ \\
\hline Adelman e Moss (2000) & $\begin{array}{l}\text { Um termo que engloba uma enorme gama de } \\
\text { softwares analíticos e soluções para agrupar, } \\
\text { consolidar, analisar e prover acesso à } \\
\text { informação de maneira que se supõem } \\
\text { permitir aos usuários tomarem melhores } \\
\text { decisões de negócio. }\end{array}$ \\
\hline Gartner Research (Hostmann, 2007) & $\begin{array}{l}\text { Um termo guarda-chuva que inclui } \\
\text { aplicações analíticas, a infraestrutura e } \\
\text { plataformas, assim como as melhores } \\
\text { práticas. }\end{array}$ \\
\hline IBM (Whitehorn e Whitehorn, 1999) & $\begin{array}{l}\text { Um termo guarda-chuva que cobre } \\
\text { amplamente os processos envolvidos em } \\
\text { extrair informações de negócio valiosas da } \\
\text { massa de dados que existe em uma típica } \\
\text { empresa. }\end{array}$ \\
\hline Business Objects (2007) & $\begin{array}{l}\text { O uso dos dados discrepantes da organização } \\
\text { para prover informação significativa e } \\
\text { análises para os funcionários, clientes, } \\
\text { fornecedores, e parceiros para maior } \\
\text { efetividade na tomada de decisão. }\end{array}$ \\
\hline Cognos (2007) & $\begin{array}{l}\text { BI associa pessoas e dados, oferecendo uma } \\
\text { variedade de maneiras de enxergar a } \\
\text { informação que traz de volta a tomada de } \\
\text { decisão baseada em fatos. }\end{array}$ \\
\hline SAS Institute (Ing, 2007) & $\begin{array}{l}\text { Entregando a informação certa para a pessoa } \\
\text { certa no tempo certo para suportar melhores } \\
\text { tomadas de decisão e para ganhar vantagem } \\
\text { competitiva. }\end{array}$ \\
\hline Oracle (2007) & $\begin{array}{l}\text { Um portfólio de tecnologia e aplicações que } \\
\text { provêem um integrado sistema ponta a ponta } \\
\text { de gestão de desempenho de empresa, } \\
\text { incluindo aplicações de gestão de } \\
\text { desempenho financeiro, aplicações } \\
\text { operacionais de BI, infraestrutura e } \\
\text { ferramentas de BI, e data warehousing. }\end{array}$ \\
\hline $\begin{array}{l}\text { Informatica, Teradata, MicroStrategy } \\
\text { (Markarian } \text { et al. 2007) }\end{array}$ & $\begin{array}{l}\text { Um processo interativo para exploração e } \\
\text { análise estruturada, informação de domínio } \\
\text { específico (frequentemente armazenada em } \\
\text { um data warehouse) para discernir } \\
\text { tendências e padrões, desse modo derivando } \\
\text { insights e desenhando conclusões. }\end{array}$ \\
\hline
\end{tabular}

Fonte: adaptado de Yeoh (2008)

$\mathrm{Na}$ tabela 2 as definições apresentadas por alguns autores, e principalmente pelos vendors de tecnologia como Business Object, SAS Institute e IBM, apresentam um foco menos técnico 
abordando os aspectos relacionados ao tratamento de dados e na conversão em informação relevante para a tomada de decisão dos usuários do sistema, conceito esse que será adotado por esse trabalho uma vez que essa abordagem lida com uma importante característica do BI que é a de prover base para a obtenção de vantagem competitiva nas organizações através da melhora do processo de tomada de decisão.

Nesse trabalho, optou-se por seguir a abordagem apresentada por Stackowiak et al. (2007), estabelecendo-se como definição de BI o processo de captura de grandes quantidades de dados oriundos de diferentes origens, assim como a análise e apresentação de um conjunto de relatórios de alto nível através de plataformas tecnológicas flexíveis e amigáveis, que transformem os dados em sua forma bruta numa base confiável para as ações de negócios. Embora acrescida de uma pequena complementação (diferentes origens e plataformas flexíveis) para torná-la mais abrangente, foi escolhida a definição de Stackowiak et al. (2007) como base para essa definição por estar alinhada com a proposta desse trabalho.

\subsubsection{Sistemas de BI}

Assume-se que os sistemas de BI são soluções responsáveis por transformar os dados em informação e conhecimento e também pela criação de ambiente para a tomada de decisão efetiva, pensamentos estratégicos e atuantes na organização, como apresentado na figura 4 (OLSZAK E ZIEMBA, 2007, p.137). Os sistemas de BI podem ser vistos como arquiteturas empresarias para a integração operacional, de aplicações de suporte a decisão e base de dados, disponibilizando aos usuários da empresa um acesso fácil às informações solicitadas. Também facilita as análises e compartilhamento das informações, e ajudam na tomada de decisão de negócio baseada na informação (CHEE et al., 2009). 


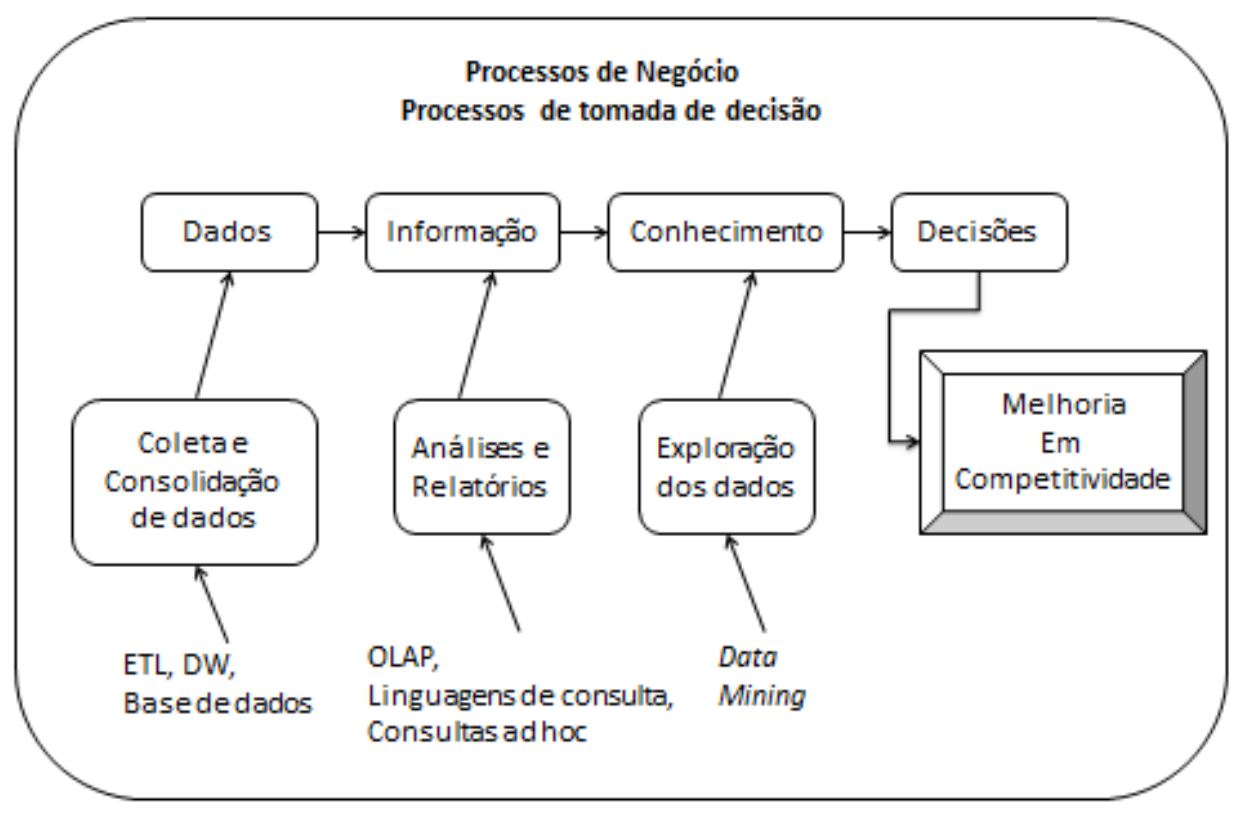

Figura 4 - O papel dos sistemas de BI na tomada de decisão Fonte: adaptado de Olszak, \& Ziemba (2007)

Para Olszak e Ziemba (2007), os sistemas de Business Intelligence fornecem recursos necessários para a tomada de decisão nas organizações contemporâneas. Os principais desafios enfrentados pelos sistemas de BI incluem:

- Exploração inteligente;

- Integração;

- Agregação;

- Análises multidimensionais de dados originados de várias fontes de informação.

Os sistemas de BI padrão combinam dados originados de sistemas de informação internos da organização e integram dados originados de áreas particulares do ambiente como estatísticas, finanças e portais de investimentos entre diversas outras bases de dados. Tais sistemas são encarregados de prover informação atualizada, adequada e confiável nos diferentes aspectos das atividades empresariais.

Ainda Olszak e Ziemba (2007) menciona que por um longo tempo, sistemas de gestão de informação (MIS) têm suportado as organizações em suas diferentes atividades. Entretanto, hoje muitos sistemas de TI têm sofrido significante depreciação. Até agora os sistemas de gestão de informação existentes (MIS, DSS, ES, EIS) não tem atendido as expectativas dos tomadores de decisão, como: 
- Tomada de decisão sob pressão do tempo;

- Competição de monitoramento;

- Posse de informação em suas organizações que incluem diferentes pontos de vista e

- Suprir análises constantes de numerosos dados e considerar diferentes variantes de desempenho da organização.

Os sistemas de gestão de informação simplesmente não são capazes de lidar bem com a integração de dados diferentes, dispersos e heterogêneos, eles não podem interpretar tais dados em qualquer amplo contexto efetivamente e eles não são capazes de suficientes descobertas de novas interdependências de dados (BUI, 2000; GRAY E WATSON, 1998). A fim de serem capazes de reagir rapidamente às mudanças que ocorrem no mercado, as organizações precisam de gerenciamento de sistemas de informação que tornem possível gerar análises diferentes de causas e efeitos nas organizações e em seus ambientes (POWER, 2001).

$\mathrm{Na}$ figura 5, um quadro da evolução dos sistemas de gestão de informação influenciada pelas limitações observadas devido às técnicas impróprias de aquisição de dados, análises, descobertas e visualizações.

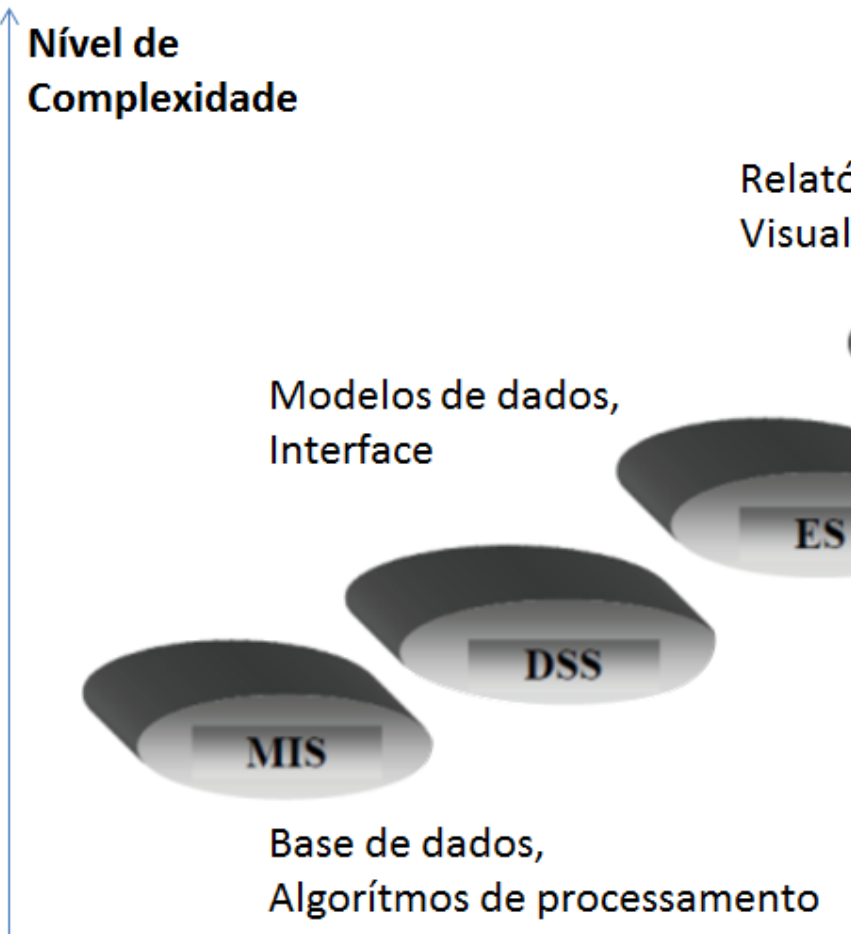

Tempo

Figura 5 - Desenvolvimento dos sistemas de gestão de informação Fonte: adaptado de Olszak e Ziemba (2007) 
Os sistemas de BI se diferenciam dos sistemas de gestão da informação (MIS) (i.e., sistemas de suporte à decisão (DSS), sistemas de informação executiva (EIS) e sistemas de suporte executivo (ES)) primeiramente pela ampla gama de temas, análises multivariadas, dados semiestruturados originários de diferentes fontes e pela apresentação de dados multidimensionais (GRAY, 2003). Os sistemas de BI podem dar suporte a tomada de decisão em todos os níveis de gestão da estrutura (OLSZAK e ZIEMBA, 2003). No nível estratégico, os sistemas de BI tornam possível estabelecer os objetivos de forma precisa e acompanhar suas realização. Os sistemas de BI permitem a construção de relatórios comparativos diferentes como resultados históricos, rentabilidade de ofertas específicas, efetividade do canal de distribuição com a realização de simulações de desenvolvimento ou previsão de resultados futuros. No nível tático, os sistemas de BI podem prover alguma base para a tomada de decisão em marketing, vendas, finanças, gestão de capital, etc. No nível operacional, os sistemas de BI são usados para a realização de análises ad hoc e para responder questões relacionadas à departamentos operacionais, atualizações financeiras constantes, vendas e cooperação com fornecedores, consumidores, etc. (OLSZAK E ZIEMBA, 2007).

Um importante aspecto a ser considerado em sistemas de BI é sua arquitetura, isso é, um conjunto de elementos técnicos e sistêmicos que o compõem, alinhados à estratégia empresarial, descrito no item a seguir.

\subsubsection{Arquitetura de BI}

O objetivo da análise de informação do negócio foi, e ainda é, criar a habilidade de avaliar o quanto eficiente é a operação da organização e consequentemente identificar oportunidades para explorar conhecimento acionável (LOSHIN, 2008).

Esse conceito de gestão de desempenho e avanço através de relatórios e análises tem evoluído para o que se define comumente como business intelligence. Enquanto muitas apresentações de front-end, relatórios, e produtos de visualização ajudam na comunicação de resultados de análises, o BI permanece bastante ligado a infraestrutura técnica do data warehouse (DW). O desafio tático está em prover uma estrutura de BI eficaz capaz de evoluir coletando dados de sistemas distribuídos diferentes, consolidando esse dados em um modelo centralizado e 
organizando-os para alimentar as aplicações de front-end a fim de dirigir as análises do negócio e seus relatórios.

A arquitetura típica de BI para centros de dados estruturados em data warehouse é apresentada na figura 6. Os dados são extraídos de sistemas operacionais e distribuídos utilizando-se tecnologias de navegadores de internet (browsers). A necessidade específica de dados são carregados para um data mart utilizado pelos usuários. Os resultados são obtidos de rotinas que fornecem os dados do data mart para responder as solicitações dos usuários web e analistas OLAP. As informações podem assumir diversas formas como relatórios personalizados, relatórios rotineiros, e respostas a solicitações específicas. Os resultados são enviados independentemente dos parâmetros pré-estabelecidos.

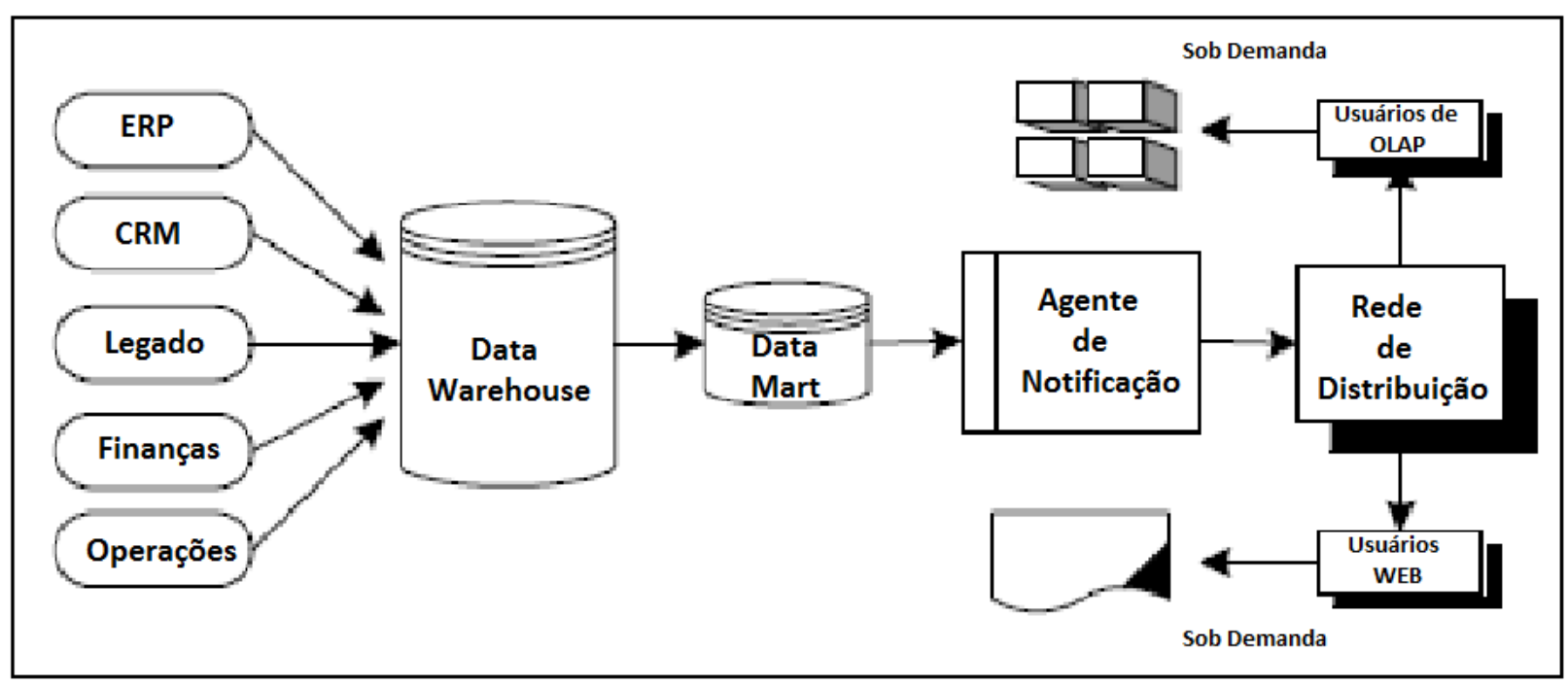

Figura 6 - Arquitetura de BI típica para dados estruturados Fonte: adaptado de Negash (2004)

\subsection{Fatores críticos de sucesso do BI}

O conceito de identificação de fatores de sucesso em negócios foi tratado inicialmente por D. Donald Daniel em 1961 (HAWKING E SELLITTO, 2010). Daniel (1961) discutiu esses fatores no nível macro onde cada indústria estabeleceria entre três a seis fatores como indicadores de sucesso ou falha. 
Certas áreas precisam ter desempenho em níveis satisfatórios para que um sistema ou uma organização possam operar com sucesso em condições competitivas. Essas áreas, portanto se tornam ingredientes importantes de um sistema de sucesso e por isso são chamados fatores críticos de sucesso. O mais relevante é que esses fatores não são mensuráveis (VODAPALLI, 2009). Rockart (1979), através de entrevistas estruturadas com executivos chefes, desenvolveu o conceito de fatores críticos de sucesso. Nas entrevistas ele identificou os objetivos dos executivos com relação às informações e os FCS. Ele argumenta que os FCS auxiliam os executivos a definir suas necessidades correntes de informação. Os FCS são aqueles fatores de desempenho que devem receber atenção dos gestores da companhia para que ela se mantenha competitiva. Enquanto não são candidatos com finalidades de planejamento estratégico, a identificação dos FCS pode auxiliar os executivos a determinarem aonde os gestores devem focar sua atenção, a desenvolver medidas para os FCS e determinar a quantidade de informação requerida e assim limitar o acúmulo desnecessário de dados. O autor conclui que os FCS são um número limitado de áreas nas quais resultados satisfatórios garantirão desempenho competitivo e sucesso para o indivíduo, departamento ou organização. FCS são as poucas áreas onde "as coisas precisam andar certo" para o negócio se desenvolver e para atingir seus objetivos.

Assim, os FCS são as características, condições ou variáveis que podem significativamente impactar no sucesso de uma firma em competir em uma particular indústria dando a ela as variáveis, condições e características bem sustentadas, mantidas e gerenciadas (LEIDECKER E BRUNO, 1987). A identificação desses parâmetros pode ajudar a esclarecer a natureza e o escopo dos recursos que precisam ser reunidos para permitir o time de projeto a concentrar seus esforços em questões prioritárias evitando desperdiçar tempo considerando o que as tecnologias disponíveis possibilitarão (GREENE E LOUGHRIDGE, 1996).

O conceito de FCS também tem sido aplicado a projetos, principalmente projetos ligados a tecnologia e sistemas de informação. Existem inúmeros estudos dos FCS na implementação e uso de sistemas de ERP (Hawking e Sellitto, 2010), entretanto, apesar do reconhecimento do BI como uma importante área de prática e pesquisa, relativamente poucos estudos têm sido conduzidos para avaliar como o BI é aplicado em geral e mais especificamente, o que poderia ser pertinente ao reconhecimento de seus FCS (CHENOWTH et al, 2006). 
A identificação do conjunto de FCS para o desenvolvimento de qualquer sistema de informação importante, como um sistema de BI, é fundamentalmente diferente do conjunto de tarefas interligadas que devem ser acompanhadas para garantir a realização do projeto (DOBBINS, 2000; YEOH, 2008). Por isso, a simples precaução de uma bem sucedida execução dos FCS podem não garantir sucesso da implementação do projeto, mas certamente pode dar sobrevida a ele. Wixon e Watson (2001) estudaram 111 organizações e encontraram que a qualidade dos dados e sistema impactam sobre o sucesso do BI com a qualidade de sistema sendo quatro vezes mais importante que a qualidade de dados. Eles também identificaram que a qualidade de sistema era afetada pelo suporte dos gestores, recursos adequados, participação dos usuários e um time de projeto habilidoso. Hawking e Sellitto (2010) apontam a ampla variedade de abordagens e medidas associada aos FCS. Alguns estudos medem fatores de implementação enquanto outros medem o sucesso de BI.

Tabela 3 - Fatores críticos de sucesso (FCS) do BI

\begin{tabular}{|l|l|}
\hline \multicolumn{1}{|c|}{ Autor } & \multicolumn{1}{|c|}{ Fatores } \\
\hline Farley (1998) & $\begin{array}{l}\text { Rápida implementação, habilidade em se } \\
\text { ajustar as necessidades do negócio, } \\
\text { informação útil, fácil de navegar }\end{array}$ \\
\hline Watson e Haley (1997) & $\begin{array}{l}\text { Suporte dos gestores, recursos adequados, } \\
\text { mudança de gestão, gerenciamento de } \\
\text { metadados } \quad\end{array}$ \\
\hline Chen et al (2000) & \begin{tabular}{l} 
Satisfação dos usuários \\
\hline Sammon e Finnegan (2000) \\
gestores, recursos adequados incluindo o \\
orçamentário e habilidades, qualidade de \\
dados, modelo de negócio flexível, mordomia \\
de dados, estratégia para métodos/ferramentas \\
automáticas de extração de dados
\end{tabular} \\
\hline Little e Gibson (2003) & $\begin{array}{l}\text { Suporte dos gestores, abordagem no negócio, } \\
\text { uso de prototipagem de DW, metadados, } \\
\text { metodologia de implementação, suporte } \\
\text { externo (consultoria) }\end{array}$ \\
\hline Mukherjee e D’Souza (2003) & $\begin{array}{l}\text { Qualidade de dados, tecnologia ajustada, } \\
\text { suporte dos gestores, objetivo de negócio } \\
\text { definidos, envolvimento dos usuários, } \\
\text { mudança de gestão }\end{array}$ \\
\hline Rudra e Yeo (2000) & $\begin{array}{l}\text { Fatores técnicos (qualidade de dados e } \\
\text { consistência de dados, etc.) }\end{array}$ \\
\hline $\begin{array}{l}\text { Fatores relacionados ao projeto (o plano de } \\
\text { projeto precisa ser compatível com as } \\
\text { demandas de negócio e do escopo da gestão } \\
\text { de projeto), fatores técnicos (seleção de } \\
\text { DBMS, carregamento de dados, e eficiência } \\
\text { do acesso de dados, etc.) }\end{array}$ \\
\hline
\end{tabular}




\begin{tabular}{|l|l|}
\hline Wixom e Watson (2001) & $\begin{array}{l}\text { Qualidade de dados, qualidade de sistema, } \\
\text { suporte dos gestores, recursos adequados, } \\
\text { participação do usuário, time de projeto } \\
\text { capacitado }\end{array}$ \\
\hline Chenweth et al (2006) & $\begin{array}{l}\text { Suporte dos gestores, defensor, arquitetura } \\
\text { (data marts), adequação da } \\
\text { organização/aceitação do usuário }\end{array}$ \\
\hline Yeoh e Koronios (2010) & $\begin{array}{l}\text { Suporte dos gestores, visão clara e caso de } \\
\text { negócio, defensor, time balanceado, } \\
\text { abordagem de desenvolvimento iterativa, } \\
\text { gestão de mudança, quadro técnico adequado, } \\
\text { qualidade de dados }\end{array}$ \\
\hline
\end{tabular}

Fonte: adaptado de Hawking e Sellitto (2010)

Através de revisão da literatura, pesquisa realizada com participantes de conferência sobre DW e entrevistas com especialistas nesse tema, Wixom e Watson (2001) desenvolveram um modelo de pesquisa para o sucesso de DW na tentativa de demonstrar o inter-relacionamento entre vários fatores e seus impactos no sucesso da implementação e/ou sistema. Na figura 7 temos a representação desse modelo apresentada no trabalho de Hawking e Sellito (2010) associada ao BI. Os autores mencionam que muitos dos fatores de sucesso identificados da literatura para a implementação e sucesso do BI não são únicos de seu ambiente. Muitos desses fatores de sucesso podem ser obtidos de outros projetos de SI e têm sido observados em implementação de portais, CRM e sistemas de informação geográfica. Entretanto, um fator de sucesso é particularmente único do BI que é a necessidade de integrar dados oriundos de diferentes sistemas (HAWKING e SELLITO, 2010).

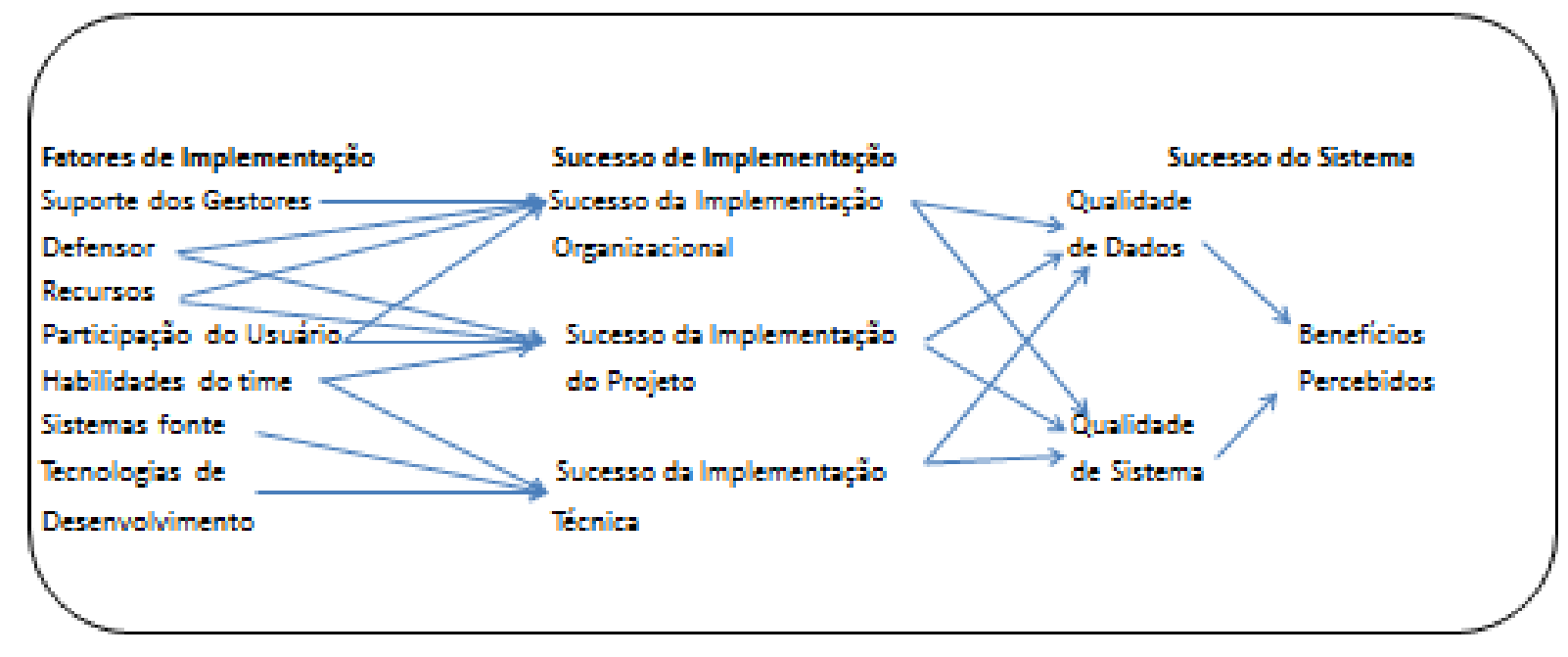

Figura 7 - Modelo de Sucesso de BI

Fonte: adaptado de Hawking e Sellitto (2010) 


\subsubsection{Diferenciando FCSs de KPIs}

Indicadores chave de desempenho (KPIs - Key Performance Indicators) usualmente são medidas de progresso em direção ao atingimento de objetivos de um projeto, sistema ou organização. KPIs permitem aos gestores tomarem ações rápidas quando existem indicadores de desempenho bem definidos ao longo do caminho em direção aos objetivos organizacionais ou de projetos.

De acordo com Cooper (2006), KPIs representam um valor particular ou características que é medida para avaliar se os objetivos da organização estão sendo atingidos. Eles refletem os FCSs, necessidades dos stakeholders, e as expectativas da organização. Para os KPIs e suas medidas serem efetivas, os objetivos das organizações precisam ser especificados, medidos, acordados, realísticos e baseado no tempo. KPIs podem usar métricas financeiras e não financeiras. Ainda de acordo com Cooper (2006), KPIs são usados em conjunto com FCS e devem ter uma meta que precisa ser atingida. O alvo para um KPI pode ser expresso como um percentual, uma taxa simples, um índice, uma média ou com parâmetros estatísticos. Qualquer que seja a escolha do KPI e da meta, elas devem ser mensuráveis. Para Malik (2005), o nível primário da etapa de elaboração de painéis de indicadores do BIS envolve determinar as questões críticas do negócio que precisam ser respondidas através da implantação desses painéis, e então transcrever essas questões para os KPIs que precisam ser capturados através dos painéis de indicadores a fim de fornecer respostas e insights. Dessa forma, o processo de definição de KPIs para painéis não é diferente da construção de infraestrutura de relatórios (ou sistemas de BI). Cada KPI deve conter os seguintes elementos: fonte(s) de dado(s), granularidade, cálculo e variância (MALIK, 2005, p.15-17).

\subsubsection{Lista de fatores críticos de sucesso (FCS)}

Vodapalli (2009) em seu trabalho estudou os FCSs relacionados à implementação de BI, também relatado por vários autores em uma ampla variedade de artigos, jornais, periódicos, relatórios, etc. Na tabela 4 são consolidados os FCS obtidos da revisão da literatura realizada pelo autor. 
Tabela 4 - Lista de fatores críticos de sucesso da revisão da literatura.

\begin{tabular}{|c|c|}
\hline $\begin{array}{l}\text { 1.Claudia Imhoff, Intelligent } \\
\text { Solutions } \\
\text { (Claudia Imhoff, 2004) }\end{array}$ & $\begin{array}{l}\text { - } \text { Arquitetura dependente } \\
\text { - } \quad \text { Forte parceria entre a comunidade de negócio e TI } \\
\text { - } \quad \text { Problemas diferente de metodologia } \\
\text { - } \\
\text { Disposição em aceitar mudanças }\end{array}$ \\
\hline $\begin{array}{l}\text { 2.Ferenc Mantfeld, CTO, Siebel } \\
\text { (Mantfeld, 2006) }\end{array}$ & $\begin{array}{l}\text { Causas para a falha de implementações de BI: } \\
\text { - Falta de planejamento (upfront) } \\
\text { - } \text { Questões de qualidade de dados } \\
\text { - } \text { Filta de antecipação de mudanças } \\
\text { - Compra one-stop } \\
\text { - Dashboards como tratamento genérico } \\
\text { - Outsourcing } \\
\text { - Considerações de desempenho } \\
\end{array}$ \\
\hline $\begin{array}{l}\text { 3. Wayne W. Eckerson, Director } \\
\text { of Reseach, The Data } \\
\text { Warehousing } \\
\text { (Eckerson, 2005) }\end{array}$ & $\begin{array}{l}\text { - Suporta todos os usuários através de suítes de BI integradas } \\
\text { - } \quad \text { Adequado à maneira de trabalho dos usuários } \\
\text { - Integra com desktop e aplicações operacionais } \\
\text { - } \quad \text { Entrega informação acionável } \\
\text { - Promove desenvolvimento rápido } \\
\text { - Prove uma plataforma extensível robusta }\end{array}$ \\
\hline $\begin{array}{l}\text { 4.Cindi Howson, Fundadora da } \\
\text { BIScorecard (Howson, 2006) }\end{array}$ & $\begin{array}{ll}\text { - } & \text { Medida de sucesso } \\
\text { - } & \text { Desenvolve uma estratégia de dados } \\
\text { - } & \text { Gerencia bem o programa } \\
\text { - } & \text { Escolha suporte aos executivos } \\
\text { - } & \text { Padronizar em uma plataforma } \\
\text { - } & \text { Alinha estratégia de BI com o negócio }\end{array}$ \\
\hline $\begin{array}{l}\text { 5.Keith Gile, Analista de } \\
\text { Indústria Senior } \\
\text { Forrester Research (Gile, 2003) }\end{array}$ & $\begin{array}{l}\text { - Criar um plano formal } \\
\text { - Classificar usuários finais analíticos / Conhecer os usuários } \\
\text { (Produtores e Consumidores) } \\
\text { - Mapear as soluções para os usuários (Determinar o que você já } \\
\text { tem e preencher os gaps) }\end{array}$ \\
\hline $\begin{array}{l}\text { 6.Dan Murray, VP e CIO da } \\
\text { Blastrac Manufacturing (Dan } \\
\text { Murray, 2009) }\end{array}$ & $\begin{array}{l}\text { - Definir o problema claramente - evitar a deformação do escopo } \\
\text { - Identificar as questões e necessidades específicas dos usuários - } \\
\text { resolver seus problemas } \\
\text { - Entender as questões fundamentais de dados - BI não é } \\
\text { somente software } \\
\text { - Selecionar o kit de ferramentas apropriado - procurar por } \\
\text { aplicações rápidas, fáceis, leves e de baixo custo } \\
\text { - Construído para flexibilidade e capacidade de resposta - Saber } \\
\text { que os usuários irão solicitar mudanças logo de início } \\
\text { - Alavancar pessoal existente - eliminar soluções que requerem } \\
\text { novo staff e/ou consultores } \\
\text { - Liderança do topo - reforce sua autoridade e posição executiva }\end{array}$ \\
\hline $\begin{array}{l}\text { 7.Ilya Dmitriev, responsável } \\
\text { pelo departamento de BI e } \\
\text { Geoespacial, Affecto Latvia Ltd } \\
\text { (Dmitriev, 2008) }\end{array}$ & $\begin{array}{l}\text { - } \quad \text { Linguagem comum } \\
\text { - } \quad \text { Aenos é mais } \\
\text { - } \quad \text { Gerenciarar a resilistência organizacional } \\
\text { - Planejamento de recursos }\end{array}$ \\
\hline $\begin{array}{l}\text { 8.InetSoft, Executive White } \\
\text { Paper } \\
\text { (InetSoft Technology, 2007) }\end{array}$ & $\begin{array}{l}\text { - Modelo econômico: BI operacional como uma aplicação } \\
\text { regular } \\
\text { - Modelo de aplicação: Envolvimento ativo para todos os } \\
\text { stakeholders } \\
\text { - Modelo de dados: armazenamento de dados operacionais e } \\
\text { dados desestruturados }\end{array}$ \\
\hline
\end{tabular}




\begin{tabular}{|c|c|}
\hline $\begin{array}{l}\text { 9.William Yeoh, Andy } \\
\text { Koronios, Jing Gao } \\
\text { Yeoh } \text { et al., 2008) }\end{array}$ & $\begin{array}{l}\text { - } \text { Gerenciamento de suporte \& Patrocínio comprometidos } \\
\text { - Gerenciamento de mudança orientado ao usuário de negócio } \\
\text { - } \quad \text { Clara visão de negócio \& caso bem estabelecido } \\
\text { - } \text { Foco em negócício e composição de gerenciamento de projeto } \\
\text { - Estratégico e quadro técnico extensível } \\
\text { - Qualidade de dados sustentável \& quadro de governança }\end{array}$ \\
\hline $\begin{array}{l}\text { 10.U.S. Army Enterprise } \\
\text { Solution Competency Center } \\
(\text { ESCC, 2009) }\end{array}$ & $\begin{array}{l}\text { - Envolvimento de alto nível do executivo, do financeiro e de TI } \\
\text { - Usuários engajados } \\
\text { - Alinhamento entre negócio e TI } \\
\text { - Apreciação difundida pelo valor dos dados por toda a } \\
\text { corporação } \\
\text { - Implementar os cinco pontos chave de melhores práticas de BI } \\
\quad \text { Programas de governança de informação de negócio } \\
\circ \text { Estratégia de informação da empresa } \\
\quad \text { Programa de qualidade de informação } \\
\quad \text { Data Warehouse da empresa } \\
\quad \text { Centro de competência organizacional } \\
\text { - Garantir alta qualidade e limpa de dados relevantes para o } \\
\text { negócio } \\
\text { Definir claramente o papel do centro de competência para o } \\
\text { sucesso do BI o que inclui a tecnologia de BI campeã e a } \\
\text { definição de padrões. Focar no alinhamento com o negócio, } \\
\text { priorização do projeto, e resolvendo a gestão e questões de } \\
\text { habilidade associadas com projetos significativos de BI } \\
\text { Ter a mentalidade de melhoria contínua a fim de realizar e } \\
\text { atingir o valor completo do negócio por ter solução de BI }\end{array}$ \\
\hline $\begin{array}{l}\text { 11.Faun deHenry, FMT Systems } \\
\text { Inc., } \\
\text { (deHenry, 2009) }\end{array}$ & $\begin{array}{l}\text { - } \quad \text { Patrocínio executivo } \\
\text { - } \quad \text { Metoctadivas realistas } \\
\text { - } \quad \text { Time } \\
\text { - } \text { Arquitetura técnica e ferramentas apropriadas } \\
\text { - } \quad \text { Mudidade de dados de escopo limitadas } \\
\text { - } \quad \text { Projetos de rápido payback } \\
\text {-Note: áreas chave onde ferramentas de DW/ETL e consultores } \\
\quad \text { de BI podem adicionar valor }\end{array}$ \\
\hline $\begin{array}{l}\text { 12.Steve Williams e Nancy } \\
\text { Williams, Elsevier Inc. }\end{array}$ & $\begin{array}{l}\text { De acordo com os autores, os erros comuns que são feitos enquanto se } \\
\text { estabelece e gerencia um programa de BI são: } \\
\text { - Utilizar práticas ad hoc para selecionar e financiar projetos de } \\
\text { BI } \\
\text { - Prover governança inadequada para a gestão do programa de BI } \\
\text { - Estabelecer um programa de governança baseado no projeto de } \\
\text { BI inicial } \\
\text { - Falha em posicionar estrategicamente o BI na organização de } \\
\text { negócio } \\
\text { - Não prover recursos adequados e fundos para suportar os } \\
\text { esforços necessários para o sucesso da iniciativa de BI }\end{array}$ \\
\hline $\begin{array}{l}\text { 13.James Markarian, CTO, } \\
\text { Informatica; } \\
\text { Stephen Brobst, CTO, Teradata; } \\
\text { e Jeff Bedell, CTO, } \\
\text { MicroStrategy } \\
\text { (Markarian } \text { et } \text { al., 2007) }\end{array}$ & $\begin{array}{l}\text { - Dados atualizados, limpos, acurados e completos } \\
\text { - Escalabilidade em termos de usuários concorrentes pelo } \\
\text { mecanismo de entrega } \\
\text { - Gerenciamento do mix de carga de trabalho para garantir os } \\
\text { objetivos de desempenho de nível de serviço } \\
\text { - Medida de tempo de resposta de questões táticas pelo tipo de } \\
\text { - } \text { usuário e análise } \\
\text { Alta disponibilidade de métricas por comunidade de usuários }\end{array}$ \\
\hline
\end{tabular}




\begin{tabular}{|c|c|}
\hline $\begin{array}{l}\text { 14.Neil McMurchy da Gartner } \\
\text { Research } \\
\text { (Neil McMurchy, 2008) }\end{array}$ & $\begin{array}{l}\text { - Uma visão estratégica de BI com implementação faseada, } \\
\text { focada na realização de benefícios } \\
\text { - Propriedade de negócio forte da estratégia de BI e seus } \\
\text { resultados } \\
\text { - Consertar a qualidade de dados e a questão de governança de } \\
\text { dados no inicio do processo } \\
\text { - Constantemente procurar em expandir o escopo da estratégia de } \\
\text { BI } \\
\text { - Investimento substancial e sustentado das habilidades de BI e } \\
\text { competências }\end{array}$ \\
\hline $\begin{array}{l}\text { 15.Lyndsay Wise } \\
\text { (Wise, 2007) }\end{array}$ & $\begin{array}{ll}\text { - } & \text { Identificar o problema de negócio } \\
\text { - } & \text { Determinar a expectativa do usuário } \\
\text { - } & \text { Entender a entrega de dados } \\
\text { - } & \text { Externar as iniciativas de treinamento } \\
\text { - Optar por uma solução vertical - ou horizontal }\end{array}$ \\
\hline $\begin{array}{l}\text { 16.Knightsbridge em parceria } \\
\text { com a BusinessWeek Research } \\
\text { Services } \\
\text { (Knightsbridge, 2006) }\end{array}$ & $\begin{array}{l}\text { - } \quad \text { Programa de governança de informação do negócio } \\
\text { - } \quad \text { Pstratégia de informação da companhia } \\
\text { - } \quad \text { Data Warehouse da empresa } \\
\text { - } \quad \text { Centros de competência de BI } \\
\text { Armadilhas de BI: } \\
\text { - Falta de adoção por parte dos usuários } \\
\text { - Requerimentos de negócio incompletos ou imprecisos } \\
\text { - } \quad \text { BI e gestão de desempenho da empresa desconectados } \\
\text { - Falta de cooperação ou colaboração entre negócio e TI } \\
\text { - Falta de habilidades de negócio requeridas dentro da } \\
\text { - } \quad \text { Fundosizina insuficientes fara fazer certo } \\
\text { - } \quad \text { Falta de habilidade de TI requerida dentro da organização }\end{array}$ \\
\hline $\begin{array}{l}\text { 17.Dan Vesset, chaves para o } \\
\text { sucesso de implantação de BI } \\
\text { para o IDC, comissionado pela } \\
\text { Oracle e intitulado "The State of } \\
\text { Business Analytics - Best } \\
\text { practices, benefits, challenges } \\
\text { and shortcomings" } \\
\text { (Vesset, 2005) }\end{array}$ & $\begin{array}{l}\text { - } \quad \text { Definir necessidades dos sistemas } \\
\text { - Transformar dados dispersos em um modelo único } \\
\text { - Gerenciar as expectativas / experiência dos usuários } \\
\text { Garantir disponibilidade do sistema }\end{array}$ \\
\hline $\begin{array}{l}\text { 18.Anthony Mano, CEO, Lisys } \\
\text { Technology Solutions } \\
\text { (Mano, 2009) }\end{array}$ & $\begin{array}{l}\text { - Requerimento do negócio: deve encontrar consistência, } \\
\text { completude, clareza e complacência } \\
\text { - Dados do negócio: acessibilidade, completude e qualidade são } \\
\text { fundamentos do sucesso de implementação } \\
\text { Tecnologia: deve complementar sistemas existentes; disponível } \\
\text { a um custo acessível; prove rápido desenvolvimento; adaptável } \\
\text { e flexível para o desenvolvimento de clientes; controle para } \\
\text { mudanças e gestão de meta dados } \\
\text { - Especialidades: know-how, aptidão e atitude compõem o } \\
\text { recurso técnico de um especialista }\end{array}$ \\
\hline $\begin{array}{l}\text { 19.Christopher Meister, Diretor, } \\
\text { Management Consulting, Auxis } \\
\text { Inc. } \\
\text { (Meister, 2009) }\end{array}$ & $\begin{array}{l}\text { Desafios de sucesso na implementação de BI } \\
\text { - Identificar os requerimentos chave e validar a prova de } \\
\text { conceito } \\
\text { - Avaliar a qualidade e a suficiência da fonte de dados } \\
\text { - Garantir flexibilidade no final da implementação } \\
\text { Passos para garantir o sucesso na implementação de BI } \\
\text { - Pensar grande, começar pequeno } \\
\text { - Utilizar técnicas de protótipos iterativos na definição de } \\
\text { requerimentos e escopo }\end{array}$ \\
\hline
\end{tabular}




\begin{tabular}{|c|c|}
\hline $\begin{array}{l}\text { 20.John Schwechel, Senior } \\
\text { Project Manager, Retail Process } \\
\text { Engineering, LLC. } \\
\text { (Schwechel, 2005) }\end{array}$ & $\begin{array}{l}\text { - } \quad \text { Ajustar expectativas: Definir o projeto } \\
\text { - Ser organizado: Criar um plano de projeto } \\
\text { - } \quad \text { Começar pelo topo: Conquistar o suporte do executivo } \\
\text { - Os melhores times entregam os melhores resultados: Gestão de } \\
\text { - } \quad \text { Sime de projeto } \\
\text { - } \quad \text { Colar no plano: Gestão de escopo } \\
\text { - Entregar o planejado: Garantia de qualidade } \\
\text { - Espalhe as notícias: Comunique cedo e com frequência } \\
\text { - Conquiste a aceitação do usuário: Gestão de mudança } \\
\text { - } \quad \text { Quantifique os resultados: Medidas de sucesso do projeto }\end{array}$ \\
\hline
\end{tabular}

Fonte: adaptado de Vodapalli (2009)

\subsubsection{Modelo de classificação de fatores críticos de sucesso (FCS)}

Para Yeoh e Korinos (2008), os FCS podem ser classificados em quatro categorias nomeadas como organizacional, processo, técnicas e dimensões ambientais ou perspectivas. No entanto, ele menciona que durante seu estudo sobre FCS, perspectiva ambiental foi considerada incompatível, pois não encontrou referência desse fator em seus resultados de pesquisa, conforme se comprova na tabela 4. Ainda para Yeoh e Korinos (2008), os fatores que devem ser considerados em cada perspectiva são melhores ilustrados com a figura 8 .

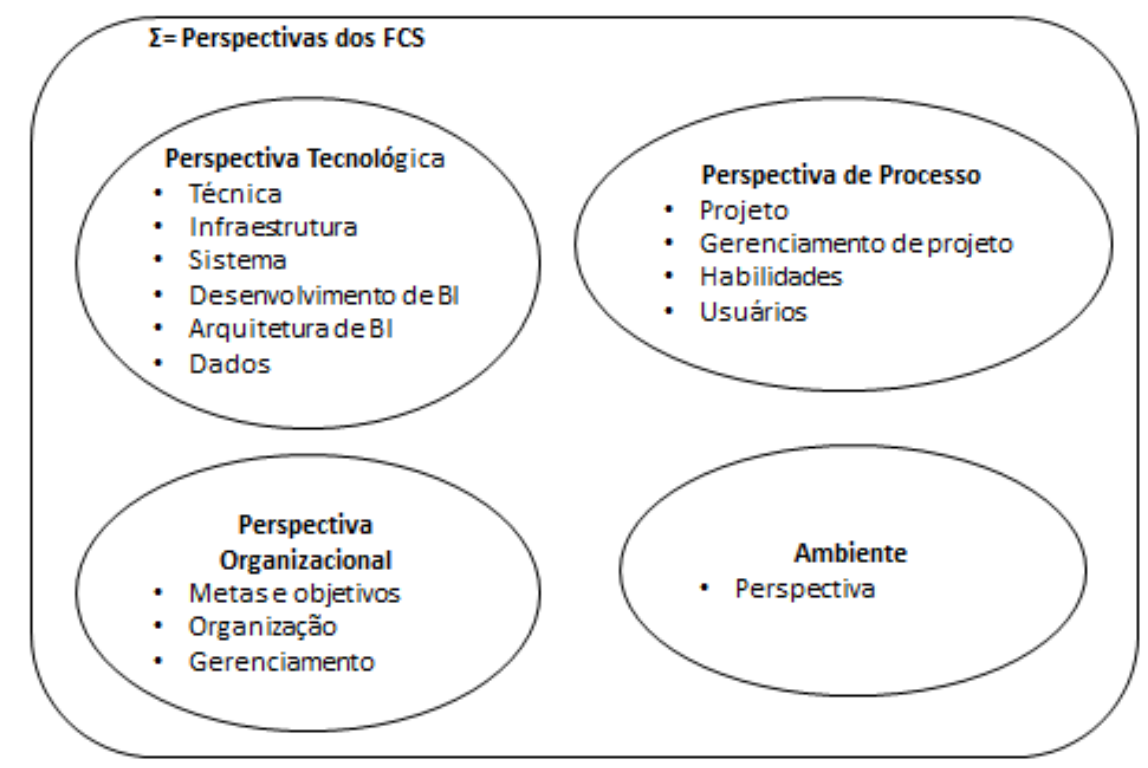

Figura 8 - Agrupamento das perspectivas críticas dos FCS Fonte: adaptado de Yeoh (2008) 
Vodapalli (2009) elabora ainda, em seu trabalho, a categorização dos FCS para BI baseado no modelo de perspectivas críticas de FCS de Yeoh (2008) e na utilização de todos os aspectos relacionados na tabela 4 resultantes da revisão da literatura.

Tabela 5 - Categorização dos FCS

\begin{tabular}{|c|c|c|}
\hline Perspectiva Organizacional & Perspectiva de Processo & Perspectiva Tecnológica \\
\hline 1. $\begin{array}{l}\text { Parceria } \\
\text { comunidade de negócio e TI }\end{array}$ & $\begin{array}{l}\text { 5. Metodologia dirigida ao } \\
\text { negócio e gestão de projeto }\end{array}$ & 11. Quadro robusto e extensível \\
\hline $\begin{array}{l}\text { 2. Suporte de uma gestão } \\
\text { comprometida e patrocínio }\end{array}$ & $\begin{array}{l}\text { 6. Uso de protótipo iterativo } \\
\text { para definir requerimentos e } \\
\text { escopo }\end{array}$ & $\begin{array}{l}\text { 12. Qualidade de dados e } \\
\text { questões de gestão }\end{array}$ \\
\hline $\begin{array}{l}\text { 3. Governança de informação } \\
\text { através do centro de } \\
\text { competência de BI }\end{array}$ & $\begin{array}{l}\text { 7. Mapa de soluções para o } \\
\text { usuário }\end{array}$ & $\begin{array}{l}\text { 13. Tecnologia apropriada / } \\
\text { ferramentas }\end{array}$ \\
\hline \multirow[t]{3}{*}{$\begin{array}{l}\text { 4. Clara visão do negócio e } \\
\text { planejamento }\end{array}$} & $\begin{array}{l}\text { 8. Composição de time } \\
\text { balanceado }\end{array}$ & 14. Aplic \\
\hline & $\begin{array}{l}\text { 9. Treinamento de usuário e } \\
\text { suporte }\end{array}$ & $\begin{array}{l}\text { 15. Considerações } \\
\text { desempenho }\end{array}$ \\
\hline & 10. Gestão de mudanças & \\
\hline
\end{tabular}

Fonte: adaptado de Vodapalli (2009)

Tabulando as variáveis de FCS de acordo com a respectiva perspectiva e os fatores listados pelos diversos autores mencionados na tabela 4, Vodapalli (2009) obteve o seguinte resultado:

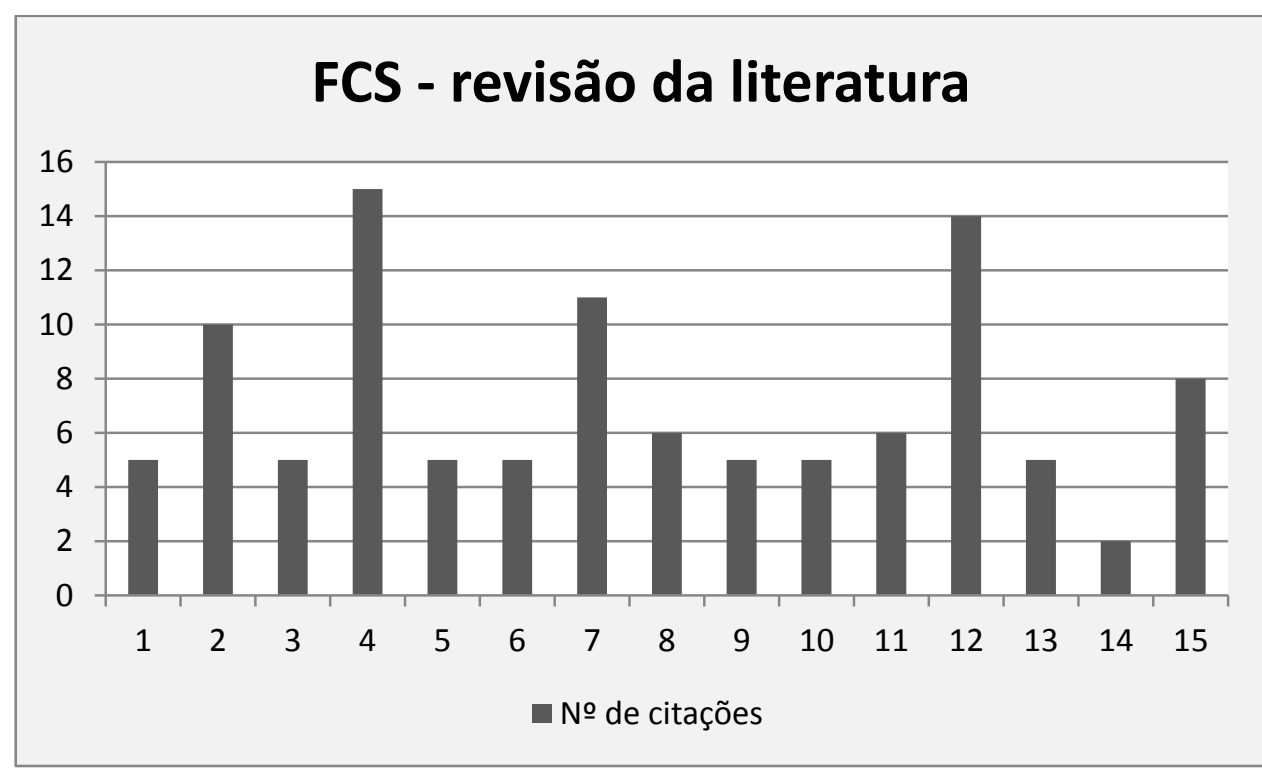

Gráfico 1 - Análise dos FCS citados na revisão da literatura Fonte: adaptado de Vodapalli (2009)

Classificando os FCS pelo número de citações na revisão da literatura, obtém-se a ordem de prioridade desses FCS. 
A tabela 6 apresenta os FCS ordenados por prioridade:

Tabela 6 - Ordem de prioridade dos FCSs da revisão da literatura

\begin{tabular}{|l|l|}
\hline $\mathbf{1}$ & Visão clara e planejamento \\
\hline $\mathbf{2}$ & Qualidade de dados e questões de gerenciamento \\
\hline $\mathbf{3}$ & Mapa de soluções para os usuários \\
\hline $\mathbf{4}$ & Suporte de gestão e patrocínio comprometido \\
\hline $\mathbf{5}$ & Considerações de desempenho \\
\hline $\mathbf{6}$ & $\begin{array}{l}\text { Composição de time balanceado } \\
\text { Robustez e escalabilidade }\end{array}$ \\
\hline $\mathbf{7}$ & $\begin{array}{l}\text { Parceria entre a comunidade de negócio e TI } \\
\text { Governança de informação através de centro de competência de BI } \\
\text { Metodologia dirigida ao negócio e gerenciamento de projeto } \\
\text { Uso de iteratividade para definir requerimentos e escopo } \\
\text { Treinamento de usuários e suporte } \\
\text { Gerenciamento de mudança } \\
\text { Tecnologia apropriada / ferramentas }\end{array}$ \\
\hline $\mathbf{8}$ & Aplicações de BI integradas \\
\hline
\end{tabular}

Fonte: adaptado de Vodapalli (2009)

Nesse trabalho, a perspectiva de processo apresentada na tabela 5 para FCS foi desconsiderada no modelo proposto (que será apresentado mais adiante) por que o objetivo é considerar fatores pré-implantação do sistema de BI. Questões como metodologia dirigida aos negócios, uso de protótipos e composição de time, são questões pertinentes ao projeto durante a fase implantação do sistema de BI. Como as unidades experimentais dessa pesquisa são usuários do sistema de BI que compartilham suas visões baseadas em suas experiências de uso do sistema, somente os aspectos pós-impantação foram incluídos como dimensões do FCS no modelo.

Os sistema de BI, que envolvem a coleta, o processamento e a análise de dados e informação de diferentes níveis de estruturação, estão por esse motivo fortemente relacionados às questões de gestão do conhecimento na empresa. Também como apresentado, essa gestão é um dos fatores críticos de sucesso em projetos de BI. Assim, no item a seguir, são detalhados os aspectos de gestão do conhecimento relevantes para esse trabalho.

\subsection{Gestão do Conhecimento (GC)}

Provavelmente não exista um segmento de atividade no mundo que atraia tanta atenção no presente quanto a gestão do conhecimento (BELLINGER; CASTRO; MILLS; 2004). Para Lin, 
Su e Chien (2006), a GC tem importância devido ao cenário de forte competição, crise econômica e mudanças aceleradas no ambiente de negócios, pressionando as organizações a buscarem melhorar seus processos através da redução de custos, aumento de eficiência e redução de impactos das crises econômicas em suas operações. Desse modo, o conhecimento foi considerado fator de extrema importância para identificar melhorias nos processos de negócio baseados em estudos e pesquisas. Em resumo, a GC também passou a ser requerida para responder efetivamente ao ambiente crescentemente competitivo. As Companhias estão examinando como alavancar ativos de conhecimento e criar maior valor (LIN; SU; CHIEN, 2006).

A GC é descrita como um procedimento, processo ou prática para concluir o processo sobre conhecimento, processo para o conhecimento, e processo do conhecimento, o qual leva a melhorar a operação interna e externa (ALRYALAT; ALHAWARI, 2008). A GC também é citada como o meio disciplinado de administrar este precioso recurso chamado conhecimento, através da promoção de uma aproximação para identificar, capturar, estruturar, organizar, recuperar, compartilhar e avaliar ativos de conhecimento do negócio (KIM; LIM; MITCHELL, 2004). Goh (2005) descreve a GC como uma metodologia de alavancagem de dados, informação, proficiência e estruturas diferentes de ativos e recursos para ampliar a inovação organizacional, reação, eficiência e capacidade. Representa uma questão significante de procedimentos organizacionais, através do exercício de tecnologias adequadas para conectar tipos dissimilares de ativos de conhecimento.

A GC está ganhando atenção e interesse nas organizações e no campo de pesquisa. Um número crescente de pesquisadores e profissionais vêm atuando na área de GC e estão explorando seus diferentes aspectos. Karadsheh (2010) comenta que as organizações estão integrando a GC em seus processos de negócio para obter mais eficiência e efetividade, o que resulta em redução de custo, se tornando mais ágil as mudanças no ambiente, e respondendo mais dinamicamente as crises. Para Dyer \& McDonough (2001), a GC se tornou um recurso estratégico para as organizações pelo fato de ser atualmente vista como base importante para se obter vantagem competitiva. Também tem sido vista pelos gestores como questão de grande relevância no que tange garantir vantagem técnica. Ademais, a GC ganha prioridade desde que o conhecimento tem sido cada vez mais considerado como um elemento competitivo para os indivíduos, firmas e nações. $\mathrm{O}$ conhecimento a respeito dos competidores, clientes, produtos, processos e sucessos e falhas passadas são consideradas um ativo para as organizações do século 21. E mais, a GC 
evolui a partir da responsabilidade distinta para um componente estratégico das soluções de negócio (DYER; MCDONOUGH, 2001).

$\mathrm{O}$ que percebemos é que a GC permite que as organizações comecem a pensar em questões sobre como melhorar seus desempenhos e processos. Para questões como essas, o conhecimento se apresenta como fator chave para ampliar as suas vantagens competitivas, o que impacta diretamente nos desempenhos. Adicionalmente, a GC tem sido incorporada na política, estratégia e processos das corporações globais, governos, e instituições (MALHOTRA, 2000). Diversos autores enfatizam que hoje muitas organizações estão colocando grande foco na adoção da GC. O objetivo de GC não é de gerenciar todo o conhecimento, mas é de gerenciar o conhecimento tido como essencial para o desenvolvimento e melhoria das organizações. Adicionalmente, a GC precisa enxergar todas as atividades da organização como um processo de produção de conhecimento para transformar a empresa em uma organização do conhecimento. Como resultado, a GC pode ajudar no crescimento de estágios aonde ele pode fomentar e expandir o processo de inovação (PARIKH, 2001).

Alavi e Leidner (1999) descreve a GC como um processo organizado e sistêmico para adquirir, organizar e trocar conhecimento entre os empregados para efetivamente utilizar o conhecimento. De acordo com Gottschalk (2002), a GC pode ser descrita como uma técnica para aumentar o processo de implementação, compartilhamento, distribuição, criação e compreensão do conhecimento da organização. Miltiadis, Pouloudi e Poulymenakou (2002) descrevem a GC como uma estrutura baseada em experiências passadas e constrói um novo mecanismo para trocar e gerar novo conhecimento. Albers e Brewer (2003) retratam a GC como um processo que contém criação, aquisição, incorporação, alocação, e aplicação de conhecimento para a melhoria da operação e vantagem competitiva da organização. A GC apresenta a informação precisa ao grupo exato no tempo certo.

Konda (2008) propõe um modelo para o processo de GC que estrutura seu ciclo de vida em três classes de interação. Cada classe de GC envolve um conjunto de processos que interage sinergicamente com outra classe da GC no modelo de processo. As classes de GC são definidas de forma que elas estão proximamente alinhadas com a mudança de objetivos do negócio. A proposta é endereçar essa questão de forma a enriquecer o ciclo de conhecimento, que continuamente busca alinhar a arquitetura de processo de GC com os objetivos estratégicos do 
negócio. O resultado amplia a habilidade da organização em responder com agilidade as necessidades de mudança de negócio e ao ambiente externo.

Na tabela 7 temos a descrição de GC na visão de diferentes autores para algumas atividades de negócio.

Tabela 7 - Taxonomia de definições de GC.

\begin{tabular}{|c|c|c|}
\hline Definições da GC & Descrição & Referências \\
\hline Papel da TI & $\begin{array}{l}\text { Processo organizado e sistemático para } \\
\text { aquisição e troca de conhecimento entre os } \\
\text { empregados com o objetivo de utilização } \\
\text { efetiva do conhecimento. }\end{array}$ & Alavi e Leidner (1999) \\
\hline $\begin{array}{l}\text { Pesquisa e } \\
\text { desenvolvimento / } \\
\text { Companhia de TI }\end{array}$ & $\begin{array}{l}\text { Necessidade de visualização de todas as } \\
\text { atividades da organização como um } \\
\text { processo de produção de conhecimento para } \\
\text { transportar a firma em uma organização de } \\
\text { aprendizagem. }\end{array}$ & Parikh (2001) \\
\hline $\begin{array}{l}\text { Tecnologia de GC } \\
\text { em firmas de lei }\end{array}$ & $\begin{array}{l}\text { Uma técnica para melhorar e abreviar o } \\
\text { processo de implementação } \\
\text { compartilhamento de distribuição, criação e } \\
\text { compreensão do conhecimento da } \\
\text { organização. }\end{array}$ & Gottschalk (2002) \\
\hline $\begin{array}{l}\text { Aprendizagem de } \\
\text { GC }\end{array}$ & $\begin{array}{l}\text { Uma estrutura baseada na experiência que } \\
\text { constrói novos mecanismos para trocar e } \\
\text { gerar novo conhecimento. }\end{array}$ & $\begin{array}{l}\text { Miltiadis e Pouloudi } \\
\text { (2003) }\end{array}$ \\
\hline $\begin{array}{l}\text { Processo de } \\
\text { inovação }\end{array}$ & $\begin{array}{l}\text { Um processo que contém criação, aquisição, } \\
\text { incorporação, alocação, e aplicação de } \\
\text { conhecimento para promover eficiência de } \\
\text { operação e vantagem competitiva para a } \\
\text { organização. }\end{array}$ & $\begin{array}{lll}\text { Albers } & \text { e } & \text { Brewer } \\
(2003) & & \end{array}$ \\
\hline $\begin{array}{l}\text { Arquitetura de } \\
\text { conhecimento }\end{array}$ & $\begin{array}{l}\text { Uma forma metodológica de administrar } \\
\text { esse recurso valioso, promovendo uma } \\
\text { abordagem incorporada para identificar, } \\
\text { capturar, estruturar, organizar, recuperar, } \\
\text { compartilhar, e avaliar ativos de } \\
\text { conhecimento da empresa. }\end{array}$ & Kim et al., (2004) \\
\hline Adoção de CRM & $\begin{array}{l}\text { Uma metodologia de alavancagem de dados, } \\
\text { informação, proficiência e diferentes } \\
\text { estruturas de ativos e recursos para melhorar } \\
\text { a inovação organizacional, reação, eficiência } \\
\text { e capacidade. }\end{array}$ & Goh (2005) \\
\hline Processo de GC & $\begin{array}{l}\text { Um procedimento, processo ou prática para } \\
\text { obter processo sobre conhecimento, } \\
\text { processo para conhecimento, e processo de } \\
\text { conhecimento os quais levam a melhoria de } \\
\text { operações internas e externas. }\end{array}$ & $\begin{array}{l}\begin{array}{l}\text { Alryalat e } \\
(2008)\end{array} \\
\text { Alhawari }\end{array}$ \\
\hline
\end{tabular}




\begin{tabular}{|l|l|l|}
\hline $\begin{array}{l}\text { Alinhamento do } \\
\text { processo de GC } \\
\text { com a estratégia de }\end{array}$ & $\begin{array}{l}\text { O modelo de processo de GC é desenhado } \\
\text { para endereçar o problema pela forma do } \\
\text { negócio }\end{array}$ & $\begin{array}{l}\text { ciclo de enriquecimento de conhecimento, } \\
\text { que continuamente procura alinhar a a } \\
\text { arquitetura de processo de GC com os } \\
\text { objetivos estratégicos do negócio. }\end{array}$
\end{tabular}

Fonte: adaptado de Karadsheh (2010)

\subsubsection{Sistema de gestão de conhecimento (SGC)}

De acordo com Alavi e Leidner (2001), o SGC se refere a uma classe de sistemas de informação aplicada para gerenciar conhecimento organizacional e é um sistema baseado em TI desenvolvido para suportar e aprimorar os processos organizacionais de criação de conhecimento, armazenamento / recuperação, transferência e aplicação. Para Steenkamp e Konda (2003), o SGC é um sistema de administração que incorpora tecnologias e recursos de conhecimento para facilitar a habilidade organizacional de gerar, conservar e empregar suprimentos de conhecimento existentes e de criar importância de negócio para a organização.

Um sistema de GC deve também incluir as seguintes funções:

- Localizar as fontes significantes de conhecimento;

- Capturar e purificar ativos de conhecimento;

- Acumular e re-autenticar ativos de conhecimento no repositório;

- Recuperar e empregar ativos de conhecimento.

O SGC é uma aplicação resultante da interação entre tecnologia e significado social/estrutura para suportar o processo de GC e pode ser classificado como um sistema de descoberta, captura, compartilhamento e aplicação desconhecimento (Becerra-Fernandez, Gonzalez, e Sabherwal, 2004 apud Karadshed, 2010). Para Maier (2002), o SGC é um sistema de tecnologia de informação e comunicação (TIC) que suporta as funcionalidades de GC como criação, construção, identificação, captura, aquisição, seleção, avaliação, organização, conexão, estruturação, formalização, visualização, alocação, retenção, manutenção, refinamento, desenvolvimento, acesso, busca e aplicação. Já para Harlow e Imam (2006), o SGC permite a criação tanto do conhecimento tácito como do conhecimento explícito. 
A importância do SGC nas organizações é a sua habilidade de suportar os objetivos estratégicos auxiliando nas tarefas dos trabalhadores do conhecimento e na execução das funções do negócio a fim de agregar valor à organização. A arquitetura do SGC compreende os papéis de GC dentro da organização, processos de GC e tecnologias de suporte (STEENKAMP E KONDA, 2003). Kaldi, Aghaie, e Khoshalhan (2008 apud Karadshed, 2010) afirmam que além de suportar os objetivos estratégicos da corporação, o SGC tem que suportar todos os outros níveis da organização. A adoção do SGC tem que tomar lugar no nível individual e em uma gama de níveis organizacionais, e sofre influência de diversos fatores. No nível organizacional, os fatores incluem a singularidade de sistemas, atributos adotados, características da companhia e mudanças de ambiente. Por outro lado, a aceitação dos usuários é influenciada por fatores como o nível de aceitação, utilidade percebida e outros fatores individuais (KALDI, et al., 2008 apud KARADSHED, 2010).

Podemos dizer portanto, que o SGC é uma combinação de GC e TI com a missão de permitir a captura, armazenamento, compartilhamento e aplicação do conhecimento por toda a empresa utilizando TI como meio de viabilização.

\subsubsection{Processo de GC}

O estudo do processo de GC estabelece modelos que descrevem as diversas etapas que constituem a gestão do conhecimento. O modelo proposto por Alavi e Leidner (2001) estabelece que o processo de GC deve ser dividido em criação do conhecimento, armazenamento e recuperação, transferência e aplicações. $O$ processo de criação de conhecimento lida com a combinação de novas fontes de conhecimento. $\mathrm{O}$ armazenamento e recuperação do conhecimento suportam a memória organizacional e permitem que os indivíduos acessem esse conhecimento. $\mathrm{O}$ armazenamento de conhecimento provê códigos e índices do conhecimento para futura recuperação. A transferência de conhecimento provê canais de comunicação e acesso rápido às fontes de conhecimento. $\mathrm{O}$ último passo do processo é a aplicação do conhecimento, o qual auxilia na aplicação do conhecimento em diferentes áreas através do fluxo de automação.

Na visão de Parikh (2001), o ciclo de GC contém quatro processos pelos quais a organização é capaz de adaptar a GC. Os quatro ciclos são a aquisição do conhecimento, organização, 
disseminação e aplicação. A aquisição do conhecimento é uma atividade com a função de encontrar e adquirir conhecimento em fontes de base de conhecimento. A empresa deve fazer esforço consciente para monitorar, procurar e definir conhecimento relevante e suas fontes. O processo de conhecimento da organização envolve refinamento, organização e armazenamento do conhecimento coletado. O conhecimento é primeiramente filtrado para identificar e cruzar a lista de dimensões que são úteis para diferentes pesquisas e projetos de desenvolvimento. A disseminação do conhecimento lida com a questão de quem recebe qual conhecimento (personalização) e como (distribuição). Nem toda a informação coletada e conhecimento são úteis para todos. Irrelevância pode confundir a interpretação e aplicação do conhecimento relevante. Finalmente, a aplicação do conhecimento pode ser considerada como uma atividade que amplia o uso do conhecimento para um novo cenário e para a aprendizagem oriunda dele. A figura 9 ilustra esse ciclo de GC.

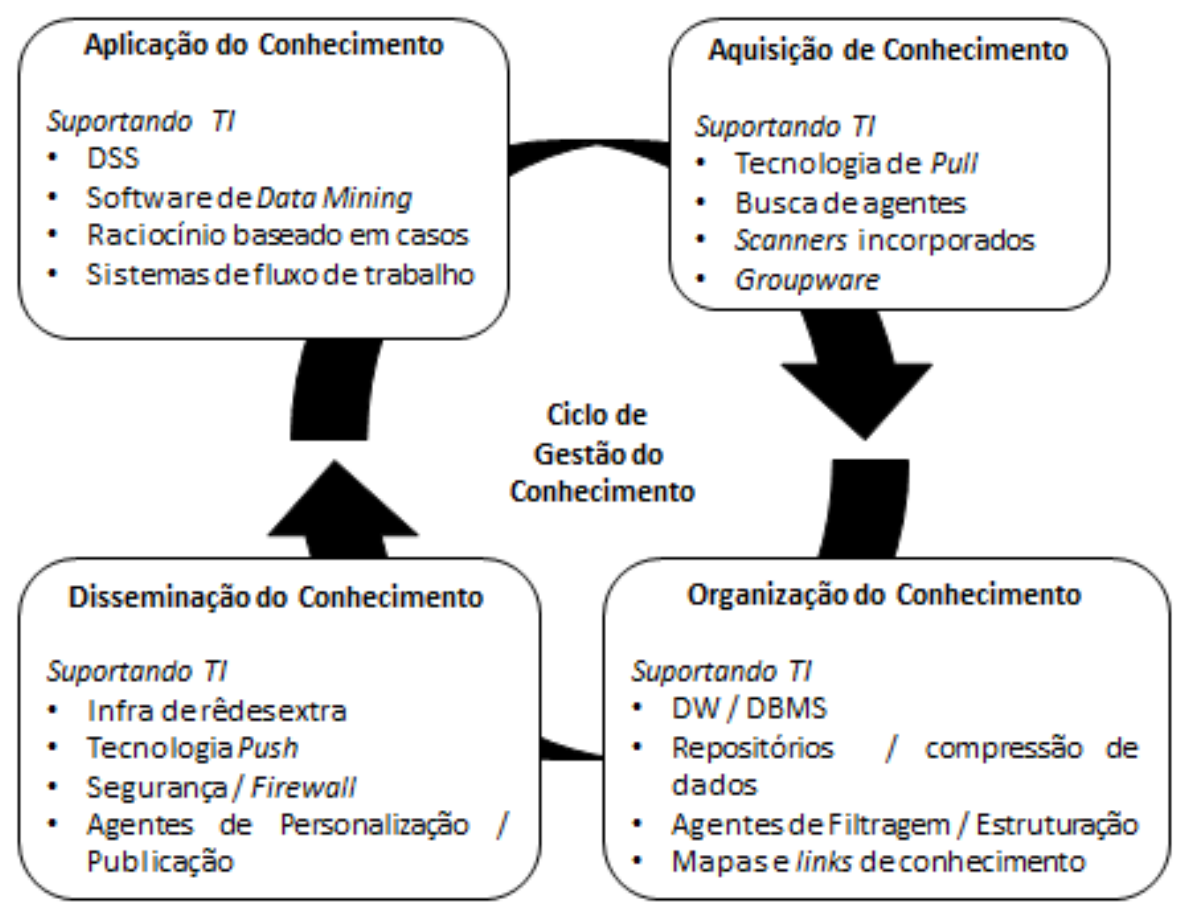

Figura 9 - Ciclo de GC.

Fonte: adaptado de Parikh (2001)

Mitiadis e Pouloudi (2003) propõem os seguintes aspectos do processo de GC:

- O valor relativo;

- A aquisição;

- A organização;

- A habilitação de reuso;

- A transferência e 
- O uso.

O processo de valor relativo demanda que os membros do time verifiquem, identifiquem, filtrem e selecionem o objetivo do conhecimento. O processo de aquisição se refere a facilidade do time de projeto em formalizar, codificar, representar, formatar e mapear os fundamentos do conhecimento para assegurar sua existência em um formato utilizável. O processo de organização consiste na armazenagem, classificação e transformação do conhecimento. O processo de habilitação de reuso suporta a adoção e o uso adicional do conhecimento. O processo de transferência tem de ser desenhado para endereçar o interesse do caminho do conhecimento, onde repositórios de conhecimento e objetos de conhecimento específico estão ligados a pessoas, e isso promove a exploração do conhecimento. $\mathrm{O}$ uso do conhecimento tem que transformar conhecimento em formatos reutilizáveis para construir significado de elevado valor e claro tem que suportar o processo de aprendizagem.

A figura 10 ilustra esse retrato da GC.

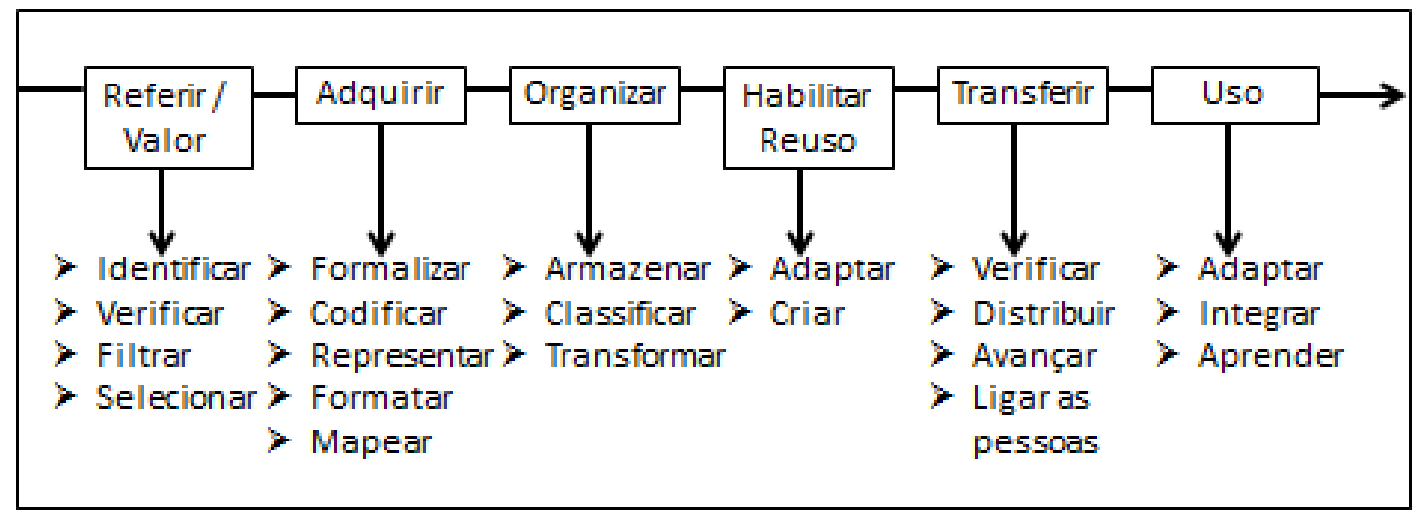

Figura 10 - Modelo que suporta a infraestrutura de GC (Modelo de processo de GC). Fonte: adaptado de Lytras e Pouloudi (2003)

Nesse trabalho, os aspectos crescimento do compartilhamento de informação e crescimento da base de conhecimento, obtidos através da pesquisa, foram endereçados à dimensão GC do modelo de pesquisa que será apresentado mais adiante, pois englobam aspectos como captura, acúmulo e recuperação do conhecimento, características que fazem parte do ciclo de gestão do conhecimento conforme apresentado na figura 9.

O segundo elemento que se destaca na análise dos fatores críticos de sucesso dos sistemas de BI é a qualidade da informação (QI). Esse item é detalhado a seguir. 


\subsection{Qualidade da Informação}

A qualidade da informação (QI) tem sido amplamente discutida devido ao crítico papel que desempenha em uma economia cada vez mais baseada em intensiva geração de dados e uma sociedade voltada para o conhecimento. Nesse cenário, uma baixa QI pode produzir enormes impactos nas organizações. Kim, Kishore e Sanders (2005) enfatizam que o governo americano, devido ao baixo nível de qualidade das informações criminais, tem perdas econômicas na ordem de bilhões de dólares, além de impactos sociais. Outros estudos enfatizam a importância da QI, Otto, Hüner e Österle (2009) comentam que dados corporativos pobres podem ter impacto negativo no sucesso da companhia. De maneira geral, nas últimas duas décadas, a questão QI tem recebido atenção por ser um elemento crítico tanto para o sucesso das corporações como para uma gestão pública eficaz.

Os sistemas de Business Intelligence (BI), que possuem como objetivo a entrega de informações acionáveis aos decisores, sofre impacto direto da QI, sendo esse um importante fator para a subutilização desses sistemas (GONSALVES, 2009). A seguir são apresentados os diversos modelos de análise para QI e discutida sua aplicabilidade aos sistemas de BI.

\subsubsection{Revisão dos modelos de qualidade da informação}

Batini et al. (2009), baseados no fato de que a literatura apresenta um grande número de técnicas para avaliar e melhorar a qualidade dos dados apresentam uma descrição sistemática e comparativa dessas metodologias. Em todas as metodologias, as definições de qualidade, dimensões e métricas para avaliar os dados são atividades críticas (BATINI et al., 2009, p. 6). Métricas múltiplas são normalmente associadas a cada dimensão de qualidade.

Um resumo de metodologias identificadas pelos acrônimos associados aos nomes da metodologia e sua referência é apresentado na tabela 8. 
Tabela 8 - Metodologias de QI.

\begin{tabular}{|c|l|l|l|}
\hline Id & Acrônimo & \multicolumn{1}{|c|}{ Nome } & \multicolumn{1}{|c|}{ Referência } \\
\hline \hline 1 & TDQM & Gerenciamento total de qualidade de dados & Wang, 1998 \\
\hline 2 & DWQ & Metodologia de qualidade de armazenamento de dados & Jeusfeld et al., 1998 \\
\hline 3 & TIQM & Gerenciamento total de qualidade de informação & English, 1999 \\
\hline 4 & AIMQ & Metodologia para avaliação de qualidade de informação & Lee et al., 2002 \\
\hline 5 & CIHI & Instituto Canadense para metodologia da saúde da informação & Long e Seko, 2005 \\
\hline 6 & DQA & Avaliação de qualidade de dados & Pipino et al, .2002 \\
\hline 7 & IQM & Medição de qualidade da informação & $\begin{array}{l}\text { Eppler e } \\
\text { Münzenmaier, 2002 }\end{array}$ \\
\hline 8 & ISTAT & Metodologia ISTAT & Falorsi et al., 2003 \\
\hline 9 & AMEQ & $\begin{array}{l}\text { Atividade baseada em medição e avaliação do produto } \\
\text { metodologia de qualidade da informação (AMEQ) }\end{array}$ & Su e Jin, 2004 \\
\hline 10 & COLDQ & $\begin{array}{l}\text { Metodologia Loshin (Efeito custo da baixa qualidade de } \\
\text { dados) }\end{array}$ & Loshin, 2004 \\
\hline 11 & $\begin{array}{l}\text { DaQuinCI } \\
\text { S }\end{array}$ & $\begin{array}{l}\text { Qualidade de dados em sistemas de informação cooperativos } \\
\text { Scannapieco } \text { et al., } \\
\text { 2004 }\end{array}$ \\
\hline 12 & QAFD & $\begin{array}{l}\text { Metodologia para a avaliação de qualidade de dados } \\
\text { financeiros }\end{array}$ & $\begin{array}{l}\text { De Amicis e Batini, } \\
\text { 2004 }\end{array}$ \\
\hline 13 & CDQ & $\begin{array}{l}\text { Metodologia compreensiva para gerenciamento de qualidade } \\
\text { de dados }\end{array}$ & $\begin{array}{l}\text { Batini e } \\
\text { Scannapieco, 2006 }\end{array}$ \\
\hline
\end{tabular}

Fonte: adaptado de Batini et al. (2009)

Em sua tese, Santos (2009) trata das dimensões de QI utilizando como referência a revisão da literatura feita por Ge e Helfert (2007). Os autores baseiam seu estudo em três aspectos relevantes para a identificação das dimensões de QI que podem ser divididas nas abordagens intuitiva, teórica e empírica. No processo de identificação das dimensões de QI temos a abordagem intuitiva, onde as dimensões são estabelecidas de acordo com a experiência dos pesquisadores e com as demandas de contexto específico. $\mathrm{Na}$ abordagem teórica são levados em consideração o problema dos dados no processo de sua produção, e na abordagem empírica, as dimensões são estabelecidas através da verificação da adequação dos dados com as necessidades de uso dos clientes. No processo de definição das dimensões de QI, as perspectivas são as mesmas das abordagens utilizadas para a sua identificação: intuitiva, teórica e empírica. Para a classificação da dimensões de QI, as abordagens utilizadas pelos autores foram hierárquica, ontológica, semiótica, sequencia de uso da informação, produto e serviço, e fontes de metadados para QI (SANTOS, 2009).

Wang e Strong (2006) apresentam quatro classes para a abordagem hierárquica:

A. Intrínseca: enfatiza a qualidade específica dos dados;

B. Contextual: representa os requisitos dos contextos específicos; 
C. Representacional: está relacionada à utilização como interpretável e de fácil entendimento;

D. Acessibilidade: relaciona-se à acessibilidade e segurança da informação.

Para a abordagem ontológica, duas categorias são propostas, interna que independe do uso (relacionada aos dados) contendo dimensões comparáveis entre aplicações distintas, e externa focada no uso e nos efeitos dos SI (relacionada ao sistema) que representam o mundo real (WANG E WANG, 1996 apud SANTOS, 2009). Santos (2009) apresenta através da revisão da literatura outras dimensões da QI como qualidade de projeto e qualidade de conformidade (aspectos de qualidade). Como abordagem da sequência de uso da informação, a obtenção da informação (acessibilidade), a interpretação da informação (interpretabilidade), a aplicabilidade da informação ao contexto específico (relevância), a informação não contém erro (integridade). Como características de produtos e serviços da informação e nos conceitos da qualidade, de conformidade aos requisitos e de atender ou exceder as expectativas dos usuários, a classificação como informações estáveis, confiáveis, úteis e usáveis. Outra classificação das dimensões de QI apresentada foi a informação subjetiva (percepção do usuário), objetiva (informação por si própria) e processo, maneira como é feito o acesso à informação.

Na tabela 9 temos a consolidação das metodologias e dimensões de QI apresentadas por Batini et al. (2009). Como podemos perceber, das dimensões listadas, seis são comumente adotadas pelas diferentes técnicas. A dimensão acuracidade é considerada em todas as metotologias de QI. Das demais dimensões, completude, circulação, consistência, tempestividade e acessibilidade são consideradas por mais de $30 \%$ das metodologias de QI.

Tabela 9 - Metodologias e dimensões de QI

\begin{tabular}{|c|c|c|c|c|c|c|c|c|c|c|c|c|c|c|c|}
\hline Dimensão & Nome Id & 1 & 2 & 3 & 4 & 5 & 6 & 7 & 8 & 9 & 10 & 11 & 12 & 13 & \\
\hline Acuracidade & $\begin{array}{l}\text { Diferença entre valor } \\
\text { armazenado e o correto }\end{array}$ & $\mathrm{X}$ & $\mathrm{X}$ & $\mathrm{x}$ & $\mathrm{x}$ & $\mathrm{X}$ & $\mathrm{x}$ & $\mathrm{x}$ & $\mathrm{X}$ & $\mathrm{x}$ & $\mathrm{x}$ & $\mathrm{x}$ & $\mathrm{x}$ & $\mathrm{x}$ & $100 \%$ \\
\hline Completude & $\begin{array}{l}\text { Não existe informação } \\
\text { faltando }\end{array}$ & $\mathrm{x}$ & $\mathrm{x}$ & $\mathrm{x}$ & $\mathrm{x}$ & & $\mathrm{x}$ & & & $\mathrm{X}$ & $\mathrm{X}$ & $\mathrm{X}$ & $\mathrm{x}$ & $\mathrm{X}$ & $77 \%$ \\
\hline Circulação & $\begin{array}{l}\text { Diferença de tempo entre } \\
\text { geração dos dados e } \\
\text { armazenamento }\end{array}$ & $X$ & & & $\mathrm{x}$ & $X$ & & $\mathrm{X}$ & $\mathrm{X}$ & & & $\mathrm{X}$ & $\mathrm{X}$ & $\mathrm{X}$ & $62 \%$ \\
\hline Consistência & $\begin{array}{l}\text { Relação entre dados } \\
\text { consistentes e dados } \\
\text { totais }\end{array}$ & $X$ & $x$ & & $\mathrm{X}$ & $x$ & $\mathrm{x}$ & $\mathrm{X}$ & & & & & & & $46 \%$ \\
\hline Tempestividade & $\begin{array}{l}\text { Dados suficientemente } \\
\text { atualizados para a } \\
\text { realização da tarefa }\end{array}$ & & & $\mathrm{x}$ & $\mathrm{x}$ & $\mathrm{X}$ & $\mathrm{X}$ & & & & $\mathrm{X}$ & & & $\mathrm{X}$ & $46 \%$ \\
\hline
\end{tabular}




\begin{tabular}{|c|c|c|c|c|c|c|c|c|c|c|c|c|c|c|c|}
\hline Acessibilidade & \begin{tabular}{|l|} 
Dados disponíveis, ou \\
facilmente e rapidamente \\
recuperáveis
\end{tabular} & & & $x$ & $x$ & & & $x$ & $x$ & & & & & & $31 \%$ \\
\hline Compreensividade & \begin{tabular}{|l|} 
Facilidade de \\
compreensão
\end{tabular} & & & & $x$ & & & $x$ & & & $x$ & & & & $23 \%$ \\
\hline Clareza & Sem dupla interpretação & & & $x$ & & & & $\mathrm{x}$ & & & $x$ & & & & $23 \%$ \\
\hline Volatilidade & $\begin{array}{l}\text { Tempo em que os dados } \\
\text { se mantém válidos }\end{array}$ & $x$ & & & & & & & & & & & & $x$ & $15 \%$ \\
\hline Singularidade & Número de replicações & & & $x$ & & & & & & & & & $\mathrm{x}$ & & $15 \%$ \\
\hline $\begin{array}{l}\text { Qtde apropriada de } \\
\text { dados }\end{array}$ & \begin{tabular}{|l|} 
Relação mínima entre \\
dados fornecidos e dados \\
necessários \\
\end{tabular} & & & & $\mathrm{x}$ & & $x$ & & & & & & & & $15 \%$ \\
\hline Credibilidade & \begin{tabular}{|l|} 
Dado considerado \\
verdadeiro e crível \\
\end{tabular} & & $\mathrm{x}$ & & $x$ & & & & & & & & & & $15 \%$ \\
\hline Interpretabilidade & $\begin{array}{l}\text { Dados em linguagem } \\
\text { apropriada, símbolos, } \\
\text { unidades e definições } \\
\text { claros }\end{array}$ & & $\mathrm{x}$ & & $\mathrm{x}$ & & & & & & & & & & $15 \%$ \\
\hline Segurança & $\begin{array}{l}\text { Número de acessos com } \\
\text { fraca restrição }\end{array}$ & & & & $\mathrm{x}$ & & & $\mathrm{x}$ & & & & & & & $15 \%$ \\
\hline Usabilidade & Dados acionáveis & & & $x$ & & & & & & & & & & & $8 \%$ \\
\hline Integridade & $\begin{array}{l}\text { Percentual de cálculos } \\
\text { corretos de dados } \\
\text { obtidos de acordo com a } \\
\text { definição }\end{array}$ & & & $x$ & & & & & & & & & & & $8 \%$ \\
\hline Concisão & $\begin{array}{l}\text { Profundidade de } \\
\text { detalhamento }\end{array}$ & & & & & & & $\mathrm{x}$ & & & & & & & $8 \%$ \\
\hline Manutenção & $\begin{array}{l}\text { Número de páginas com } \\
\text { informação pendente }\end{array}$ & & & & $x$ & & & & & & & & & & $8 \%$ \\
\hline Aplicabilidade & Número de páginas órfãs & & & & & & & $x$ & & & & & & & $8 \%$ \\
\hline Conveniência & $\begin{array}{l}\text { Caminhos de navegação } \\
\text { dificultosos }\end{array}$ & & & & & & & $x$ & & & & & & & $8 \%$ \\
\hline Velocidade & $\begin{array}{l}\text { Tempo de resposta de } \\
\text { rede }\end{array}$ & & & & & & & $\mathrm{x}$ & & & & & & & $8 \%$ \\
\hline Rastreabilidade & $\begin{array}{l}\text { Páginas sem descrição de } \\
\text { origem }\end{array}$ & & & & & & & $x$ & & & & & & & $8 \%$ \\
\hline Correção & $\begin{array}{l}\text { Facilidade de correção } \\
\text { dos dados }\end{array}$ & & & & & & & $\mathrm{x}$ & & & & & & & $8 \%$ \\
\hline Objetividade & $\begin{array}{l}\text { Dados não enviesados e } \\
\text { imparciais }\end{array}$ & & & & $x$ & & & & & & & & & & $8 \%$ \\
\hline Relevância & $\begin{array}{l}\text { Dados aplicáveis e úteis } \\
\text { para a tarefa }\end{array}$ & & & & $x$ & & & & & & & & & & $8 \%$ \\
\hline Reputação & $\begin{array}{l}\text { Informação } \\
\text { considerada em termos } \\
\text { de fonte ou conteúdo }\end{array}$ & & & & $x$ & & & & & & & & & & $8 \%$ \\
\hline $\begin{array}{l}\text { Facilidade de } \\
\text { operação }\end{array}$ & $\begin{array}{l}\text { Dados fáceis de serem } \\
\text { operados e aplicados } \\
\text { em diferentes tarefas }\end{array}$ & & & & $\mathrm{x}$ & & & & & & & & & & $8 \%$ \\
\hline Interatividade & Páginas personalizáveis & & & & & & & $\mathrm{x}$ & & & & & & & $8 \%$ \\
\hline & & 5 & 5 & 8 & 16 & 4 & 5 & 14 & 3 & 2 & 5 & 3 & 4 & 5 & \\
\hline
\end{tabular}

Fonte: adaptado de Batini et al. (2009) 
No contexto $e$-Business, o modelo apresentado por Kim et al. (2005) para a qualidade de dados apresenta as dimensões da informação, conteúdo, forma e tempo. Para os autores, as três dimensões podem à primeira vista representar uma mesma característica, entretanto a forma de apresentação da informação e aspectos temporais da entrega da informação estão intimamente relacionados com o conteúdo da informação.

Desta forma, no modelo e-Business Quality (EQ), temos:

Tabela 10 - QI de e-Business

\begin{tabular}{|c|c|c|}
\hline Dimensão (EQ) & Significado & Construto (EQ) \\
\hline Conteúdo & $\begin{array}{l}\text { Essa dimensão lida com questão do } \\
\text { conteúdo intrínseco de informação } \\
\text { que é voltada para prover os } \\
\text { usuários com informação acurada, } \\
\text { relevante e completa, assim } \\
\text { tratando inicialmente o problema } \\
\text { da informação irrelevante em } \\
\text { sistemas de e-business. }\end{array}$ & $\begin{array}{l}\text { - } \text { Acurácia } \\
\text { - Relevância } \\
\text { - Completude }\end{array}$ \\
\hline Forma & $\begin{array}{l}\text { Essa dimensão lida com a questão } \\
\text { de apresentação da informação que } \\
\text { é orientada para aperfeiçoar a } \\
\text { cognição dos dosuários, } \\
\text { endereçando inicialmente o } \\
\text { problema cognitivo geral. }\end{array}$ & $\begin{array}{l}\text { - Qualidade estrutural de interface } \\
\text { - Qualidade do empacotamento de } \\
\text { informação } \\
\text { - Acessibilidade }\end{array}$ \\
\hline Tempo & $\begin{array}{l}\text { Essa dimensão lida com a questão } \\
\text { de entrega da informação que é } \\
\text { orientada para prover aos usuários } \\
\text { um melhor controle sobre aspectos } \\
\text { temporais de suas ações } \\
\text { fornecendo o senso de orientação } \\
\text { temporal. }\end{array}$ & $\begin{array}{l}\text { - } \text { Manutenção do histórico } \\
\text { - } \quad \text { Entrega da informação } \\
\text { - } \quad \text { Circulação da informação }\end{array}$ \\
\hline
\end{tabular}

Fonte: adaptado de Khan; Strong; Wang (2002)

Em pesquisa que avalia como as empresas produzem seus produtos informação e a eficiência de seu serviço de distribuição aos consumidores (Khan; Strong; Wang, 2002), os autores apresentam o seguinte mapeamento dos aspectos da QI, abordando suas diversas dimensões.

Tabela 11 - Especificação de QI

\begin{tabular}{|c|c|c|}
\hline & Atende a especificação & Satisfaz ou excede as expectativas do consumidor \\
\hline $\begin{array}{l}\text { Qualidade do } \\
\text { produto }\end{array}$ & $\begin{array}{l}\text { Informação sólida } \\
\begin{aligned} \text { - } & \text { Livre de erro } \\
\text { - } & \text { Representação concisa } \\
\text { - } & \text { Completude } \\
\text { - } & \text { Representação } \\
& \text { consistente }\end{aligned}\end{array}$ & $\begin{array}{l}\text { Informação útil } \\
\text { - } \text { Quantidade apropriada } \\
\text { - } \text { Relevância } \\
\text { - Compreensibilidade } \\
\text { - Interpretabilidade } \\
\text { - Objetividade }\end{array}$ \\
\hline
\end{tabular}




\begin{tabular}{|c|c|c|}
\hline Qualidade do & Informação fidedigna & Informação acionável \\
serviço & $\bullet$ Tempestividade & - Credibilidade \\
& $\bullet$ Segurança & - Acessibilidade \\
& & \\
& & - Fácil de manipular \\
& & - Reputação \\
\hline
\end{tabular}

Fonte: adaptado de Khan; Strong; Wang (2002)

O quadrante informação sólida possui dimensões de QI tangíveis e comparáveis à especificação. Não atender a especificação é normalmente independente da tarefa ou decisão. O quadrante informação fidedigna apresenta dimensões que geralmente não podem ser avaliadas antecipadamente pelas características dos dados na base. Qualquer serviço só pode ser avaliado depois de sua execução. O quadrante informação útil possui dimensões dependentes das características das tarefas, i.e., a informação é suficiente para se cumprir determinada tarefa. $\mathrm{O}$ quadrante informação acionável possui dimensões que distinguem um serviço de outro.

Zhu e Wang (2010), analisando a QI para a Intelligence Community (IC), comunidade essa que utiliza grandes quantidades de informação oriundas de diversas fontes a fim de produzir inteligência para a tomada de decisão e definição de políticas, necessita de um produto informação de elevada qualidade. Baseado em diversas discussões sobre o assunto, os autores definiram 16 dimensões aplicáveis à IC apresentadas na tabela 12.

Tabela 12 - Metodologias de QI

\begin{tabular}{|l|l|}
\hline \multicolumn{1}{|c|}{ Dimensão } & \multicolumn{1}{c|}{ Nome } \\
\hline \hline Acessibilidade & $\begin{array}{l}\text { A medida em que os dados estão disponíveis, ou facilmente e rapidamente } \\
\text { recuperáveis }\end{array}$ \\
\hline $\begin{array}{l}\text { Quantidade de } \\
\text { informação }\end{array}$ & A medida em que o volume de dados é apropriado para a realização da tarefa \\
\hline Credibilidade & A medida em que o dado é considerado verdadeiro e crível \\
\hline Reputação & $\begin{array}{l}\text { A medida em que a informação é bastante considerada em termos de fonte ou } \\
\text { conteúdo }\end{array}$ \\
\hline Completude & $\begin{array}{l}\text { A medida em que não existe informação faltando apresenta amplitude suficiente } \\
\text { para a realização da tarefa }\end{array}$ \\
\hline $\begin{array}{l}\text { Representação } \\
\text { concisa }\end{array}$ & A medida em que os dados são representados de forma compacta \\
\hline $\begin{array}{l}\text { Representação } \\
\text { consistente }\end{array}$ & A medida em que os dados são apresentados no mesmo formato \\
\hline Fácil de operar & $\begin{array}{l}\text { A medida em que os dados são fáceis de serem operados e aplicados em diferentes } \\
\text { tarefas }\end{array}$ \\
\hline
\end{tabular}




\begin{tabular}{|l|l|}
\hline Livre de erros & A medida em que os dados são corretos e confiáveis \\
\hline Interpretabilidade & $\begin{array}{l}\text { A medida em que os dados estão em linguagem apropriada, símbolos, unidades e } \\
\text { definições são claros }\end{array}$ \\
\hline Objetividade & A medida em que os dados não são enviesados, sem preconceitos, e imparciais \\
\hline Relevância & A medida em que os dados são aplicáveis e úteis para a tarefa \\
\hline Segurança & $\begin{array}{l}\text { A medida que o acesso aos dados é apropriadamente restrito para garantir a } \\
\text { segurança }\end{array}$ \\
\hline Tempestividade & $\begin{array}{l}\text { A medida em que os dados são suficientemente atualizados para a realização da } \\
\text { tarefa }\end{array}$ \\
\hline Compreensibilidade & A medida em que os dados são facilmente compreendidos \\
\hline Valor adicionado & A medida em que os dados são benéficos e provêem vantagens de seu uso \\
\hline
\end{tabular}

Fonte: adaptado de Zhu e Wang (2010)

Strong, Lee e Wang (1997, p. 104) no estudo a respeito do processo de produção de dados, discute a transformação dos dados em informação útil para o consumidor de dados. Os autores identificaram três agentes no sistema de produção de dados: os geradores de dados, os detentores da custódia, i.e., os que provêm e gerenciam os recursos computacionais, e os consumidores de dados. A partir desse levantamento, os autores definem que dados de alta qualidade são dados adequados, que atendem as necessidades do consumidor.Na tabela 13 temos as categorias e dimensões definidas pelos autores.

Tabela 13 - Categoria e dimensões de QD

\begin{tabular}{|l|l|}
\hline \multicolumn{1}{|c|}{ Categoria de QD } & \multicolumn{1}{|c|}{ Dimensões de QD } \\
\hline \hline QD Intrínseca & Acuracidade \\
& Objetividade \\
& Credibilidade \\
& Reputação \\
\hline \hline QD Acessibilidade & Acessibilidade \\
& Segurança de acesso \\
\hline \hline QD Contextual & Relevância \\
& Valor adicionado \\
& Tempestividade \\
& Completude \\
& Quantidade de dados \\
\hline \hline QD Representacional & Interpretabilidade \\
& Facilidade de entendimento \\
& Representação concisa \\
& Representação consistente \\
\hline
\end{tabular}

Fonte: adaptado de Strong et al.(1997)

Negash, Ryan e Igbaria (2002) avaliaram a questão qualidade da informação nos sistemas de suporte a seus clientes baseado na web, considerado crítico em um mercado cada vez mais 
global e orientado a serviço. Nesse trabalho, três hipóteses foram testadas, a primeira é que a QI é associada positivamente com a efetividade do sistema de suporte ao usuário via web. A segunda hipótese é que o sistema de qualidade também é positivamente associado, e por último, que a qualidade do serviço é positivamente associada.

A figura 11 mostra o modelo de impacto da qualidade na efetividade do sistema de suporte ao cliente baseado na web.

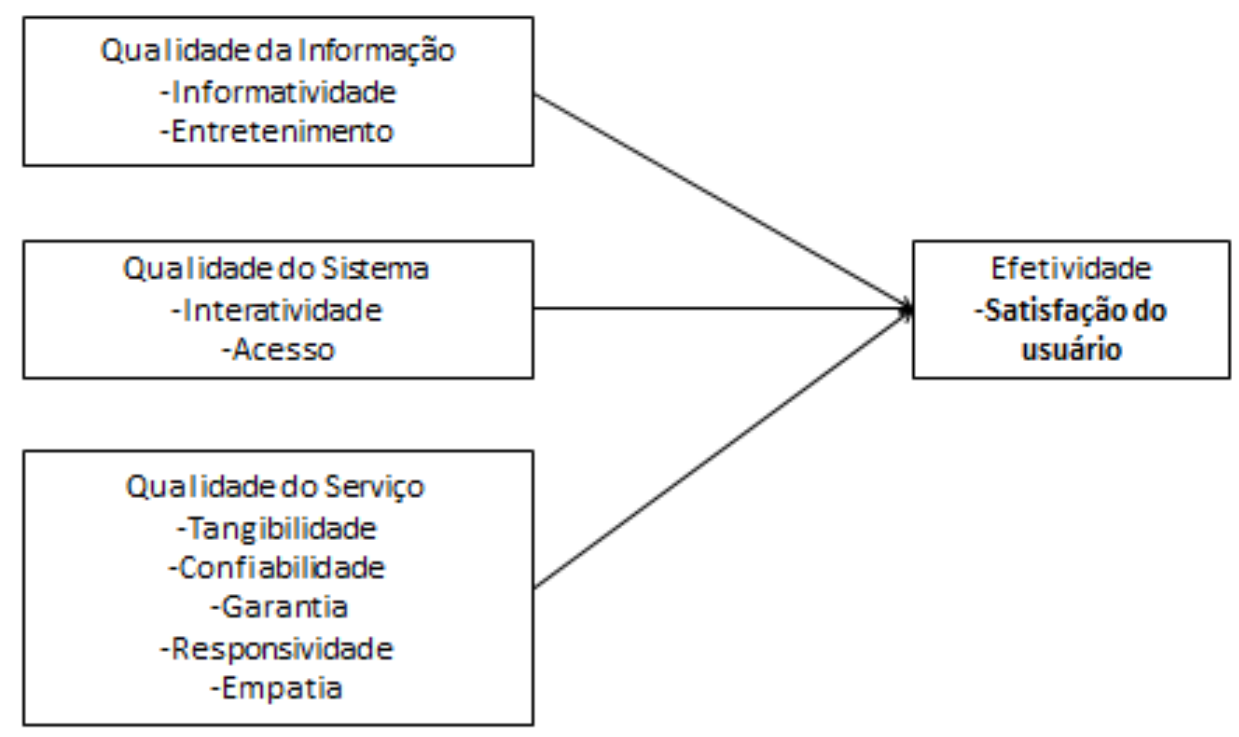

Figura 11 - Efetividade

Fonte: adaptado de Negash et al. (2003)

As dimensões confiáveis adotadas foram a informatividade, entretenimento, interatividade, acesso, tangibilidade, confiabilidade, responsividade, garantia, empatia e satisfação.

\subsubsection{Como o usuário entende QI}

De acordo com Wang e Strong (1996), pesquisa feita com 500 empresas americanas de médio porte, com receita anual maior que U\$ 20 milhões, mostra que muitas das bases de dados apresentam inconsistência e que um número surpreendente delas apresentam grande quantidade 
de erros. Como resultado, 60\% delas têm sérios problemas de qualidade de informação (QI). No entanto, o problema de qualidade vai além da exatidão dos dados, aspectos como completude e acessibilidade são fatores relevantes na garantia da qualidade da informação. O conceito "adequado para uso" enfatiza a importância de se interpretar a QI pelo ponto de vista do usuário consumidor da informação e não somente pelo aspecto técnico. $\mathrm{O}$ sucesso na implantação de sistemas informatizados provedores de informação nas corporações depende da percepção por parte dos usuários de que, entre outros fatores, as informações a que tem acesso são adequadas para seu uso, i.e., atendem suas necessidades, auxiliam na execução de suas tarefas, são completos e de fácil consulta.

Baseado no fato de que grande parte das pesquisas a respeito de QI apresentam uma abordagem intuitiva ou teórica, em seu trabalho, Wang e Strong (1996) procuraram uma abordagem empírica realizando pesquisa diretamente com usuários de informação, buscando dessa maneira definir as dimensões que são consideradas relevantes pelo ponto de vista do consumidor.

Como resultado da pesquisa, Wang e Strong (1996) apresentam o modelo representado na figura 12.

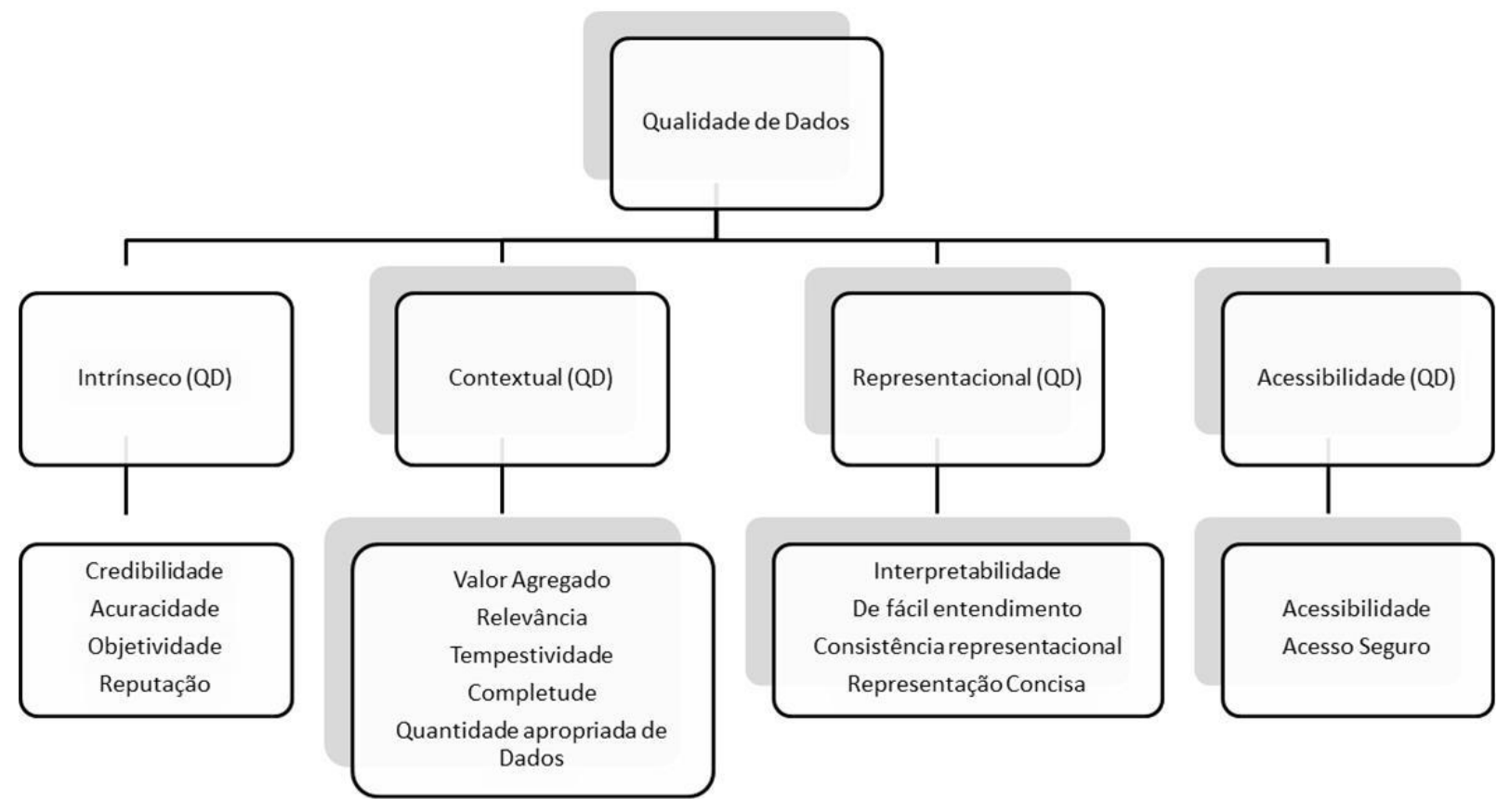

Figura 12 - Dimensões de Wang e Strong Fonte: adaptado de Delone e Mclean (2003)

O modelo de sucesso de SI de DeLone e McLean (2003) toma como base as pesquisas de Shannon e Weaver (1949), a teoria de influência da informação de Mason (1978) bem como estudos empíricos do MIS. Shannon e Weaver (1949) definiram o nível técnico das 
comunicações como a acurácia e eficiência dos sistemas de comunicação que produzem informação. O nível semântico é o sucesso da informação em transportar o significado pretendido. O nível de efetividade é o efeito da informação no receptor.

- Nível técnico -> Acurácia e eficiência

- Nível semântico -> Significado

- Nível de efetividade -> Usabilidade

No modelo de sucesso de SI de DeLone e McLean (2003), a qualidade dos sistemas medem o sucesso técnico, a QI mede o sucesso semântico e o uso, satisfação do usuário, impactos individuais e impactos organizacionais medem o sucesso da efetividade.

Na figura 13 temos a representação do modelo de QI de DeLone e McLean (2003).

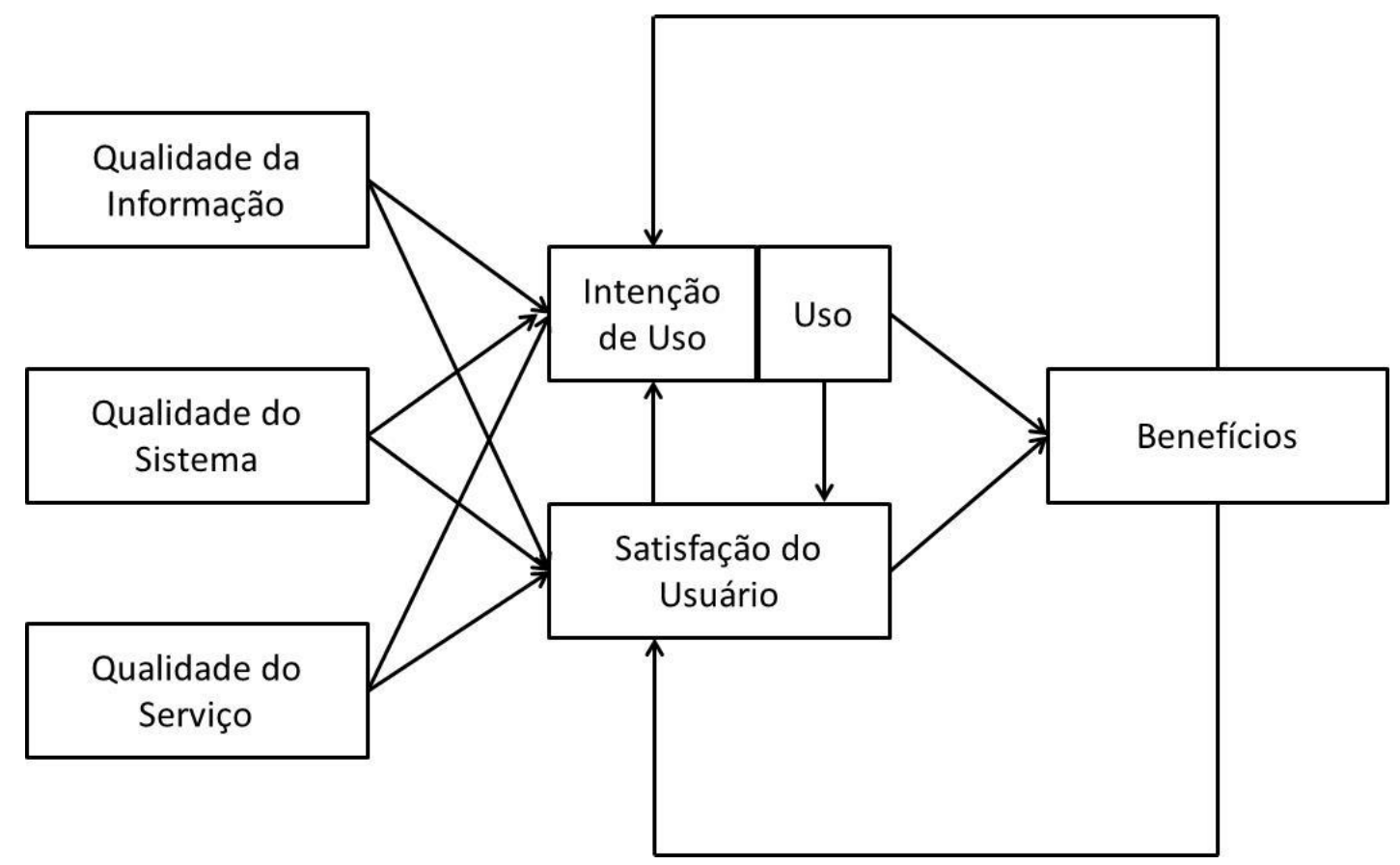

Figura 13 - Modelo de sucesso de SI

Fonte: adaptado de Delone e Mclean (2003)

A seguir será apresentado o conceito de impactos individuais, que representa muitos dos componentes citados na revisão da literatura como benefícios esperados para os sistemas de BI. 


\subsection{Impactos individuais}

Santos (2009) apresenta em sua tese a cadeia de valor dos construtos de sucesso de sistemas de Doll e Torkzadeh (1991) baseado na teoria de atitude/comportamento. Essa cadeia engloba crenças, atitudes, comportamento e impactos sociais e econômicos da TI. As crenças sobre os comportamentos são medidas através da utilidade, que é o grau em que a pessoa acredita que o uso de um determinado sistema melhora seu desempenho no trabalho, e da facilidade de uso percebidas, que é o grau em que uma pessoa acredita que o uso de um determinado sistema não requer esforço. Nos estudos de sucesso de TI, o comportamento é medido pelo uso dos SI. O impacto sobre o trabalho individual é de grande importância para o sucesso do sistema pois é uma consequência direta do uso (SANTOS, 2009).

Na tabela 14 temos as definições dos impactos da TI no trabalho adotando-se as quatro dimensões definidas por Doll e Torkzadeh (1999 apud SANTOS, 2009).

Tabela 14 - Definições dos impactos da TI no trabalho

\begin{tabular}{|c|c|c|}
\hline Dimensões & Definição & Referências \\
\hline Produtividade & $\begin{array}{l}\text { O quanto um aplicativo } \\
\text { melhora os resultados de um } \\
\text { usuário em relação ao tempo }\end{array}$ & $\begin{array}{l}\text { Braverman (1974), Curley e } \\
\text { Pyburn (1982), Hirschheim e } \\
\text { Faduhar (1985), Kraemer e } \\
\text { Danziger (1990), Liff (1990), } \\
\text { Sulck e Marucheck (1993), } \\
\text { Weick (1990) e Zuboff (1988) }\end{array}$ \\
\hline Inovação & $\begin{array}{l}\text { O quanto um aplicativo ajuda } \\
\text { os usuários a criar e testar } \\
\text { novas ideias }\end{array}$ & $\begin{array}{l}\text { Curley e Pyburn (1982), } \\
\text { Davis (1991), Harvey et al. } \\
\text { (1993), Hirschhorn (1981), } \\
\text { LArson e Fielden (1985), } \\
\text { Long (1993), Zuboff (1988) }\end{array}$ \\
\hline Satisfação do cliente & $\begin{array}{l}\text { O quanto um aplicativo ajuda } \\
\text { o usuário a criar valor para os } \\
\text { clientes internos e externos da } \\
\text { firma }\end{array}$ & $\begin{array}{l}\text { Curley e Pyburn } \\
\text { Filiatrault et al. (1982), } \\
\text { Harvey e Filiatrault } \\
\text { Harvey et al. } \\
\text { Hirschhorn (1993), } \\
\text { Schlesinger e Haskett (1991) }\end{array}$ \\
\hline
\end{tabular}




\begin{tabular}{|l|l|l|}
\hline Controle gerencial & $\begin{array}{l}\text { O quanto um aplicativo ajuda } \\
\text { a regular os processos de }\end{array}$ & $\begin{array}{l}\text { Braverman, Hirschhorn } \\
\text { (1984), Kraemer e Danziger }\end{array}$ \\
trabalho o desempenho & $\begin{array}{l}\text { (1990), Shaiken (1985) e } \\
\text { Zuboff (1988) }\end{array}$ \\
\hline
\end{tabular}

Fonte: adaptado de Santos(2009)

\subsection{Benefícios esperados para sistemas de BI}

A avaliação de sistemas de TI e SI é uma questão complexa e com o crescimento dos investimentos nesses sistemas por parte das empresas, as técnicas de avaliação ganharam mais relevância, pois comumente essas decisões de investimento dependem da capacidade de defesa através da indicação de resultados de ganho de eficiência ou redução de custos ao negócio, em outras palavras, a comprovação de ganhos financeiros. Usualmente essas técnicas de avaliação financeira são compatíveis com sistemas relacionados a benefícios operacionais e ao ganho de eficiência, no entanto, bastante limitadas quando se trata de resultados no nível estratégico.

Os sistemas de BI são tecnologias que fornecem significativo valor ao negócio através da melhoria da efetividade na tomada de decisão da gestão, i.e., com forte viés no nível estratégico, o que faz com que sua avaliação através de métodos tradicionais como VPL e ACB (análise de custo-benefício) sejam insuficientes.

Existem muitos elementos que contribuem para uma sabia decisão de investimento. Muitas das técnicas utilizam ACB para medir cada projeto proposto. $\mathrm{O}$ cálculo do impacto econômico como retorno do investimento (ROI), taxa interna de retorno (TIR), e/ou VPL são então aplicadas para comparar o valor ou contribuição de cada uma das alternativas. Com esses métodos, seria plausível supor que projetos com elevado impacto econômico teriam prioridade de investimento e que os de menor impacto econômico, pouca prioridade de investimento, no entanto, não é isso que ocorre. A lista final dos projetos aprovados para investimento podem apresentar pouca semelhança a lista de projetos com elevado impacto econômico, isso porque existem outros fatores que influenciam no processo geral de decisão de investimento além do custo e benefícios derivados do ACB. Técnicas financeiras clássicas como VPL e CBA não são inteiramente adequadas para avaliar TI de maneira efetiva (PARKER E BANSON, 1988). 
Apesar do significativo progresso na avaliação dos retornos de produtividade da TI, a inabilidade das análises econômicas de empresas tradicionais em contabilizar os impactos intangíveis de TI tem levado a procura por uma abordagem mais inclusiva e compreensiva para se medir o valor de negócio de TI. Os executivos frequentemente enfrentam dificuldades quando tentam determinar os benefícios trazidos pela TI à organização (TALLON, et al, 2000, p.2). A identificação dos benefícios potenciais propostos pelos projetos de SI é um grande desafio e uma importante tarefa. A pobre identificação desses benefícios pode explicar porque o paradoxo da produtividade tem sido tolerado (CHANGCHIT et al, 1998). Parece que tem crescido a visão de que se os métodos de avaliação tem que ser melhorados, medidas adicionais precisam ser consideradas como o valor percebido, a utilidade de TI no suporte a decisão, e o aumento da satisfação dos clientes (MURPHY E SIMON, 2002).

Irani e Love (2001), em seu estudo sobre avaliação dos benefícios de BI, consideram que os sistemas de BI são sistemas de benefícios estratégicos e provavelmente os benefícios intangíveis resultantes de seu uso são significantes. A falha em identificar de maneira adequada esses benefícios e mensurá-los pode resultar na falta de suporte adequado por parte dos executivos patrocinadores, que frequentemente estão focados exclusivamente no taxa de retorno sobre o investimento.

Na figura 14 temos a representação da categorização dos benefícios de BI apresentados por Irani e Love (2001).

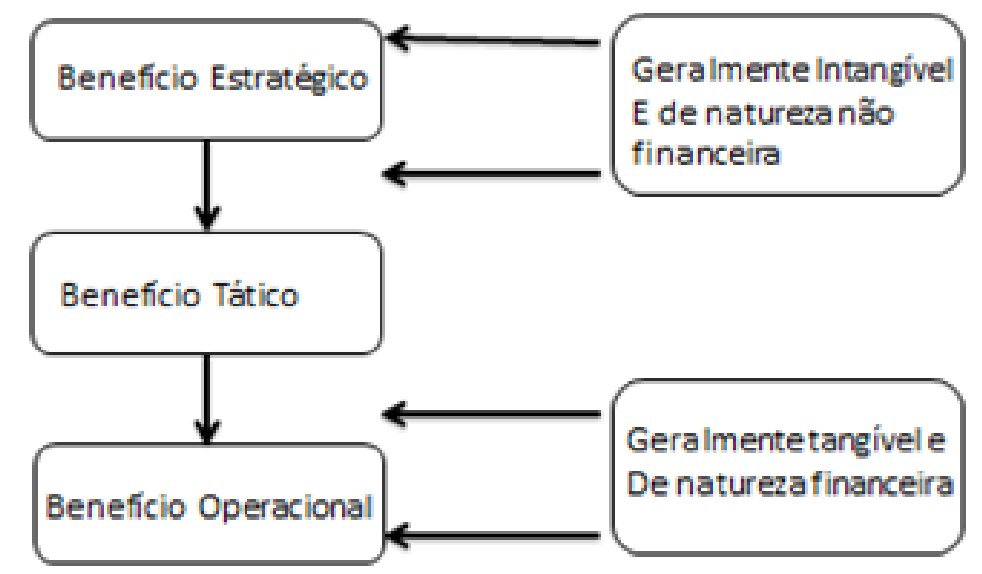

Figura 14 - Natureza dos benefícios estratégico, tático e operacional. Fonte: Adaptado de (Irani e Love, 2001) 
Conforme apresentado no item 2.6.4, na visão de Stackowiak et al. (2007), BI é um processo de captura de grande quantidade de dados além de sua análise e a apresentação de um conjunto de relatórios de alto nível que resumem a essência desses dados capturados como base para as ações de negócio, possibilitando aos gestores tomar decisões fundamentais diariamente. Assim, a expectativa de um sistema de BI é uma maior capacidade de análise de dados, a elaboração de um conjunto de relatórios com elevado nível de informação e a transformação da essência dos dados como base no processo de definição das ações de negócio. Gibson (2004) alega que os possíveis benefícios intangíveis do BI são o aumento do conhecimento do negócio, a melhoria dos processos de trabalho e a geração de um relacionamento mais efetivo. Em seu trabalho, Zeng et al. (2006) descreve que BI pode ser definido como o processo de coleta, tratamento e difusão da informação que tem como objetivo a redução da incerteza na realização das decisões estratégicas. Ainda na visão de Zeng et al. (2006), as tecnologias de BI são categorizadas em função dos métodos de entrega de informação, que podem ser relatórios, análises estatísticas, análises Ad-Hoc e análises preditivas, resultando portanto em benefícios como a redução de incerteza nas decisões estratégicas, na disponibilização de acesso aos dados e informações, no auxilio nas tomadas de decisão do negócio e na geração de relatórios com possibilidades de recursos de análises estatísticas avançadas. Tvrdíková (2007) considera como característica básica das ferramentas de BI a sua habilidade de coletar dados de fontes heterogêneas para aplicar métodos analíticos avançados, e também a habilidade de suportar demandas de diversos usuários. Já na visão de Golfarelli et al. (2004), BI que inclui um data warehouse efetivo e também um componente reativo capaz de monitorar os processos operacionais críticos para permitir tomadores de decisão táticos e operacionais a adaptar suas ações de acordo com a estratégia da companhia, sugerindo então que os benefícios esperados são a capacidade de monitoramento dos processos operacionais críticos, e a disponibilização de informação capaz de suportar a bem informada tomada de decisão táticas e operacionais, ações alinhadas com a estratégia da companhia.

Para Gangadharan e Swamy (2004) o BI pode ser definido como resultado de análises em profundidade dos dados de negócio detalhados, incluindo base de dados e tecnologias de aplicação, assim como análises práticas. Os autores ainda ampliam a definição de BI como ferramenta muito mais ampla, que inclui a gestão do conhecimento potencialmente de forma abrangente, planejamento dos recursos do negócio, sistemas de suporte a decisão e data mining, sugerindo que os benefícios do BI podem ser expressos por possibilitar a análise em 
profundidade do negócio, a gestão do conhecimento e a viabilização do planejamento de recursos do negócio.

A ênfase dada por Ranjan (2009) sobre o BI se dá em torno da melhora do desempenho geral da companhia e que na tentativa das empresas em manterem contato com um grande número de clientes, foram adotados um crescente número de aplicações orientadas a canais, como call center e e-commerce, e estabeleceram um novo desafio na gestão dos dados que é a criação de uma maneira efetiva de integração em tempo real das aplicações da empresa. Dessa forma, na visão do autor, as empresas têm adotado as ferramentas e sistemas de BI com a expectativa de aprender com o passado para projetar o futuro, de promover o atingimento de objetivos e metas estabelecidas pela estratégia de negócio. O autor sugere como benefícios do BI:

- A eliminação de excesso de adivinhação na organização, i.e., tomada de decisão guiada por informação;

- A elevação da comunicação entre departamentos enquanto coordena atividades;

- A habilitação da companhia em responder rapidamente às mudanças das condições financeiras, preferências dos consumidores e operações da cadeia de suprimentos.

- A melhora do desempenho geral da companhia;

- A melhora da tempestividade;

- O aumento da qualidade da informação.

Colin White (2006) apresenta o conceito de BI operacional e descreve que a sua principal entrega é a disponibilização da informação certa no tempo certo para o usuário de negócio correto, o que se traduzem nos benefícios como:

- possibilitar ao usuário reagir rapidamente para resolver problemas de negócio;

- satisfazer novos requerimentos de negócio;

- a detecção de fraude;

- a gestão de riscos;

- a segmentação de clientes;

- a gestão de trabalho em rede;

- a gestão de inventário. 
Para Hannula (2003) as companhias precisam considerar, quando planejam sua estratégia, as pressões e mudanças causadas pelo ambiente de negócio para ser ter sucesso em uma economia digital global. A mudança rápida no ambiente de negócio gera o aumento na necessidade por tempestividade, informação do negócio e conhecimento. Aliado a isso, a quantidade de informação disponível vem crescido de maneira acentuada com o avanço das tecnologias de informação e comunicação. BI e sistemas de gerenciamento de informação tem papel central na produção de informação up-to-date para a tomada de decisão eficaz e estratégica. Através de pesquisa e examinando as atividades de BI em organizações, o autor lista os benefícios esperados significativos para os usuários dos sistemas BI,

- Melhor qualidade de informação;

- Melhor percepção das ameaças e oportunidades;

- Crescimento da base de conhecimento;

- Aumento do compartilhamento de informação;

- Melhoria da eficiência;

- Facilidade de aquisição e analise de informação;

- Tomada de decisão mais rápida;

- Economia de tempo;

- Redução de custos.

A proposta do BI é a de ajudar no controle do vasto estoque e fluxo de informação de negócio ao redor e dentro da organização, primeiramente identificando e então processando a informação, transformando-a em um condensado e proveitoso conhecimento gerencial e em inteligência (LÖNNQVIST E PIRTTIMÄKI, 2006).

Lönnqvist e Pirttimäki (2006) descrevem as dificuldades e a importância de se ter uma metodologia de medida dos benefícios dos sistemas de BI. Para eles, o BI é adotado em diferentes companhias com características que variam bastante. Para algumas o BI pode significar um projeto de pesquisa de um mercado único enquanto para outras companhias pode significar um processo continuo que produz vários produtos de BI e serviços que são utilizados por varias pessoas. Esse é o caso de maior probabilidade de se ter efeito sobre como BI pode ser medido.

A tabela 15 compara as medidas de benefícios de sistemas de BI para duas diferentes propostas, a primeira que se destina principalmente em justificar o investimento sobre o sistema e a 
segunda proposta para entender o quanto as atividades de BI ajudam na gestão, i.e., se os produtos de BI satisfazem as necessidades dos usuários e se o processo é eficiente.

Tabela 15 - Dois tipos de medição de BI

\begin{tabular}{|c|c|c|}
\hline $\begin{array}{c}\text { Proposta para } \\
\text { Medição }\end{array}$ & $\begin{array}{c}\text { Usuários principais da informação de } \\
\text { medição }\end{array}$ & Benefícios esperados \\
\hline Gestão do processo de BI & 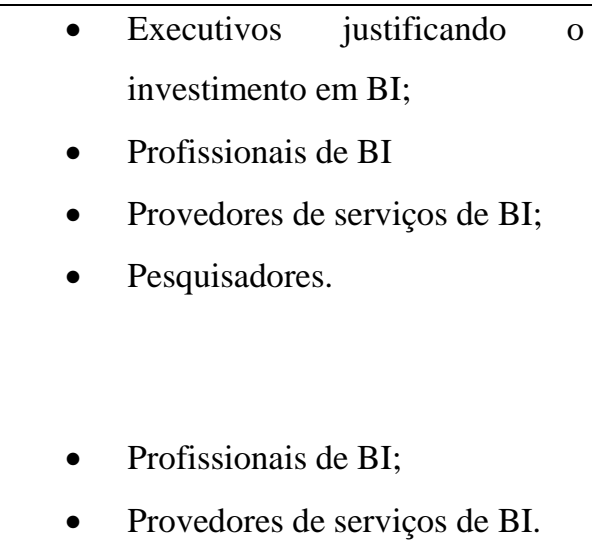 & 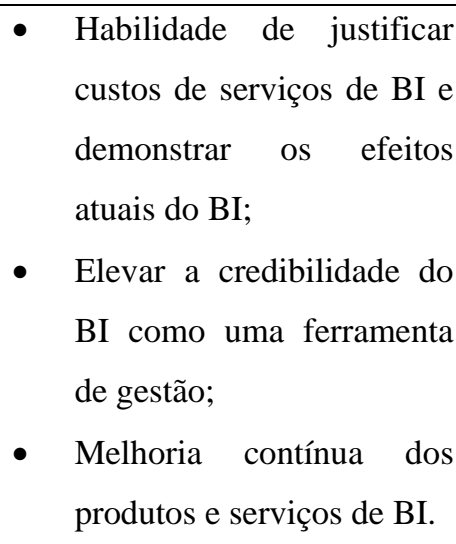 \\
\hline
\end{tabular}

Fonte: Adaptado de (Lönnqvist e Pirttimäki, 2006)

A literatura apresenta um conjunto de modelos de processos de BI, que se diferenciam pelo número de fases, estrutura dos ciclos, fontes de informação, método de armazenamento de informação, e tipo de agregação da informação.

Como exemplo típico de um modelo de BI de quatro fases:

- Identificação da necessidade de informação;

- Aquisição de informação;

- Análise de informação;

- Armazenamento e utilização de informação;

e como uma boa maneira de se medir a efetividade do BI por avaliar a contribuição do BI para uma especifica decisão olhando para o beneficio ou detrimento que esta decisão especifica trouxe para a companhia, são a economia de tempo, redução de custos, supressão de custos e aumento de receita (LÖNNQVIST E PIRTTIMÄKI, 2006).

Na tabela 16 é apresentada uma compilação dos benefícios esperados para sistemas de BI baseado na revisão da literatura. Esses benefícios foram obtidos através de características descritas nas diferentes definições para BI. 
Tabela 16 - Compilação de diferentes pesquisas dos Benefícios esperados do BI

\begin{tabular}{|c|c|}
\hline $\begin{array}{c}\text { Empresas vendedoras/Autores } \\
\text { (data) }\end{array}$ & Benefícios esperados do BI \\
\hline Stackowiak et al (2007) & $\begin{array}{l}\text { - } \quad \text { Capacidade de análise de dados; } \\
\text { - } \quad \text { Apresentação de relatórios de alto nível; } \\
\text { - Transformar dados em ações de negócio. }\end{array}$ \\
\hline Moss e Atre (2003) & $\begin{array}{l}\text { - Informações se suporte a decisão; } \\
\text { - } \quad \text { Fácil acesso aos dados de negócio. }\end{array}$ \\
\hline Chang (2006) & $\begin{array}{l}\text { - Acurácia, tempestividade, dados críticos, informação e } \\
\text { conhecimento que suportem as tomadas de decisão estratégicas e } \\
\text { operacionais e a avaliação de risco num ambiente de negócio } \\
\text { incerto e dinâmico; } \\
\text { - Fonte de dados, informação e conhecimento de origem interna e } \\
\text { externa. }\end{array}$ \\
\hline Gangadharan e Swami (2004) & $\begin{array}{l}\text { - Possibilitar análises aprofundadas dos dados de negócio } \\
\text { detalhados; } \\
\text { - } \quad \text { Gestão do conhecimento; } \\
\text { - Possibilitar o planejamento de recursos de negócio. }\end{array}$ \\
\hline Kulkarni e King (1997) & - Geração de produto da análise dos dados de negócio. \\
\hline Moss, L e Hoberman S (2004) & $\begin{array}{l}\text { - A transformação dos dados em informação, informação em } \\
\text { conhecimento e conhecimento em planos para direcionar ações de } \\
\text { negócios lucrativas; } \\
\text { - Gestão de conteúdo/conhecimento. }\end{array}$ \\
\hline Adelman e Moss (2000) & $\begin{array}{l}\text { - A capacidade de agrupar, consolidar, e analisar a informação; } \\
\text { - Prover acesso à informação de maneira a permitir aos usuários } \\
\text { tomarem melhores decisões de negócio. }\end{array}$ \\
\hline Gibson (2004) & $\begin{array}{l}\text { - Aumento do conhecimento do negócio; } \\
\text { - Melhoria dos processos de trabalho; } \\
\text { - Relacionamento mais efetivo. }\end{array}$ \\
\hline Zeng et al. (2006) & $\begin{array}{l}\text { - } \quad \text { Redução de incerteza nas decisões estratégicas; } \\
\text { - } \quad \text { Prover acesso aos dados e informações; } \\
\text { - } \quad \text { Geraçãã na tomada de deciatórios, análises estatísticas, ad-Hoc e preditivas. }\end{array}$ \\
\hline Tvrdíkova (2007) & $\begin{array}{l}\text { - Possuir a habilidade de coleta de dados de fontes heterogêneas; } \\
\text { - } \quad \text { Fornecer recursos analíticos avançados; } \\
\text { - Suportar as demandas de diversos usuários. }\end{array}$ \\
\hline Golfarelli et al. (2004) & $\begin{array}{l}\text { - Gerar a capacidade de monitoramento dos processos operacionais } \\
\text { críticos; } \\
\text { - Disponibilizar informação que permita aos tomadores de decisão } \\
\text { táticos e operacionais ações alinhadas com a estratégia da } \\
\text { companhia. }\end{array}$ \\
\hline IBM (Whitehorn e Whitehorn, 1999) & $\begin{array}{l}\text { - Extração de informações de negócio valiosas da massa de dados } \\
\text { existente em uma típica empresa. }\end{array}$ \\
\hline Ranjan (2009) & 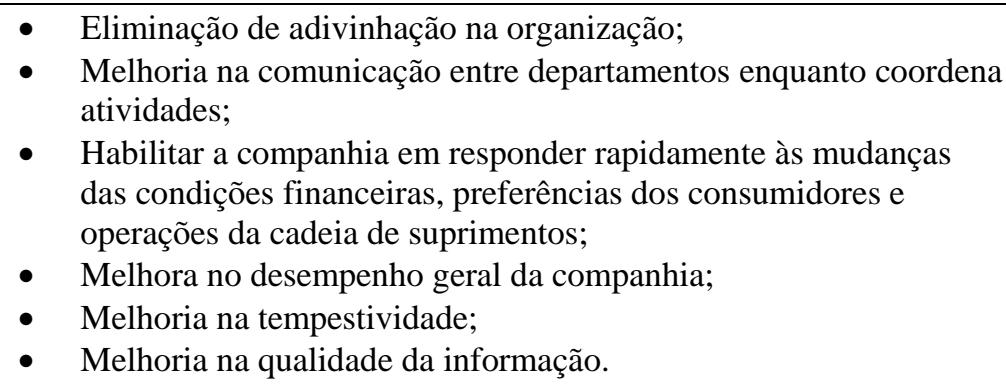 \\
\hline
\end{tabular}




\begin{tabular}{|c|c|}
\hline Colin White (2006) & 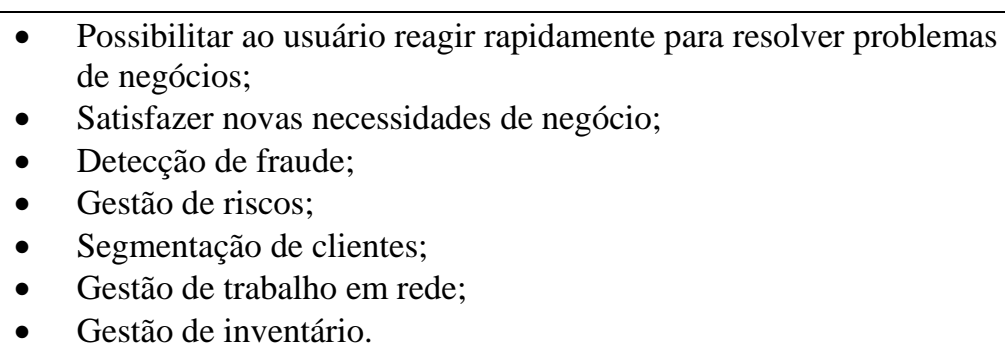 \\
\hline Business Objects (2007) & $\begin{array}{l}\text { - } \quad \text { Consolidação de dados discrepantes da organização; } \\
\text { - } \quad \text { Geração de informação significativa; } \\
\text { parceiros; } \\
\text { - } \quad \text { Gerar maior efetividade na tomada de decisão. }\end{array}$ \\
\hline Hannula e Pirttimäki (2003) & $\begin{array}{l}\text { - } \quad \text { Melhoria na QI; } \\
\text { - } \quad \text { Melhoria na percepção de ameaças e oportunidades; } \\
\text { - } \quad \text { Melhoria no compartilhamento de informação; } \\
\text { - } \quad \text { Tomada de decisão mais rápida; } \\
\text { - Redução de custos. }\end{array}$ \\
\hline Lönnqvist (2006) & $\begin{array}{l}\text { - } \quad \text { Melhoria na percepção da necessidade de informação; } \\
\text { - } \quad \text { Aquisição de informação; } \\
\text { - } \quad \text { Análise da informaçazo; } \\
\text { Armazenamento e utilização de informação. }\end{array}$ \\
\hline Cognos (2007) & $\begin{array}{l}\text { - Associar pessoas e dados; } \\
\text { - Oferecer uma variedade de possibilidades de enxergar a } \\
\text { informação; } \\
\text { - Suportar a tomada de decisão baseada em fatos. }\end{array}$ \\
\hline SAS Institute (Ing, 2007) & $\begin{array}{l}\text { - Entregar a informação certa para a pessoa certa no tempo certo; } \\
\text { - Suportar melhores tomadas de decisão; } \\
\text { - } \quad \text { Promover vantagem competitiva. }\end{array}$ \\
\hline Oracle (2007) & $\begin{array}{l}\text { - Integração de sistemas ponta a ponta; } \\
\text { Possibilitar a gestão de desempenho da empresa, incluindo } \\
\text { aplicações de gestão desempenho financeiro, aplicações } \\
\text { operacionais de BI, fundação e ferramentas de BI, e data } \\
\text { warehousing. }\end{array}$ \\
\hline $\begin{array}{l}\text { Informatica, Teradata, MicroStrategy } \\
\text { (Markarian et al. 2007) }\end{array}$ & $\begin{array}{l}\text { - Gerar um processo interativo para exploração e análise } \\
\text { estruturada; } \\
\text { - Prover informação de domínio específico (frequentemente } \\
\text { armazenada em um data warehouse) para discernir tendências e } \\
\text { padrões; } \\
\text { - Possibilitar insights e conclusões. }\end{array}$ \\
\hline
\end{tabular}

Fonte: Elaborada pelo autor.

Observando a informação consolidada na tabela 16, podemos notar que os autores apresentam diferentes definições para os benefícios esperados do BI, entretanto, algumas vezes são descrições diferentes para o mesmo conceito.

Uma primeira consolidação das descrições dos benefícios gerou a informação de distribuição dos benefícios do BI apresentados na tabela 17. 
Tabela 17 - Distribuição dos benefícios esperados do BI

\begin{tabular}{|l|c|c|}
\hline \multicolumn{1}{|c|}{ Benefício } & Frequência & Relativo \\
\hline Ações de negócio & 10 & $15,60 \%$ \\
\hline Acesso aos dados de negócio, compartilhamento & 10 & $15,60 \%$ \\
\hline Análise de dados & 9 & $14,10 \%$ \\
\hline Informações de suporte a decisão estratégica & 8 & $12,50 \%$ \\
\hline Gestão do conhecimento & 6 & $9,40 \%$ \\
\hline Geração de relatórios & 5 & $7,80 \%$ \\
\hline Gestão de recursos de negócio & 5 & $7,80 \%$ \\
\hline Aumento de lucratividade & 5 & $7,80 \%$ \\
\hline Qualidade da informação & 4 & $6,30 \%$ \\
\hline Avaliação de risco do ambiente de negócio & 4 & $6,30 \%$ \\
\hline Analytics, relatórios ad-Hoc, predições & 4 & $6,30 \%$ \\
\hline Informações de suporte a decisão operacional & 2 & $3,10 \%$ \\
\hline Informação de origem externa & 1 & $1,60 \%$ \\
\hline
\end{tabular}

Fonte: Elaborada pelo autor.

Em pesquisa realizada por Hannula e Pirttimäki (2003), conduzida em 50 companhias Finlandesas de grande porte a fim de examinar as áreas chaves de melhoria nas atividades de $\mathrm{BI}$, bem como os benefícios obtidos, e assim tentar traçar um prospecto do futuro. Um conjunto de benefícios esperados para o BI foi testado buscando-se entender o nível de significância de cada elemento desse conjunto.

O resultado obtido dessa pesquisa é apresentado no gráfico 2.

\section{Benefícios Esperados das Atividades de BI}

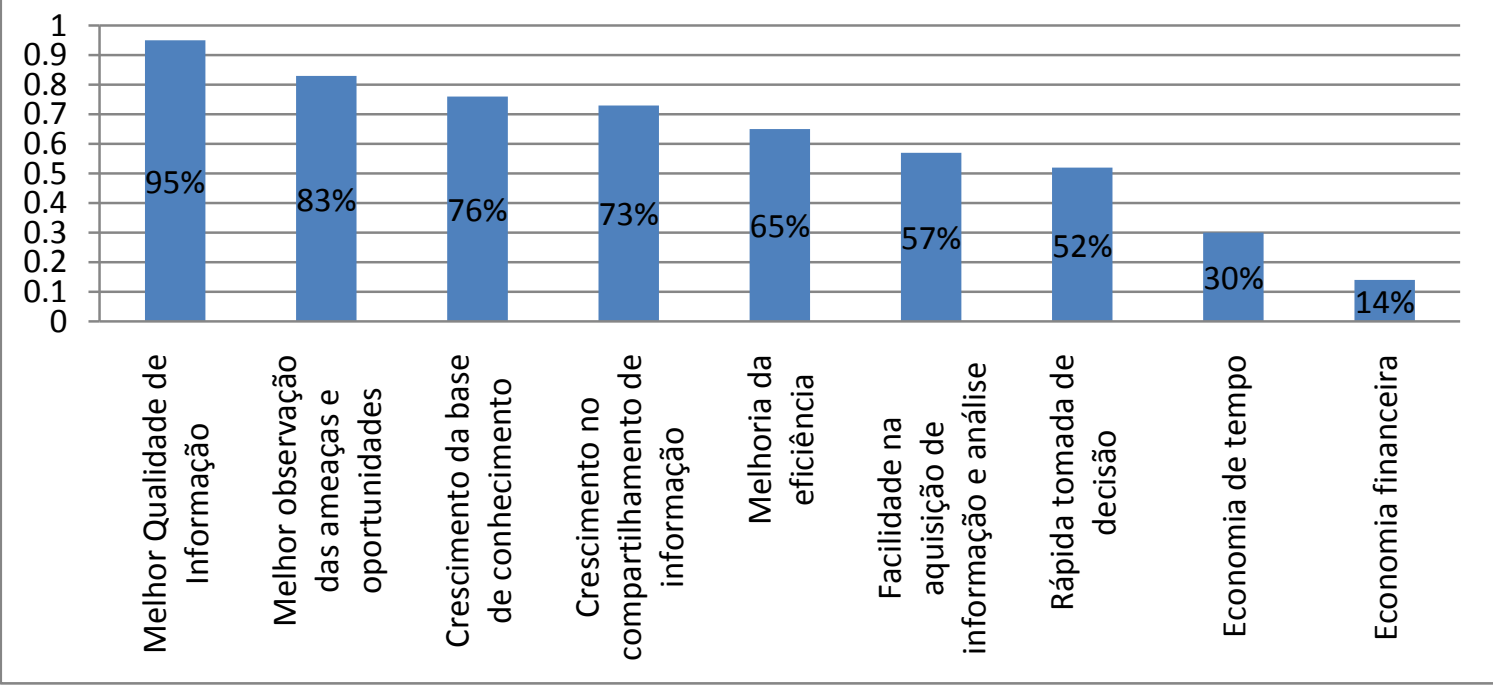

Gráfico 2 - Benefícios esperados das atividades de BI Fonte: Adaptado de Hannula e Pirttimäki (2003). 
A melhoria da qualidade da informação fornecida pelo sistema de BI é o beneficio mais significativo para 95\% dos entrevistados, seguido pela melhoria na observação das ameaças e oportunidades, crescimento da base de conhecimento, melhoria no compartilhamento de informação, melhora da eficiência, maior facilidade na aquisição de informação e análise, maior velocidade na tomada de decisão, economia de tempo, e por fim a economia financeira o benefício menos relevante para os entrevistados.

Em 2007, uma pesquisa patrocinada pela $\operatorname{SAS}^{6}$ e realizada pela Computerworld Research $^{7}$ para melhor entender a questão ao redor do BI e implementação de gerenciamento de desempenho. A pesquisa foi realizada com 227 respondentes de TI. Os resultados de pesquisa mostram que o beneficio chave esperado para o BI é a melhora do processo de tomada de decisão, assim como a qualidade e relevância das decisões feitas. Setenta por cento dos respondentes de TI indicaram esse aspecto como o maior beneficio de $\mathrm{BI}$, enquanto $55 \%$ o indicaram como o maior benefício de gestão de desempenho. Os demais benefícios e suas respectivas participações são a produção de uma visão unificada da informação de todo o negócio (57\%), melhor alinhamento entre recursos e estratégia (56\%), acelera o processo de tomada de decisão (53\%), e responde a necessidade dos usuários por disponibilidade de dados no tempo adequado (52\%). São, portanto os principais benefícios de BI apontados pelos respondentes de TI.

O gráfico 3 apresenta os resultados obtidos na pesquisa conduzida pela Computerworld.

\footnotetext{
6 SAS Institute é um desenvolvedor de softwares analíticos baseado na Carolina do Norte, Estados Unidos. Possui o maior market share para analytics avançada e é possui um dos maiores softwares privados do mundo.

${ }^{7}$ Computerworld é um revista de TI que prove informação para lideres sêniores de TI.
} 


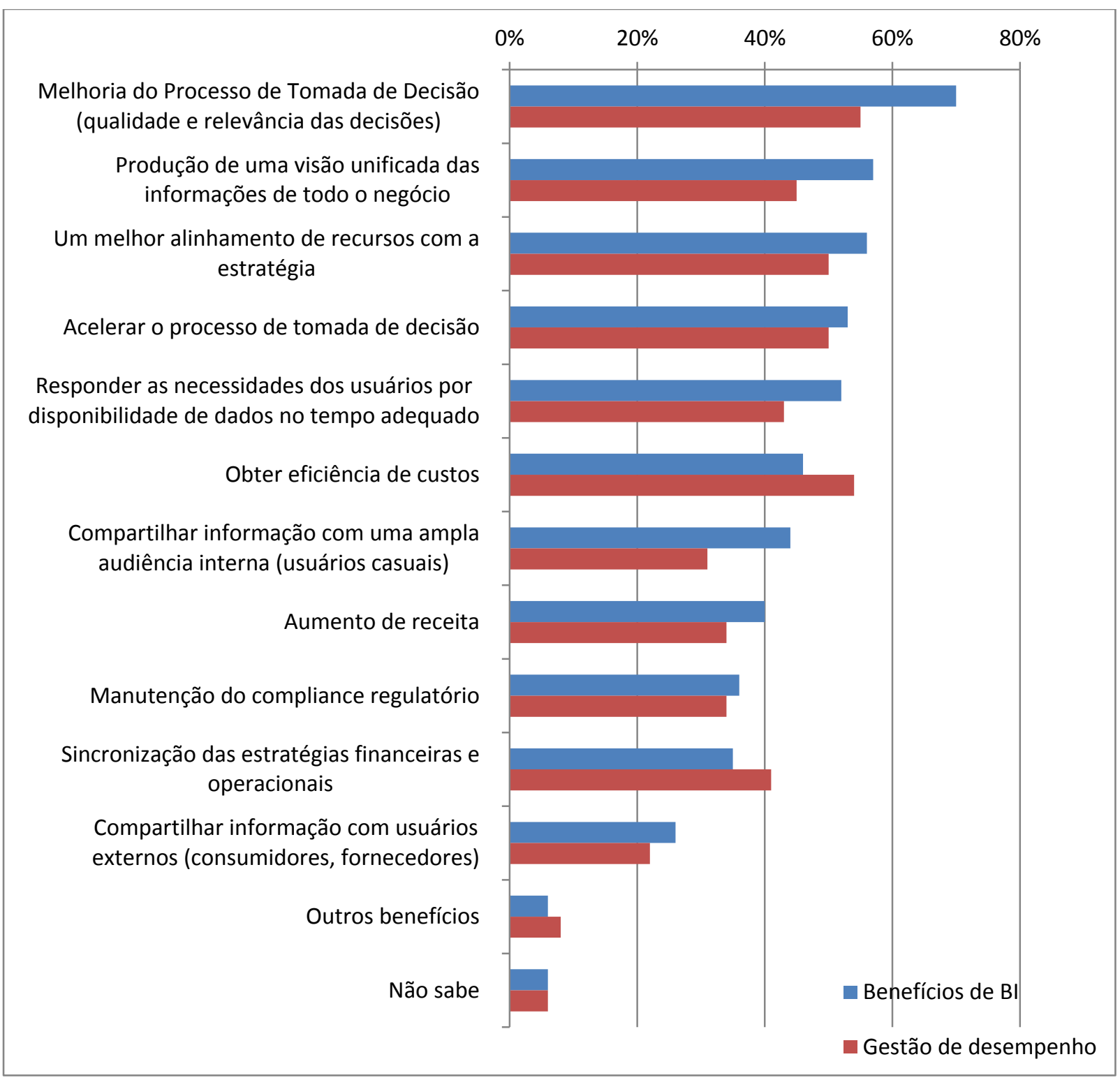

Gráfico 3 - Principais benefícios esperados das ferramentas de BI e ferramentas de gerenciamento de desempenho.

Fonte: Computerworld (2007).

Para a identificação dos BE mais relevantes, adotou-se como critério de seleção os que apresentaram um percentual igual ou maior que 40\%, tanto na indicação feita através das pesquisas com os usuários de sistemas de BI como os BE listados através de revisão da literatura.

$\mathrm{Na}$ tabela 18 é apresentado os BE tomando como base o critério mencionado, frequência igual ou maior que $40 \%$, selecionando portanto os BE mais citados nas diferentes pesquisas. 
Tabela 18 - Consolidação dos benefícios esperados mais significativos de acordo com pesquisas sobre o assunto e revisão da literatura

\begin{tabular}{|c|c|c|}
\hline Computerworld (2007) & Hannula e Pirttimäki (2003) & Revisão da literatura \\
\hline 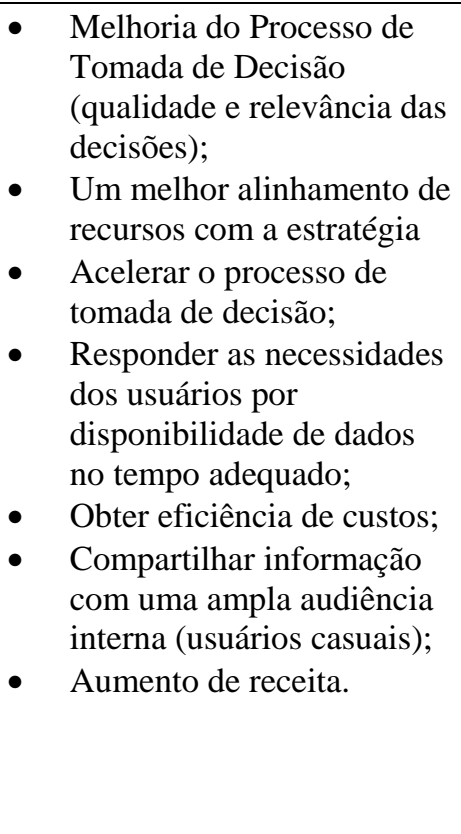 & $\begin{array}{l}\text { - } \quad \text { Melhor Qualidade de } \\
\text { Informação; } \\
\text { - } \quad \text { Melhor observação das } \\
\text { ameaças e oportunidades; } \\
\text { - } \quad \text { Crescimento da base de } \\
\text { conhecimento; } \\
\text { - } \quad \text { Crescimento no } \\
\text { compartilhamento de } \\
\text { informação; } \\
\text { - Melhoria da eficiência; } \\
\text { - Facilidade na aquisição } \\
\text { - } \quad \text { Re informida tomada e análise; } \\
\text { - } \quad \text { decisão; } \\
\text { Economia de tempo. }\end{array}$ & 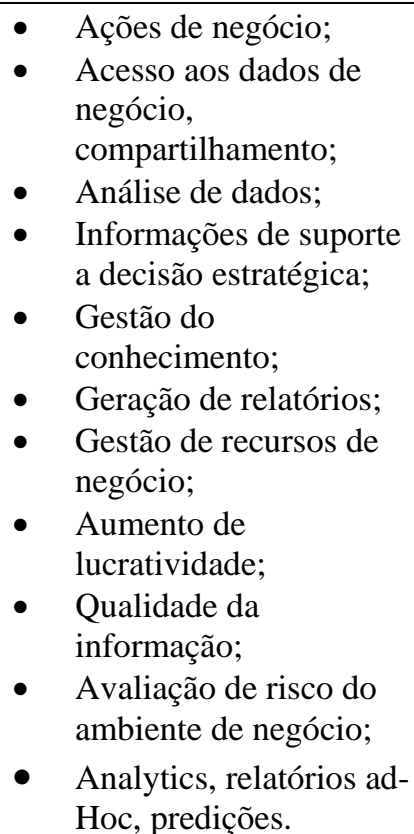 \\
\hline
\end{tabular}

Fonte: Elaborado pelo autor

Os BE apresentados na tabela 18 foram agrupados e relacionados às teorias apresentadas por Santos (2009) e aos conceitos apresentado nesse trabalho na fundamentação teórica.

$\mathrm{Na}$ figura 15 temos a representação gráfica dos construtos do modelo conceitual para a dimensão BE e as questões da revisão da literatura que resultaram nessa associação. 


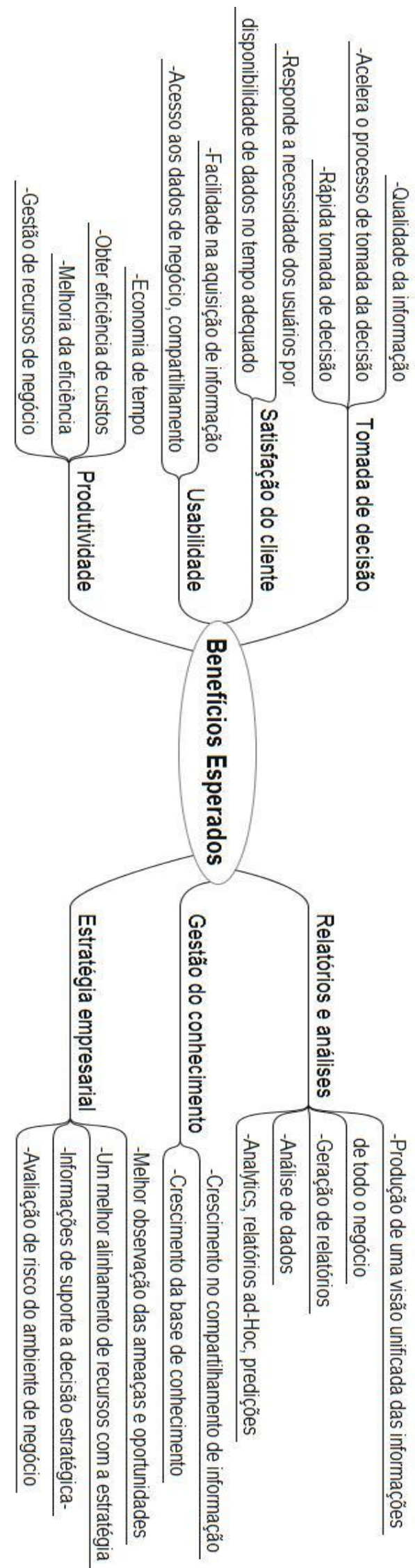

Figura 15 - Representação gráfica das variáveis observadas para a VL Benefícios Esperados. Fonte: Elaborado pelo autor 
Chee et al. (2009) descreve os vários setores onde os sistemas de BI têm sido aplicados como transporte, bancos, assistência médica, varejo, indústria e farmacêutica.

A tabela 19 retrata as aplicações contemporâneas dos sistemas de BI nas diversas áreas, e seus benefícios, de acordo com os autores.

Tabela 19 - Aplicações contemporâneas dos sistemas de BI

\begin{tabular}{|c|c|}
\hline Aplicações de BI & Benefícios \\
\hline $\begin{array}{l}\text { Indústria de Transporte } \\
\text { - Genericamente, provedores de serviços de } \\
\text { transporte utilizam diversas ferramentas e } \\
\text { plataformas oferecidas pelos vendedores } \\
\text { de BI às quais possibilitam a entrega de } \\
\text { informação para o tomador de decisão } \\
\text { como ferramentas padrão de consulta, } \\
\text { ferramentas de relatórios, ferramentas de } \\
\text { processamento analítico em tempo real } \\
\text { (OLAP), ferramentas de visualização de } \\
\text { dados, e ferramentas de mineração de } \\
\text { dados. } \\
\text { Indústria de linha aérea utiliza mineração } \\
\text { de texto para extrair automaticamente } \\
\text { informação útil das diferentes fontes de } \\
\text { escrita como relatórios de incidentes. }\end{array}$ & $\begin{array}{l}\text { - Os benefícios diretos da utilização de soluções de } \\
\text { BI na indústria de transporte são a redução no } \\
\text { tempo de virada para a preparação de relatórios, } \\
\text { acesso direto e mais rápido aos dados desejados } \\
\text { para suportar a tomada de decisão, analisar o fluxo } \\
\text { dos negócios com relação aos serviços, regiões, } \\
\text { clientes, preços, moedas, e fatores de mercado em } \\
\text { tempo, etc. } \\
\text { A enorme base de dados mantida pelas empresas } \\
\text { aéreas tem interpretação humana limitada e a } \\
\text { terminologia aparece diferente para um } \\
\text { computador. Portanto, a descoberta do novo, } \\
\text { conhecimento previamente desconhecido pode ser } \\
\text { encontrado de uma maneira oportuna por se } \\
\text { utilizar a mineração de texto. } \\
\text { Um relatório de incidente é preparado sempre que } \\
\text { um evento ocorre e pode conduzir a um problema. } \\
\text { As minerações de texto de relatórios de incidentes } \\
\text { de empresas aéreas podem identificar um dilema } \\
\text { em potencial. Mineração de texto pode ser usada } \\
\text { com esse largo conjunto de relatórios de dados de } \\
\text { incidentes para validar teorias predeterminadas e } \\
\text { para refugar novos padrões de conhecimento. }\end{array}$ \\
\hline $\begin{array}{l}\text { Bancos } \\
\text { - A indústria bancaria depende da } \\
\text { plataforma de BI para tomar decisões mais } \\
\text { efetivas em poucas áreas como análises do } \\
\text { consumidor, análises de operações e } \\
\text { financeiras, análise de vendas e marketing, } \\
\text { análises de promoção, e análises de risco e } \\
\text { fraude. }\end{array}$ & $\begin{array}{l}\text { - Aplicações de BI ajudam a gestão para a melhoria } \\
\text { das decisões operacionais e estratégicas baseadas } \\
\text { numa melhor e oportuna informação. } \\
\text { - Consumidores potenciais são identificados através } \\
\text { da análise dos dados de compras. Oportunidades de } \\
\text { vendas cruzadas serão reconhecidas via análises do } \\
\text { comportamento dos consumidores. }\end{array}$ \\
\hline
\end{tabular}




\begin{tabular}{|c|c|}
\hline $\begin{array}{l}\text { Indústria da Assistência Médica } \\
\text { - A implementação de BI na indústria de } \\
\text { assistência médica tem possibilitado que } \\
\text { os dados sejam entregues além dos } \\
\text { escritórios administrativos e diretamente } \\
\text { aos staffs clínicos que podem fazer o } \\
\text { melhor uso deles. } \\
\text { A fim de alimentar uma ampla adoção, } \\
\text { interfaces interativas e amigáveis têm sido } \\
\text { desenhadas para prover os usuários com } \\
\text { dados simples e relevantes como o } \\
\text { número de pacientes, tratamentos } \\
\text { necessários, e seu período de } \\
\text { hospitalização. }\end{array}$ & $\begin{array}{l}\text { - O processo de tomada de decisão do negócio tem } \\
\text { se tornado mais efetivo aonde os usuários podem } \\
\text { acessar qualquer tipo de informação com um } \\
\text { rápido e consistente tempo de resposta, } \\
\text { independente do volume de dados analisado ou } \\
\text { questões perguntadas. } \\
\text { - A aplicação de interoperabilidade do BI reduz o } \\
\text { custo de operação na indústria da assistência } \\
\text { médica através da eliminação da cara integração } \\
\text { personalizada no sistema de computação. }\end{array}$ \\
\hline $\begin{array}{l}\text { Varejo } \\
\text { - O BI é implementado para a demanda de } \\
\text { previsão na indústria de varejo através da } \\
\text { geração de estimativas confiáveis tanto } \\
\text { para a demanda de curto quanto para a de } \\
\text { longo prazo baseadas na disponibilidade } \\
\text { de dados dos clientes. } \\
\text { - Além da previsão de demanda, BI também } \\
\text { é usado para monitorar a lealdade do } \\
\text { cliente pela avaliação de qual cliente é leal } \\
\text { e qual é um provável a partir. }\end{array}$ & $\begin{array}{l}\text { - Quando estimativas confiáveis de demanda do } \\
\text { cliente são geradas, os planos da companhia de } \\
\text { serviço e distribuição de produto estaria sempre na } \\
\text { posição para atender as expectativas do cliente. } \\
\text { - Monitorando a lealdade do cliente, fatores que } \\
\text { influenciam suas decisões de ficar ou partir podem } \\
\text { ser determinadas a fim de se imaginar melhores } \\
\text { estratégias para retê-lo. }\end{array}$ \\
\hline $\begin{array}{l}\text { Indústria de Manufatura } \\
\text { - Sistemas de BI permitem a indústria a } \\
\text { rastrear seu inventário de uso através da } \\
\text { localização e hora usando alertas para } \\
\text { notificações instantâneas de níveis baixos } \\
\text { de inventário. } \\
\text { - Além disso, sistemas de BI permitem as } \\
\text { indústrias analisarem dados de múltiplas } \\
\text { fontes a fim de estabelecer objetivos de } \\
\text { desempenho e criar sofisticados modelos } \\
\text { de rentabilidade e financeiros. }\end{array}$ & $\begin{array}{l}\text { - Com a funcionalidade de monitoramento de } \\
\text { inventário, a indústria pode reduzir o excesso de } \\
\text { capacidade e garantir suprimento suficiente para } \\
\text { sua produção. } \\
\text { - Além disso, sistemas de BI também ajudam a } \\
\text { indústria no gerenciamento financeiro pela } \\
\text { identificação de áreas onde eles podem aumentar } \\
\text { os lucros e melhorar a eficiência. }\end{array}$ \\
\hline $\begin{array}{l}\text { Indústria Farmacêutica } \\
\text { - Sistemas de BI ajudam as companhias } \\
\text { farmacêuticas a identificar quais produtos } \\
\text { são mais lucrativos e a monitorar o } \\
\text { comportamento dos consumidores na } \\
\text { compra dos produtos. }\end{array}$ & $\begin{array}{l}\text { - Pelo rastreamento de perto do desempenho de } \\
\text { vendas e comportamento dos consumidores, as } \\
\text { companhias farmacêuticas estão aptas a estabelecer } \\
\text { uma melhor estratégia de marketing e a garantir } \\
\text { uma alocação adequada dos fundos de marketing. }\end{array}$ \\
\hline
\end{tabular}

Fonte: Adaptado de Chee et al. (2009).

As aplicações dos sistemas de BI são amplas e podem ser adequadas para diferentes necessidades da indústria. Devido à natureza única de cada indústria, as organizações têm diferentes demandas para os seus sistemas de BI. A tabela 19 ilustra a significativa diferença na aplicação do sistema de BI de um banco quando comparado com empresas no setor de transporte. Para Chee et.al.(2009), essa diversidade de aplicações faz com que para garantir o sucesso na implementação do sistema de BI, as partes interessadas precisam ter consciência não somente das necessidades do negócio, mas também do substancial benefício que o sistema de 
BI pode trazer para a organização mais do que as diversas funcionalidades alardeadas pelos vendedores de BI.

No próximo item faremos a introdução de modelos apresentados para sistemas de meio virtual, onde o uso do sistema está relacionado com a percepção, por parte dos usuários, dos benefícios e riscos desses sistemas refletindo na confiança e lealdade dos consumidores. Esses conceitos servirão de base para a proposição de um modelo alternativo que será apresentado no capítulo 5 .

\subsection{Valor Percebido / Usabilidade Percebida}

Com a popularização da internet e sua crescente importância sobre as atividades econômicas, áreas de estudo como satisfação e lealdade tem recebido um novo impulso como consequência da incorporação de negócios através do meio virtual, semelhantemente, outros conceitos como credibilidade e usabilidade estão adquirindo relevância devida especialmente a importante participação no provisionamento de serviços através da internet (GUINALÍU et.al., 2006). Ainda na visão de Guinalíu et.al.(2006), usabilidade tem sido apresentada como o fator chave quando os serviços da organização utilizam a internet. De fato, usabilidade é de importância crítica para se alcançar a satisfação do usuário (KIM E EOM, 2002). Também para Ranganathan e Ganapathy (2002), o conceito usabilidade é importante quando tenta identificar as dimensões de qualidade de um website.

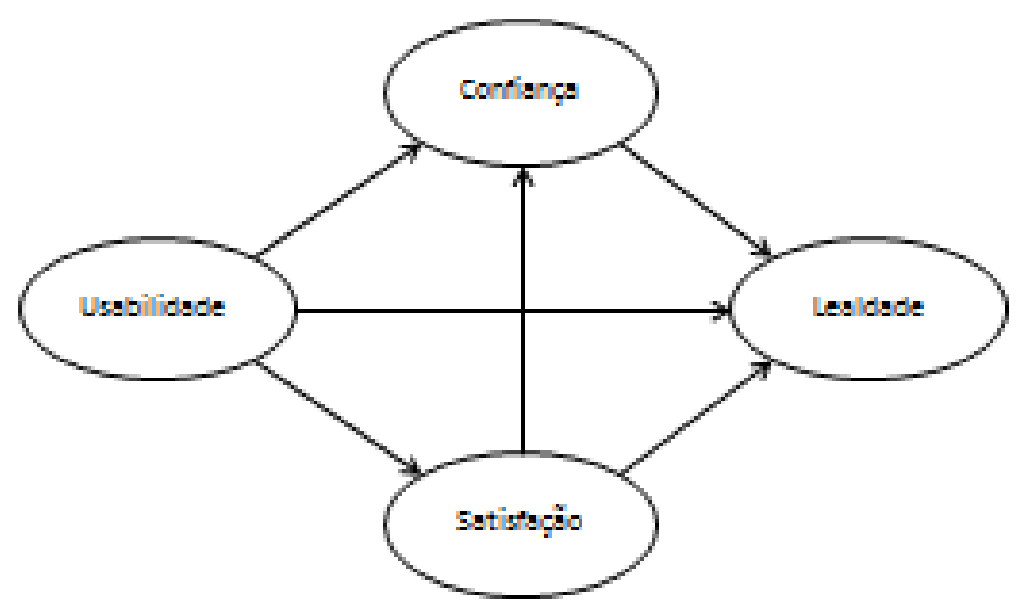

Figura 16 - Modelo estrutural do relacionamento entre usabilidade percebida do website, confiança, satisfação e lealdade.

Fonte: Adaptado de Guinalíu et.al., 2006. 
Confiança é definida como um grupo de crenças mantidas pela pessoa oriunda de suas percepções sobre certos atributos. Em marketing, isso envolve a marca, produtos ou serviços, equipe de vendas, e o estabelecimento onde os produtos ou serviços são comprados ou vendidos.

No modelo em questão, Guinalíu et.al.(2006) estabelece os seguintes argumentos sobre a influência da usabilidade sobre a confiança:

- Uma maior usabilidade favorece uma melhor compreensão dos conteúdos e tarefas que o consumidor deve realizar para atingir o objetivo, e.g. fazer uma ordem. Isso reduz a verossimilhança do erro ou melhorar o nível de confiança do consumidor.

- Usabilidade é relacionada à habilidade do consumidor de saber onde ele esta a qualquer momento e o que pode ser feito. Autoconfiança pode ser definida como o sentimento do consumidor de segurança e habilidade sobre sua decisão e comportamentos, portanto podemos estabelecer um claro relacionamento entre usabilidade e autoconfiança.

- Um desenho adequado favorece sentimentos de prazer no uso do website. Consequentemente, uma maior usabilidade oferece uma confortável atmosfera que pode favorecer uma maior disposição por parte do consumidor.

- Honestidade é relacionada à transparência da informação. Uma grande usabilidade favorece uma grande transparência, assumindo-se que a honestidade (confiança) pode ser melhorada.

- Uma maior usabilidade pode ser percebida como um sinal de benevolência. Portanto, quanto mais fácil o uso, isso poderia ser interpretado como o desejo de ajuste as necessidades do consumidor.

A satisfação é definida como uma condição afetiva do consumidor que resulta da avaliação global de todos os aspectos que permeiam o relacionamento com o consumidor. $\mathrm{O}$ desenvolvimento da satisfação segue um processo similar ao da confiança. Satisfação mostra uma atitude favorável do consumidor. Essa é uma resposta de consistência de longo prazo do comportamento da companhia. Com cada nova experiência, a percepção individual é alimentada por nova informação. É isso que determina o nível de satisfação a qualquer tempo.

A lealdade é uma consequência do crescimento de importância dos serviços de internet. A lealdade a um website parece depender da habilidade do consumidor em gerenciar e controlar esse website. Supõem-se que a familiaridade do consumidor com um website diminui a 
probabilidade de migração do consumidor para outro website. A aquisição dessa habilidade necessária não depende unicamente do tempo dedicado pelo consumidor no uso do website, mas também nas facilidades que o website oferece ao usuário.

Como grande frequência os consumidores possuem ou têm acesso à informação incompleta e distante do ideal. Como resultado, eles habitualmente se deparam com pelo menos algum grau de risco ou incerteza em seus processos de decisão de compra através de websites (KIM et.al., 2008). Wilkie e Pessemier (1973) em seu estudo sobre modelos de atitude investigam questões sobre a utilização de modelos de atitude multiatributos em marketing. De acordo com os autores, escalas de atitudes unidimensionais (por exemplo concorda - discorda) oferece uma medida eficiente quanto se trata de um instrumento estruturado podendo, portanto prover por exemplo uma medida resumo do efeito da marca. Um objeto multiatributo (por exemplo produto ou marca) é visto como um pacote de atributos que conduzem para custos e benefícios desejáveis para os indivíduos ou segmentos do mercado. Os aspectos gerais são colocados para refletir a escolha da cognição individual (crenças) como o grau com o qual os atributos que certos objetos possuem são ponderados pela importância (importância) para cada indivíduo.

Assim, o risco não pode ser considerado o único fator a que os consumidores são sensíveis no contexto de aquisição pela internet, o beneficio percebido pelo consumidor também é um incentivo a esse comportamento de consumo (KIM et.al., 2008).

Peter e Tarpey (1975) em seu estudo sobre estratégias de decisão do consumidor avaliam uma classe de modelos de consumidores tomadores de decisão rotulados pelos autores de cognitivoracional devido ao seu foco na organização de variáveis chaves de risco e utilidade. Suas estratégias de decisão se comparam a um consumidor que opera de maneira similar ao homem racional da teoria econômica no comportamento de objetivo dirigido, calculado e previsível baseado em algum conhecimento de custos e benefícios de escolhas alternativas. Esses modelos podem ser descritos como modelos de utilidade aditiva que levam a três estratégias básicas. Primeiro a estratégia de risco percebido na qual geralmente assume-se que o consumidor busca minimiza, ou pelo menos reduzir, qualquer utilidade esperada negativa associada com o comportamento de aquisição; segundo, existem os modelos de atitude focados nos benefícios dos produtos que são positivamente avaliados; e terceiro a estratégia com ênfase no conceito de valência, que se refere a percepção, por parte dos consumidores, de características desejáveis e não desejáveis nos produtos, atribuindo-se valência positiva quando os produtos apresentam 
características percebidas desejáveis e valência negativa quando apresentam características não desejáveis. Para Kim et.al. (2008), esse cenário de valência é derivado da combinação do risco percebido e benefício percebido o qual assume que os consumidores percebem os produtos como tendo tanto atributos positivos como negativos, e para uma tomada de decisão o consumidor busca maximizar o resultado de valência ponderando entre os atributos positivos e negativos. Kim et.al. (2008) apresenta um modelo teórico com o objetivo de examinar os efeitos diretos e indiretos da confiança sobre a intenção de aquisição do consumidor através de website. A lógica desse modelo é que o consumidor toma a decisão de aquisição (AQUISIÇÃO) baseada em sua intenção de aquisição (INTENÇÃO). A intenção (INTENÇÃO) do consumidor é afetada pela sua percepção de benefícios (BENEFÍCIO), risco (RISCO), e confiança (CONFIANÇA) com relação a entidade ofertante na internet. O consumidor será mais propenso a se engajar na aquisição pela internet quando perceber que os riscos são baixos, os benefícios percebidos são altos, e quando a confiança é alta (efeito direto). A confiança do consumidor também eleva sua intenção de aquisição indireta por reduzir sua percepção do risco (efeito indireto).

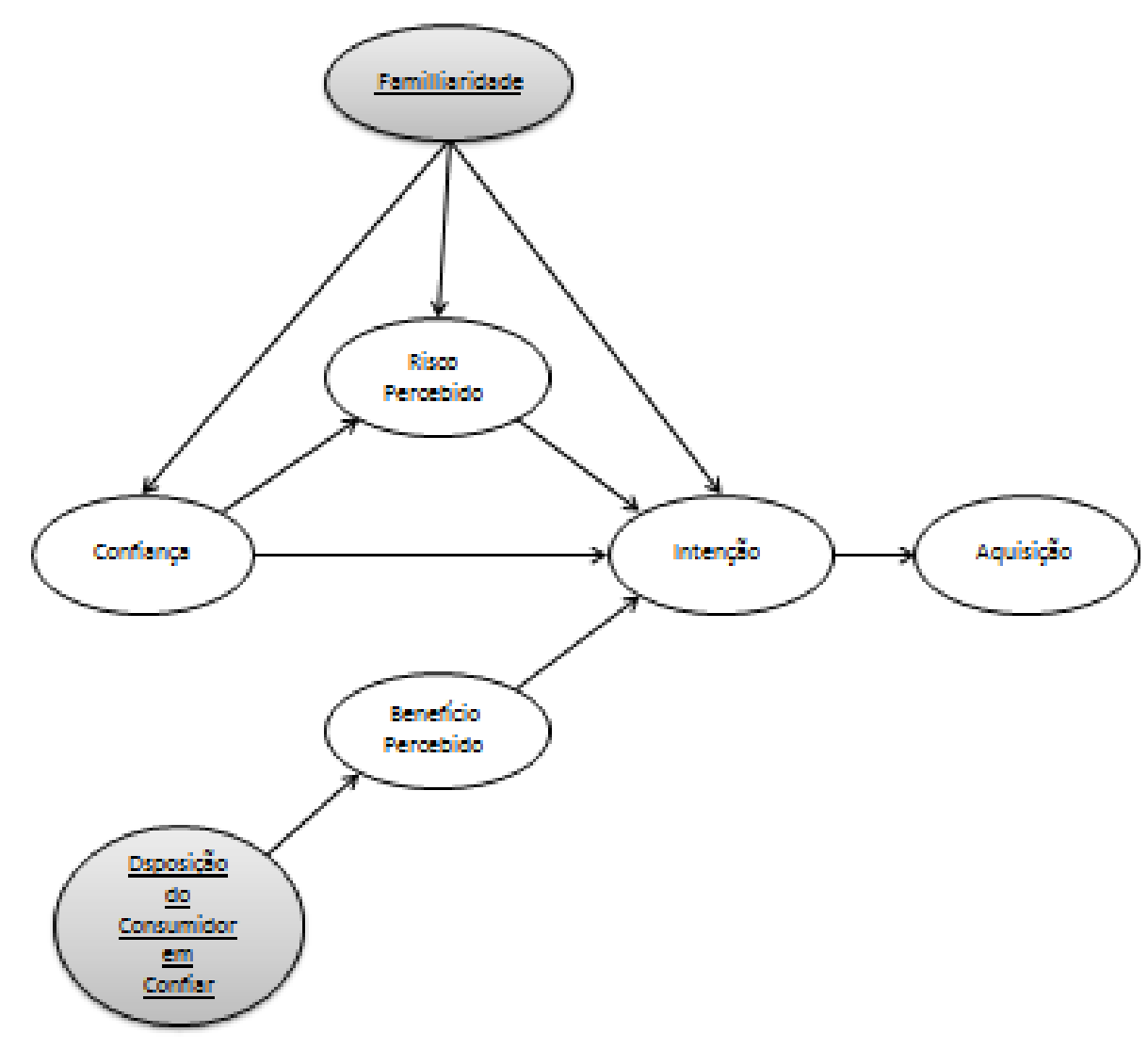

Figura 17 - Modelo de tomada de decisão do consumidor baseado na confiança. Fonte: Adaptado de Kim et.al., 2008. 
Para Kim et al. (2008), os antecedentes de confiança e risco percebidos pelo consumidor podem sem providos pelos gestores de negócios de internet com insights e ferramentas que podem ser construidas para construir essa confiança e administrar os riscos percebidos inerentes as experiências de compra online. No comércio tradicional, a relação de confiança é afetada por características do cliente, vendedor, companhia, e a interação entre as partes envolvidas. O mesmo ocorre no contexto de comércio eletrônico. Kim et al. (2008) apresenta quatro categoria de antecedentes que impactam na confiança e riscos percebidos pelo consumidor.

- Baseado em cognição (observação): esse antecedente está associado com as observações e percepções do consumidor (preocupação com informações sobre qualidade, proteção percebida da privacidade, proteção da segurança, imagem da marca, design desejado) em relação aos recursos e características da entidade crível.

- Baseado em emoção (afeto): esse antecedente da confiança está relacionado com interações indiretas com a companhia baseado nas referências de terceiros (confiança de terceiros, referências, comentários, recomendações, etc.),

- Baseado na experiência: esse antecedente da confiança está relacionado as experiências dos consumidores com a companhia e com a compra pela internet de maneira geral.

- Orientado pela personalidade: esse antecedente da confiança está relacionado com as características do consumidor, sua disposição e hábitos de compras, que quando de natureza muito estável, apresenta maior grau de dificuldade na condução, por parte dos vendedores por internet, de uma relação de confiança.

Assim, Kim et al. (2008) define em seu modelo de pesquisa as seguintes dimensões:

Tabela 20 - Dimensões do modelo de tomada de decisão do consumidor baseada em confiança

\begin{tabular}{|l|l|l|}
\hline \multicolumn{2}{|c|}{ Antecedentes } & Dimensões \\
\hline Qualidade da informação & Baseado em cognição (observação) & Confiança, risco \\
\hline Proteção percebida da privacidade & Baseado em cognição (observação) & Confiança, risco \\
\hline Proteção percebida da segurança & Baseado em cognição (observação) & Confiança, risco \\
\hline Presença de uma terceira parte & Baseado em afeto & Confiança, risco \\
\hline Reputação positiva & Baseado em afeto & Confiança, risco \\
\hline Familiaridade & Baseado em experiência & Confiança, risco, intenção \\
\hline Disposicao do consumidor em confiar & Orientado à personalidade & Confiança \\
\hline
\end{tabular}

Fonte: Adaptado de Kim et al., (2008).

No próximo capítulo, a partir dos conceitos apresentados, será apresentado o modelo que orientará essa pesquisa. 


\section{MODELO DE PESQUISA}

\subsection{Suporte conceitual ao problema de pesquisa}

Como apresentado no capítulo 1, o presente estudo tem como objetivo especificar e validar um modelo que relacione os impactos dos fatores críticos de sucesso (FCS) dos sistemas de BI e seus benefícios esperados (BE) ao uso das informações disponibilizadas aos clientes desses sistemas por meio de revisão bibliográfica e pesquisa quantitativa com usuários de BI em áreas de negócio de empresas brasileiras.

O objetivo desse capítulo é então apresentar o modelo conceitual que será utilizado, elaborado a partir das referencias apresentadas no capítulo anterior, descritas a seguir. O modelo de sistemas de informação proposto por Delone e Mclean (2003), que relaciona a dimensão intenção de uso e uso com a dimensão QI, e a dimensão benefício com as dimensões intenção de uso e satisfação do usuário, foi usado para especificar a relação entre benefícios esperados e uso do modelo de pesquisa. A partir desse modelo, estudos complementares foram realizados analisando as dimensões QI e BE. Como consequência dessa análise, a inclusão da dimensão impactos individuais (II), relação essa estudada por Santos (2009) e relatada na revisão da literatura em BE.

Como mencionado, o presente estudo trata de sistemas de BI, que conforme descrito no capítulo 2, disponibilizam informação aos usuários em um processo que pode ser considerado semelhante ao descrito por Kim et al. (2008). Em um sistema de BI, o produto a ser adquirido pelo usuário é a informação considerada capaz de melhorar a qualidade da tomada de decisão, alicerçada agora em dados, associados às considerações intuitivas habituais, como um componente técnico capaz de possibilitar decisões mais assertivas. Pode-se inferir então que nesse contexto o usuário possua portanto, o "desejo" por maior suporte para a sua tomada de decisão, o que indicaria a existência de intenção de aquisição desse produto. Semelhantemente ao processo de compra pela internet, o usuário, na decisão pela aquisição e consequentemente o uso das informações do sistema de BI, avalia seus benefícios percebidos, os riscos e a credibilidade dessas informações. O modelo proposto por Kim et al. (2008) de tomada de decisão do consumidor baseado na confiança (fig. 16), tem como objetivo modelar a forma 
como ocorre o processo de decisão do usuário pelo uso das informações de determinado sistema de BI.

Dessa maneira, decidiu-se adotar o modelo de tomada de decisão do consumidor baseada na confiança como aproximação para um modelo alternativo proposto nesse trabalho, o que levou a necessidade da inclusão de uma dimensão que pudesse suprir certas questões do modelo de Kim et al. (2008) não atendidas pelas dimensões QI, BE e II. Uma avaliação detalhada dos conceitos adotados no modelo de Kim et al. (2008) mostrou que a dimensão FCS seria um bom candidato capaz de suprir essa necessidade pois influenciam os aspectos de risco percebido. Nesse modelo baseado em confiança, os benefícios esperados têm correlação, e portanto influenciam o aspecto credibilidade das informações disponibilizadas pelo sistema. Assim, como o modelo de Kim et al. (2008), o modelo proposto nesse trabalho também apresenta intersecção entre algumas das variáveis observáveis para os construtos BE e FCS, o que é aceitável uma vez que consideramos, por exemplo, QI como um componente da dimensão BE, entretanto QI também influencia a dimensão FCS uma vez que impacta tanto no risco percebido quanto na credibilidade das informações.

\subsection{Modelo conceitual}

O modelo conceitual proposto sugere que o uso da informação disponibilizada em um sistema de BI é influenciada pelos benefícios esperados para esse sistema e seus fatores críticos de sucesso, conforme sugere o modelo de sucesso de implementação de sistemas de BI de Yeoh e Koronio (2010). O construto FCS, além da influência sobre o construto uso, também pode impactar sobre os BE. Esse modelo define a hipótese de que a dimensão FCS influencia os BE e USO por integrar fatores das perspectivas organizacional e tecnológica que remetem ao risco percebido pelo usuário. O modelo também levanta a hipótese de que a dimensão BE constrói a reputação do produto entregue pelo SBI, i.e., é um fator de confiança para o usuário.

Na figura 18 são apresentadas as relações entre os construtos, e a seguir são especificadas as hipóteses correspondentes. 
H1: A influência da dimensão BE sobre o USO. Essa hipótese está fundamentada no modelo de Kim et al. (2008) que mostra o beneficio identificado pelo consumidor como um fator que inpacta em sua decisão de compra através do sistema.

H2: A influência da dimensão FCS sobre o USO. Essa hipótese está fundamentada no modelo de Yeoh e Koronios (2010) que apresenta os FCS como fatores que impactam no sucesso da implementação de sistemas de BI.

H3: A influência da dimensão FCS sobre os BE. Essa hipótese está fundamentada no modelo de Yeoh e Koronios (2010) e no conceito de sucesso de BI de Wixon e Watson (2001), que conceituam o impacto dos FCS sobre os benefícios esperados pelo usuário (BE), considerado pelos autores como o sucesso do sistema de BI.

\section{Modelo conceitual da pesquisa}

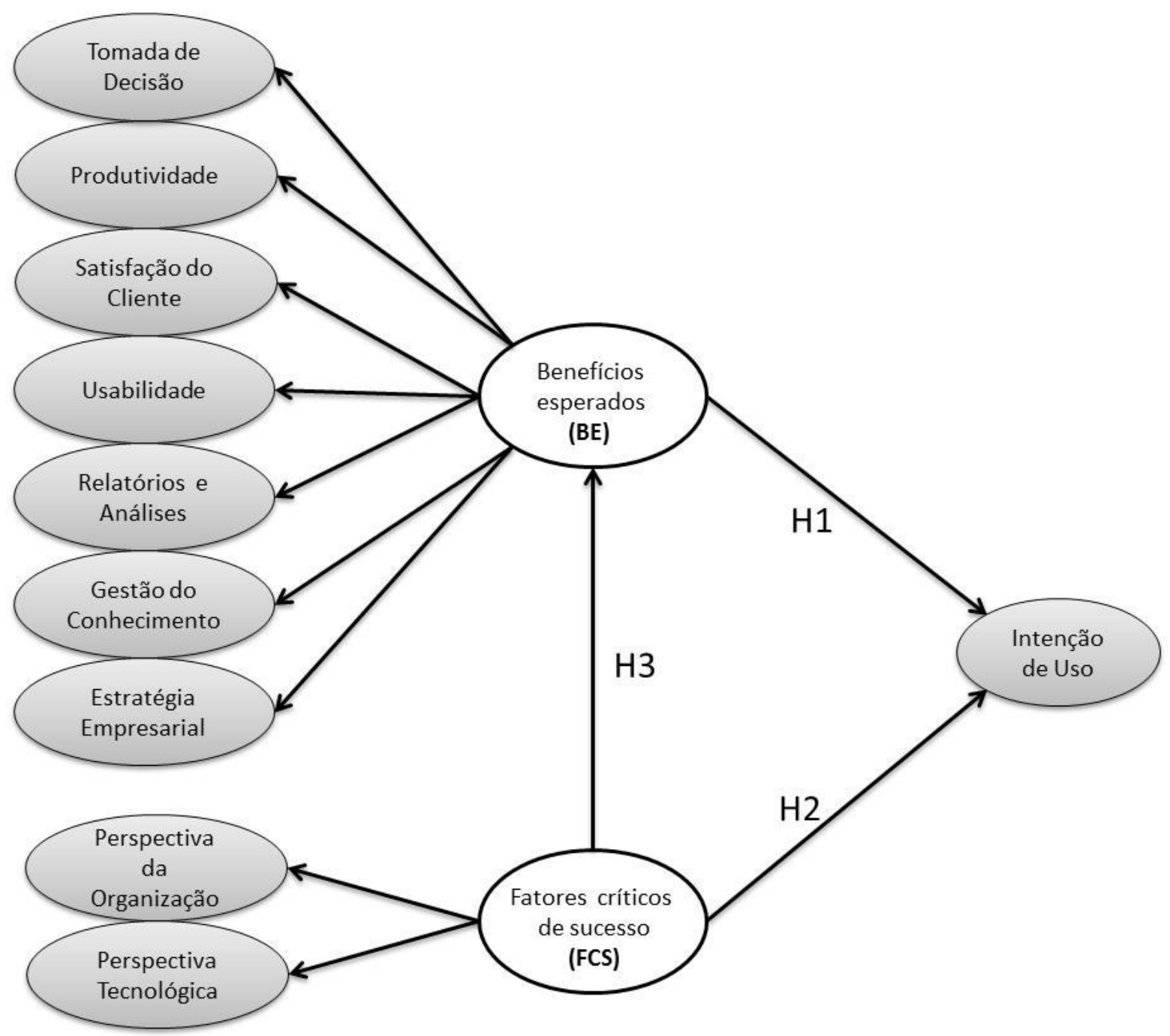

Figura 18 - Modelo Conceitual de Pesquisa.

Fonte: Elaborado pelo autor 


\subsection{Dimensão BE (Benefícios esperados para sistemas de BI)}

Para a definição das variáveis latentes da dimensão BE, que é uma variável latente (VL) de primeira ordem, assumiu-se, como comentado no iem 2.9, que os benefícios esperados relevantes seriam os que apresentaram nas pesquisas um percentual igual ou maior que $40 \%$ de indicação por parte dos respondentes como os benefícios mais importantes para os usuários de BI. Critério semelhante foi adotado para os benefícios esperados listados através de revisão da literatura.

Encontramos na tese de Santos (2009) o estudo da influência da qualidade da informação (QI) sobre os impactos individuais (II). As variáveis observadas adotadas pelo autor para os construtos QI e II apresentam sobreposição conceitual com as variáveis observadas para o construto BE. Desta forma, para esse trabalho, decidiu-se adotar parte das VLs e indicadores do modelo de Santos (2009), adequados ao modelo conceitual, e suas respectivas questões de pesquisa, conforme apresentado na tabela 23.

Os construtos tomada de decisão, satisfação de clientes, usabilidade e produtividade estão relacionados com as VLs II e QI do modelo de pesquisa da tese de Santos (2009). Desta forma, os indicadores adotados para esses construtos foram os validados pela pesquisa de Santos (2009), conforme apresentado na coluna "variável observada” da tabela 23.

Outros benefícios foram mencionados como relatórios e análises, que se referem à capacidade do sistem de BI entregar aos usuários informação em forma de relatórios e a apresentação de flexibilidade de manuseio desses relatórios possibilitando análises em diferentes níveis de complexidade das informações, chegando à manipulação estatística avançada dos dados. O compartilhamento de informação e fortalecimento da base de conhecimento são aspectos do construto gestão do conhecimento, e a observação de oportunidades de ameaças, avaliação de risco e alinhamento estratégico nos remete ao modelo SWOT de Porter e foram associados ao construto estratégia empresarial. A tabela 22 temos a descrição dos construtos da dimensão $\mathrm{BE}$, sua relação com os resultados de pesquisa e revisão da literatura e as referências que dão origem aos indicadores de cada construto. 
Tabela 21 - Consolidação dos resultados de pesquisa da dimensão BE

\begin{tabular}{|c|c|c|c|c|}
\hline Construto & Resultado de pesquisa & Origem & \multicolumn{2}{|c|}{ Referência } \\
\hline Tomada de decisão & $\begin{array}{l}\text { - } \text { Qualidade da informação } \\
\text { - } \text { Acelera o processo de tomada de } \\
\text { decisão } \\
\text { - } \quad \text { Rápida tomada de decisão }\end{array}$ & $\begin{array}{l}\text { Impactos } \\
\text { Individuais }\end{array}$ & $\begin{array}{l}\text { Santos, } \\
\text { (2009) }\end{array}$ & G.D. \\
\hline $\begin{array}{l}\text { Satisfação do } \\
\text { cliente }\end{array}$ & $\begin{array}{llr}- & \text { Responde a necessidade dos } \\
& \text { usuários por disponibilidade de } \\
& \text { dados no tempo adequado }\end{array}$ & $\begin{array}{l}\text { Impactos } \\
\text { Individuais }\end{array}$ & $\begin{array}{l}\text { Santos, } \\
\text { (2009) }\end{array}$ & G.D. \\
\hline Usabilidade & $\begin{array}{l}\text { - Facilita na aquisição da informação } \\
\text { - Acesso aos dados de negócio, } \\
\text { compartilhamento }\end{array}$ & $\begin{array}{l}\text { Qualidade } \\
\text { da } \\
\text { Informação }\end{array}$ & $\begin{array}{l}\text { Santos, } \\
\text { (2009) }\end{array}$ & G.D. \\
\hline Produtividade & $\begin{array}{ll}\text { - } & \text { Economia de tempo } \\
\text { - } & \text { Eficiência de custos } \\
\text { - } & \text { Melhoria de eficiência } \\
\text { - } & \text { Gestão de recursos de negócio** }\end{array}$ & $\begin{array}{l}\text { Impactos } \\
\text { Individuais }\end{array}$ & $\begin{array}{l}\text { Santos, } \\
\text { (2009) }\end{array}$ & G.D. \\
\hline $\begin{array}{l}\text { Relatórios } \\
\text { análises }\end{array}$ & $\begin{array}{l}\text { - } \text { Produção de uma visão unificada } \\
\text { das informações de todo o negócio } \\
\text { - Geraçào de relatórios ad-hoc, } \\
\text { analytics, predições }\end{array}$ & $\begin{array}{l}\text { Revisão da } \\
\text { literautra }\end{array}$ & Pesquisa & \\
\hline $\begin{array}{l}\text { Gestão do } \\
\text { conhecimento }\end{array}$ & $\begin{array}{l}\text { - Crescimento no compartilhamento } \\
\text { de informação } \\
\text { - Aumento da base de conhecimento }\end{array}$ & $\begin{array}{l}\text { Revisão da } \\
\text { literatura }\end{array}$ & Pesquisa & \\
\hline $\begin{array}{l}\text { Estratégia } \\
\text { empresarial }\end{array}$ & 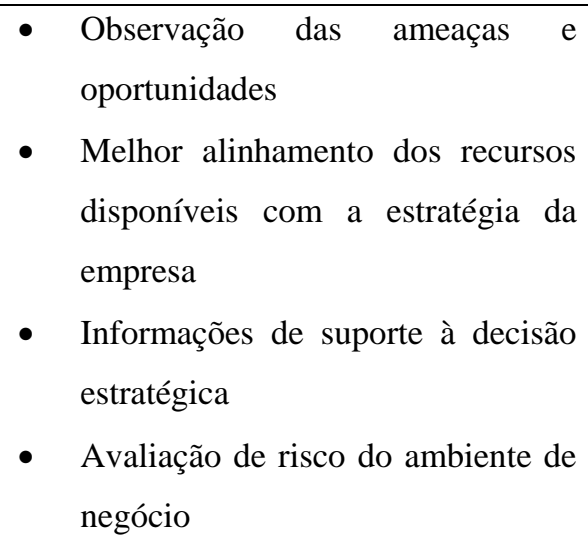 & $\begin{array}{l}\text { Revisão da } \\
\text { literatura }\end{array}$ & Pesquisa & \\
\hline
\end{tabular}

Fonte: Elaborado pelo autor

** Indicador definido pelo autor 


\subsection{Variáveis do construto BE}

Do construto QI apresentado por Santos (2009), a VL usabilidade é adotada no modelo de BE devido aos fatores mencionados nos resultados de pesquisa como facilidade na aquisição da informação e acesso aos dados de negócio que remetem à usabilidade. As VLs de primeira ordem do construto II também apresentadas na pesquisa de Santos (2009) se mostraram compatíveis com os resultados de pesquisa do construto BE, com exceção da VL de primeira ordem "inovação".

Como resultado, apresentamos na tabela 23 as VLs de primeira ordem e as variáveis indicadoras adotadas para o construto BE como resultado da interação do modelo de pesquisa validado na tese de Santos (2009) e os resultados obtidos da revisão da literatura. A tabela mostra também as questões que serão adotadas no questionário (mais detalhes sobre o questionário no próximo capítulo).

Tabela 22 - Variáveis do construto BE

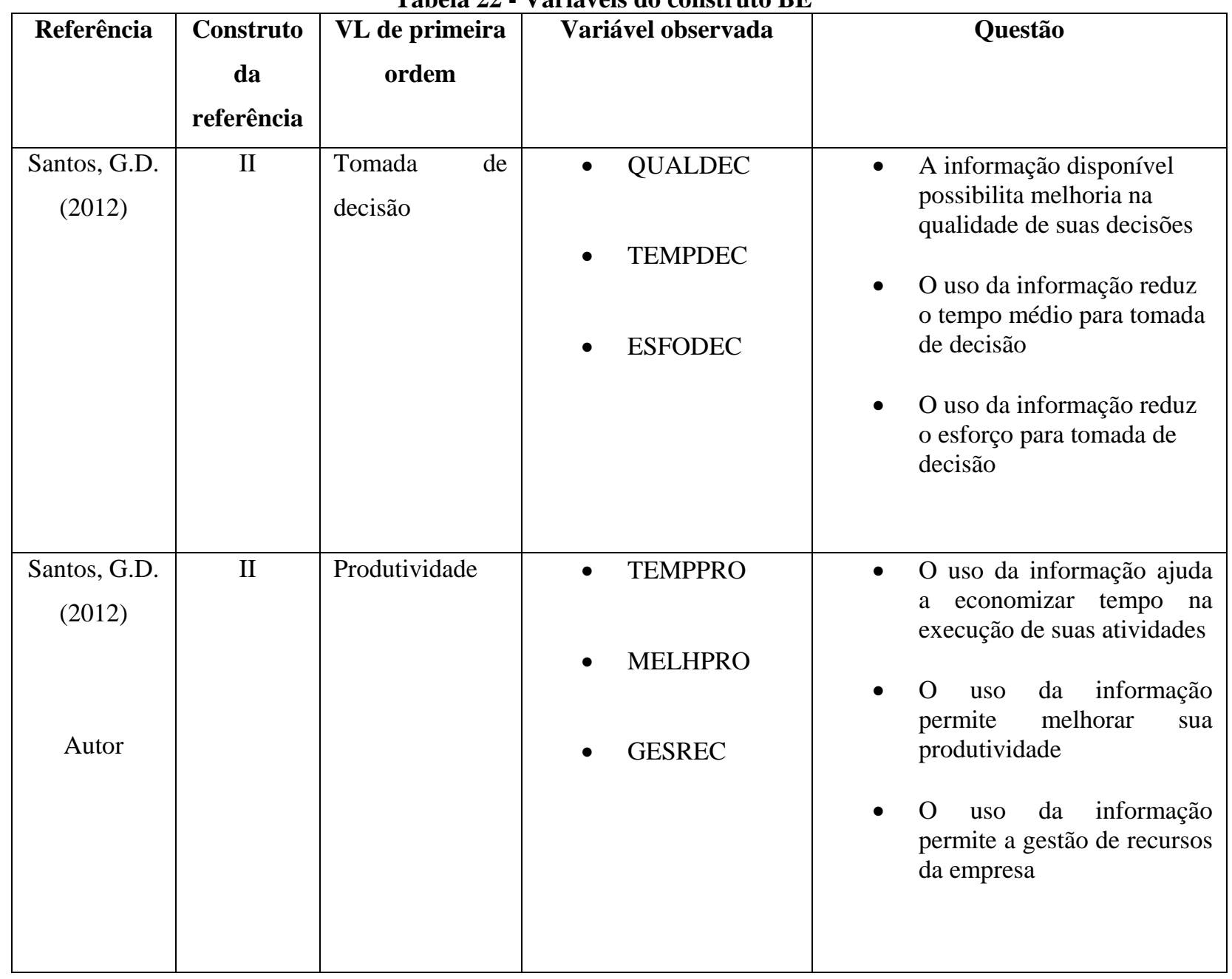




\begin{tabular}{|c|c|c|c|c|}
\hline $\begin{array}{c}\text { Santos, G.D. } \\
\text { (2012) }\end{array}$ & II & $\begin{array}{l}\text { Satisfação do } \\
\text { Cliente }\end{array}$ & $\begin{array}{ll}\text { - } & \text { SERVCLI } \\
\text { - } & \text { SATICLI } \\
\text { - } & \text { NECECLI }\end{array}$ & 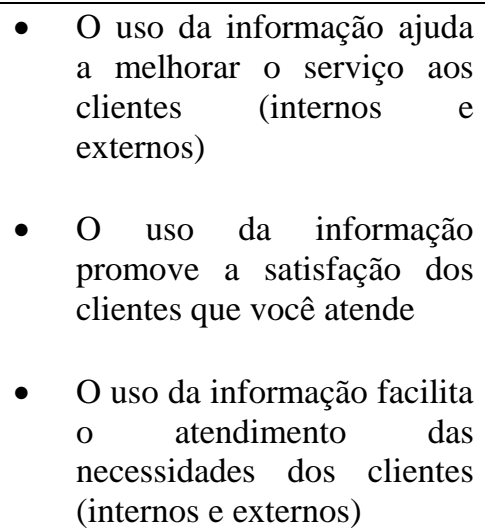 \\
\hline $\begin{array}{c}\text { Santos, G.D. } \\
\text { (2012) }\end{array}$ & QI & Usabilidade & $\begin{array}{ll}\text { - } & \text { CREDIBIL } \\
\text { - } & \text { ACESSIBI } \\
\text { - } & \text { FACILIDA } \\
\text { - } & \text { REPUTACA } \\
\text { - } & \text { VALORADI }\end{array}$ & 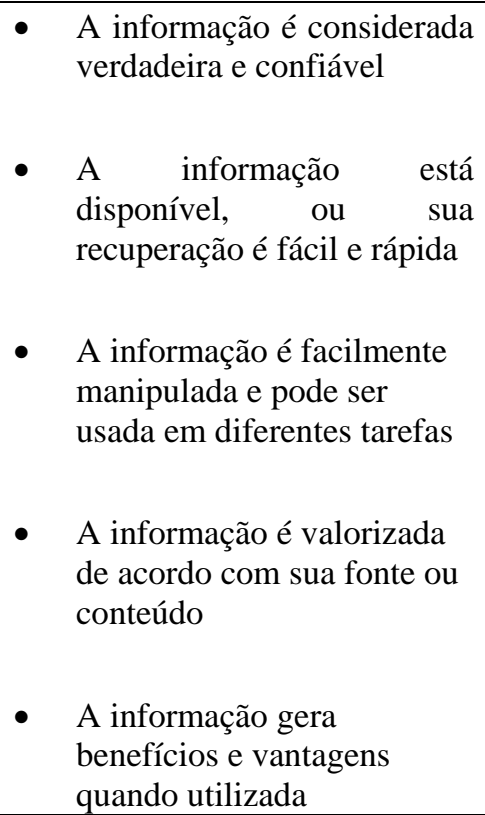 \\
\hline Autor & & $\begin{array}{l}\text { Relatórios } \mathrm{e} \\
\text { Análises }\end{array}$ & $\begin{array}{ll}\text { - } & \text { RELVISAO } \\
\text { - } & \text { ANALDADOS } \\
\text { - } & \text { RELAVANC }\end{array}$ & 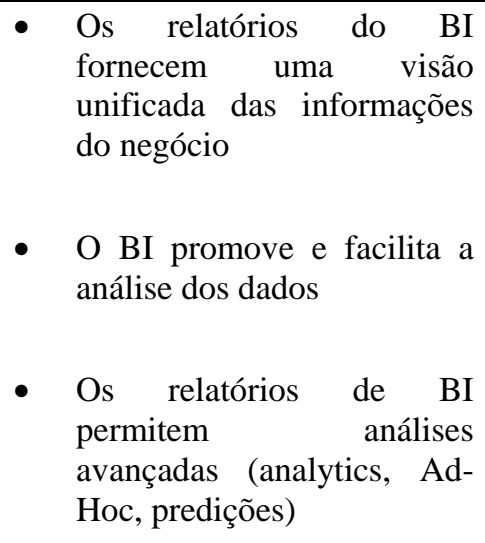 \\
\hline Autor & & $\begin{array}{l}\text { Gestão do } \\
\text { conhecimento }\end{array}$ & $\begin{array}{ll}\text { - } & \text { INFOCOMP } \\
\text { - } & \text { BASECONH }\end{array}$ & $\begin{array}{l}\text { - } \begin{array}{l}\text { Aumentou } \\
\text { compartilhamento das } \\
\text { informações da empresa }\end{array} \\
\text { - } \begin{array}{l}\text { Cresceu a base de } \\
\text { conhecimento da companhia }\end{array}\end{array}$ \\
\hline
\end{tabular}




\begin{tabular}{|c|c|c|c|}
\hline Autor & $\begin{array}{l}\text { Estratégia } \\
\text { Empresarial }\end{array}$ & $\begin{array}{ll}\text { - } & \text { OBSOPORT } \\
\text { - } & \text { ALINHESTR } \\
\text { - } & \text { INFOESTRAT } \\
\text { - INFRISCO }\end{array}$ & $\begin{array}{l}\text { - } \begin{array}{l}\text { Observa-se mais facilmente } \\
\text { as ameaças e oportunidades } \\
\text { ao negócio }\end{array} \\
\text { - } \begin{array}{l}\text { Melhor alinhamento entre } \\
\text { os recursos e a estratégia da } \\
\text { empresa }\end{array} \\
\text { - A informação disponível é } \\
\text { útil nas decisões } \\
\text { estratégicas } \\
\text { - A informação permite } \\
\text { avaliar melhor os riscos do } \\
\text { ambiente de negócio }\end{array}$ \\
\hline
\end{tabular}

Fonte: Elaborado pelo autor

\subsection{Variáveis do construto fatores críticos de sucesso (FCS)}

Para as variáveis do construto FCS foram considerados os fatores apresentados na tabela 4 onde é feita a categorização dos FCS tomando-se o cuidado de separar fatores pré-projeto como a clara visão do negócio e planejamento, gestão de metodologia e projeto dirigidos ao negócio, e composição de time balanceado, do pós-projeto, uma vez que nosso estudo se baseia em pesquisa com usuários do sistema de BI já em operação e que não necessariamente participaram do projeto e implantação do sistema. Olhando para a perspectiva do processo, Yeoh e Koronos (p.27, 2009) apontam que os fatores a serem considerados são as abordagens dirigidas ao negócio e ao desenvolvimento iterativo. Para os pesquisadores, esses fatores permitem que o time de TI possa se concentrar nas melhores oportunidades de melhoria da implantação do sistema, selecionando parâmetros e os desenvolvendo em comum entendimento com todos os interessados do negócio. Desta forma, na perspectiva do processo, os fatores são na grande maioria de pré-projeto, e mesmo quando têm papel no estágio pós-implantação, são para adaptações e adequação de novos requerimentos, o que foge ao conhecimento de nosso grupo de interesse nessa pesquisa, que são usuários do sistema, desta forma, a VL perspectiva de processo foi desconsiderada no modelo de pesquisa.

Na tabela 24 são apresentadas as VLs de primeira ordem do construto FCS. 
Tabela 23 - Variáveis do construto FCS

\begin{tabular}{|c|c|c|c|}
\hline Referência & VL de primeira ordem & Variável observada & Questão \\
\hline Yeoh et al (2008) & Perspectiva da Organização & $\begin{array}{l}\text { - } \text { PARCERIA } \\
\text { - GESCOMP } \\
\text { - GOVINF }\end{array}$ & $\begin{array}{l}\text { - } \begin{array}{l}\text { Existe parceria entre a comunidade de } \\
\text { negócios e TI (nível) }\end{array} \\
\text { - } \begin{array}{l}\text { Existe comprometimento da gestão com } \\
\text { suporte e patrocínio (nível) }\end{array} \\
\text { - } \begin{array}{l}\text { Existe governança da informação através } \\
\text { do centro de competência de BI (nível) }\end{array}\end{array}$ \\
\hline Yeoh et al (2008) & Perspectiva Tecnológica & $\begin{array}{ll}\text { - } & \text { ESTRUT } \\
\text { - } & \text { GERQUAL } \\
\text { - } & \text { TECFERR } \\
\text { - } & \text { APLICBI } \\
\text { - } & \text { CONDESEMP }\end{array}$ & $\begin{array}{l}\text { - Apresenta estrutura robusta \& escalável } \\
\text { - (Questão de gerenciamento \& qualidade de } \\
\text { dados). O sistema oferece informação } \\
\text { adequada a necessidade da área. } \\
\text { - (Tecnologia/ferramentas apropriadas). A } \\
\text { tecnologia utilizada no sistema é fácil de } \\
\text { usar e possui os recursos necessários. } \\
\text { - (Aplicações de BI integradas). O sistema } \\
\text { de BI está integrado aos dados de origens } \\
\text { de diferentes sistemas. } \\
\text { - (Considerações de desempenho).O sistema } \\
\text { apresenta bom desempenho nas diferentes } \\
\text { consultas de dados. }\end{array}$ \\
\hline
\end{tabular}

Fonte: Elaborado pelo autor

\subsection{Variáveis do construto USO}

Na tabela 25 são apresentadas as variáveis do construto USO, que adota os parâmetros do construto aquisição do modelo de pesquisa de Kim et al. (2008) sobre a decisão do consumidor, baseado na confiança, da realização de compra através de plataformas de comércio eletrônico (e-commerce), por ser uma boa aproximação a escolha de uso das informações dos disponibilizadas nos SBI.

Tabela 24 - Variáveis do construto USO

\begin{tabular}{|c|c|c|c|}
\hline Referência & VL de primeira ordem & Variável observada & Questão \\
\hline Kim et al., 2008 & Uso & $\begin{array}{ll}\text { - } & \text { CONSULTA } \\
\text { - } & \text { RECOMENDA } \\
\text { - } & \text { REUTILIZA }\end{array}$ & 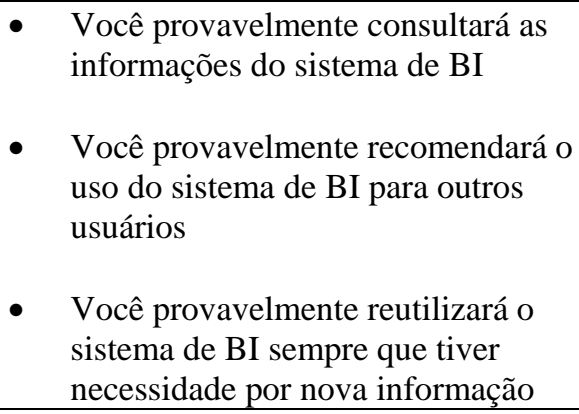 \\
\hline
\end{tabular}

Fonte: Elaborado pelo autor 
Conforme mencionado anteriormente, o presente estudo trata de sistemas de BI que disponibiliza informação aos usuários a fim de suportar a tomada de decisão. A tecnologia empregada para acesso a informação do BIS é muito semelhante a tecnologia de comércio eletrônico, e o comportamento de uso do sistema semelhante ao comportamento descrito por Kim et.al. (2008). Nesse modelo assume-se que em um sistema de BI, o produto ofertado ao usuário e a informação e que ele deve considerá-la capaz de melhorar sua tomada de decisão possibilitanto ações mais assertivas. Portanto, o usuário na decisão pela aquisição e uso das informações do sistema de BI, avalia seus benefícios percebidos, os riscos e a credibilidade dessas informações.

O modelo proposto por Kim et.al. (2008) de tomada de decisão do consumidor baseado na confiança (fig. 16), a princípio espelha a maneira consistente o processo de decisão do usuário pelo uso das informações de determinado sistema de BI. Assim, adotou-se o modelo de tomada de decisão do consumidor baseado na confiança como aproximação para a o modelo proposto nesse trabalho, indicando que os FCS influenciam os aspectos de risco percebido e que os benefícios esperados influenciam o aspecto credibilidade das informações disponibilizadas pelo sistema.

A seguir é apresentado o modelo de mensuração e estrutural, elaborado com base nas considerações apresentadas nesse item. 


\subsection{Modelo de mensuração e estrutural}

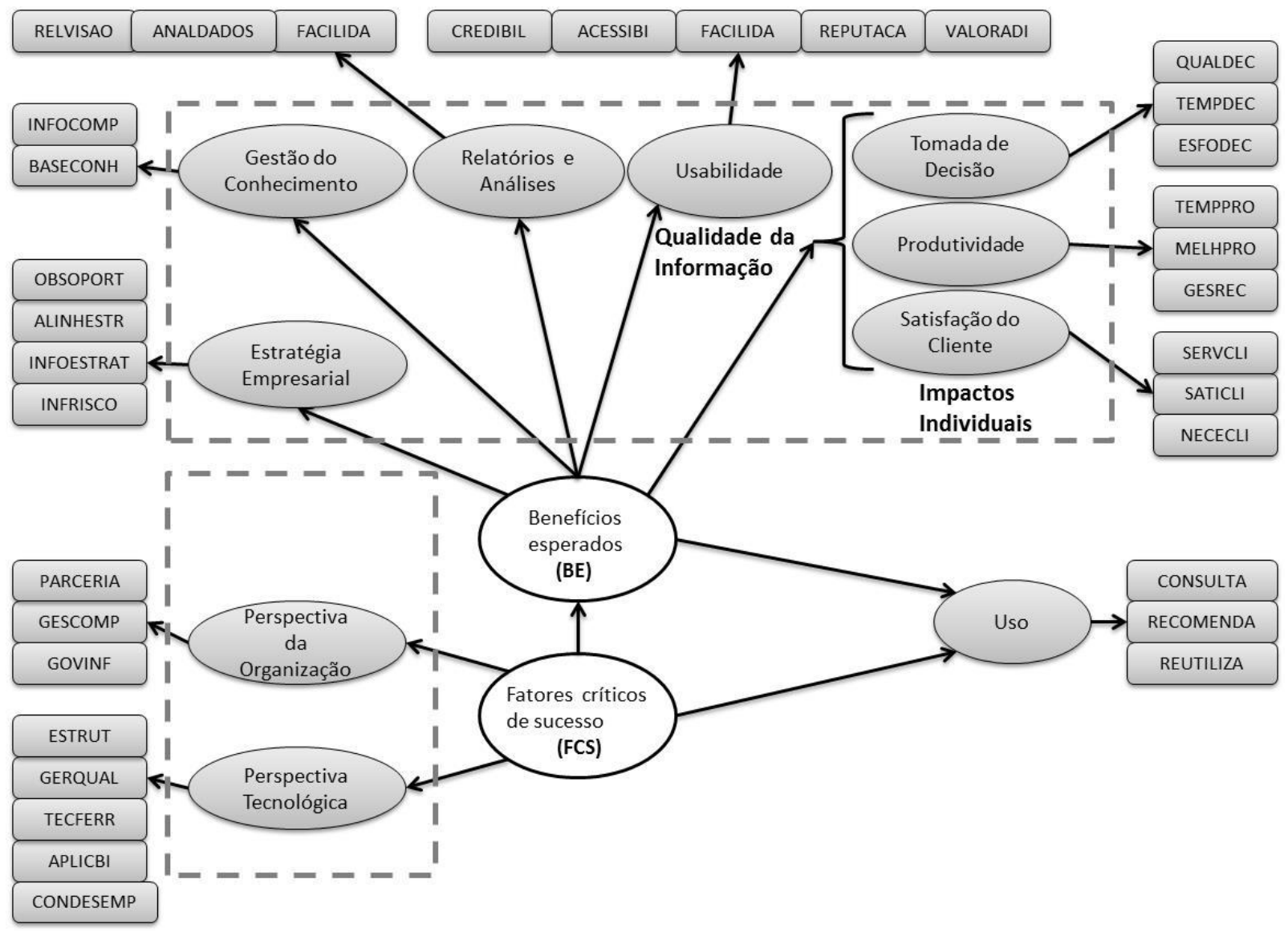

Figura 19 - Modelo estrutural e de mensuração Fonte: Elaborado pelo autor

O modelo de mensuração é formado por 34 variáveis observadas. Dentro das linhas tracejadas estão agrupadas as variáveis de primeira ordem que compõem as dimensões. No grupo superior estão as variáveis de primeira ordem que definem a dimensão benefícios esperados (BE). As variáveis tomada de decisão, produtividade e satisfação do cliente estao agrupadas pois são variáveis que compõem a dimensão impactos individuais conforme revisão da literatura. No grupo à esquerda estão as variáveis de primeira ordem que compõem a dimensão fatores críticos de sucesso (FCS), e no grupo à direita temos a composição da dimensão uso.

Os caminhos do modelo estrutural que representam a teoria e fundamentam os objetivos e hipótese da pesquisa são:

- $\quad \mathrm{BE}=>\mathrm{USO}$ (Construto e caminho de influência propostos nesse trabalho);

- $\quad \mathrm{FCS}=>$ USO (Construto e caminho de influência propostos nesse trabalho);

- $\quad \mathrm{FCS}=>$ BE (Caminho de influência proposto nesse trabalho). 
A relação entre FCS e BE é representada pela influência da variável perspectiva tecnológica (FCS) sobre a variável usabilidade (BE).

\section{Comentários sobre o modelo proposto}

O modelo proposto, conforme figura 19, sugere que o uso da informação disponibilizada em um sistema de BI é influenciada, conforme sugere o modelo de sucesso de implementação de sistemas de BI de Yeoh e Koronio (2010), pelos benefícios esperados para esse sistema e seus fatores críticos de sucesso. Os benefícios esperados influenciam a confiança do usuário na informação fornecida pelo sistema de BI. Os FCS influenciam os BE e o USO pois apresentam fatores que levam a identificação do risco pelo usuário do uso desse sistema.

\subsection{Modelo alternativo}

O modelo inicial estabelece a relação entre FCS, BE e USO para sistemas de BI. Kim et al. (2008) apresenta um modelo de tomada de decisão do consumidor baseado em confiança para aquisições através de plataforma de comércio eletrônico, conforme apresentado anteriormente no item 2.10, que relaciona beneficio percebidos, risco percebido e confiança a intenção de consumo resultando na aquisição. Os construtos risco, confiança e intenção do modelo são impactados pela familiaridade do usuário com o sistema adotado de comércio eletrônico, e o construto confiança também sofre influência do que foi chamado pelo autor de disposição do consumidor em confiar no sistema.

Assim, nesse estudo será também analisado um modelo alternativo que inclua esses fatores de acordo com o modelo proposto por Kim (2008). O objetivo dessa proposta é verificar se o modelo de decisão pelo uso dos sistemas de BI baseado em confiança tem boa aderência, apresentando resultados superiores aos resultados do modelo conceitual proposto.

O modelo alternativo de pesquisa proposto estabelece então um paralelo com o modelo da figura 16 assumindo a dimensão perspectiva organizacional dos FCS como risco percebido, benefícios esperados (BE) como benefícios percebidos, intenção de uso e aquisição da 
informação como uso (USO), e usabilidade (BE) como confiança. A dimensão perspectiva tecnológica equivale no modelo proposto à variável familiaridade (FAM).

A dimensão perspectiva organizacional, por envolver aspectos como gestão comprometida com a implantação de um BIS, aspecto esse apontado como relevante para o desenvolvimento e manutenção de um projeto de BI, representa grande risco para a adequada utilização dos BIS, por isso foi considerada como a variável de risco percebido do modelo. A dimensão perspectiva tecnológica engloba aspectos técnicos como integração do SBI com outros aplicativos, infraestrutura, tecnologia e ferramentas. Portanto, tem grande proximidade com a variável familiaridade do modelo de Kim et al. (2008) que considera a interação e facilidade de uso da tecnologia pelo consumidor. Usabilidade relaciona indicadores como credibilidade e reputação estabelecendo aspectos de confiança no sistema.

Na tabela 25 é apresentada as equivalências de dimensões descritas no item 3.7.1, definições e argumentação para a as respectivas equivalências.

Tabela 25 - Tabela de equivalências

\begin{tabular}{|c|c|c|c|c|}
\hline $\begin{array}{c}\text { Revisão } \\
\text { realizada } \\
\text { pelo autor }\end{array}$ & Descrição & Referência & $\begin{array}{c}\text { Modelo de } \\
\text { Kim et al. } \\
\text { (2008) }\end{array}$ & Argumentação \\
\hline $\begin{array}{l}\text { Perspectiva } \\
\text { tecnológica } \\
\text { (FCS) }\end{array}$ & $\begin{array}{l}\text { - Infraestrutura } \\
\text { tecnológica, robusta, } \\
\text { escalonável; } \\
\text { Ferramentas de fácil } \\
\text { utilização; } \\
\text { - } \quad \text { Recursos de uso; } \\
\text { - Integração com outros } \\
\text { - } \text { sistemas; } \\
\text { Gestão da qualidade } \\
\text { das informações; } \\
\text { Desempenho do } \\
\text { sistema. }\end{array}$ & $\begin{array}{l}\text { YEOH et } \\
\text { al. }(2008)\end{array}$ & $\begin{array}{l}\text { Familiaridade } \\
\text { (FAM) }\end{array}$ & $\begin{array}{l}\text { Se refere ao quanto } \\
\text { se é familiarizado } \\
\text { com o sistema, aos } \\
\text { seus recursos, e } \\
\text { facilidade de uso. } \\
\text { Portanto, o impacto } \\
\text { que a tecnologia } \\
\text { pode gerar sobre a } \\
\text { escolha de uso do } \\
\text { sistema pelo usuário. }\end{array}$ \\
\hline
\end{tabular}




\begin{tabular}{|c|c|c|c|c|}
\hline $\begin{array}{l}\text { Usabilidade } \\
\text { (BE) }\end{array}$ & 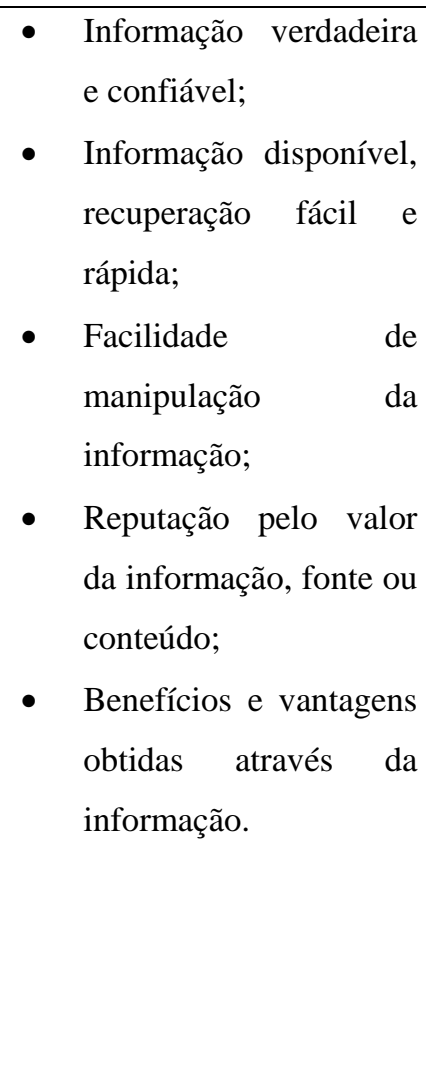 & $\begin{array}{l}\text { SANTOS } \\
(2009)\end{array}$ & $\begin{array}{l}\text { Confiança } \\
\text { (TRUST) }\end{array}$ & $\begin{array}{l}\text { Se refere à } \\
\text { confiabilidade do } \\
\text { sistema, se é crível, } \\
\text { se cumpre } \\
\text { prometido } \\
\text { apresenta } \\
\text { comprometimento. } \\
\text { Portanto, se o } \\
\text { sistema pode ser } \\
\text { adotado pois } \\
\text { entregará } \\
\text { informações } \\
\text { necessárias no tempo } \\
\text { prometido e com a } \\
\text { qualidade necessária. }\end{array}$ \\
\hline $\begin{array}{l}\text { Perspectiva } \\
\text { organizacional } \\
\text { (FCS) }\end{array}$ & $\begin{array}{l}\text { - } \mathrm{O} \text { grau de parceria } \\
\text { entre comunidade de } \\
\text { negócio e TI; } \\
\text { - Comprometimento da } \\
\text { gestão com o projeto de } \\
\text { BI; } \\
\text { - Nível de governança da } \\
\text { informação. }\end{array}$ & $\begin{array}{l}\text { YEOH et } \\
\text { al. (2008) }\end{array}$ & $\begin{array}{l}\text { Risco } \\
\text { percebido }\end{array}$ & $\begin{array}{l}\text { Se refere ao risco } \\
\text { sobre o produto (não } \\
\text { funciona, defeitos), } \\
\text { riscos financeiros } \\
\text { (fraude), e a } \\
\text { percepção do usuário } \\
\text { de riscos inerentes } \\
\text { ao uso do sistema. }\end{array}$ \\
\hline
\end{tabular}

Fonte: Elaborado pelo autor

Na figura 20 temos a representação estrutural e de mensuração do modelo alternativo. 


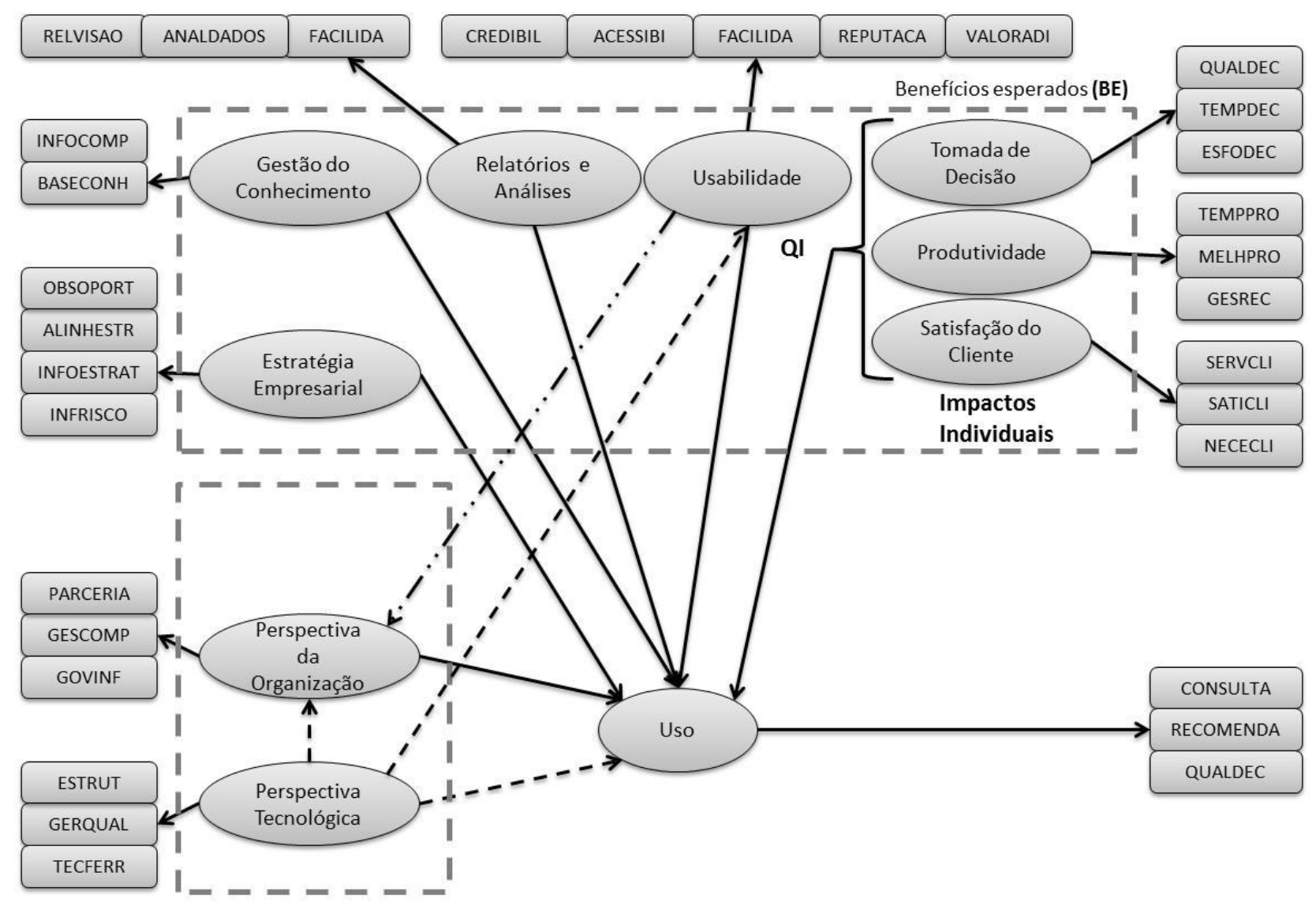

Figura 20 - Modelo estrutural e de mensuração do modelo alternativo Fonte: Elaborado pelo autor

\subsection{Outros aspectos presentes no modelo de pesquisa}

As demais variáveis utilizadas na pesquisa visam contextualizar o respondente, sua relação com a empresa, sua experiência como usuário de sistema de BI, e algumas características da empresa em questão que por sua influência podem servir como variáveis de controle.

Tabela 26 - Variáveis de controle

\begin{tabular}{|l|l|l|}
\hline \multicolumn{1}{|c|}{ Variável } & \multicolumn{1}{|c|}{ Escala } & \multicolumn{1}{c|}{ Descrição } \\
\hline Sexo & Nominal & Homem, mulher \\
\hline Tempo de organização & Ordinal & $\begin{array}{l}\text { Tempo de trabalho do respondente na organização em } \\
\text { que atua, estabelecendo um parâmetro de experiência } \\
\text { com o SBI. }\end{array}$ \\
\hline Posição na organização & Nominal & $\begin{array}{l}\text { Nível hierárquico na empresa, estabelecendo sua área } \\
\text { de atuação. }\end{array}$ \\
\hline
\end{tabular}




\begin{tabular}{|l|l|l|}
\hline Indústria & Nominal & Indústria de atuação da companhia onde trabalha. \\
\hline Número de empregados & Ordinal & $\begin{array}{l}\text { Quatro faixas de funcionários, estabelecendo porte da } \\
\text { empresa. }\end{array}$ \\
\hline
\end{tabular}

Fonte: Elaborado pelo autor 


\section{METODOLOGIA DE PESQUISA}

\subsection{Pesquisa}

\subsubsection{Tipologias de pesquisa}

Raupp e Beuren (2003) comentam a falta de uniformidade na abordagem das tipologias de delineamento de pesquisa, conforme apresentado na tabela 27.

Tabela 27 - Tipologias de delineamento de pesquisas com agrupamento

\begin{tabular}{|c|c|c|}
\hline Andrade (2002) & Vergara (1997) & Santos (1999) \\
\hline $\begin{array}{l}\text { Quanto a natureza } \\
\text { - Trabalho científico original } \\
\text { - Resumo de assunto }\end{array}$ & 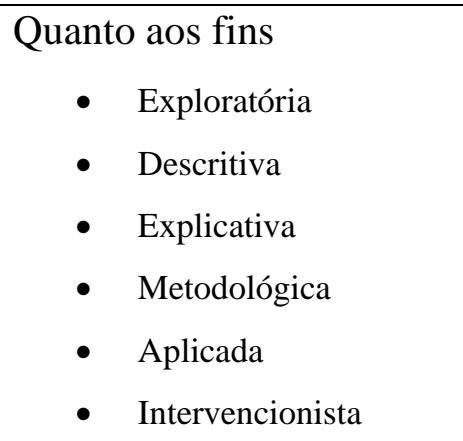 & $\begin{array}{l}\text { Quanto aos objetivos } \\
\text { - Exploratória } \\
\text { - Descritiva } \\
\text { - Explicativa }\end{array}$ \\
\hline $\begin{array}{l}\text { Quanto aos objetivos } \\
\begin{array}{l}\text { - } \\
\text { - } \\
\text { - }\end{array} \text { Pesquisa exploratória } \\
\text { Pesquisa explicativa }\end{array}$ & $\begin{array}{l}\text { Quanto aos meios } \\
\text { - } \text { Pesquisa de campo } \\
\text { - } \text { Pesquisa de laboratório } \\
\text { - Telematizada } \\
\text { - Documental } \\
\text { - Bibliográfica } \\
\text { - Experimenttal } \\
\text { - Expost facto } \\
\text { - Participantes } \\
\text { - Pesquisa-ação } \\
\text { - Estudo de caso }\end{array}$ & 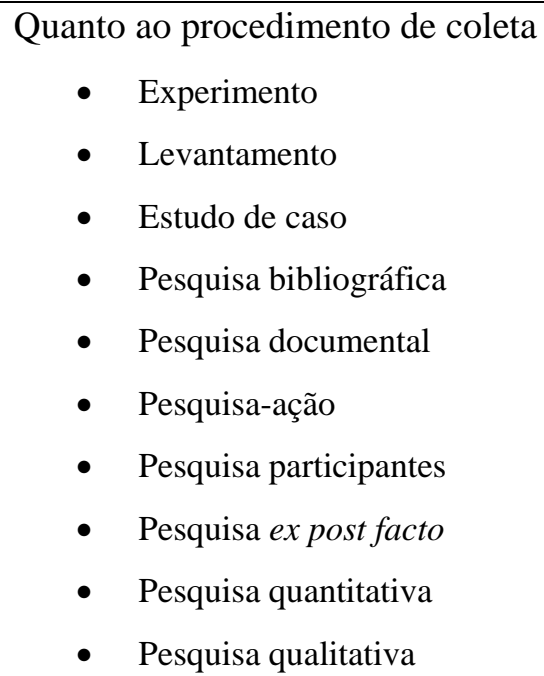 \\
\hline
\end{tabular}




\begin{tabular}{|c|c|c|}
\hline Quanto ao procedimento & Quanto às fontes de informação \\
- Pesquisa de campo & Campo \\
- Pesquisa de fontes de papel & & Laboratório \\
\hline Quanto ao objeto & \\
- Pesquisa bibliográfica & \\
- Pesquisáfica de laboratório & \\
\hline Pesquisa de campo & \\
\hline
\end{tabular}

Fonte: Adaptado de Raupp e Beuren (2003)

Entretanto, considerando-se as particuliaridades das ciências sociais, eles acreditam serem mais aplicáveis a esta área do conhecimento, as tipologias agrupadas em três categorias específicas:

- Quanto aos objetivos: pesquisa exploratória, descritiva e explicativa;

- Quanto aos procedimentos: o estudo de caso, o levantamento, a pesquisa bibliográfica, documental, participante e experimental;

- Quanto a abordagem do problema: a pesquisa qualitativa e a quantitativa.

A seguir esses itens serão detalhados e será definida a abordagem utilizada nesse trabalho.

\subsubsection{Quanto a abordagem do problema}

Na visão de Martins (1997), os métodos de pesquisa podem ser classificados de diferentes formas, no entanto, a distinção mais comum é entre métodos quantitativos e qualitativos.

Ainda segundo Martins (1997), o método qualitativo foi desenvolvido nas ciências sociais para permitir o estudo de fenômenos sociais e culturai. Richardson (1999, p.80 apud Raupp e Beuren, 2003) menciona que os estudos que empregam uma metodologia qualitativa podem descrever a complexidade de determinado problema, analisar a interação de certas variáveis, compreender e classificar processos dinâmicos vividos por grupos sociais.

O método quantitativo, de acordo com Martins (2003), foi desenvolvido originalmente nas ciências sociais para o estudo de fenômenos naturais. Como exemplo de métodos quantitativos temos survey, experimentos de laboratório, métodos formais (ex.:econometria) e métodos 
numéricos tais como modelos matemáticos. Para Raupp e Beuren (2003), diferentemente da pesquisa qualitativa, a abordagem quantitativa caracteriza-se pelo emprego de instrumentos estatísticos, tanto na coleta quanto no tratamento dos dados. Os autores complementam dizendo que esse procedimento não é tão profundo na busca do conhecimento da realidade dos fenômenos, uma vez que se preocupa com o comportamento geral dos acontecimentos.

\subsubsection{Quanto aos objetivos}

Quanto aos objetivos, as pesquisas podem ser classificadas me três grandes grupos: exploratórias, descritivas e explicativas.

As pesquisas exploratórias têm como principal finalidade obter uma maior compreensão de um determinado problema, ainda não muito estudado e sobre o qual não há ainda uma teoria fundamentada. Nesse sentido, torna-se uma abordagem útil para estruturar melhor o conhecimento e construir hipóteses. Na visão de Raupp e Beuren (2003), a caracterização do estudo como pesquisa exploratória normalmente ocorre quando há pouco conhecimento sobre a temática a ser abordada. Através do estudo exploratório busca-se conhecer com maior profundidade o assunto, de modo a torná-lo mais claro ou construir questões importantes para a condução da pesquisa. Uma característica interessante da pesquisa exploratória é o aprofundamento de conceitos preliminares sobre determinada temática não contemplada de modo satisfatório anteriormente.

A pesquisa descritiva tem como principal objetivo descrever características de determinada população ou fenômeno ou o estabelecimento de relações entre as variáveis. Uma de suas características mais significativas esta na utilização de técnicas padronizadas de coleta de dados, como exemplos, o uso de questionários ou a observação sistemática (RAUPP e BEUREN, 2003).

A pesquisa explicativa visa identificar os fatores que determinam ou contribuem para a ocorrência dos fenômenos. Por explicar a razão e o porquê das coisas, esse é o tipo de pesquisa que mais aprofunda o conhecimento da realidade (RAUPP e BEUREN, 2003). 


\subsubsection{Justificativa das escolhas metodológicas desse trabalho}

Em relação aos objetivos, esse trabalho é de caráter exploratório devido à busca por um maior entendimento sobre o uso dos sistemas de BI e também pelo fato de não existir uma teoria bem fundamentada sobre essa questão. Yin (2003) comenta que em geral, questões do tipo quais podem ser exploratórias e nessa pesquisa busca-se principalmente responder perguntas do tipo qual, comparando-se modelos e testando hipóteses a priori, o que leva a estudos quantitativos que segundo Martins (1997), é um método desenvolvido originalmente nas ciências naturais para estudos de fenômenos naturais. Survey, experimentos de laboratório, métodos formais, e métodos numéricos tais como modelos matemáticos são aceitos em ciências sociais. Assim, em relação à abordagem do problema, esse trabalho adotará o método quantitativo.

\subsection{Método de análise dos dados}

Agora será apresentado o SEM por ser uma técnica multivariada que permite ao pesquisador tratar todas as suas questões de pesquisa com um só método abrangente. A técnica de modelagem de equações estruturais (SEM) é uma extensão de técnicas multivariadas, como regressão múltipla e análie fatorial (HAIR, 2009).

\subsection{Modelo de equações estruturais (SEM)}

\subsubsection{Introdução}

Modelos de equações estruturais (SEM) são uma técnica (ou, se considerarmos a existência de diferentes métodos de estimação e ajuste dessas equações, uma coleção de técnicas) aplicável ao estudo de redes de relacionamentos entre um conjunto de variáveis, sejam elas diretamente observáveis (indicadores) ou latentes (constructos). Pode-se dizer que o SEM generaliza a tradicional análise fatorial no sentido de que ele permite ao pesquisador estabelecer relações de dependência entre as diversas variáveis latentes que compõem o modelo a ser testado. O SEM estabelece tal relação entre variáveis latentes a partir de variáveis observadas diretamente ou até mesmo de outros constructos (quando consideradas relações de segunda ordem). O modelo 
de equações estruturais atinge tal grau de generalização que permite ao pesquisador estabelecer a priori quais indicadores são correlacionados entre si, além de permitir a um mesmo indicador, ou um particular constructo, afetar diretamente mais de um constructo.

Um dos principais propósitos da análise estatística de dados é o teste de hipóteses a partir de um modelo pré-determinado. Como sugerido no parágrafo acima, o SEM se presta a esse papel ao permitir o pesquisador testar e especificar as relações de dependência entre indicadores e constructos definidas a partir de teoria e pesquisas realizadas a priori. Tal poder tem lhe garantido um lugar especial na lista das principais técnicas de análises de dados em ciências sociais e da saúde. Como descrito em termos bem diretos por Maccallum e Austin (2000), através do SEM pode-se estimar e testar padrões hipotéticos de relações (lineares) direcionais e não-direcionais entre um conjunto de variáveis observadas (mensuradas) e não-observadas (latentes). Aliás, bem usada, essa é uma das grandes forças do SEM, pois trata-se de um instrumento que deve sempre ser utilizado em parceria com a teoria e as pesquisas obtidas a priori. Essas sugerem a forma geral do modelo SEM específico que, por sua, ajuda a validá-las ou refutá-las.

Cabe observar que além do seu alcance e generalidade, o SEM possui ainda um outro atrativo que é fato de poder ser representado graficamente e de modo extremamente intuitivo.

Por exemplo, valem as seguintes regras:

- O efeito de um elemento A (indicadores ou construtos) sobre outro elemento B do modelo é representado por uma seta de A para B: A -> B;

- Se dois elementos devem ser correlacionados entre si, o pesquisador pode indicar isso por uma seta curva e bidirecional entre os elementos.

A figura 21 é um exemplo de como um modelo pode ser especificado graficamente. 


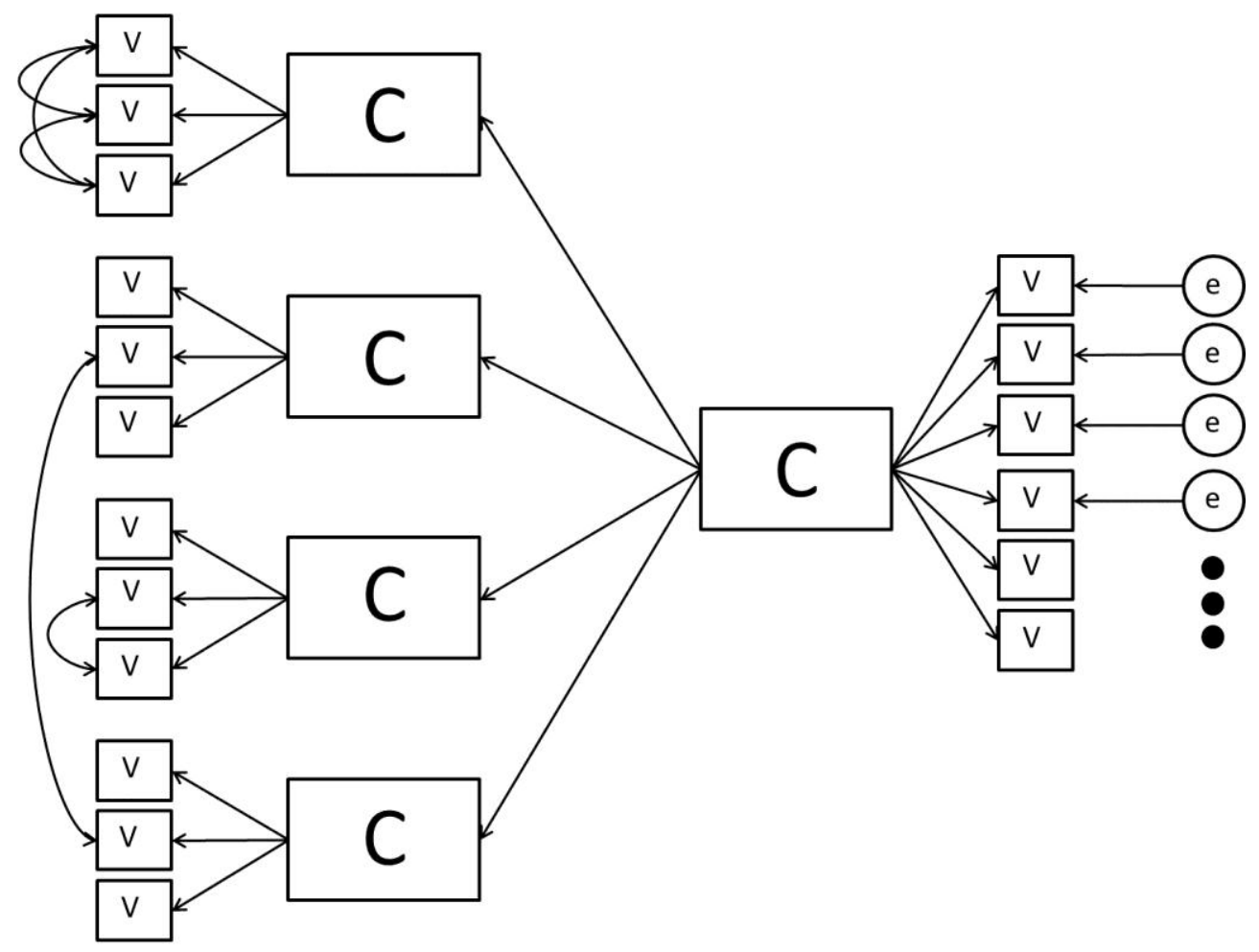

Figura 21 - Exemplo de representação gráfica de um modelo SEM Fonte: Elaborado pelo autor

A figura 21 apresenta a representação gráfica ou pictórica de um modelo específico SEM. Setas diretas indicam uma relação direta; em geral, a seta aponta para o sujeito do efeito e parte do objeto do efeito. Curvas curvas indicam uma relação de dependência mútua entre dois elementos. As caixas marcadas com $\mathbf{V}$ representam os indicadores, enquanto que as caixas rotuladas de $\mathbf{C}$ indicam os construtos. Os círculos com a inscrição e representam os erros associados ao modelo.

\subsubsection{Formalização do SEM}

Esta seção pretende oferecer ao leitor uma introdução mais formal, embora breve, aos modelos de equações estruturais. Para uma exposição mais detalhada, ver Bartholomew (1987), Duncan (1975) ou Johnson e Wichern (2002).

Uma medida ou indicador é uma variável observada diretamente pelo pesquisador, enquanto que uma variável latente ou construto é uma variável que não pode ser observada exata ou diretamente por ele. Em geral, um construto é inferido através de uma coleçãode indicadores e, portanto, costuma ser rotulado com o nome da característica que melhor os representa. Um 
exemplo de construto seria o 'bem-estar mental' de um paciente. É evidente que tal medida não pode ser obtida diretamente através de um simples questionário ou exames clínicos. No entanto, o 'bem-estar mental' pode ser inferido indiretamente através de variáveis como 'horas de sono', 'nível de estresse', 'atividade física' etc (MACCALLUM; AUSTIN, 2000). Em outros termos, seguindo a terminologia usual de modelos de regressão, um indicador também pode ser chamado de variável independente ou exógena e os construtos de variáveis independentes ou endógenas. Cabe observar que uma variável endógena pode também exercer efeito sobre outra variável endógena.

As relações entre duas variáveis podem associativas, indicando correlação entre dois elementos do modelo, diretas, indicando os efeitos diretos ou relações direcionais entre dois elementos, e indiretas, indicando um efeito indireto entre dois elementos do modelo não diretamente ligados. Em outras palavras, efeitos indiretos seriam como efeitos de segunda ordem, enquanto que os efeitos diretos seriam como efeitos de primeira ordem de um elemento sobre outro. A figura 17 representa como tais relações podem ser apresentadas graficamente. Esse tipo de representação gráfica chama-se diagrama de caminhos. O diagrama de caminhos também define (graficamente) aquilo que se chama de modelo, isto é, a relação determinada a priori entre os diversos indicadores e constructos cujas relações são de interesse do pesquisador.

Em termos matemáticos, o modelo de equações estruturais (lineares) é determinado pelas equações:

1) $\eta=B \eta+\Gamma \xi+\zeta$,

2) $Y=\Lambda_{y} \eta+\varepsilon$,

3) $X=\Lambda_{x} \xi+\delta$,

Onde $\eta \in \mathbb{R}^{m}$ e $\xi \in \mathbb{R}^{n}$ representam o "efeito" e a "causa", respectivamente. As variáveis $X \in \mathbb{R}^{q}$ e $Y \in \mathbb{R}^{p}$ são observações ou indicadores associados, nessa ordem, aos construtos $\eta$ e $\xi$. Por essa razão, as equações (2) e (3) são chamadas de equações de mensuração. Os erros relacionados a cada uma dessas equações são dados pelas variáveis $\zeta \in \mathbb{R}^{m}, \varepsilon \in \mathbb{R}^{p}$ e $\delta \in \mathbb{R}^{q}$. O vetor $\eta$, chamado acima de efeito, encarna, em geral, o construto final que o pesquisador deseja explicar como sendo causado pelos construtos $\xi$. Embora se use frequentemente os termos causa e efeito, cabe observar que os modelos de equações estruturais, assim como outros 
modelos estatísticos, estabelece relações de dependência e não de causa e efeito stricto sensu. Daí a importância de uma teoria fundamentando as relações preconizadas pelo modelo e o seu papel como forma de validação de hipóteses feitas a priori. As matrizes $B \in \mathbb{R}^{m X m}, \Gamma \in \mathbb{R}^{m X n}$, $\Lambda_{y} \in \mathbb{R}^{p X m}$ e $\Lambda_{x} \in \mathbb{R}^{q X n}$ definem o modelo ao estabelecer como os indicadores e construtos se relacionam linearmente entre si. Para evitar redundância, assume-se que diag $B=0$ e que $I-B$ é não singular. Sob um ponto de vista probabilístico, os erros, em geral, são assumidos como variáveis aleatórias Normais independentes entre si e com média zero e matrizes de variância-covariância $\operatorname{Cov} \zeta=\Psi, \operatorname{Cov} \varepsilon=\Theta_{\varepsilon}$ e $\operatorname{Cov} \delta=\Theta_{\delta}$. Além disso, o construto $\xi$ é considerado como um vetor aleatório Normal independente de $\varepsilon$ e tal que $\operatorname{Cov} \xi=\Phi$.

De modo geral, o processo de estimação considera a estrutura de covariância das observações, i.e.,

$$
\operatorname{Cov}\left[\frac{Y}{X}\right]=\left[\begin{array}{cc}
\Sigma_{Y Y} & \Sigma_{X Y} \\
\Sigma_{Y X} & \Sigma_{X X}
\end{array}\right]=\left[\begin{array}{cc}
\operatorname{Cov} Y & \operatorname{Cov}(X, Y) \\
\operatorname{Cov}(Y, X) & \operatorname{Cov} X
\end{array}\right]
$$

Mais precisamente, a estrutura acima permite duas coisas:

i. escrever as componentes $\Sigma_{Y Y}, \Sigma_{X X}$ e $\Sigma_{X Y}$ em função dos parâmetros do modelo $B, \Gamma, \Lambda_{y}, \Lambda_{x}$ $, \Psi, \Theta_{\varepsilon}, \Theta_{\delta}$, e $\Phi$;

ii. igualar a matriz de covariâncias escrita em função dos parâmetros conforme indicado acima à matriz de covariâncias amostral

$$
S=\left[\begin{array}{ll}
\mathrm{S}_{Y Y} & \mathrm{~S}_{X Y} \\
\mathrm{~S}_{Y X} & \mathrm{~S}_{X X}
\end{array}\right]
$$

A estimação dos parâmetros, então, se dá resolvendo o sistema de equações lineares determinado

pela igualdade

$$
\hat{\Sigma}=S
$$

A equação acima dificilmente pode ser resolvida analiticamente e, de modo geral, sua resolução baseia-se em métodos numéricos iterativos. Os critérios de parada mais comuns são, normalmente, os mínimos quadrados ou a máxima verossimilhança. 


\subsubsection{PLS}

O SEM é em si uma técnica que permite a combinação de um modelo de mensuração a um modelo estrutural avaliados simultaneamente, entretanto exitem mais de um modelo de estimação dos coeficientes de mensuração e estruturais do modelo. A técnica de análise de matriz de covariâncias (SEMMC), como apresentado no item anterior, é a técnica mais utilizada. Mais recentemente, a modelagem de equações estruturais baseada em partial least square (SEMPLS) tem recebido maior destaque na literatura acadêmica (ZWICKER.; SOUZA; BIDO, 2008).

Tabela 28 - Diferenças entre a SEMPLS e SEMMC

\begin{tabular}{|c|c|c|}
\hline Critério & SEMPLS & SEMMC \\
\hline Objetivo & Predição & $\begin{array}{l}\text { Explicação: modelos causais, } \\
\text { teste de teoria }\end{array}$ \\
\hline Abordagem & Baseado em variância & Baseado em coveriância \\
\hline Precisão & $\begin{array}{l}\text { Consistente } \text { conforme } \text { o } \\
\text { tamanho da amostra e a } \\
\text { quantidade de indicadores } \\
\text { aumentam }\end{array}$ & Ótimo para amostras grandes \\
\hline Variáveis latentes (VL) & $\begin{array}{l}\text { As VL são combinações } \\
\text { lineares dos indicadores, os } \\
\text { esccores fatoreiais são } \\
\text { estimados explicitamente }\end{array}$ & 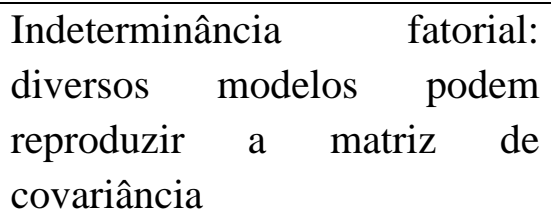 \\
\hline Modelo de mensuração & $\begin{array}{l}\text { Pode haver indicadores } \\
\text { formativos ou reflexivos }\end{array}$ & $\begin{array}{l}\text { Apenas indicadores reflexivos. } \\
\text { Para modelar VL com } \\
\text { indicadores formativos usa-se a } \\
\text { abordagem MIMIC (a) }\end{array}$ \\
\hline Requisitos quanto à teoria & $\begin{array}{l}\text { Mais flexível, contexto mais } \\
\text { exploratório }\end{array}$ & $\begin{array}{l}\text { Fortemente dependente da } \\
\text { teoria }\end{array}$ \\
\hline Distribuição dos dados & $\begin{array}{l}\text { Não há suposições, por isso, } \\
\text { se diz que é soft }\end{array}$ & $\begin{array}{lrr}\text { Dependendo } & \text { do } & \text { método de } \\
\text { estimação, } & \text { as } & \text { variáreis } \\
\text { deveriam } & & \text { apresentar } \\
\text { distribuição } & & \text { normal } \\
\text { multivariada. } & \end{array}$ \\
\hline
\end{tabular}




\begin{tabular}{|c|c|c|}
\hline Tamanho da amostra & $\begin{array}{l}\text { Análise do poder estatístico } \\
\text { com a porção do modelo que } \\
\text { possui o maior número de } \\
\text { preditores ou } 10 \text { vezes o } \\
\text { maior número de preditores } \\
\text { (indicadores formativos ou } \\
\text { setas estruturais chegando na } \\
\text { VL, o que for maior). Sendo } \\
\text { o mínimo recomendado de } 30 \\
\text { a } 100 \text { casos. }\end{array}$ & $\begin{array}{l}\text { Idealmante baseado na análise } \\
\text { do poder estatístico, sendo o } \\
\text { mínimo recomendado da } \\
\text { ordem de } 200 \text { casos. }\end{array}$ \\
\hline $\begin{array}{l}\text { Identificação (estimação } \\
\text { única dos parâmentros) }\end{array}$ & $\begin{array}{l}\text { Para modelo recursivo é } \\
\text { sempre identificado }\end{array}$ & $\begin{array}{l}\text { Depende do modelo e deve ter } \\
\text { pelo menos de } 3 \text { a } 4 \\
\text { indicadores por VL. Necessário } \\
\text { impor restrição aos parâmetros. } \\
\text { Três problemas: às vezes o } \\
\text { modelo não converge, soluções } \\
\text { impróprias e indeterminância } \\
\text { fatorial }\end{array}$ \\
\hline $\begin{array}{l}\text { Significância dos } \\
\text { parâmetros }\end{array}$ & $\begin{array}{l}\text { Estimada por métodos não- } \\
\text { paramétricos, por exemplo, } \\
\text { boostrap }\end{array}$ & $\begin{array}{l}\text { Geralmente, estimada por } \\
\text { métodos paramétricos, mas } \\
\text { bootstrap é uma opção }\end{array}$ \\
\hline Complexidade & $\begin{array}{l}\text { Capaz de lidar com alta } \\
\text { complexidade ( } 100 \text { cosntrutos } \\
\text { e } 1000 \text { indicadores) }\end{array}$ & $\begin{array}{l}\text { Complexidade de média a } \\
\text { moderada (menos de } 100 \\
\text { indicadores) }\end{array}$ \\
\hline $\begin{array}{l}\text { Inclusão de restrições nos } \\
\text { parâmetros do modelo (b) }\end{array}$ & $\begin{array}{l}\text { Mesmo que não haja seta } \\
\text { entre as VL, é suposto que } \\
\text { elas tenham correlação entre } \\
\text { si (sem setas bidirecionais). } \\
\text { Não é possível impor } \\
\text { restrições aos parâmetros do } \\
\text { modelo }\end{array}$ & $\begin{array}{l}\text { Se não houver setas entre as } \\
\text { VL, é suposto que a correlação } \\
\text { entre elas seja zero. É possível } \\
\text { impor restrições em qualquer } \\
\text { parâmetro do modelo. }\end{array}$ \\
\hline
\end{tabular}

(a) MIMIC (múltiplos indicadores e múltiplas causas)

Mackenzie, Podsakoff e Jarvis (2005) apresentam esse tipo de modelo.

(b) Incluído pelos autores. Essas características são próprias dos softwares disponíveis e não do método.

Fonte: Adaptado de Zwicker, Souza e Bido, 2008.

Esse trabalho, por se tratar de um pesquisa quantitativa de caráter exploratório na qual se pretende testar as relações entre diversas variáveis simultaneamente, adotou-se a técnica de modelo de equações estruturais. Como detalhado na tabela 28, o SEMPLS apresenta um menor grau de dependência da teoria além de permitir o uso de uma amostra reduzida de dados em relação ao SEMMC. Dessa foram, adotou-se o SEMPLS como técnica estatística para essa pesquisa. 


\section{MÉTODO DE PESQUISA}

Esse trabalho, com base no modelo de pesquisa proposto apresentado na figura 17, utiliza métodos quantitativos com o objetivo de realizar a verificação empírica das hipóteses induzidas por esse modelo.

As unidades experimentais são indivíduos que trabalham em empresas privadas e públicas, e que já utilizaram e/ou utilizam em suas áreas de negócio um sistema de business intelligence na execução de seu trabalho.

\subsection{Tipo de Pesquisa}

A pesquisa realizada foi do tipo levantamento social (survey), realizada por meio de questionário autoaplicado, de questões predominantemente fechadas.

A amostra foi estabelecida através de rede de relacionamento previamente existente em empresas com sistemas de BI implantados atendendo diferentes diretorias e gerências.

O questionário foi distribuído para um grupo de cinco empresas de diferentes segmentos da indústria com respondentes das áreas de negócio que utilizam alguma solução de BI em seus departamentos, e uma consultoria de recrutamento e seleção que ajudou na indicação de profissionais de outras empresas com experiência no uso de BIS, auxiliando também no acompanhamento do número de questionários respondidos.

As cinco empresas escolhidas foram selecionada por serem empresas com as quais já havia relacionamento prévio, tendo-se o conhecimento e o contato com os responsáveis e os usuários pelos sistemas de BI em áreas de negócio desses grupos. Essa seleção não objetiva a representatividade da população mas permite o teste do modelo proposto.

O apoio da empresa de consultoria de recrutamento agregou novas empresas à pesquisa, chegando à um total de 11 empresas. 


\subsection{Questionário e coleta de dados}

O questionário possui inicialmente questões relativas às características dos respondentes com o objetivo de se estabelecer variáveis de controle para o modelo de pesquisa. As demais questões se referem à percepção e crença dos respondentes as variáveis do modelo, em função de sua experiência com o uso no ambiente de trabalho do sistema de BI.

O questionário foi disponibilizado eletronicamente através do aplicativo limesurvey em um servidor de internet e é composto de três etapas:

Introdução - Características do respondente: Foram coletados dados como nome do respondente, organização onde trabalha, local e data em que respondeu o questionário.

Etapa 1 - Informações gerais do respondente: Foram coletados dados como a indústria em que trabalha escolhendo entre as seguintes opções: Telecom, Banco, Serviços de TI, Setor Público, Varejo, Indústria, e outros, e nesse caso, especificando a indústria. O número de empregados da organização onde trabalha com as seguintes opções, entre 1 e 10 funcionários, entre 11 e 25 funcionários, entre 25 e 100 funcionários, e acima de 100 funcionários. A posição atual do respondente na organização, quanto tempo atua nessa indústria e a que área pertence na empresa.

Etapa 2 - Nessa etapa foi utilizada uma escala numérica de cinco pontos para cada um dos indicadores definidos no modelo de mensuração como apresentado no capítulo 3. Nessa etapa foram coletadas as características de fatores críticos de sucesso, intenção de uso da informação do sistema e os benefícios esperados para SBI.

O questionário completo encontra-se no anexo I.

Antes da aplicação do instrumento de pesquisa foi realizado um pré-teste com três colaboradores de uma empresa de telecom responsáveis por gerenciar o sistema de BI de suas diretorias e dois pesquisadores doutores da academia com vivência profissional na área de TI.

A coleta dos dados foi realizada de fevereiro/2014 a maio/2014. 


\subsubsection{Tamanho da amostra}

O método adotado nesse trabalho para examinar as relações simultâneas entre as variáveis do modelo proposto foi a modelagem de equações estruturais com o uso do Partial Least Squares (SEMPLS), como explicado anteriormente. O critério para se determinar o tamanho da amostra utilizando o método SEMPLS foi o de selecionar no modelo a VL que apresenta o maior número de preditores e assumir uma amostra de tamanho 10 vezes o número de preditores, sendo o mínimo recomendado de 30 a 100 casos (ZWICKER.; SOUZA; BIDO, 2008). O software GPower 3.1 também foi utilizado para confrontar os resultados. Pelo critério proposto por Zwicker, Souza e Bido (2008), chega-se que a amostra adequada é igual ou superior à 50 unidades experimentais, já para o GPower 3.1, essa amostra deveria ser de 120 unidades experimentais.

\subsubsection{Softwares adotados na análise dos dados}

Utilizamos durante o trabalho os seguintes softwares: Office 2010, Mendeley, SPSS 13.0, GPower 3.1 e SmartPLS R 3.1.0. 


\section{ANÁLISE DOS RESULTADOS}

\subsection{Tratamento e análise preliminar dos dados}

Devido ao envolvimento de pessoas comprometidas com a pesquisa dentro das organizações selecionadas e do acompanhamento da empresa de consultoria de recrutamento e seleção, todos os questionários foram completamente respondidos.

A fim de evitar respondentes pouco comprometidos com a pesquisa e também indivíduos que foram marcados como outliers, pois se enquadram tanto na categoria de ingênuos por considerarem todos os indicadores como extremamente positivos quanto na de pessimistas por considerarem todos minimamente bons. Assim, eliminaram-se observações com muito pouca variabilidade, ou seja, aquelas que apresentavam respostas (quase) constantes em um dos extremos. Interessante notar que não foram observados indivíduos com respostas constantes nos valores intermediários da escala, e.g., indivíduos para os quais todas as respostas são indiferentes (e.g.3).

Foram enviados 200 questionários divididos entre as cinco empresas selecionadas e mais 160 questionários para os respondentes selecionados através do banco de dados da empresa de recrutamento. Dos questionários enviados, 134 foram respondidos e desses 116 foram considerados válidos.

\subsection{Análise da amostra obtida}

Sendo assim, o número obtido de questionários válidos é de 116 de um total de 134 respostas obtidas originalmente, que estão distribuídos da seguinte forma, de acordo com as variáveis de caracterização dos respondentes: 
Tabela 29 - Caracterização da Amostra Válida

\begin{tabular}{|c|c|c|c|}
\hline \multicolumn{2}{|c|}{ Variáveis Externas } & \multicolumn{2}{|l|}{\begin{tabular}{|l} 
Amostra \\
Válida
\end{tabular}} \\
\hline \multirow[t]{2}{*}{ Sexo } & $M$ & 105 & $90,5 \%$ \\
\hline & $\mathrm{F}$ & 11 & $9,5 \%$ \\
\hline Total & & 116 & $100 \%$ \\
\hline \multirow[t]{8}{*}{ Indústria } & Telecom & 49 & $42,2 \%$ \\
\hline & Serviços de TI & 23 & $19,8 \%$ \\
\hline & Varejo & 18 & $15,5 \%$ \\
\hline & Setor Público & 9 & $7,8 \%$ \\
\hline & Indústria & 6 & $5,2 \%$ \\
\hline & Consultoria & 5 & $4,3 \%$ \\
\hline & Mercado financeiro & 4 & $3,4 \%$ \\
\hline & Agronegócio & 2 & $1,7 \%$ \\
\hline Total & & 116 & $100,0 \%$ \\
\hline \multirow[t]{2}{*}{ Funcionários } & $25-100$ & 19 & $16,4 \%$ \\
\hline & $>100$ & 97 & $83,6 \%$ \\
\hline Total & & 116 & $100,0 \%$ \\
\hline
\end{tabular}

Fonte: Elaborado pelo autor

A seguir são apresentadas graficamente a distribuição das características gerais das amostras obtidas no que se refere aos setores de atuação das empresas dos respondentes, as áreas de negócio em que atuam dentro das corporações e os cargos que ocupam.

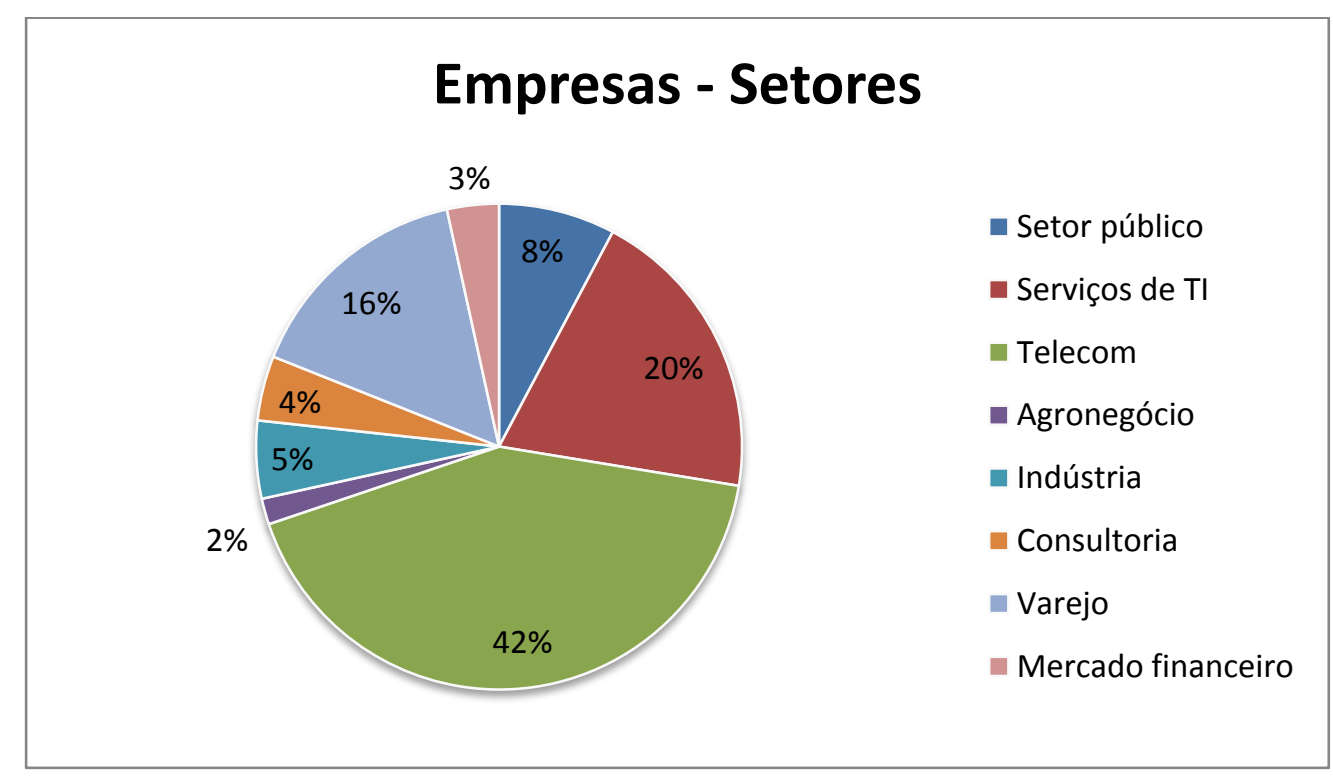

Figura 22 - Composição da amostra em relação aos setores de atuação das empresas Fonte: Elaborado pelo autor 
Na figura 22 tem-se a composição da amostra com relação aos setores de atuação das empresas dos respondentes. O setores de telecomunicação e serviços de TI compõem a maior parte da amostra (62\%), isso devido ao porte das empresas e ao grau de relacionamento com as áreas usuárias de sistemas de BI.

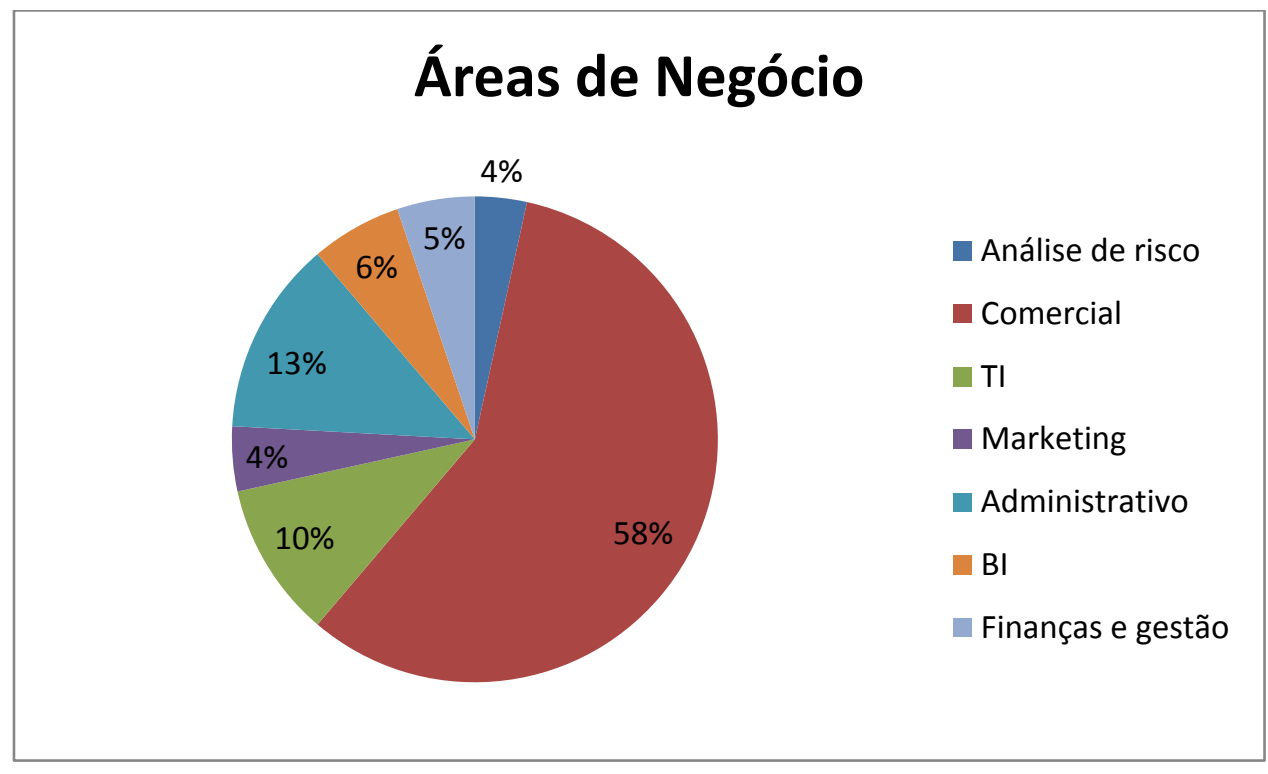

Figura 23 - Composição da amostra em relação as áreas de negócio de atuação dos respondentes dentro das organizações em que atuam

Fonte: Elaborado pelo autor

Na figura 23 tem-se a composição das áreas de negócio em que atuam os respondentes dentro das organizações. Como pode-se perceber, a maior parte dos respondentes $(58 \%)$ atua na área comercial. No caso da indústria de telecomunicações, a área comercial engloba não somente o departamento de vendas, mas toda a inteligência necessária para a elaboração de novos produtos, ofertas e precificação. Nessa área, o entendimento do usuário, acompanhamento de seu comportamento dentro da rede de comunicação e a inteligência competitiva são de grande relevância. 


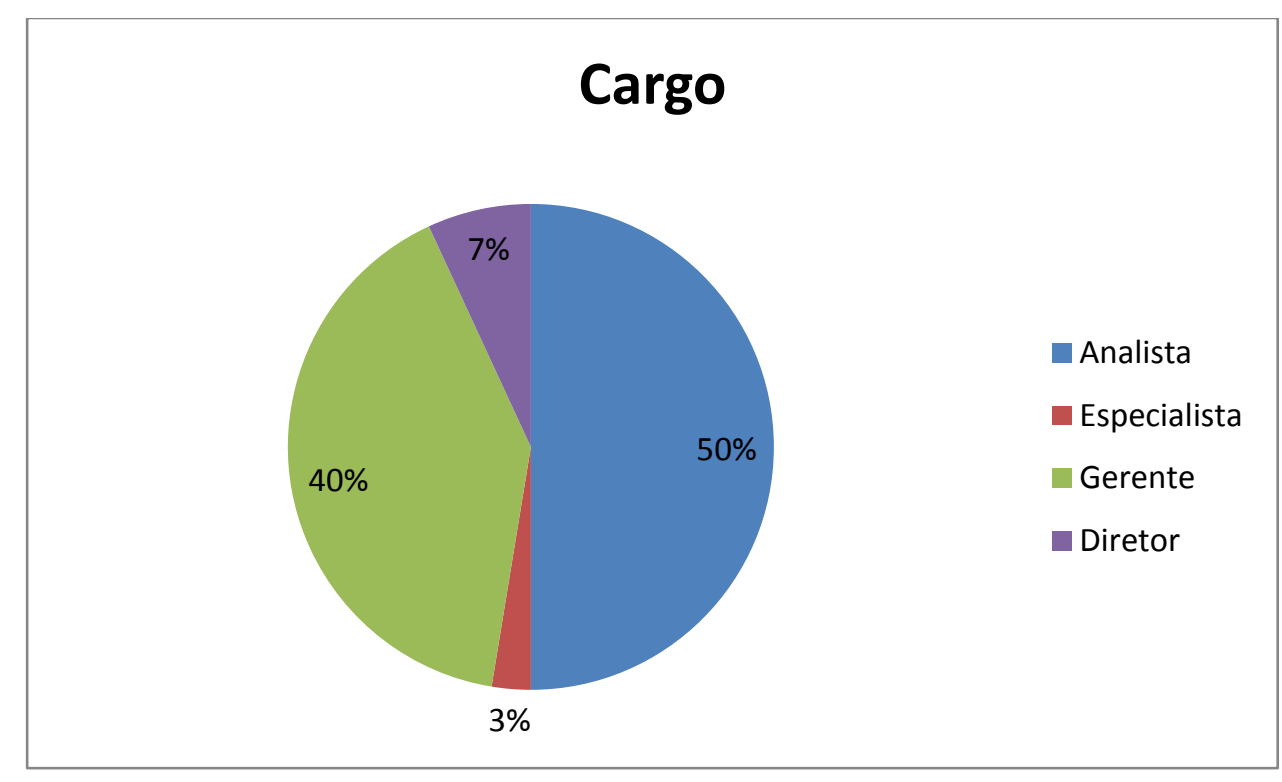

Figura 24 - Composição da amostra em relação aos cargos dos respondentes nas organizações em que atuam

Fonte: Elaborado pelo autor

Como mostra a figura 24, a grande maioria dos respondentes (90\%) é composta de analistas e gerentes. Normalmente, os analistas utilizam os sistemas de BI com uma visão mais operacional, o que não ocorre com os gerentes que buscam as informações nos sistemas de BI para definirem mudanças estratégicas em suas operações.

\subsection{Hipóteses do modelo conceitual}

Conforme mencionado anteriormente, considerando-se o modelo de pesquisa apresentado na figura 17, afirma-se que o uso pelo usuário das informações disponibilizadas pelo sistema de BI está positivamente associada aos benefícios esperados e aos FCS. Desta forma, propõe-se:

Hipótese 1: A influência da dimensão BE sobre o USO. Essa hipótese está fundamentada nos modelos de DeLone e McLean (2003) e de Kim et al. (2008) que mostram o beneficio identificado pelo consumidor como um fator que impacta positivamente em sua decisão de uso da informação através do sistema.

Hipótese 2: A influência da dimensão FCS sobre o USO. Essa hipótese está fundamentada no modelo de Yeoh e Koronios (2010) que apresenta os FCS como fatores que impactam positivamente no sucesso da implementação de sistemas de BI. 
Hipótese 3: A influência da dimensão FCS sobre os BE. Essa hipótese está fundamentada no modelo de Yeoh e Koronios (2010) e no conceito de sucesso de BI de Wixon e Watson (2001), que conceituam o impacto positivo dos FCS sobre os benefícios percebidos pelo usuário (BE), considerado pelos autores como o sucesso do sistema de BI.

\subsection{Interpretação dos resultados}

Este capítulo é dedicado à análise dos dados obtidos, avaliando as condições dos dados e análise dos modelos SEM. Inicialmente é feita a análise dos dados, incluindo a verificação dos dados perdidos e atípicos, análise do modelo SEM de pesquisa e readequação do modelo.

Após verificação, o número de questionários considerados válidos é de 116 de um total de 134 respostas obtidas originalmente.

\subsection{Análise dos dados}

Na tabela 30 é apresentada as estatísticas descritiva das variáveis coletadas.

Importante notar que todas a variáveis atingiram nota máxima na pesquisa, o que indica que todas as características apresentadas no modelo conceitual foram reconhecidas e avaliadas como merecedora de nota máxima baseada nas experiências de uso dos sistemas de BI pelos usuários ou por algum usuário. Isso já não ocorreu com relação as notas mínimas. Carateristicas como esforço na decisão, valor adicional e base do conhecimento receberam nota mínima 3. Isso indica que todos consideraram através de suas experiências com os sistemas de BI em suas empresas que há melhoria nas atividade do trabalho e que os sistemas de BI também contribuíram para a gestão do conhecimento. 
Tabela 30 - Estatística descritiva dos dados

Estatística Descritiva

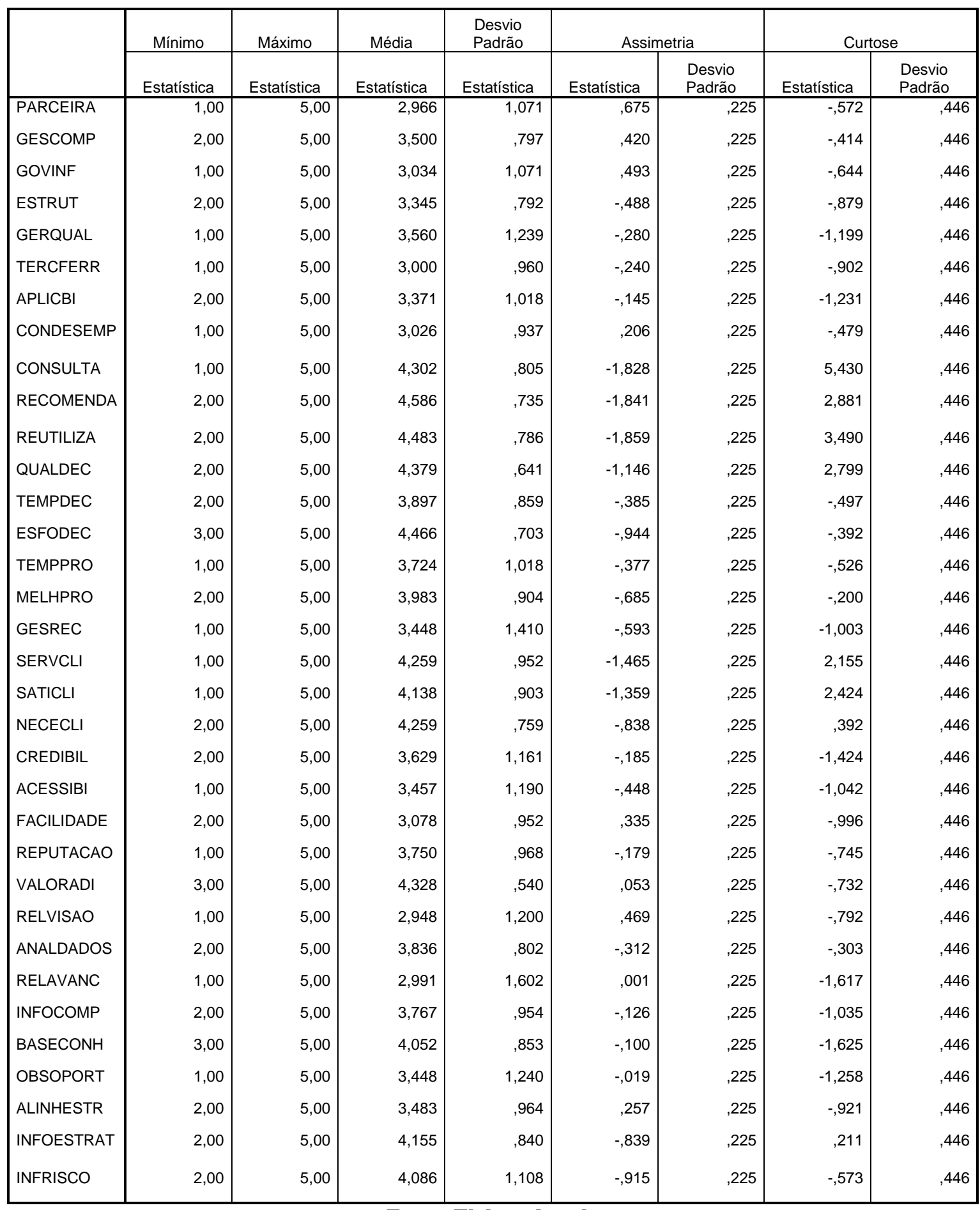

Fonte: Elaborado pelo autor

Na tabela 31 temos os indicadores que receberam na pesquisa o menor valor da escala, 1. 
Tabela 31 - Indicadores que atingiram o menor valor de pesquisa

\begin{tabular}{|l|l|r|}
\hline \multicolumn{2}{|c|}{ VL } & \multicolumn{1}{|c|}{ Indicador } \\
\hline $\begin{array}{l}\text { Benefícios } \\
\text { Esperados }\end{array}$ & IIE) & GESREC \\
& & SATICLI \\
& & SERVCLI \\
& TEMPPRO \\
\cline { 2 - 3 } & Estratégia & OBSOPORT \\
\cline { 2 - 3 } & Usabilidade & ACESSIBI \\
& & REPUTACAO \\
\cline { 2 - 3 } & Relatórios & RELAVANC \\
& & RELVISAO \\
\hline Fatores & Tecnologia & CONDESEMP \\
Críticos de & & GERQUAL \\
Sucesso & & TECFERR \\
\cline { 2 - 3 } & & GOVINF \\
& Organização & PARCEIRA \\
\hline & & CONSULTA \\
\cline { 2 - 3 } & Uso &
\end{tabular}

Fonte: Elaborado pelo autor

$\mathrm{Na}$ tabela 32 temos os indicadores que apresentaram a menor assimetria, o que mostra uniformidade nas respostas indicando que os usuários de sistemas de BI consultados tiveram experiências parecidas com aspectos estratégicos do sistema como a melhora na observação de oportunidades, no compartilhamento de informação e na elevação da base de conhecimento.

Tabela 32 - Indicadores com baixa assimetria

\begin{tabular}{|c|c|c|}
\hline & $\mathrm{VL}$ & Indicador \\
\hline \multirow{5}{*}{$\begin{array}{l}\text { Benefícios } \\
\text { Esperados } \\
\text { (BE) }\end{array}$} & Estratégia & OBSOPORT \\
\hline & Usabilidade & VALORADI \\
\hline & Conhecimento & BASECONH \\
\hline & & INFOCOMP \\
\hline & $\begin{array}{l}\text { Relatórios e } \\
\text { Análises }\end{array}$ & RELAVANC \\
\hline Fatores & Tecnologia & APLICBI \\
\hline Críticos de & & \\
\hline Sucesso & & \\
\hline (FCS) & & \\
\hline
\end{tabular}

Fonte: Elaborado pelo autor

Para melhor interpretação dos agrupamentos foi realizada a análise fatorial exploratória (EFA). Na tabela 33 temos o resultado da análise fatorial exploratória que mostra as 8 variáveis sintéticas com autovalores superiores a 1 , critério da raiz latente. As variáveis foram filtradas obedecendo o critério de fator igual ou superior à 0,5 . A EFA explora os dados e fornece 
informação sobre quantos fatores são necessários para melhor representar os dados. Com EFA, todas as variáveis medidas são relacionadas com cada fator por uma estimativa de carga fatorial (Hair, 2009, p.589).

Tabela 33 - Análise fatorial exploratória (EFA)

Matrix dos componentes rotacionados (VARIMAX)

\begin{tabular}{|c|c|c|c|c|c|c|c|c|}
\hline & \multicolumn{8}{|c|}{ Componentes } \\
\hline & 1 & 2 & 3 & 4 & 5 & 6 & 7 & 8 \\
\hline MELHPRO & ,819 & & & & & & & \\
\hline BASECONH & ,789 & & & & & & & \\
\hline INFOCOMP & ,785 & & & & & & & \\
\hline RELVISAO & ,759 & & & & & & & \\
\hline SATICLI & ,745 & & & & & & & \\
\hline QUALDEC & ,739 & & & & & & & \\
\hline NECECLI & ,672 & & & & & & & \\
\hline OBSOPORT & ,671 & & & & & & & \\
\hline ALINHESTR & ,668 & & & & & & & \\
\hline TEMPDEC & 633 & ,517 & & & & & & \\
\hline RELAVANC & ,610 & ,579 & & & & & & \\
\hline SERVCLI & ,606 & & & & & & & \\
\hline CONSULTA & 601 & & & & & & & \\
\hline FACILIDADE & ,558 & & & & & & & \\
\hline ESFODEC & ,555 & & & & & & & \\
\hline INFOESTRAT & ,546 & &,- 510 & & & & & \\
\hline GESREC & & ,678 & & & & & & \\
\hline ANALDADOS & & 637 & & & & & & \\
\hline TEMPPRO & 620 & ,636 & & & & & & \\
\hline INFRISCO & ,523 &,- 565 & & & & & & \\
\hline CREDIBIL & &,- 543 & & & & & & \\
\hline APLICBI & & & ,622 & & & & & \\
\hline RECOMENDA & & & ,588 & & & & & \\
\hline TERCFERR & &, 500 &, 551 & & & & & \\
\hline GERQUAL & & & ,503 & & & & & \\
\hline ESTRUT & & & & & & & & \\
\hline PARCEIRA & & & & 617 & & & & \\
\hline CONDESEMP & & & &, 506 & & & & \\
\hline GOVINF & & & & & ,856 & & & \\
\hline GESCOMP & & & & & ,505 & & & \\
\hline REUTILIZA & , 518 & & & & &,- 576 & & \\
\hline ACESSIBI & & & & & & & & \\
\hline REPUTACAO & & & & & & & &, 509 \\
\hline VALORADI & & & & & & & & \\
\hline
\end{tabular}

Fonte: Elaborado pelo autor 
Tabela 34 - Matriz de correlação das VLs do modelo conceitual

\begin{tabular}{|c|c|c|c|c|c|c|c|c|c|c|c|c|}
\hline & 岗 & 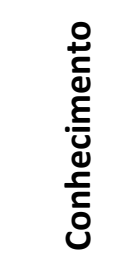 & 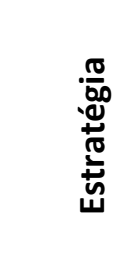 & y & 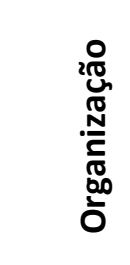 & $\begin{array}{l}\frac{0}{2} \\
\frac{\pi}{0} \\
\frac{0}{2} \\
\frac{2}{2} \\
\frac{2}{0} \\
\frac{0}{2} \\
0\end{array}$ & 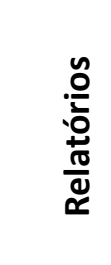 & 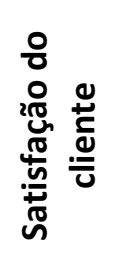 & $\begin{array}{l}\frac{\pi}{80} \\
\frac{0}{0} \\
\frac{0}{0} \\
\stackrel{d}{-}\end{array}$ & 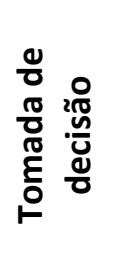 & $\begin{array}{l}\frac{0}{0} \\
\frac{\pi}{0} \\
\frac{0}{\overline{0}} \\
\frac{0}{\pi} \\
\end{array}$ & ํㅗ \\
\hline $\mathrm{BE}$ & 1 & 0 & 0 & 0 & 0 & 0 & 0 & 0 & 0 & 0 & 0 & \\
\hline onhecimento & 0,863 & 1 & 0 & 0 & 0 & 0 & 0 & 0 & 0 & 0 & 0 & 0 \\
\hline Estratégia & 0,748 & 0,774 & 1 & 0 & 0 & 0 & 0 & 0 & 0 & 0 & 0 & 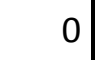 \\
\hline FCS & 0,213 & 0,092 & $-0,002$ & 1 & 0 & 0 & 0 & 0 & 0 & 0 & 0 & 0 \\
\hline Organização & 0,154 & 0,058 & 0,163 & 0,685 & 1 & 0 & 0 & 0 & 0 & 0 & 0 & 0 \\
\hline Produtividade & 0,766 & 0,574 & 0,427 & 0,255 & 0,098 & 1 & 0 & 0 & 0 & 0 & 0 & 0 \\
\hline Relatórios & 0,746 & 0,491 & 0,401 & 0,139 & $-0,013$ & 0,839 & 1 & 0 & 0 & 0 & 0 & 0 \\
\hline $\begin{array}{l}\text { Satisfação } \\
\text { do cliente }\end{array}$ & 0,708 & 0,564 & 0,391 & 0,076 & 0,024 & 0,341 & 0,357 & 1 & 0 & 0 & 0 & 0 \\
\hline $\begin{array}{r}\text { Tecnologia } \\
\text { Tomada }\end{array}$ & 0,187 & 0,084 & $-0,091$ & 0,926 & 0,360 & 0,275 & 0,183 & 0,073 & 1 & 0 & 0 & 0 \\
\hline de decisão & 0,774 & 0,698 & 0,544 & 0,414 & 0,297 & 0,666 & 0,424 & 0,520 & 0,372 & 1 & 0 & 0 \\
\hline Usabilidade & 0,707 & 0,522 & 0,394 & 0,199 & 0,140 & 0,339 & 0,478 & 0,546 & 0,177 & 0,361 & 1 & 0 \\
\hline Uso & 0,524 & 0,455 & 0,289 & 0,127 & 0,097 & 0,300 & 0,233 & 0,577 & 0,103 & 0,513 & 0,407 & 1 \\
\hline
\end{tabular}

Fonte: Elaborado pelo autor

Observando os resultados da EFA e a matriz de correlação percebe-se que o construto gestão do conhecimento é fortemente correlacionado com a estratégia empresarial $(0,774)$. Isso pode ser uma indicação da necessidade de readequação dos indicadores.

Na tabela 35 temos a correlação entre os indicadores dos construtos do modelo de pesquisa e sua distribuição, possibilitando identificar os indicadores apontados pelos respondentes de maneira mais uniforme e os com grande assimetria indicando uma opinião comum com relação à determinado quesito. 
Tabela 35 - Matrizes de correlação dos indicadores das VL e sua distribuição

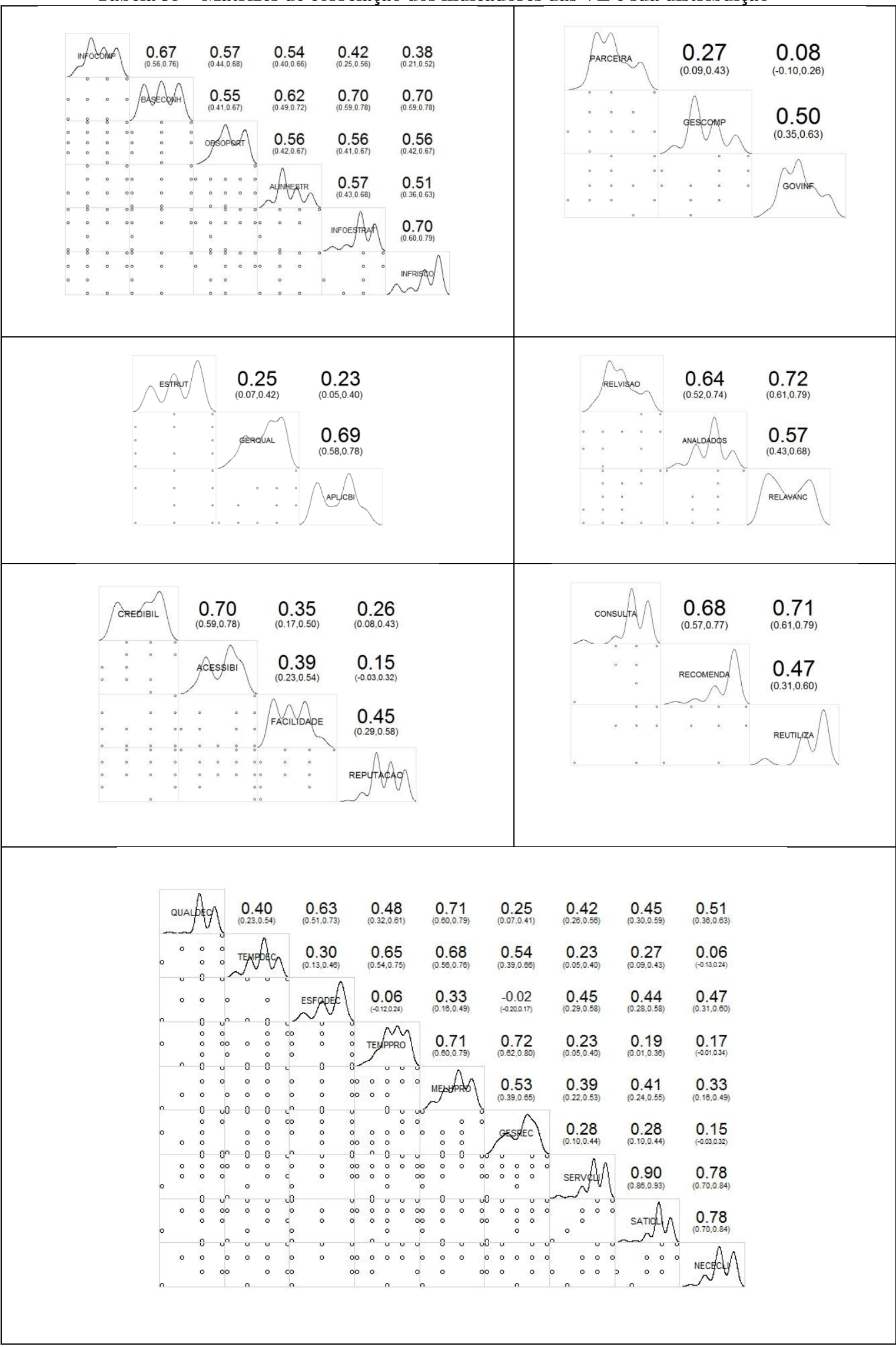




\subsubsection{Análise do modelo de equações estruturais inicial}

A técnica estatística escolhida para a avaliação do modelo foi o PLS. A técnica PLS visa examinar a significância das relações e o $\mathrm{R}^{2}$ resultante utilizando o método dos mínimos quadrados ordinários e suas técnicas de estimação. Para isso o software escolhido foi o SmartPLS 2.0.M3.

De acordo com Pinto (2012), a técnica PLS é basicamente uma sequência de regressões em termos de vetores de cargas, com as seguintes etapas:

I. A parte principal do algoritmo que é o cálculo por aproximação interativa dos scores das variáveis latentes, onde são realizadas as combinações lineares dos respectivos indicadores de cada uma delas;

II. A estimação das cargas das variáveis latentes de forma a refletir o quão fortemente cada uma das outras variáveis latentes estão conectadas com uma variável latente específica através de três possíveis métodos de ponderação, o centróide utilizando os sinais das correlações entre cada variável latente e suas variáveis adjacentes, o fator utilizando como pesos as correlações entre os scores fatoriais das variáveis latentes e o caminho onde se utiliza a orientação ou direção dos caminhos entre variáveis latentes.

III. O cálculo por aproximação dos scores das variáveis latentes do modelo estrutural através da realização de combinações lineares entre cada variável latente e as variáveis latentes adjacente utilizando as cargas calculadas para cada variável;

IV. A estimação das cargas do modelo de mensuração onde são calculadas como as covariâncias de cada variável latente e seus indicadores (modo reflexivo) ou como as cargas de regressão resultantes do cálculo de mínimos quadrados entre cada variável latente e seus respectivos indicadores (modo reflexivo).

Essas quatro etapas descritas são executadas até que os incrementos entre as cargas do modelo de mensuração fiquem abaixo de um determinado valor limite. 


\subsubsection{Análise de cargas e relevância de variáveis}

$\mathrm{Na}$ figura 25 é apresentado o modelo estrutural conceitual utilizado no SmartPLS 2.0.M3, seus construtos e as respectivas cargas dos indicadores. Conforme figura, todos os indicadores apresentam cargas significantes (Estatística $t \geq 2,0 \rightarrow$ intervalo de confiança $\geq 95 \%$ ). Os $t$ values foram obtidos a partir da execução do bootstrap no SmartPLS 2.0.M3 com n=116 obedecendo o tamanho da amostra válida com 1000 repetições (BIDO et al., 2010).

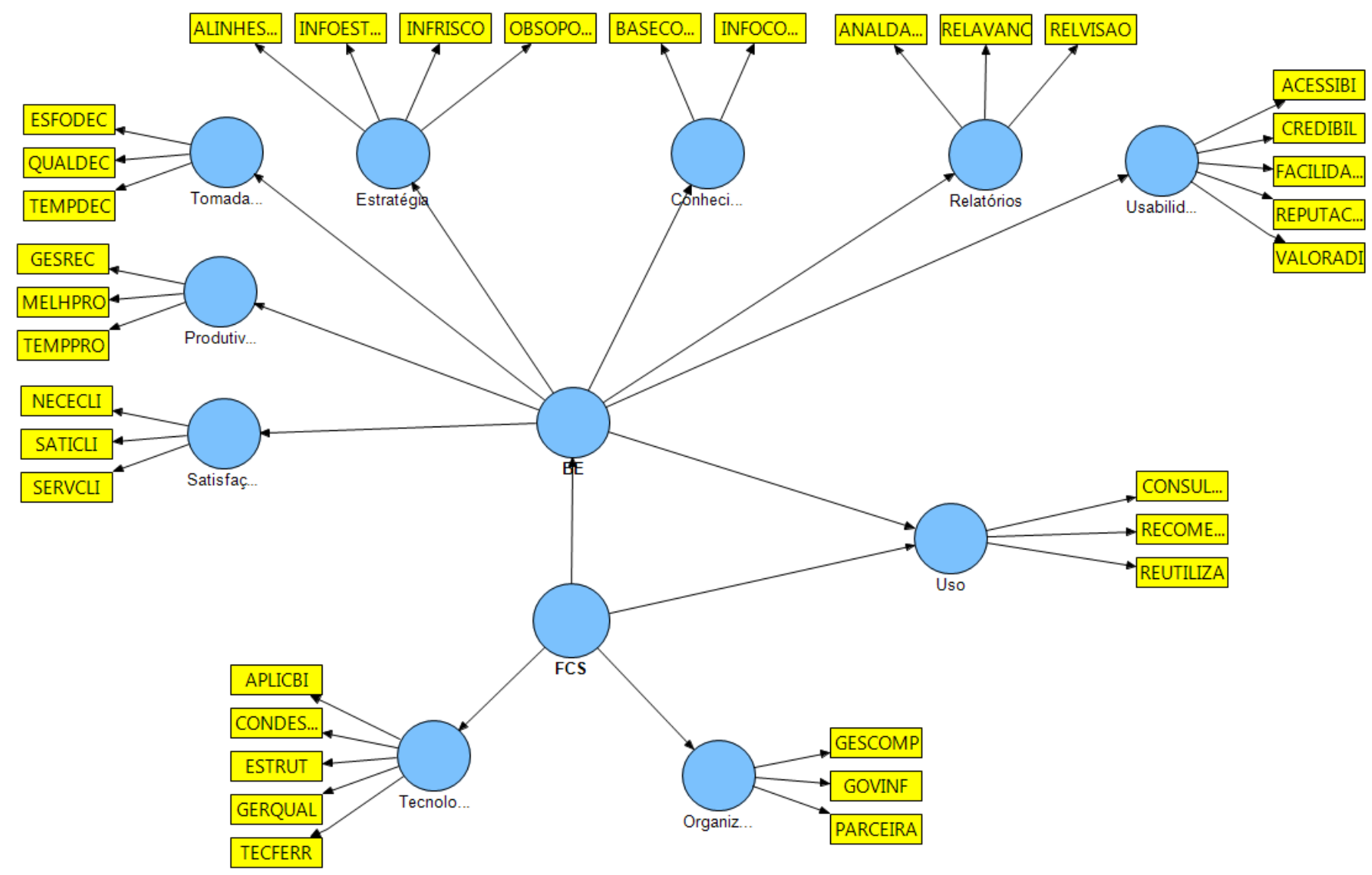

Figura 25 - Modelo estrutural conceitual Fonte: Elaborado pelo autor

Na tabela 36 é apresentado os valores da estatística $t$ obtidas para os indicadores do modelo conceitual, conforme mostrado na figura 25 , confirmando que todos os indicadores apresentam cargas relevantes. 
Tabela 36 - Resumo das estatísticas $t$ do indicadores do modelo conceitual

Estatística $t$

\begin{tabular}{|l|r|}
\hline ACESSIBI <- Usabilidade & 9,7 \\
ALINHESTR <- Estratégia & 30,0 \\
ANALDADOS <- Relatórios & 18,7 \\
APLICBI <- Tecnologia & 6,3 \\
BASECONH <- Conhecimento & 91,7 \\
CONDESEMP <- Tecnologia & 38,2 \\
CONSULTA <- Uso & 61,5 \\
CREDIBIL <- Usabilidade & 13,9 \\
ESFODEC <- Tomada de decisão & 17,4 \\
ESTRUT <- Tecnologia & 11,9 \\
FACILIDADE <- Usabilidade & 9,3 \\
GERQUAL <- Tecnologia & 7,4 \\
GESCOMP <- Organização & 3,4 \\
GESREC <- Produtividade & 13,2 \\
GOVINF <- Organização & 2,1 \\
INFOCOMP <- Conhecimento & 54,5 \\
INFOESTRAT <- Estratégia & 36,8 \\
INFRISCO <- Estratégia & 35,7 \\
MELHPRO <- Produtividade & 83,7 \\
NECECLI <- Satisfação do cliente & 64,9 \\
OBSOPORT <- Estratégia & 29,0 \\
PARCEIRA <- Organização & 7,4 \\
QUALDEC <- Tomada de decisão & 44,8 \\
RECOMENDA <- Uso & 9,7 \\
RELAVANC <- Relatórios & 35,7 \\
RELVISAO <- Relatórios & 71,1 \\
REPUTACAO <- Usabilidade & 6,9 \\
REUTILIZA <- Uso & 21,7 \\
SATICLI <- Satisfação do cliente & 106,7 \\
SERVCLI <- Satisfação do cliente & 56,3 \\
TECFERR <- Tecnologia & 22,2 \\
TEMPDEC <- Tomada de decisão & 11,0 \\
TEMPPRO <- Produtividade & 44,3 \\
VALORADI <- Usabilidade & 4,0 \\
\hline & Fonte: Elaborado pelo autor \\
\hline
\end{tabular}

Fonte: Elaborado pelo autor

Os scores fatoriais para o modelo conceitual de pesquisa apresentado na figura 25 é reproduzido em tabela no anexo II. 


\subsubsection{Análise de Multicolinearidade}

Quando uma variável independente é a combinação linear de outras variáveis independentes, ocorre a multicolinearidade. Uma maior dependência tende a elevar os valores dos erros padrão para os estimadores de cada variável podendo esses estimadores tornarem-se instáveis. Uma abordagem utilizada para avaliar a multicolinearidade é a análise da matriz de correlação das variáveis independentes adotadas no modelo. Define-se a tolerância (TOL) como a porcentagem da variação da variável independente que não pode ser explicada pelas demais variáveis independentes.

$$
T O L=1-R_{V I,}^{2} \text { outras } V I
$$

Pequenos valores de TOL indicam que determinada VI apresenta grande correlação com as demais. Define-se por Variance Inflation Factor (VIF), o inverso de TOL.

$$
V I F=\frac{1}{T O L}
$$

Pequenos valores de TOL têm grande impacto no valor de VIF demonstrando em que grau o erro padrão de estimação é afetado pela multicolinearidade. Como regra prática, valores de VIF maiores do que 10 indicam problema de multicolinearidade (Hair, et al., 2010). No modelo conceitual em questão, por se tratar de indicadores reflexivos, não ocorre o problema de multicolinearidade no modelo de mensuração.

No anexo III é possível observar os valores de VIF para cada variável independente. Foi utilizado o software estatístico $\mathrm{R}$ para essa análise. Algumas variáveis independentes apresentam valores de VIF maiores do que 10, não satisfazendo o teste de ausência de multicolinearidade significativa.

\subsubsection{Validade convergente (Cargas, AVEs)}

A validade convergente tem por objetivo testar a relação de um indicador com outros indicadores da mesma variável latente refletindo as diferenças nas características dos 
indicadores que estão sendo medidos. A validade convergente é obtida por meio da variância média extraída (AVE) e para que essa condição seja satisfeita é recomendado que o valor mínimo de AVE seja de 0,5 (Chin, 1998).

Na tabela 37 temos os valores de AVE para as variáveis do modelo conceitual. Bido e Godoy et al. (2010) comentam que o software PLS não realiza, para as variáveis de segunda ordem, o cálculo de AVE corretamente, sugerindo que nesses casos sejam calculados manualmente. Portanto, foi realizado o cálculo manual das variáveis BE e FCS.

Tabela 37 - AVEs de cada variável do modelo conceitual de pesquisa

\begin{tabular}{|r|r|}
\multicolumn{1}{|c}{ Variáveis } & \multicolumn{1}{l}{ AVE } \\
Conhecimento & $\mathbf{0 , 5 3 9 7}$ \\
Bstratégia & 0,8447 \\
FCS & $\mathbf{0 , 3 4 4 0}$ \\
Organização & 0,5164 \\
Produtividade & 0,7498 \\
Relatórios & 0,7887 \\
Satisfação do cliente & 0,8876 \\
Tecnologia & 0,5117 \\
Tomada de decisão & 0,6323 \\
Usabilidade & 0,4201 \\
Uso & 0,7321 \\
\hline
\end{tabular}

Fonte: Elaborado pelo autor

Como podemos notar, somente duas variáveis ficaram com a variância média extraída (AVE) abaixo de 0,5, a variável latente de primeira ordem USABILIDADE e a variável latente de segunda ordem FCS, não atendendo ao critério de validade convergente. No caso da variável latente de primeira ordem USABILIDADE, o valor de AVE ficou um pouco abaixo de 0,5, de forma geral, houve predominância de valores maiores que 0,5 .

\subsubsection{Confiabilidade composta}

Hair et al. (2010) e Chin (1998) recomendam que para a verificação da confiabilidade das variáveis latentes seja utilizado o indicador de validade composta e não o alpha de Cronbach, com um valor mínimo recomendado de 0,7 . 
$\mathrm{Na}$ tabela 38 temos o resumo das confiabilidades compostas das variáveis. Os valores de confiabilidade composta satisfizeram o critério mínimo recomendado.

\begin{tabular}{|c|c|}
\hline Variáveis & Confiabilidade Composta \\
\hline BE & 0,9353 \\
\hline Conhecimento & 0,9158 \\
\hline Estratégia & 0,9118 \\
\hline FCS & 0,8107 \\
\hline Organização & 0,76 \\
\hline Produtividade & 0,8995 \\
\hline Relatórios & 0,9179 \\
\hline Satisfação do cliente & 0,9595 \\
\hline Tecnologia & 0,8376 \\
\hline Tomada de decisão & 0,8364 \\
\hline Usabilidade & 0,777 \\
\hline Uso & 0,8907 \\
\hline
\end{tabular}

Fonte: Elaborado pelo autor

\subsubsection{Validade discriminante}

A validade discriminante tem por objetivo avaliar até que ponto as escalas medem o que se propõem medir e essa validade é realizada através das cargas cruzadas entre as variáveis. A validade discriminante é confirmada quando as variáveis latentes não apresentam forte relacionamento entre si, i.e., que os indicadores apresentem carga mais alta na sua respectiva variável latente do que em outras.

No apêndice IV temos a análise da validade discriminante onde espera-se que as variáveis latentes não apresentem um forte relacionamento entre si, i.e., que os indicadores de cada variável tenham carga mais alta na sua respectiva variável latente do que em qualquer outra, indicando a existência de validade discriminante. Na tabela do apêndice IV, com raras exceções, têm-se a validade discriminante confirmada. 
Tabela 39 - Correlação entre as VLs. Na diagonal principal o valor de $\sqrt{\text { AVE. }}$

\begin{tabular}{|c|c|c|c|c|c|c|c|c|c|c|}
\hline Variáveis Latentes & 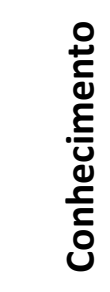 & 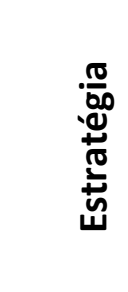 & 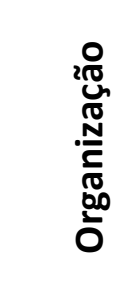 & 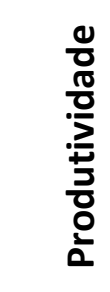 & 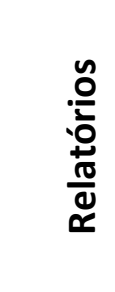 & 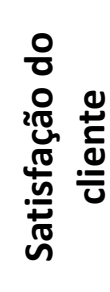 & 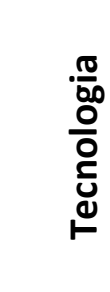 & 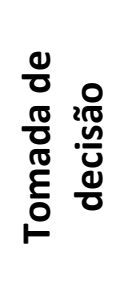 & 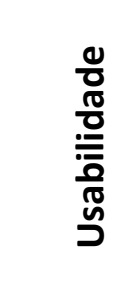 & $\stackrel{\circ}{\circ}$ \\
\hline Conhecimento & 0,919 & $\overline{0}$ & 0 & 0 & $\overline{0}$ & 0 & $\overline{0}$ & $\overline{0}$ & & $\overline{0}$ \\
\hline Estratégia & 0,774 & 0,849 & 0 & 0 & 0 & & 0 & 0 & & 0 \\
\hline Organização & 0,058 & 0,163 & 0,719 & 0 & 0 & 4 & 0 & 0 & & 0 \\
\hline Produtividade & 0,574 & 0,427 & 0,098 & 0,866 & 0 & 0 & 0 & 0 & & 0 \\
\hline Relatórios & 0,491 & 0,401 & $-0,013$ & 0,839 & 0,888 & 0 & 0 & 0 & 0 & 0 \\
\hline Satisfação do cliente & 0,564 & 0,391 & 0,024 & 0,341 & 0,357 & 0,942 & 0 & 0 & 0 & 0 \\
\hline Tecnologia & 0,084 & $-0,091$ & 0,360 & 0,275 & 0,183 & 0,073 & 0,715 & 0 & & 0 \\
\hline Tomada d & 0,698 & 0,544 & 0,297 & 0,666 & 0,424 & 0,520 & 0,372 & 0,795 & 0 & 0 \\
\hline Usabilidade & 0,522 & 0,394 & 0,140 & 0,339 & 0,478 & 0,546 & 0,177 & 0,361 & 0,648 & 0 \\
\hline Uso & 0,455 & 0,289 & 0,097 & 0,300 & 0,233 & 0,577 & 0,103 & 0,513 & 0,407 & 0,856 \\
\hline
\end{tabular}

Na tabela 39 temos a matriz de correlação entre as VLs de primeira ordem. Na diagonal principal temos a $\sqrt{A V E}$ para cada variável latente. Para a existência de validade discriminante é necessário que os valores da $\sqrt{A V E}$ para cada variável latente seja maior do que as respectivas correlações com as demais variáveis latentes.

A análise da tabela 39 mostra que existe validade discriminante para o modelo inicial de pesquisa.

A seguir é apresentada a matriz de correlação para as variáveis latentes de segunda ordem. Os valores na diagonal principal da matriz representam os valores de $\sqrt{A V E}$.

Tabela 40 - Correlação entre as VLs de segunda ordem.

Na diagonal principal o valor de $\sqrt{\mathrm{AVE}}$.

\begin{tabular}{|c|c|c|}
\hline $\begin{array}{l}\text { Variáveis } \\
\text { Latentes de } \\
\text { segunda } \\
\text { ordem }\end{array}$ & BE & FCS \\
\hline $\mathrm{BE}$ & 0,735 & 0 \\
\hline FCS & 0,213 & 0,587 \\
\hline
\end{tabular}

Fonte: Elaborado pelo autor 
Como se pode observar na tabela 40 , o valor da $\sqrt{A V E}$ de cada variável latente é superior ao valor de correlação, confirmando a validade discriminante para as variáveis latentes de segunda ordem do modelo conceitual.

\subsubsection{Avaliação do Modelo Estrutural}

O teste do modelo estrutural tem como objetivo examinar as relações entre as variáveis latentes. Pinto (2012) comenta a utilização de indicadores para a avaliação do modelo estrutural através de um índice de adequação que leva em consideração tanto a adequação do modelo estrutural quanto o de mensuração. Na visão de Bido; Godoy et al. (2010) o GoF é um índice calculado a partir da media geométrica entre $\mathrm{R}^{2}$ médio (adequação do modelo estrutural) e a AVE média (adequação do modelo de mensuração), podendo-se fazer a escolha com base no ponto de corte da AVE, considerando-se adequado um valor de GoF superior a 0,5.

A tabela 41 apresenta os valores de GoF, $\mathrm{R}^{2}$, AVE e um resumo dos caminhos e suas respectivas siginificâncias. Também é apresentada a contribuição de cada variável exógena (BE, FCS) para o $\mathrm{R}^{2}$ da variável endógena (Uso).

Tabela 41 - Avaliação do modelo conceitual

\begin{tabular}{|c|c|c|c|c|c|c|c|c|c|c|}
\hline \multicolumn{11}{|c|}{ Modelo Conceitual } \\
\hline \multicolumn{5}{|c|}{ Avaliação de aderência } & \multicolumn{6}{|c|}{ Análise da contribuição de BE e FCS para o uso } \\
\hline $\begin{array}{l}\text { Tipo de } \\
\text { variável }\end{array}$ & $\begin{array}{l}\text { Variável } \\
\text { Latente }\end{array}$ & $\mathbf{R}^{\mathbf{2}}$ & AVE & GoF & Caminho & $\begin{array}{l}\text { Coeficiente } \\
\text { Padronizado }\end{array}$ & $\mathbf{t}$ & Correlação & \begin{tabular}{|} 
Correlação \\
$\mathrm{X}$ \\
Coeficiente
\end{tabular} & $\begin{array}{l}\text { Contribuição } \\
\text { do } R^{2} \text { na } \\
\text { amostra (\%) }\end{array}$ \\
\hline Endógena & Uso & 0,277 & 0,732 & 0,450 & $\mathrm{~N} / \mathrm{A}$ & \multicolumn{5}{|c|}{$\mathrm{N} / \mathrm{A}$} \\
\hline \multirow{2}{*}{ Exógena } & BE & $\mathrm{N} / \mathrm{A}$ & 0,540 & N/A & $\mathrm{BE}=>\mathrm{Uso}$ & 0,522 & 1,735 & 0,524 & 0,2735 & $99 \%$ \\
\hline & FCS & $\mathrm{N} / \mathrm{A}$ & 0,344 & $\mathrm{~N} / \mathrm{A}$ & $\mathrm{FCS}=>$ Uso & 0,019 & 0,219 & 0,127 & 0,0024 & $1 \%$ \\
\hline
\end{tabular}

Fonte: Elaborado pelo autor

Pode-se notar que o valor de GoF não atende o critério mínimo proposto por Bido et al.(2010), que é de 0,5 . Outro fator relevante é a contribuição da variável $\mathrm{BE}$ para o $\mathrm{R}^{2}$ muito superior à contribuição da variável FCS.

Na figura 26 são apresentados os valores dos fatores para o modelo conceitual. 


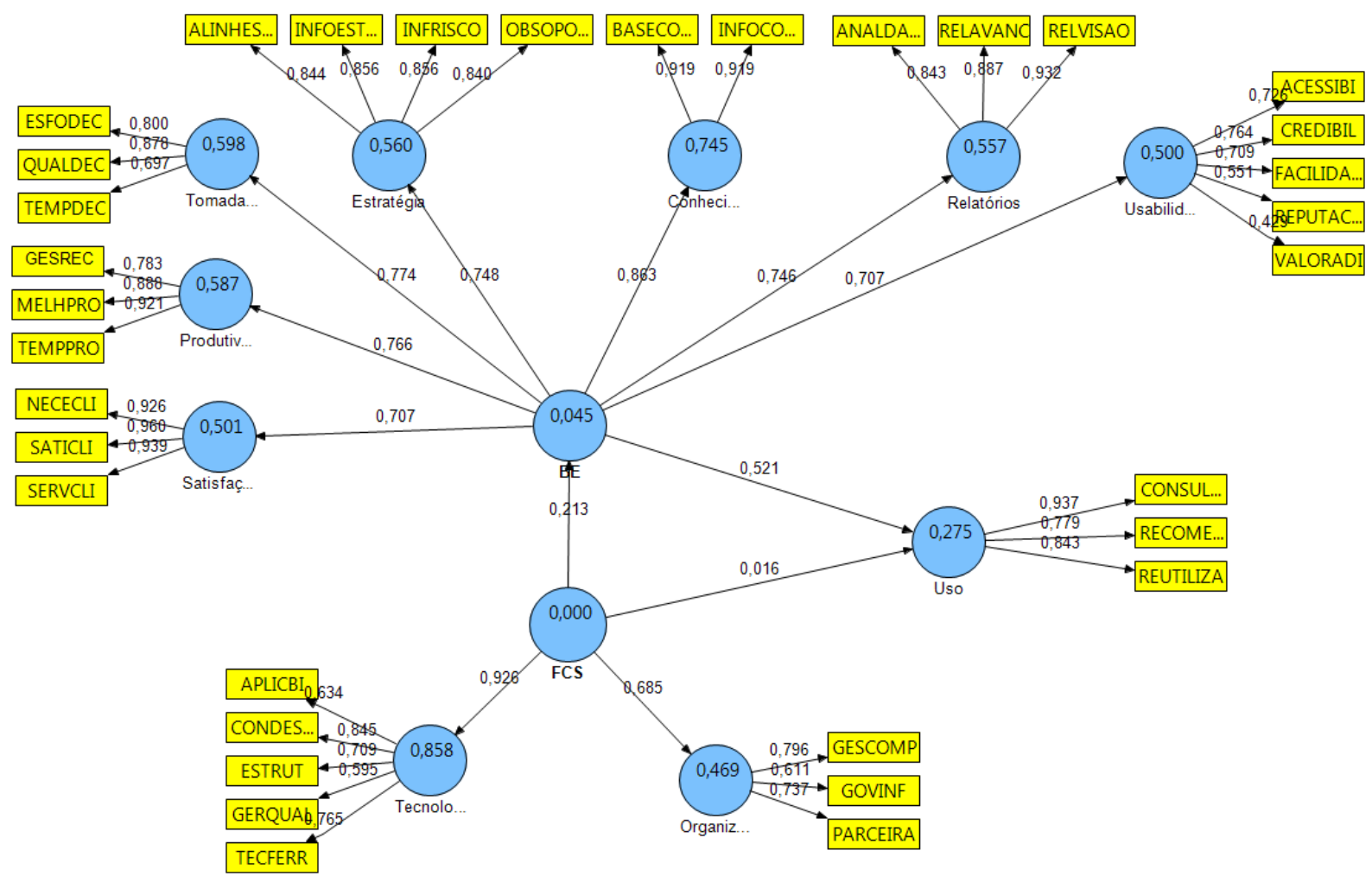

Figura 26 - Modelo estrutural conceitual e as respectivas cargas fatoriais Fonte: Elaborado pelo autor

\subsubsection{Comentários sobre o modelo conceitual}

O modelo conceitual de pesquisa não atendeu em parte dos critérios mínimos da técnica PLS. O que se percebe é que os construtos de primeira ordem tecnologia e organização, que representam os FCS, e alguns de seus indicadores não atingiram os valores mínimos para critérios de variância média extraída e significância estatística.

A seguir, um modelo ajustado é proposto com o objetivo de melhoria da qualidade dos fatores de relacionamento entre as variáveis propostas no modelo conceitual.

\subsubsection{Modelo ajustado}

A premissa adotada no modelo ajustado foi a de tratar a variável latente de segunda ordem FCS pois como visto no item 6.5.7 não apresentou contribuição relevante sobre a variável latente Uso. Nesse contexto, foi alterada a relação entre perspectiva organizacional e perspectiva 
tecnológica sobre a VL Uso, removendo-se a VL de segunda ordem FCS do modelo. Os resultados obtidos na EFA e os valores do VIF, além da significância estatística, levou à exclusão de alguns indicadores do modelo. Do construto Satisfação foi removido o indicador SERVCLI, do construto Tecnologia foram excluídos os indicadores CONDESEMP, ESTRUT e TECFERR, do construto Organização foi excluído o indicador PARCEIRA e do construto Uso o indicador RECOMENDA.

Na figura 27 são apresentados os valores dos fatores para o modelo ajustado.

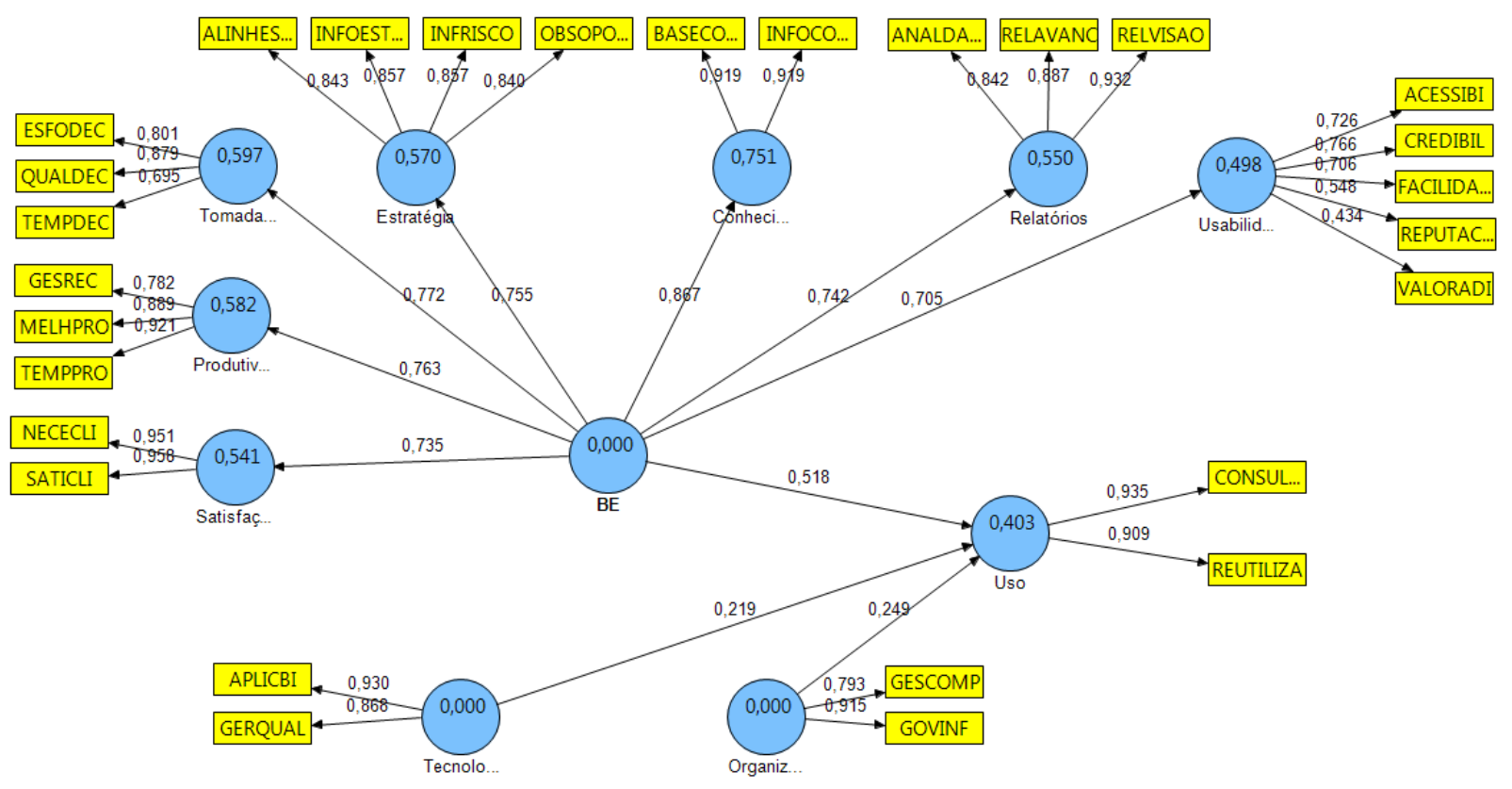

Figura 27 - Modelo estrutural ajustado e as respectivas cargas fatoriais Fonte: Elaborado pelo autor

A seguir serão realizadas as avaliações do modelo ajustado.

\subsubsection{Análise do modelo ajustado}

Na tabela 42 é apresentado os valores da estatística $t$ obtidas para os indicadores do modelo ajustado, conforme mostrado na figura 27 , confirmando que todos os indicadores apresentam cargas relevantes. 
Tabela 42 - Resumo das estatísticas $t$ do indicadores do modelo ajustado

Estatística $t$

\begin{tabular}{|l|r|}
\hline ACESSIBI <- Usabilidade & 9,8 \\
ALINHESTR <- Estratégia & 31,9 \\
ANALDADOS <- Relatórios & 18,2 \\
APLICBI <- Tecnologia & 15,2 \\
BASECONH <- Conhecimento & 100,0 \\
CONSULTA <- Uso & 64,0 \\
CREDIBIL <- Usabilidade & 14,5 \\
ESFODEC <- Tomada de decisão & 17,4 \\
FACILIDADE <- Usabilidade & 9,1 \\
GERQUAL <- Tecnologia & 8,9 \\
GESCOMP <- Organização & 7,8 \\
GESREC <- Produtividade & 13,8 \\
GOVINF <- Organização & 11,3 \\
INFOCOMP <- Conhecimento & 53,2 \\
INFOESTRAT <- Estratégia & 37,1 \\
INFRISCO <- Estratégia & 35,1 \\
MELHPRO <- Produtividade & 86,0 \\
NECECLI <- Satisfação do cliente & 92,0 \\
OBSOPORT <- Estratégia & 28,7 \\
QUALDEC <- Tomada de decisão & 48,1 \\
RELAVANC <- Relatórios & 36,7 \\
RELVISAO <- Relatórios & 71,1 \\
REPUTACAO <- Usabilidade & 6,8 \\
REUTILIZA <- Uso & 32,7 \\
SATICLI <- Satisfação do cliente & 135,0 \\
TEMPDEC <- Tomada de decisão & 10,8 \\
TEMPPRO <- Produtividade & 41,7 \\
VALORADI <- Usabilidade & 4,2 \\
\hline
\end{tabular}

Fonte: Elaborado pelo autor

Os scores fatoriais para o modelo ajustado apresentado na figura 27 é reproduzido em tabela no apêndice VII.

No anexo VI é possível observar os valores de VIF para cada variável independente do modelo ajustado, calculado também utilizando-se o software estatístico R. Algumas variáveis independentes apresentam valores de VIF maiores do que 10, não satisfazendo o teste de ausência de multicolinearidade significativa, no entanto observa-se uma considerável melhora em relação ao modelo conceitual. 
Com relação a validade convergente, que tem por objetivo testar a relação de um indicador com outros indicadores da mesma variável latente refletindo as diferenças nas características dos indicadores que estão sendo medidos, os valores de AVE são relacionados na tabela 43.

Tabela 43 - AVEs de cada variável do modelo ajustado
\begin{tabular}{r|r|}
\multicolumn{2}{c}{ Variáveis } \\
AVE
\end{tabular}
\begin{tabular}{r|r} 
BE & $\mathbf{0 , 5 3 9 7}$ \\
Conhecimento & 0,8447 \\
Estratégia & 0,7211 \\
Organização & 0,7331 \\
Produtividade & 0,7496 \\
Relatórios & 0,7887 \\
Satisfação do cliente & 0,9113 \\
Tecnologia & 0,8095 \\
Tomada de decisão & 0,6326 \\
Usabilidade & 0,4201 \\
Uso & 0,8505 \\
\hline
\end{tabular}

Fonte: Elaborado pelo autor

Como podemos notar, no modelo ajustado, somente uma variável apresentou variância média extraída (AVE) abaixo de 0,5, a variável latente de primeira ordem USABILIDADE, não atendendo, a rigor, ao critério de validade convergente. Entretanto como somente uma variável apresentou AVE inferior ao recomentdado com um valor próximo de 0,5, considerou-se que o modelo ajustado atende satisfatoriamente aos critérios de validade convergente.

$\mathrm{Na}$ tabela 44 temos o resumo das confiabilidades compostas das variáveis. Os valores de confiabilidade composta satisfizeram o critério mínimo recomendado de 0,7.

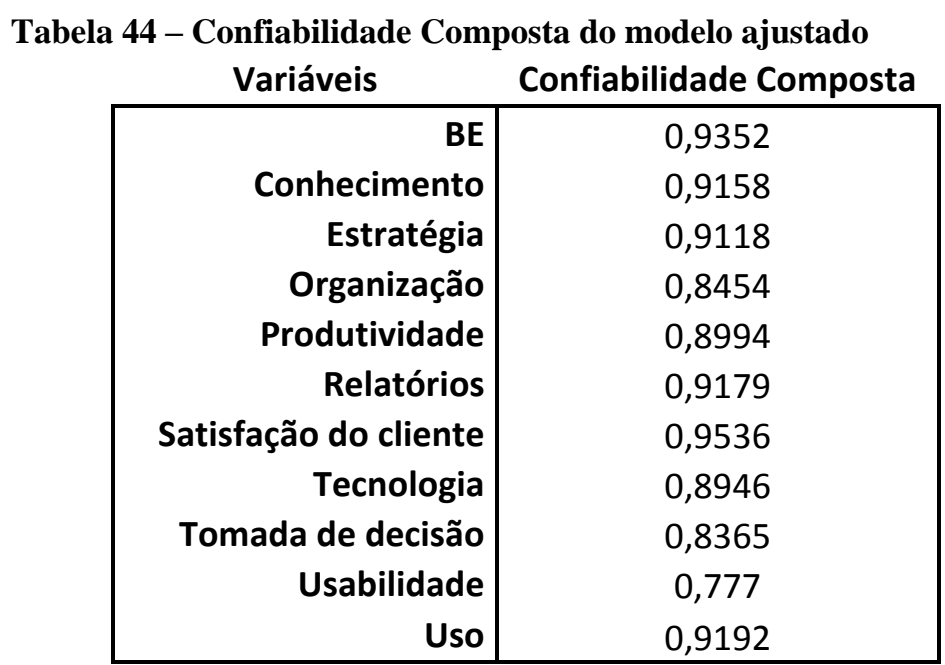

Fonte: Elaborado pelo autor 
Com relação a validade discriminante, que tem por objetivo avaliar até que ponto as escalas medem o que se propõem medir sendo essa validade realizada através das cargas cruzadas entre as variáveis, é apresentada no apêndice $\mathrm{V}$ a tabela com a análise da validade discriminante onde espera-se que as variáveis latentes não apresentem um forte relacionamento entre si, i.e., que os indicadores de cada variável tenham carga mais alta na sua respectiva variável latente do que em qualquer outra, indicando a existência de validade discriminante. Observando-se a tabela do apêndice $\mathrm{V}$, nota-se que somente o indicador VALORADI do construto USABILIDADE apresentou valor superior no construto CONHECIMENTO.

Tabela 45 - Correlação entre as VLs. Na diagonal principal o valor de $\sqrt{\text { AVE. }}$

\begin{tabular}{|c|c|c|c|c|c|c|c|c|c|c|}
\hline Variáveis Latentes & 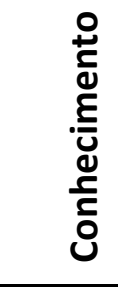 & 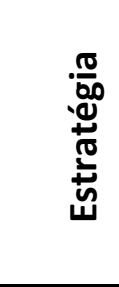 & 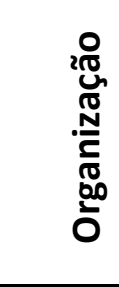 & $\begin{array}{l}\frac{0}{0} \\
\frac{\pi}{0} \\
\frac{0}{0} \\
: \frac{1}{+} \\
\frac{7}{0} \\
0 \\
\frac{0}{2}\end{array}$ & 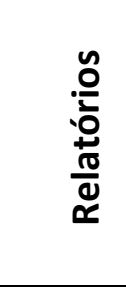 & 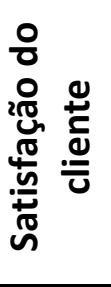 & 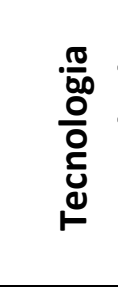 & 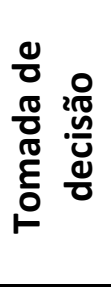 & $\begin{array}{l}\frac{0}{0} \\
\frac{\pi}{0} \\
\frac{\underline{0}}{\overline{0}} \\
\overline{0} \\
\stackrel{0}{D}\end{array}$ & $\stackrel{\circ}{\supset}$ \\
\hline Conhecimento & 0,919 & 0 & 0 & 0 & 0 & 0 & 0 & 0 & 0 & 0 \\
\hline Estratégia & 0,774 & 0,849 & 0 & 0 & 0 & 0 & 0 & 0 & 0 & 0 \\
\hline Organização & $-0,110$ & 0,030 & 0,856 & 0 & 0 & 0 & 0 & 0 & 0 & 0 \\
\hline Produtividade & 0,574 & 0,427 & $-0,060$ & 0,866 & 0 & 0 & 0 & 0 & 0 & 0 \\
\hline Relatórios & 0,491 & 0,400 & $-0,082$ & 0,838 & 0,888 & 0 & 0 & 0 & 0 & 0 \\
\hline Satisfação do cliente & 0,606 & 0,478 & 0,151 & 0,324 & 0,350 & 0,955 & 0 & 0 & 0 & 0 \\
\hline Tecnologia & 0,057 & $-0,113$ & 0,117 & $-0,079$ & $-0,125$ & 0,074 & 0,900 & 0 & 0 & 0 \\
\hline Tomada de decisão & 0,698 & 0,544 & 0,038 & 0,665 & 0,422 & 0,532 & 0,205 & 0,795 & 0 & 0 \\
\hline Usabilidade & 0,524 & 0,395 & 0,098 & 0,338 & 0,476 & 0,570 & 0,183 & 0,362 & 0,648 & 0 \\
\hline Uso & 0,488 & 0,381 & 0,288 & 0,336 & 0,246 & 0,529 & 0,262 & 0,498 & 0,355 & 0,922 \\
\hline
\end{tabular}

Fonte: Elaborado pelo autor

$\mathrm{Na}$ tabela 45 temos a matriz de correlação entre as VLs de primeira ordem. Na diagonal principal temos a $\sqrt{A V E}$ para cada variável latente. Para a existência de validade discriminante é necessário que os valores da $\sqrt{A V E}$ para cada variável latente seja maior do que as respectivas correlações com as demais variáveis latentes.

Como se pode observar na tabela 46 , o valor da $\sqrt{A V E}$ de cada variável latente é superior ao valor de correlação, confirmando a validade discriminante para as variáveis latentes de primeira ordem do modelo ajustado. 
Quanto ao teste do modelo estrutural que tem como objetivo examinar as relações entre as variáveis latentes, são apresentados na tabela 46 os valores de GoF, $\mathrm{R}^{2}$, AVE e um resumo dos caminhos e suas respectivas siginificâncias. Também é apresentada a contribuição de cada variável exógena (BE, Tecnologia e Organização) para o $\mathrm{R}^{2}$ da variável endógena (Uso).

Tabela 46 - Avaliação do modelo ajustado

\begin{tabular}{|c|c|c|c|c|c|c|c|c|c|c|}
\hline \multicolumn{11}{|c|}{ Modelo Ajustado } \\
\hline \multicolumn{5}{|c|}{ Avaliação de aderência } & \multicolumn{6}{|c|}{ Análise da contribuição de BE e FCS para o uso } \\
\hline $\begin{array}{l}\text { Tipo de } \\
\text { variável }\end{array}$ & $\begin{array}{l}\text { Variável } \\
\text { Latente }\end{array}$ & $\mathbf{R}^{\mathbf{2}}$ & AVE & GoF & Caminho & $\begin{array}{l}\text { Coeficiente } \\
\text { Padronizado }\end{array}$ & $\mathbf{t}$ & Correlação & $\begin{array}{c}\text { Correlação } \\
\mathbf{X} \\
\text { Coeficiente }\end{array}$ & $\begin{array}{l}\text { Contribuição } \\
\text { do } R^{2} \text { na } \\
\text { amostra (\%) }\end{array}$ \\
\hline Endógena & Uso & 0,403 & 0,851 & 0,585 & $\mathrm{~N} / \mathrm{A}$ & \multicolumn{5}{|c|}{ N/A } \\
\hline \multirow{3}{*}{ Exógena } & BE & $\mathrm{N} / \mathrm{A}$ & 0,540 & N/A & $\mathrm{BE}=>$ Uso & 0,518 & 6,812 & 0,530 & 0,2745 & $68 \%$ \\
\hline & Tecnologia & N/A & 0,344 & N/A & Tecnologia=>Uso & 0,219 & 3,037 & 0,262 & 0,0574 & $14 \%$ \\
\hline & Organização & N/A & 0,733 & N/A & Organização=>Uso & 0,249 & 3,370 & 0,288 & 0,0717 & $18 \%$ \\
\hline
\end{tabular}

Fonte: Elaborado pelo autor

Pode-se perceber que o valor de GoF atende o critério mínimo proposto por Bido et al.(2010), que é de 0,5. Outro fator relevante é uma melhor distribuição na contribuição das variáveis exógenas para o $\mathrm{R}^{2}$, sendo ainda a participação da variável BE predominante.

O modelo ajustado foi considerado aceitável pois apresentou consistência diante dos testes de validação realizados, o que indica que os construtos propostos para avaliar o uso dos sistemas de BI são adequados para atender o objetivo de pesquisa. Embora a qualidade do modelo tenha sido satisfatória e tenha atendido os critérios de validação normalmente exigidos em análises PLS, com o objetivo de avaliar outras possibilidade para a avaliação do uso de sistemas de BI, foi testado um modelo alternativo baseado no modelo de decisão de compra do usuário de comércio eletrônico baseado em confiança de Kim et al.(2008).

\subsubsection{Modelo de pesquisa alternativo}

Kim et al. (2008) apresenta um modelo de tomada de decisão do consumidor baseado em confiança para aquisições via comércio eletrônico que relaciona beneficio percebido, risco percebido e confiança a intenção de consumo resultando na compra. Os construtos risco, confiança e intenção do modelo são impactados pela familiaridade do usuário com o sistema de comércio eletrônico, e o construto confiança também sofre influência do que foi chamado pelo 
autor de disposição do consumidor em confiar no sistema, como conceituado na figura 17. A equivalência de conceitos e o modelo alternativo proposto são apresentados na tabela 25 e na figura 20 respectivamente.

O modelo alternativo estabelece um paralelo com o modelo da figura 17, assumindo perspectiva organizacional do FCS como risco percebido, benefícios esperados como benefícios percebidos, intenção de uso da informação como intenção e aquisição, e usabilidade (QI) como confiança. O construto perspectiva tecnológica assume no modelo a variável familiaridade. A perspectiva organizacional, por envolver aspectos como gestão comprometida com a implantação de um SBI, aspecto esse apontado como crucial para o desenvolvimento do projeto, representa um grande risco para uma utilização satisfatória dos SBI, por isso foi considerada a variável de risco do modelo. A perspectiva tecnológica engloba aspectos técnicos como integração do SBI com outros aplicativos, infraestrutura, tecnologias e ferramentas. Apresenta, portanto proximidade com a variável familiaridade do modelo de Kim et al. (2008) que considera a facilidade de uso da tecnologia pelo consumidor. Usabilidade relaciona indicadores como credibilidade e reputação estabelecendo o conceito de confiança. Portanto, o modelo alternativo proposto, levando-se em consideração o modelo de Kim et al. (2008), é o representado na figura 28.

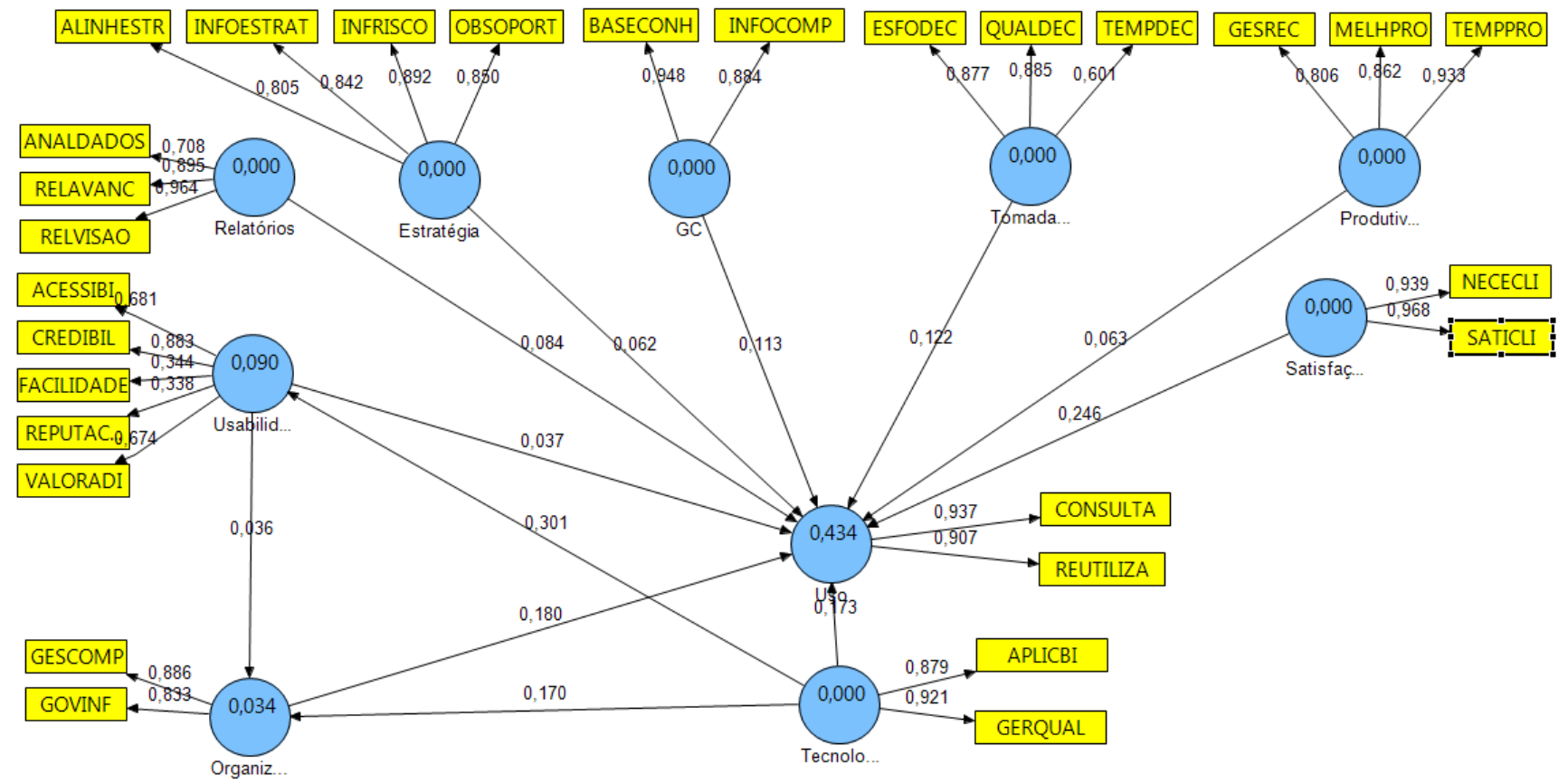

Figura 28 - Modelo de pesquisa alternativo baseado no modelo de Kim et al. (2008). Fonte: Elaborado pelo autor 
Porttanto, através das equivalências adotadas, temos: o construto organização (perspectiva organizacional - FCS), por representar o risco percebido, recebe influência do construto usabilidade (BE) que equivale a dimensão confiança (TRUST) do modelo de Kim et al. (2008). O construto tecnologia (perspectiva tecnológica - FCS) influencia a usabilidade, a organização e o uso pois equivale à dimensão familiaridade do modelo de Kim et al. (2008).

\subsubsection{Análise do modelo alternativo}

Para o modelo alternativo da figura 28 , obtivemos os valores dos scores fatoriais apresentados na apêndice VIII.

Tabela 47 - Estatística t dos indicadores das VL do modelo alternativo de pesquisa

Estatística t

\begin{tabular}{|c|c|}
\hline ACESSIBI <- Usabilidade & 4,6 \\
\hline ALINHESTR <- Estratégia & 14,9 \\
\hline ANALDADOS <- Relatórios & 4,7 \\
\hline APLICBI <- Tecnologia & 12,7 \\
\hline BASECONH $<-$ GC & 78,0 \\
\hline CONSULTA <- Uso & 32,7 \\
\hline CREDIBIL <- Usabilidade & 10,3 \\
\hline ESFODEC <- Tomada de decisão & 27,8 \\
\hline FACILIDADE <- Usabilidade & 1,4 \\
\hline GERQUAL <- Tecnologia & 13,8 \\
\hline GESCOMP <- Organização & 5,1 \\
\hline GESREC $<-$ Produtividade & 7,7 \\
\hline GOVINF <- Organização & 3,5 \\
\hline INFOCOMP <- GC & 25,3 \\
\hline INFOESTRAT <- Estratégia & 21,4 \\
\hline INFRISCO <- Estratégia & 54,4 \\
\hline MELHPRO <- Produtividade & 21,1 \\
\hline NECECLI <- Satisfação do cliente & 72,1 \\
\hline OBSOPORT <- Estratégia & 33,4 \\
\hline QUALDEC <- Tomada de decisão & 26,4 \\
\hline RELAVANC $<-$ Relatórios & 12,0 \\
\hline RELVISAO <- Relatórios & 15,6 \\
\hline REPUTACAO <- Usabilidade & 1,6 \\
\hline REUTILIZA <- Uso & 49,0 \\
\hline SATICLI <- Satisfação do cliente & 113,2 \\
\hline TEMPDEC <- Tomada de decisão & 4,8 \\
\hline TEMPPRO <- Produtividade & 18,8 \\
\hline VALORADI <- Usabilidade & 5,5 \\
\hline
\end{tabular}

Fonte: Elaborado pelo autor 
$\mathrm{Na}$ tabela 47 temos os valores de significância estatística obtidos para o modelo alternativo. O indicador FACILIDADE do construto usabilidade e o indicador Reputação também do construto usabilidade, apresentaram indicadores com estatística $\mathrm{t}<2,0$ não garantindo significância estatistica. Entretanto, os indicadores apresenta um nível de significância próximo de 2, podendo ser considerados no modelo.

Com relação a validade convergente, os valores de AVE são relacionados na tabela 48.

Tabela 48 - AVEs de cada variável do modelo alternativo
\begin{tabular}{|r|r|} 
Variáveis & AVE \\
Estratégia & 0,7187 \\
GC & 0,8401 \\
Organização & 0,7387 \\
Produtividade & 0,7544 \\
Relatórios & 0,7444 \\
Satisfação do cliente & 0,9095 \\
Tecnologia & 0,8112 \\
Tomada de decisão & 0,6380 \\
Usabilidade & 0,3859 \\
Uso & 0,8502 \\
\hline
\end{tabular}

Fonte: Elaborado pelo autor

Como podemos notar, no modelo alternativo, somente uma variável apresentou variância média extraída (AVE) abaixo de 0,5, a variável latente de primeira ordem USABILIDADE, não atendendo, a rigor, ao critério de validade convergente. Resultado semelhante foi apresentado pelo modelo ajustado.

Tabela 49 - Confiabilidade Composta do modelo alternativo

\begin{tabular}{|r|c|}
\multicolumn{1}{|c|}{ Variáveis } & Confiabilidade Composta \\
\hline Estratégia & 0,9108 \\
GC & 0,9130 \\
Organização & 0,8496 \\
Produtividade & 0,9018 \\
Relatórios & 0,8958 \\
Satisfação do cliente & 0,9526 \\
Tecnologia & 0,8957 \\
Tomada de decisão & 0,8372 \\
Usabilidade & 0,7351 \\
Uso & 0,9190 \\
\hline
\end{tabular}

Fonte: Elaborado pelo autor 
$\mathrm{Na}$ tabela 49 temos o resumo das confiabilidades compostas das variáveis. Os valores de confiabilidade composta satisfizeram o critério mínimo recomendado de 0,7.

Com relação a validade discriminante, é apresentada no apêndice IX a tabela com a análise da validade discriminante onde espera-se que os indicadores de cada variável tenham carga mais alta na sua respectiva variável latente do que em qualquer outra. Observando-se a tabela do apêndice IX, nota-se que os indicadores FACILIDADE e REPUTAÇÃO do construto Usabilidade apresentaram valores superior no construto Relatórios.

Tabela 50 - Correlação entre as VLs. Na diagonal principal o valor de $\sqrt{\text { AVE. }}$

\begin{tabular}{|c|c|c|c|c|c|c|c|c|c|c|}
\hline Variáveis Latentes & 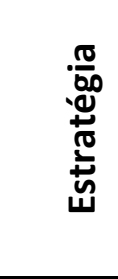 & U্ড & 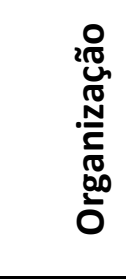 & 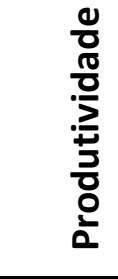 & $\begin{array}{l}\tilde{0} \\
\stackrel{0}{0} \\
\frac{0}{0} \\
\frac{\pi}{0} \\
\check{x}\end{array}$ & 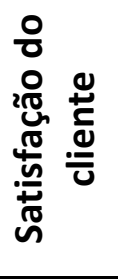 & 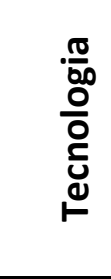 & 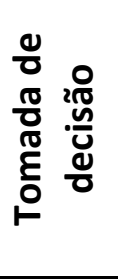 & $\begin{array}{l}\frac{0}{0} \\
\frac{\pi}{0} \\
\frac{0}{00} \\
\frac{0}{00} \\
0\end{array}$ & ڤ̊ \\
\hline Estratégia & 0,848 & 0 & 0 & 0 & 0 & 0 & 0 & 0 & 0 & 0 \\
\hline GC & 0,784 & 0,917 & 0 & 0 & 0 & 0 & 0 & 0 & 0 & 0 \\
\hline Organização & 0,076 & $-0,038$ & 0,859 & 0 & 0 & 0 & 0 & 0 & 0 & 0 \\
\hline Produtividade & 0,374 & 0,512 & $-0,048$ & 0,869 & 0 & 0 & 0 & 0 & 0 & 0 \\
\hline Relatórios & 0,395 & 0,504 & $-0,067$ & 0,833 & 0,863 & 0 & 0 & 0 & 0 & 0 \\
\hline Satisfação do cliente & 0,463 & 0,636 & 0,203 & 0,311 & 0,405 & 0,954 & 0 & 0 & 0 & 0 \\
\hline Tecnologia & $-0,063$ & 0,083 & 0,181 & $-0,121$ & $-0,122$ & 0,087 & 0,901 & 0 & 0 & 0 \\
\hline Tomada de decisão & 0,542 & 0,679 & 0,149 & 0,554 & 0,335 & 0,557 & 0,221 & 0,799 & 0 & 0 \\
\hline Usabilidade & 0,444 & 0,590 & 0,087 & 0,155 & 0,274 & 0,558 & 0,301 & 0,351 & 0,621 & 0 \\
\hline Uso & 0,406 & 0,504 & 0,274 & 0,334 & 0,335 & 0,540 & 0,253 & 0,510 & 0,412 & 0,922 \\
\hline
\end{tabular}

Fonte: Elaborado pelo autor

$\mathrm{Na}$ tabela 50 temos a matriz de correlação entre as VLs de primeira ordem. Na diagonal principal temos a $\sqrt{A V E}$ para cada variável latente. Para a existência de validade discriminante é necessário que os valores da $\sqrt{A V E}$ para cada variável latente seja maior do que as respectivas correlações com as demais variáveis latentes. Como se pode observar, o valor da $\sqrt{A V E}$ de cada variável latente é superior ao valor de correlação, confirmando a validade discriminante para as variáveis latentes de primeira ordem do modelo ajustado. 
Quanto ao teste do modelo estrutural, são apresentados na tabela do apêndice $\mathrm{X}$ os valores de GoF, $\mathrm{R}^{2}$, AVE e um resumo dos caminhos e suas respectivas siginificâncias. Também é apresentada a contribuição de cada variável exógena (Estratégia, GC, Organização, Produtividade, Relatórios, Satisfação do Cliente, Tecnologia, Tomada de Decisão e Usabilidade) para o $\mathrm{R}^{2}$ da variável endógena (Uso).

Podemos verificar que o valor de GoF atende o critério mínimo proposto por Bido et al.(2010), que é de 0,5 . Outro fator identificado é a contribuição predominante da variável exógenas Satisfação do Cliente no valor $\mathrm{R}^{2}$.

\subsubsection{Comentários sobre o modelo alternativo}

O modelo Alternativo pode ser considerado aceitável pois apresentou consistência diante dos testes de validação realizados, com alguma restrição para o construto Usabilidade. A qualidade do modelo foi satisfatória e atende razoavelmente os critérios de validação normalmente exigidos em análises PLS. O modelo alternativo foi fundamentado no modelo de decisão de compra do usuário de comércio eletrônico baseado em confiança de Kim et al.(2008). Esse resultado aponta indícios de que os sistemas de BI podem ser estudados como um sistema cujo uso está baseado na confiança do usuário na informação fornecida, i.e., que o uso das informações disponibilizadas pelos sistemas de BI, por parte do usuário, pode seguir uma estratégia semelhante à aquisição de produtos por meio eletrônico, baseando-se no aspecto confiança. 


\section{CONSIDERAÇÕES FINAIS}

\subsection{Sobre os resultados alcançados}

Dois dos modelos foram considerados aceitáveis (modelo ajustado e modelo alternativo) indicando que os construtos propostos para avaliar o uso dos sistemas de BI são adequados e possibilitam atender os objetivos de pesquisa. Entretanto, os resultados do modelo ajustado foram mais consistentes do que os obtidos no modelo alternativo, principalmente no que se refere aos scores fatoriais e as significâncias das relações entre construtos. Como se trata de um estudo exploratório, há a necessidade de mais estudos para uma melhor adequação dos construtos no modelo alternativo.

O construto gestão do conhecimento (GC) do modelo conceitual possui somente dois indicadores, o que pode afetar o critério de estabilidade do modelo PLS. Além disso, através da análise fatorial exploratória, identificou-se forte correlação dos indicados desse construto com outros construtos como VL estratégia empresarial. Assim, os indicadores do construto gestão do conhecimento podem ser mais indicados para outros construtos da dimensão BE.

Esse estudo teve como argumento inicial verificar a influência de fatores que pudessem esclarecer a questão da subutilização, apontada nas pesquisas realizadas pelo Gartner, de sistemas de BI. Uma importante contribuição desse trabalho foi a geração de um modelo para o estudo de sistemas de BI que o compara ao modelo de aquisição através da web, modelo esse que relaciona o comportamento de uso das informações disponibilizadas pelo sistema de BI com a confiança do usuário.

É necessário ponderar no modelo alternativo o construto usabilidade que se mostrou de pouca influência sobre o uso do sistema de BI, o que nos leva a considerar um novo conjunto de indicadores que reforcem o aspecto confiança gerado pela usabilidade do sistema. 


\subsection{Avaliação das hipótese}

As hipóteses definidas para o modelo conceitual foram:

Hipótese 1: A influência da dimensão BE sobre o USO;

Hipótese 2: A influência da dimensão FCS sobre o USO;

Hipótese 3: A influência da dimensão FCS sobre os BE.

Para o modelo ajustado, outras hipóteses foram formuladas:

Hipótese 1A: A influência da dimensão BE sobre o USO => confirmada, relação de influência significante;

Hipótese 2A: A influência da variável Tecnológica (FCS) sobre o USO => confirmada, relação de influência significativa;

Hipótese 3A: A influência da variável Organização (FCS) sobre o USO=> confirmada, relação de influência significativa.

Para o modelo alternativo, as hipóteses são:

Hipótese 1B: A influência da variável Satisfação sobre o USO => confirmada, relação de influência significante;

Hipótese 2B: A influência da variável Produtividade sobre o USO => rejeitada;

Hipótese 3B: A influência da variável Tomada de Decisão sobre o USO => confirmada;

Hipótese 4B; A influência da variável GC sobre o USO => confirmada;

Hipótese 5B: A influência da variável Estratégia sobre o USO $\Rightarrow>$ rejeitada;

Hipótese 6B: A influência da variável Relatórios sobre o USO => rejeitada;

Hipótese 7B: A influência da variável Usabilidade sobre o USO => rejeitada;

Hipótese 8B: A influência da variável Usabilidade sobre o Organizacional => rejeitada;

Hipótese 9B: A influência da variável Tecnológica sobre o USO => confirmada;

Hipótese 10B: A influência da variável Tecnológica sobre a Usabilidade => confirmada;

Hipótese 11B: A influência da variável Tecnológica sobre o Organizacional => confirmada; 
Com relação ao modelo ajustado, a dimensão FCS foi desmembrada em suas variáveis latentes de primeira ordem, e a hipótese das variáveis da dimensão FCS influenciar os BE foi removida. As hipótese 1A, 2A e 3A foram confirmadas. As hipóteses 1A, 2A e 3A associadas a variável latentes Uso foram comprovadas. Tanto as variáveis latentes de primeira ordem Perspectiva Organizacional e Perspectiva Tecnológica quanto a variável latente de segunda ordem BE apresentam coeficientes positivos em relação a variável latente Uso.

Com relação ao modelo alternativo, a dimensão BE foi desmembrada em suas variáveis latentes de primeira ordem e novos relacionamentos foram estabelecidos baseados na equivalência do modelo de Kim et al.(2008). A variável Usabilidade (BE) equivale à Confiança, a variável Tecnolóogica (FCS) equivale à Familiaridade, e a variável Organizacional equivale à Risco. Nesse modelo, as hipóteses 1B, 3B, 4B, 9B, 10B e 11B foram confirmadas. Algumas das variáveis latentes de primeira ordem da dimensão BE se mostraram não representativas, como Produtividade, Estratégia, Relatórios e Usabilidade.

A hipótese 9B, 10B e 11B associadas as variáveis latentes Usabilidade, Perspectiva Organizacional e Uso também foram comprovadas. A variável latente Perspectiva Tecnológica apresenta coeficiente de relação positivo em relação às variáveis latentes mencionadas confirmando as expectativas teóricas.

\subsection{Conclusões}

O tema central desse trabalho é estabelecer um modelo da relação entre fatores críticos e sucesso e benefícios esperados sobre o uso de sistemas de BI pelo usuário. Esse objetivo foi atingido uma vez que os modelos ajustado e alternativo propostos estabelecem essas relações e trazem à tona novas perspectivas para a intenção de uso dos sistemas de BI. A percepção de que o uso das informações fornecidas pelos sistemas de BI é influenciado entre outros fatores pela confiança (usabilidade) do usuário nas informações e no sistema podem ajudar a melhorar os resultados referentes à utilização desses sistemas. Do aspecto benefícios esperados para os sistemas de BI, todas as variáveis latentes são relevantes para o usuário na decisão pelo uso do sistema, que consistem nas variáveis referentes aos impactos individuais que correspondem às questões de melhoria de desempenho nas atividades profissionais, à usabilidade que corresponde às questões de acessibilidade, reputação, facilidade e credibilidade, características 
de confiança, além de gestão do conhecimento, estratégia empresarial e relatórios e análises. A usabilidade, que é uma das características de qualidade de informação, estabelece a confiança do usuário no sistema que influencia no uso, embora o resultado obtido no modelo alternativo não tenha sido satisfatório. Essa variável não se mostrou efetiva sobre o uso do sistema nem sobre a perspectiva tecnológica, que no modelo alternativo, corresponde ao risco percebido. Os fatores críticos de sucesso são representados no modelo pelas dimensões de perspectiva organização e perspectiva tecnológica por se tratarem de fatores críticos de sucesso pós implantação do sistema de BI. A perspectiva tecnológica atende as necessidades técnicas do sistema de BI, sua infraestrutura, integração com outros sistemas e o gerenciamento da qualidade das informações. Essas características são compatíveis com o conceito de familiaridade do modelo de Kim et al.(2008). A familiaridade do usuário com o uso da tecnologia ocorre seja porque o usuário já utilizou o sistema ou porque teve experiência com sistemas semelhantes. Obtivemos confirmação através do modelo da relação positiva da perspectiva tecnológica (familiaridade) sobre a usabilidade, uso e perspectiva tecnológica. Um aspecto citado como resultado de pesquisa como sendo critico para a implantação e uso dos sistemas de BI é a existência de um patrocinador para o projeto. O fator perspectiva organizacional tem como indicadores o comprometimento dos gestores com o sistema, a governança e a parceria entre TI e áreas de negócio, ou seja, foca nas questões de gestão do sistema.

Fatores relacionados aos benefícios esperados pelos usuários se mostraram mais relevantes do que os fatores relacionados com os aspectos tecnológicos e organizacionais (FCS). Na visão do usuário, que define o nível de utilização do sistema de BI, as características percebidas da informação entregue pelo sistema são os fatores que definem o Uso, ou seja, uma informação que propicie a melhoria na execução do trabalho (II), que tenha qualidade (QI), que gere a gestão do conhecimento, que possibilite a identificação de ameaças e oportunidades, e que tenha um formato flexível e amigável (relatórios). Aspectos tecnológicos, embora relevantes, pesam menos na decisão de uso da sistema de BI por parte do usuário. O mesmo ocorre com a administração do sistema (perspectiva organizacional).

Como aplicabilidade dos resultados, esse trabalho trouxe algumas contribuições para o entendimento de fatores que influenciam no uso dos sistemas de BI, possibilitando um posicionamento mais adequado pelos responsáveis pelo sistema, atentando-se aos aspectos estabelecidos na dimensão BE, que como mostrado, são mais relevantes do que os FCS. 


\subsection{Limitações e sugestões de pesquisa}

A busca de respostas para problemas de pesquisa é um processo cíclico, uma vez que não termina com a resposta obtida. Novos problemas são identificados com base no delineamento da pesquisa e das respostas encontradas. Essa é a razão pela qual no final de teses e dissertações, depois de feitas as conclusões, recomenda-se trabalhos futuros de investigação em razão do trabalho não abordar todas as possíveis discussões a respeito da temática proposta (RAUPP e BEUREN, 2003).

Esse trabalho trouxe algumas contribuições no entendimento de como ocorre a escolha, por parte do usuário, de adoção de um sistema de BI. A relação encontrada em sistemas de comércio eletrônico com o consumidor apresenta semelhanças com a adoção do sistema de BI pelo usuário. Fatores como risco percebido, benefícios percebidos, confiança e familiaridade influenciando o ato de aquisição por parte do consumidor apresentam paralelo com o modelo proposto inicialmente, tanto pelo aspecto tecnológico quando pelo aspecto operacional.

Os resultados obtidos nesse trabalho podem ser utilizados por organizações para melhorar o entendimento dos fatores que afetam a intenção de uso das informações fornecidas pelos sistemas de BI com a possível redução da subutilização do sistema. Além disso, a abordagem dos sistemas de BI como um sistema de "venda" de informação pode ser utilizada em futuras pesquisas estabelecendo uma nova maneira de se abordar a dinâmica de gestão dos sistemas de BI.

Outra sugestão é a realização de novos estudos focados na confiança dos usuários nas informações entregues pelos sistemas de BI a fim de melhor caracterizar essa variável e seus indicadores no contexto de um sistema que trata no nível estratégico de informações semiestruturadas, que nesse trabalho foi associada a variável Usabilidade, e que apresentou limitações nos testes realizados no modelo alternativo. 
ALAVI, M.; LEIDNER, D. E. Knowledge Management and Knowledge Management Systems: Conceptual Foundations and Research Issues. [S.1: s.n.]. Disponível em: <http://flora.insead.edu/fichiersti_wp/inseadwp1999/99-34.pdf>. Acesso em: 19 set. 2012.

ALAVI, M.; LEIDNER, D. E. Knowledge Management Systems: Issues, Challenges, and Benefits. Communications of the Association for Information Systems, Atlanta: [s.n.], v. 1, n. 2, p. 1-37, Feb. 1999.

AVEN, T. A conceptual framework for linking risk and the elements of the data-informationknowledge-wisdom (DIKW) hierarchy. Reliability Engineering \& System Safety, Amsterdam: [s.n.], v. 111, p. 30-36, Mar. 2013.

BARTHOLOMEW, D. J. Latent Variable Models and Factor Analysis. London: Griffin. 1987.

BATINI, C.; CAPPIELLO, C.; FRANCALANCI, C.; MAURINO, A. Methodologies for data quality assessment and improvement. ACM Computing Surveys (CSUR), [S.1.: s.n.]. v. 41, n. 3, p. 1-52, 2009.

BELlingER, G.; CASTRO, D.; MILLS, A. Data, information, knowledge, and wisdom. [S.l.: s.n.]. 2004. Disponível em: <www.systems-thinking.org/dikw/dikw.htm >. Acesso em: 21 set. 2013.

BIDO, D. D. S.; SILVA, D. DA; SOUZA, C. A. DE; GODOY, ARILDA, S. Mensuração com indicadores formativos nas pesquisas em administração de empresas: Como lidar com a multicolinearidade entre eles? Administração: Ensino e Pesquisa, Rio de Janeiro: [s.n.], p. 245-269, 2010.

BIDO, D. D. S.; GODOY, A. S.; ARAUJO, B. F. V. B. D.; LOUBACK, J. C. Articulação entre a aprendizagem individual, grupal e organizacional: um estudo no ambiente industrial. RAM. Revista de Administração Mackenzie, São Paulo: [s.n.], v.11, n.2, p. 68-95, 2010.

BOEHM, B.; BOSE, P. A Collaborative Spiral Software Process Model Based on Theory W. Reston, 1994. Disponível em:

<http://reference.kfupm.edu.sa/content/c/o/a_collaborative_spiral_software_process_125746.p df>. Acesso em: 24 set. 2012. doi: 10.1109/spcon.1994.344423.

Business Intelligence Ranked Top Technology Priority by CIOs for Fourth Year in a Row. Sidney, 2009. Disponível em: <https://www.gartner.com/it/page.jsp?id=888412>. Acesso em: 18 jul. 2012. 
BRUCKNER, R. M.; LIST, B.; SCHIEFER, J. Risk-Management for Data Warehouse Systems. In: THIRD INTERNATIONAL CONFERENCE, DAWAK 2001, 3., 2001, Munich. Proceedings... New York: Springer-Verlag, 2001. p. 219-220.

CARR, N. G. It Doesn't Matter. Harvard Business Review, Watertown: [s.n.], p. 1-17, May 2003.

CHANGCHIT, C.; JOSHI, K. D.; LEDERER, A. L. Process and reality in information systems benefit analysis. Information Systems J, [S.1.]: Wiley, v. 8, n. 2, p. 145-162, abr. 1998.

CHEE, T.; CHAN, L.-K.; CHUAH, M.-H. et al. Business intelligence systems: state-of-the-art review and contemporary applications. In: SYMPOSIUM ON PROGRESS IN INFORMATION \& COMMUNICATION TECHNOLOGY, 2009, Kuala Lumpur. Anais... Kuala Lumpur: [s.n.], 2009. p. 96-101. Disponível em: <http://spict.utar.edu.my/SPICT09CD/contents/pdf/SPICT09_A-5_1.pdf>. Acesso em: 24 jan. 2014.

CHENOWETH, T.; CORRAL, K.; DEMIRKAN, H. Seven key interventions for data warehouse success. Communications of the ACM, New York: ACM, v. 49, n. 1, p. 114-119, Jan. 2006.

CHIN, W. W. The partial least squares approach to structural equation modeling. In: G. A. Marcoulides (Ed.); Modern Methods for Business Research, Mahwah: [s.n.], v. 295, p.295336, 1998. Disponível em:<http://psycnet.apa.org/psycinfo/1998-07269-010>. Acesso em: 12 dez. 2013.

COOPER, L. CSFs, KPIs, Metrics, Outcomes and Benefits - Part I. DIRTY Weekly Reader, [S.1.: s.n.], v. 2, n. 40, 2006.

Disponivel em: <http://www.itsmsolutions.com/newsletters/DITYvol2iss40.htm>. Acesso em: 11 nov. 2013.

DANIEL, D. R. Management information crisis. Harvard Business Review, Watertown: [s.n.], v. 39, n. 5, p. 111-121, Sept./Oct. 1961.

DAVENPORT, Thomas H.; HARRIS, Jeanne G. Competição Analítica: vencendo através da nova ciência. Rio de Janeiro: Elsevier, 2007. 264 p.

DELONE, William H.; MCLEAN, Ephraim R. The DeLone and McLean model of information systems success: a ten-year update. Journal of Management Information Systems, Armonk: [s.n.], v. 19, n. 4, p. 9-30, 2003.

DEWEY, J. Logic: The Theory of Inquiry, 1938. The later works, New York: [s.n.], v. 12., p. $1-18,1996$. 
DRUCKER, P. F. The next information revolution. Forbes ASAP. 8/24/1998 ASAP, v. 162, n.4, p.46-58, 1998. Disponível em: http://web.b.ebscohost.com/ehost/delivery?sid=4d5f9f5deb21-475a-9160-0dc4425eeff6\%40sessionmgr111\&vid=3\&hid=125. Acesso em: 10 jan. 2014.

DUNCAN, O. D. Introduction to Structural Equations Models. New York. Academic Press, 1975.

GANGADHARAN, G. R.; SWAMI, N. S. Business intelligence systems: design and implementation strategies. In: INTERNATIONAL CONFERENCE INFORMATION TECHNOLOGY INTERFACES ITI, 26., 2004, [S.1.]. Paper... [S.1.], p. 139-144, 2004.

Gartner Reveals Five Business Intelligence Predictions for 2009 and Beyond. Egham, 2009. Disponível em: <http://www.gartner.com/newsroom/id/856714>. Acesso em: 18 jul. 2012.

Gartner Says Worldwide Business Intelligence, Analytics and Performance Management Software Market Surpassed the \$12 Billion Mark in 2011. Stamford, 2012. Disponível em: <https://www.gartner.com/newsroom/id/1971516?brand=1>. Acesso em: 18 jul. 2012.

GE, M.; HELFERT, M. A review of information quality research: develop a research agenda. In: INTERNATIONAL CONFERENCE ON INFORMATION QUALITY, 12., 2007, Cambridge. Proceedings... Cambridge, MA: [s.n.], 2007.

GIBSON, M.; ARNOTT, D.; JAGIELSKA, I.; MELBOURNE, A. Evaluating the intangible benefits of business intelligence: Review \& research agenda. In: 2004 IFIP INTERNATIONAL CONFERENCE ON DECISION SUPPORT SYSTEMS (DSS2004): DECISION SUPPORT IN AN UNCERTAIN AND COMPLEX WORLD, 2004, Prato. Proceedings... Prato: IFIP, 2004. p. 295-305.

GOH, A. L. S. Adoption of Customer Relationship Management (CRM) Solutions as an Effective Knowledge Management (KM) Tool: A Systems Value Diagnostic. Journal of Knowledge Management Practice, [S.1.: s.n.], v. 6, Feb. 2005.

GOLFARELLI, M.; RIZZI, S.; CELLA, I. Beyond data warehousing: what's next in business intelligence? In: ACM INTERNATIONAL WORKSHOP ON DATA WAREHOUSING AND OLAP, 7., 2004, Washington. Proceedings... Washington: ACM, 2004. p. 1-6.

GONSALVES, A. BI Still Hindered By Technical Problems. [S.1.: s.n.], 2009. Disponível em: $<$ http://www.informationweek.com/software/information-management/bi-still-hindered-bytechnical-problems/d/d-id/1085700>. Acesso em: 2 fev., 2014.

GORRY, G. A.; MORTON, M. S. S. A framework for management information systems. Sloan Management Review, [S.1.: s.n.], v. 13, n. 1, p. , 1971. 
GRAY, P. Business intelligence: A new name or the future of DSS. In: BUI, T.; SROKA, H.; STANEK, S.; GOLUCHOWSKI, J. (Eds.). DSS in the uncertainty of the Internet age. Katowice: University of Economics, 2003.

GREENE, F.; LOUGHRIDGE, B.; WILSON, T. The management information needs of academic heads of department in universities: A critical success factors approach. British Library, London: Research and Development Dept., v.1, n.3, p. 1-3, 1996.

GUINALÍU, M.; GURREA, R.; FLAVIÁN, C. The role played by perceived usability, satisfaction and consumer trust on website loyalty. Information e Management, Amsterdam: [s.n.], v. 43, n. 1, p. 1-14, Jan. 2006.

HAIR, Jr, J. F. ANDERSON, R. E.; TATHAM, R. L.; BLACK, W. C. Análise multivariada de dados. 6. ed. Porto Alegre: Bookman, 2009.

HANNULA, M.; PIRTTIMÄKI, V. Business intelligence empirical study on the top 50 Finnish companies. Journal of American Academy of Business, Cambridge: [s.n.], v. 2, n. 2, p. 593599, 2003.

HAWKING, P.; SELLITTO, C. Business Intelligence (BI) Critical Success Factors. In: AUSTRALASIAN CONFERENCE ON INFORMATION SYSTEMS, 21., 2010, Brisbane. Proceedings... Brisbane: [s.n.], 2010.

HIGUERA, R. P.; HAIMES, Y. Y. Software Risk Management. . Pittsburgh, Pennsylvania: [s.n.], 1996. Disponível em: <http://www.sei.cmu.edu/reports/96tr012.pdf>. Acesso em: 24 set. 2012.

IMPLEMENTATION OF Business Intelligence and Performance Tools and Solutions. Computerworld, [S.1.: s.n.], p. 1-12, Mar. 2007.

INTRODUCTION TO Business Intelligence \& Data Warehouse. Copenhagen, Denmark: Platon A/S, 2009. VÍDEO.

IRANI, Z.; LOVE, P. E. D. The propagation of technology management taxonomies for evaluating investments in information systems. Journal of Management Information Systems, Armonk: [s.n.], v. 17, n. 3, p. 161-177, 2001.

JAGIELSKA, I.; DARKE, P.; ZAGARI, G. Business Intelligence Systems for Decision Support: Concepts, Processes and Practice. In: $7^{\mathrm{TH}}$ INTERNATIONAL CONFERENCE OF THE INTERNATIONAL SOCIETY FOR DECISION SUPPORT SYSTEMS, 2003, Ustron. Proceedings... Ustron: [s.n.], July 2003. p. 215-228.

JOHNSON, R. A.; WICHERN, D. A. Applied Multivariate Statistical Analysis. 5th ed. New Jersey: Prentice Hall, 2002. 
JURISON, J. Software project management: the manager' $s$ view. Communications of the Association for Information Systems, [S.1.]: AISeL, v. 2, p. 1-57, Sept. 1999.

KAHN, B. K.; STRONG, D. M.; WANG, R. Y. Information quality benchmarks: product and service performance. Communications of the ACM, New York: ACM, v. 45, n. 4, p. 184-192, Apr. 2002.

KARADSHED, L. A. A framework for integrating knowledge management with risk management for information technology projects. Southfield: Lawrence Technological University, 2010.

KEY Issues for Business Intelligence and Performance Management Initiatives. Business. [S.l: s.n.], 2008.

KIM, D. J.; FERRIN, D. L.; RAO, H. R. A trust-based consumer decision-making model in electronic commerce: The role of trust, perceived risk, and their antecedents. Decision Support Systems, Amsterdam: [s.n.], v. 44, n. 2, p. 544-564, Jan. 2008.

KIM, E. B.; EOM, S. B. Designing effective cyber store user interface. Industrial Management + Data Systems, [S.1.]: MCB UP, v. 102, n. 5, p. 241-251, 2002.

KIM, Y. J.; KISHORE, R.; SANDERS, G. L. From DQ to EQ: understanding data quality in the context of e-business systems. Communications of the ACM, New York: ACM, v. 48, n. 10, p. 75-81, 2005.

KONTIO, JYRKI. The Riskit Method for Software Risk Management, version 1.00. [S.1: s.n.], $\quad 1997 . \quad$ Disponível em: <http://www.soberit.hut.fi/T-76.115/0203/palautukset/groups/pmoc/de/riskit.pdf>. Acesso em: 24 set. 2012.

LEIDECKER, J. K.; BRUNO, A. V. CSF Analysis and the Strategy Development Process. In: TAYLOR, B. (Ed.), Strategic Planning and Management Handbook, New York: Van Nostrand Reinhold, 1987. p. 333-351.

LIN, Y.; SU, H.-Y.; CHIEN, S. A Knowledge-enabled procedure for customer relationship management. Industrial Marketing Management, [S.1.]: Elsevier, v. 35, n. 4, p. 446-456, May 2006. Disponível em: <ftp://mail.im.tku.edu.tw/Prof_Shyur/Enterprise Information System/11080614474205703.pdf>. Acesso em: 15 jan. 2014.

LONGARAY, A. A.; RAUPP, F. M.; BEUREN, I. M.; DE SOUSA, M. A. B.; COLAUTO, R. e PORTON, R. D. B. Como elaborar trabalhos monográficos em contabilidade: teoria e prática. São Paulo: Atlas, 2003.

LÖNNQVIST, A.; PIRTTIMÄKI, V. The measurement of business intelligence. Information Systems Management, [S.1.: s.n.], v. 23, n. 1, p. 32-40, 2006. 
LUFTMAN, J.; BEN-ZVI, T. Key Issues for IT Executives 2011: Cautious Optimism in Uncertain Economic Times. Mis Quarterly Executive, Bloomington: [s.n.], v. 10, n. 4, p. 203$212,2011$.

LUFTMAN, J.; ZADEH, H. S.; DERKSEN, B.; SANTANA, M.; RIGONI, E. H.; HUANG, Z. (David). Key Information Technology and Management Issues 2012-2013: An International Study. Journal of Information Technology, Basingstoke: Palgrave Macmillan, v. 28, p. 354366, Dec. 2013. doi:10.1057/jit.2013.22.

MACCALlUM, R. C.; AUSTIN, J. T. Applications of structural equation modeling in psychological research. Annual Review of Psychology, Columbus, v. 51, p. 201-226, Feb. 2000. doi:10.1146/annurev.psych.51.1.201.

MACHADO-DA-SILVA, C. L.; FONSECA, V. S. Competitividade Organizacional: uma Tentativa de Reconstrução Analítica. Revista de Administração Contemporânea, [S.1.]: Spell, v. 14, [s.n.], p. 33-49, 2010.

MALIK, S. Enterprise Dashboards: design the best practices for IT. [S.1.]: John Wiley \& Sons, Inc., 2005. 240 p. ISBN: 978-0-471-73806-0.

MARAKAS, G. M. Decision Support Systems in the 21st Century. New Jersey: Prentice Hall, 1999. 528 p.

MARTINS, G. A. Manual para elaboração de monografias. São Paulo: Atlas, 1998.

MAY, L. J. Major Causes of Software Project Failures. [S.1.: s.n.], v. 11, n. 7, p. 9-12, 1998. Disponível em:

<http://paulhadrien.info/backup/LSE/IS470/literaturereview/MajorCausesofSoftwareProjectFai lures.pdf>. Acesso em: 20 set. 2012.

MOSS, T., L.; ATRE, S. Business Intelligence Roadmap: The Complete Project Lifecycle for Decision-Support Applications. 3rd ed. Boston: Addison -Wesley, 2004. 545 p. ISBN: 0201-78420-3.

MORTON, M. S. Corporation of the 1990s: Information Technology and Organizational Transformation. Oxford: Oxford University Press, 1991.

MURPHY, K. E.; SIMON, S. J. Intangible benefits valuation in ERP projects. Information Systems Journal, [S.1.]: John Wiley \& Sons, v. 12, n. 4, p. 301-320, Oct. 2002. DOI: 10.1046/j.1365-2575.2002.00131.x.

NEGASH, S. Business Intelligence. Communications of the Association for Information Systems, Kennesaw: [s.n.], v. 13, p. 177-195, 2004. 
NEGASH, S.; RYAN, T.; IGBARIA, M. Quality and effectiveness in web-based customer support systems. Information \& Management, Amsterdam: [s.n.], v. 40, n. 8, p. 757-768, Sept. 2003.

OLSZAK, C. M.; ZIEMBA, E. Business Intelligence as a Key to Management of an Enterprise. [S.1: s.n.], June 2003.

OLSZAK, C. M.; ZIEMBA, E. Approach to Building and Implementing Business Intelligence Systems. Interdisciplinary Journal of Information, Knowledge, and Management, Santa Rosa: Informing Science institute, v. 2, p. 135-148, 2007.

OTTO, B.; HÜNER, K. M.; ÖSTERLE, H. Identification of Business Oriented Data Quality Metrics. [S.l: s.n.]. MIT, 2009.

PARKER, M. M.; BENSON, R. J. Information Economics: Linking Business Performance to Information Technology. London: Prentice-Hall, v. 2, junho 1975. Disponível em: <http://www.jstor.org/discover/pgs/index?id=10.2307/2489044> Acesso em: 11 out. 2013.

PETER, J. P.; TARPEY, L. X. A Comparative Analysis of Three Consumer Decision Strategies. Journal of Consumer Research, [S.i.: s.n.], v. 2, n. 1, p. 29-37, 1975.

PINTO, S. A. O. Estruturas de gestão de informações para inteligência de negócio nas organizações eo impacto individual nas atividades. 2012. 280 p. Tese (Doutorado em Administração) - Faculdade de Economia, administração e Contabilidade, Universidade de São Paulo, São Paulo, 2012.

POWER, D. J. Supporting Decision-Makers: An Expanded Framework. In: 2001 INFORMING SCIENCE CONFERENCE, 2001, Krakow. Proceedings... Krakow: Cracow University of Economics, 2001. p. 431-436.

RANGANATHAN, C.; GANAPATHY, S. Key dimensions of business-to-consumer web sites. Information \& Management, Amsterdam, v. 39, n. 6, p. 457-465, May 2002.

RANJAN, J., Business Intelligence: concepts, components, techniques and benefits. Journal of Theoretical and Applied Information Technology, Islamabad, v. 9., n. 1, p. 60-70, Nov. 2009.

RAUPP, F. M.; BEUREN, I. M. Como elaborar trabalhos monográficos em contabilidade: teoria e prática. São Paulo: Atlas, 2003.

ROCKART, J. F., Chief executives define their own data needs. Harvard Business Review, Watertow: [s.n.], v.57, n.2, p.81-93, 1979. Disponível em: <http://europepmc.org/abstract/MED/10297607/reload=0;jsessionid=2tP6iBv4RKFyTD0U8K Ts.20>. Acesso em: 15 mar. 2014. 
SANTOS, G. D. Estudo empírico da relação entre qualidade da informação e impacto individual no contexto organizacional. [S.1.], Universidade de São Paulo, 2009.

SHARMAK, W.; SCHERER, R. J.; KATRANUSCHKOV, P. Configurable KnowledgeBased Risk Management Process Model Within the General Construction Project Process Model. [S.1: s.n.]. 2007. Disponível em: <http://itc.scix.net/data/works/att/w78-2007-046-123Sharmak.pdf>. Acesso em: 25 set. 2012.

SHIH, F. J. Triangulation in nursing research: issues of conceptual clarity and purpose. Journal of Advanced Nursing, [S.1.]. v. 28, n. 3, p. 631-41, Sept. 1998.

SIMON, H. A. Comportamento administrativo: estudo dos processos decisórios nas organizações administrativas. Rio de Janeiro: Fundação Getulio Vargas, 1970. 277 p.

STACKOWIAK, R.; RAYMAN, J.; GREENWALD, R. Oracle Data Warehousing and Business Intelligence Solutions. Indianapolis: Wiley Publishing, Inc, 2007.

STRONG, D. M.; LEE, Y. W.; WANG, R. Y. Data quality in context. New York: ACM Press, 1997. Disponível em: <http://portal.acm.org/citation.cfm?id=253769.253804>. Acesso em: 22 mar. 2013.

TALLON, P.; KRAEMER, K. L.; GURBAXANI, V. Executives' Perceptions of the Business Value of Information Technology: A Process-Oriented Approach. Irvine: [s.n.], 2001.

PEREIRA, M. T. F.; BECKER, J. L.; LUNARDI, G. L. Relação entre Processo de Trabalho e Processo Decisório Individuais : uma análise a partir do Impacto da Tecnologia da Informação. RAC Eletrônica, Rio de Janeiro, v. 1, n. 1, p. 151-166, 2007.

TVRDIKOVA, M. Support of decision making by business intelligence tools. In: 6TH INTERNATIONAL CONFERENCE ON COMPUTER INFORMATION SYSTEMS AND INDUSTRIAL MANAGEMENT APPLICATIONS, 2007, Minneapolis. Proceedings... Minneapolis: IEEE, 2007. p. 364-368. doi: 10.1109/CISIM.2007.64.

VITT, E.; LUCKEVICH, M.; MISNER, S., Business Intelligence: Making Better Decisions Faster. Washington: Microsoft Press, 2002. 202 p.

VODAPALLI, T. Critical Success Factors of BI Implementation. Copenhagen: IT University of Copenhagen. 2009.

WANG, R. Y.; STRONG, D. M. Beyond Accuracy: What Data Quality Means to Data Consumers. Journal of Management Information Systems, [S.1.: s.n.], v. 12, n. 4, p. 5-34, 1996. 
WIJNBERG, N. M.; VAN DEN ENDE, J.; WIT, O. DE. Decision Making at Different Levels of the Organization and the Impact of New Information Technology: Two Cases from the Financial Sector. Group Organization Management, [S.1.: s.n.], v. 27, n. 3, p. 408-429, Sept. 2002. doi:10.1177/1059601102027003005

WILKIE, W.; PESSEMIER, E. Issues in Marketing's Use of Multi-Attribute Attitude Models. Journal of Marketing Research, Chicago, v. 10, n. 4, p. 428-441, 1973. doi: 10.2307/314939.

WIXOM, B.; WATSON, H. An empirical investigation of the factors affecting data warehousing success. MIS Quarterly, Minneapolis: [s.n.], v. 25, n. 1, p. 17-41, 2001.

YEOH, W.; KORONIOS, A.; GAO, J. Managing the Implementation of Business Intelligence Systems: A Critical Success Factors Framework. International Journal of Enterprise Information Systems, Hershey: [s.n.], v. 4, n. 3, p. 79-94, 2008.

YEOH, W.; KORONIOS, A. Critical Success Factors For Business Intelligence Systems. Journal of Computer Information Systems, Leesburg: [s.n.], v. 50, n. 3, p. 23-32, 2010.

YIN, R. K. Case Study Research: Design and Methods. Thousand Oaks: Sage Publications, 2003. $181 \mathrm{p}$.

ZENG, L.; XU, L.; SHI, Z. Techniques, process, and enterprise solutions of business intelligence. In: INTERNATIONAL CONFERENCE ON SYSTEMS, MAN AND CYBERNETICS, 6., 2006, Taipei. Anais... Taipei: IEEE, 2006. p. 4722-4726. Disponível em: <http://ieeexplore.ieee.org/xpls/abs_all.jsp?arnumber=4274659>. Acesso em: 4 nov. 2013. doi: 10.1109/ICSMC.2006.385050.

ZHU, H.; WANG, R. Y. An Information Quality Framework for Verifiable Intelligence Products. In: CHAN, Y; TALLEY, T. M. M.(Eds.). Data Engineering: International series in Operations Research \& Management Science. Cambridge: Springer, v. 132, p. 315-333, 2010 .

ZWICKER, R.; SOUZA, C. A.; BIDO, D. S. Uma revisão do modelo do grau de informatização de empresas: novas propostas de estimação e modelagem usando PLS (partial least squares). In: XXXII ENCONTRO DA ANPAD, 32., 2008, Rio de Janeiro. Proceedings... Rio de Janeiro:[s.n.], 2008. p. 1-16. 


\section{APÊNDICE}

\subsection{Apêndice I - Questionário}

\section{Questionário}

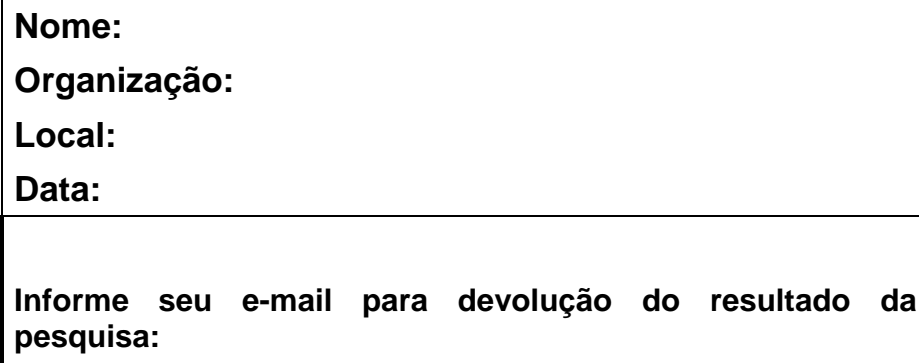

Etapa 1: Informações gerais (conte-me um pouco sobre você)

1. Em que indústria você trabalha?

$\square$ Telecom

$\square$ Banco

$\square$ Serviços de TI

$\square$ Setor Público

$\square$ Varejo

Indústria

$\square$ Outros Especifique:

2. Número de empregados de sua organização?

1-10 funcionários

11-25 funcionários

25-100 funcionários

$\square$ Mais que 100 funcionários

3. Qual é a sua posição atual nessa organização?

4. Faz quantos anos que está na indústria? 
5. Qual a sua área de atuação na empresa?

\begin{abstract}
Etapa 2: Essa etapa tem por finalidade capturar dos respondentes suas experiências com sistemas de BI através da leitura das características técnicas e de gestão do(s) sistema(s) com $o$ (s) qual(is) tiveram contato no ambiente de trabalho.
\end{abstract}

Qual o nível atribuído por você para os diferentes aspectos citados nas questões a seguir com relação a sua experiência com sistemas de Bl.

Fatores críticos de sucesso (FCS):

Por favor, classifique as seguintes perspectivas sobre o sistema de BI utilizado em sua área de negócio na empresa adotando a escala abaixo:

1. Discordo totalmente; 2. Discordo; 3. Sou Indiferente; 4. Concordo;

5. Concordo totalmente.

a. Perspectiva da organização

1. Existe parceria entre a comunidade de negócio \& TI

2. Existe comprometimento dos gestores e executivos com o suporte e patrocínio

3. Existe área de governança da informação através do centro de competência de BI (BICC)

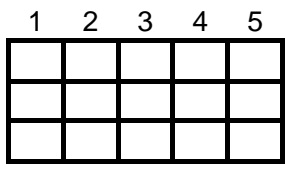

b. Perspectiva tecnológica

1. O sistema é robusto e escalável

2. O sistema fornece informação adequada a necessidade da área

3. A tecnologia utilizada no sistema é fácil de usar e possui os recursos necessários

4. O sistema de $\mathrm{Bl}$ está integrado aos dados de origens de diferentes sistemas

5. O sistema apresenta bom desempenho nas diferentes consultas de dados

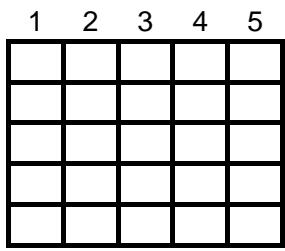

Intenção de uso das informações (USO):

Por favor, classifique as seguintes perspectivas sobre o sistema de BI utilizado em sua área de negócio na empresa adotando a escala abaixo:

1. Discordo totalmente; 2. Discordo; 3. Sou Indiferente; 4. Concordo;

5. Concordo totalmente.

a. Intenção de uso

1. Existe a intenção de consultar as informações do sistema de BI

2. Você recomenda o uso do sistema de BI para outros usuários

3. Você reutilizará o sistema de BI sempre que tiver necessidade por nova informação

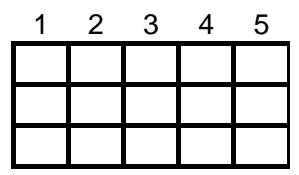


Benefícios esperados para os sistemas de BI

Por favor, classifique as seguintes perspectivas sobre o sistema de BI utilizado em sua área de negócio na empresa adotando a escala abaixo:

1. Discordo totalmente; 2. Discordo; 3. Sou Indiferente; 4. Concordo;

5. Concordo totalmente.

a. Tomada de decisão

1. A informação disponível possibilita melhoria na qualidade de suas decisões

2. O uso da informação reduz o tempo médio para tomada de decisão

3. O uso da informação reduz o esforço para a tomada de decisão

b. Produtividade

1. O uso da informação ajuda a economizar tempo na execução de suas atividades

2. O uso da informação permite melhorar sua produtividade

3. O uso da informação permite a gestão de recursos da empresa

c. Satisfação do cliente

1. O uso da informação ajuda a melhorar o serviço aos clientes (internos e externos)

2. O uso da informação promove a satisfação dos clientes que você atende

3. O uso da informação facilita o atendimento das necessidades dos clientes (internos e externos)

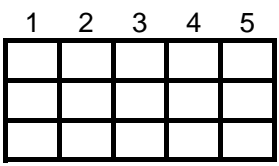

c. Usabilidade

1. A informação é considerada verdadeira e confiável

2. A informação está disponível, ou sua recuperação é fácil e rápida

3. A informação é facilmente manipulada e pode ser usada em diferentes tarefas

4. A informação é valorizada de acordo com sua fonte ou conteúdo

5. A informação gera benefícios e vantagens quando utilizada

c. Relatórios e análises

1. Os relatórios do BI fornecem uma visão unificada das informações do negócio

2. O BI promove e facilita a análise dos dados

3. Os relatórios de BI permitem análises avançadas (analytics, Ad-hoc, predições)

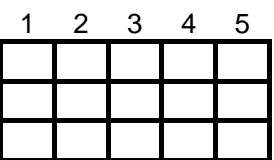

c. Gestão do conhecimento

1. O uso do $\mathrm{Bl}$ aumentou o compartilhamento das informações da empresa

2. Com o uso do Bl cresceu a base de conhecimento da companhia

c. Eficiência e mercado

1. O BI facilitou na identificação de ameaças e oportunidades ao negócio

2. A adoção do BI otimizou o uso dos recursos dirigido a estratégia adotada

3. A informação disponibilizada é útil nas decisões estratégicas

4. A informação permite avaliar melhor os riscos do ambiente de negócio
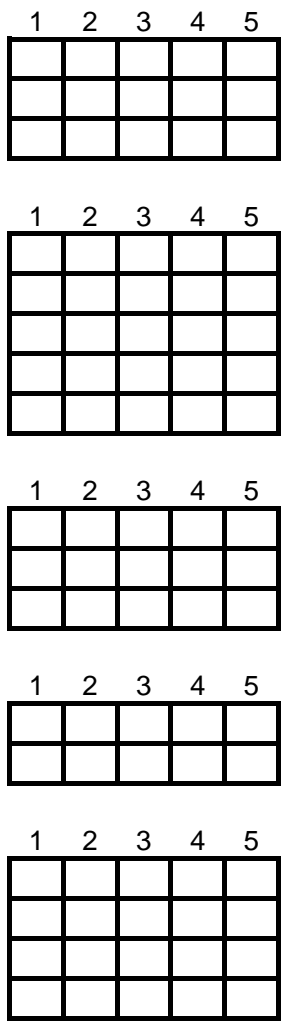
9.2 Apêndice II - Cargas fatoriais do modelo conceitual

\begin{tabular}{|c|c|c|c|}
\hline & VL & Indicador & \\
\hline \multirow{23}{*}{$\begin{array}{l}\text { Benefícios } \\
\text { Esperados } \\
\text { (BE) }\end{array}$} & \multirow[t]{9}{*}{ II } & ESFODEC & 0,800 \\
\hline & & GESREC & 0,783 \\
\hline & & MELHPRO & 0,888 \\
\hline & & NECECLI & 0,926 \\
\hline & & QUALDEC & 0,878 \\
\hline & & SATICLI & 0,960 \\
\hline & & SERVCLI & 0,939 \\
\hline & & TEMPDEC & 0,697 \\
\hline & & TEMPPRO & 0,921 \\
\hline & \multirow[t]{4}{*}{ Estratégia } & ALINHESTR & 0,844 \\
\hline & & INFOESTRAT & 0,856 \\
\hline & & INFRISCO & 0,856 \\
\hline & & OBSOPORT & 0,840 \\
\hline & \multirow[t]{5}{*}{ Usabilidade } & ACESSIBI & 0,726 \\
\hline & & CREDIBIL & 0,764 \\
\hline & & FACILIDADE & 0,709 \\
\hline & & REPUTACAO & 0,551 \\
\hline & & VALORADI & 0,429 \\
\hline & \multirow[t]{2}{*}{ Conhecimento } & BASECONH & 0,919 \\
\hline & & INFOCOMP & 0,919 \\
\hline & \multirow[t]{3}{*}{ Relatórios } & ANALDADOS & 0,843 \\
\hline & & RELAVANC & 0,888 \\
\hline & & RELVISAO & 0,932 \\
\hline \multirow{11}{*}{$\begin{array}{l}\text { Fatores } \\
\text { Críticos de } \\
\text { Sucesso } \\
\text { (FCS) }\end{array}$} & \multirow[t]{5}{*}{ Tecnologia } & APLICBI & 0,634 \\
\hline & & CONDESEMP & 0,845 \\
\hline & & ESTRUT & 0,709 \\
\hline & & GERQUAL & 0,595 \\
\hline & & TECFERR & 0,765 \\
\hline & \multirow[t]{3}{*}{ Organização } & GESCOMP & 0,796 \\
\hline & & GOVINF & 0,611 \\
\hline & & PARCEIRA & 0,737 \\
\hline & \multirow[t]{3}{*}{ Uso } & CONSULTA & 0,937 \\
\hline & & RECOMENDA & 0,779 \\
\hline & & REUTILIZA & 0,843 \\
\hline
\end{tabular}




\subsection{Apêndice III - Análise de Multicolinearidade do modelo conceitual}

\section{$\underline{\text { Análise de Colinearidade }}$}

\section{Análise dos Dados}

O código abaixo faz com que os dados para análise sejam carregados na variável RawDT e os nomes das variáveis utilizadas exibidas.

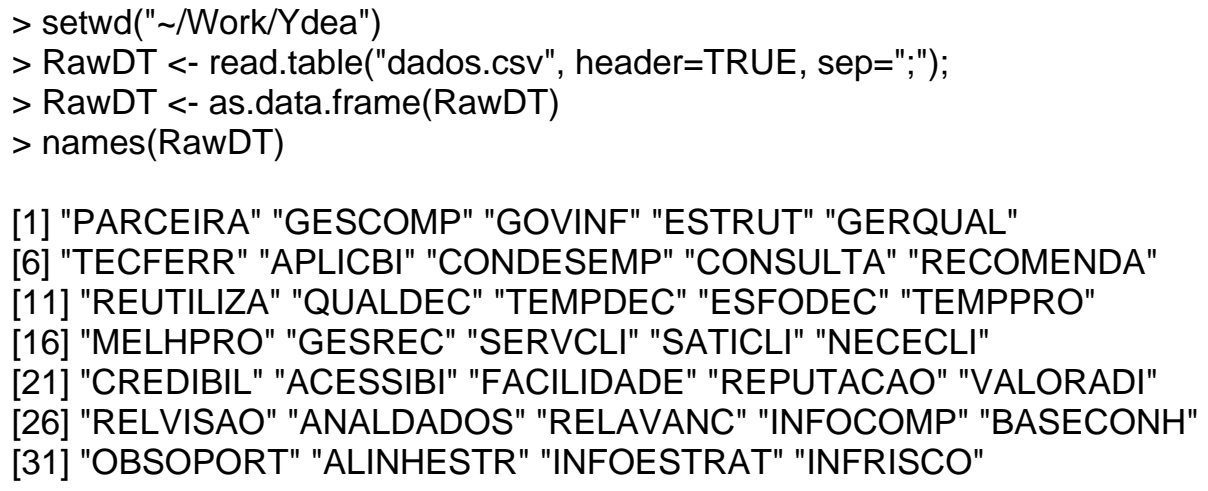

O objetivo agora é verificar se eles apresentam multicolinearidade e, para isso, aplicaremos três diagnósticos a esse conjunto de dados.

\subsection{Análise de Correlação}

Numa primeira etapa, verificou-se apenas a correlação entre as variáveis. Embora seja uma análise mais simples, pois ela só é capaz de identificar dependência linear entre pares de observaçõess, decidiu-se por mantê-la aqui, pois revela que apenas dois pares de variáveis são fortemente correlacionadas (positivamente). Mesmo assim, a correlação entre estes pares é inferior a 90\%, o que nos leva a crer que, em pares, as variáveis não são linearmente dependentes. O código abaixo identifica os pares de variáveis do modelo com correlação superior a $80 \%$.

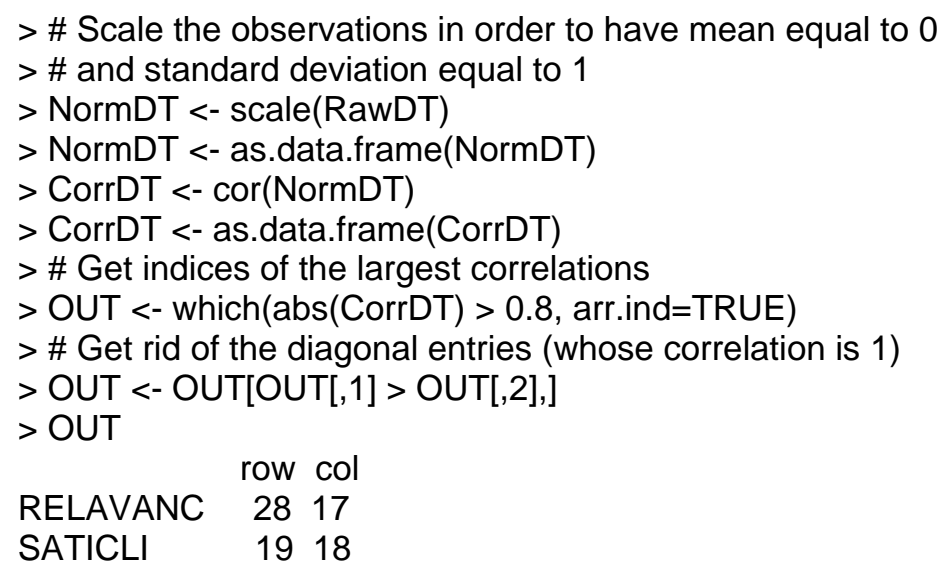

$>\operatorname{names}($ NormDT) $[\mathrm{c}(18,19)]$

[1] "SERVCLI" "SATICLI"

$>\operatorname{cor}($ NormDT[,18] ,NormDT[,19]) 
[1] 0.8997614

$>\operatorname{names}($ NormDT) $[\mathrm{c}(17,28)]$

[1] "GESREC" "RELAVANC"

$>\operatorname{cor}($ NormDT[,17],NormDT[,28])

[1] 0.8380982

Conforme antecipado no início dessa seção, o resultado acima indica que os pares de variáveis SERVCLI e SATICLI, e GESREC e RELAVANC são altamente correlacionados com valores iguais a 0,8998 e 0,8381 , respectivamente.

\subsection{Fator de Inflação da Variância - VIF}

Definindo-se $\mathrm{C}=\left(\mathrm{X}^{\prime} \mathrm{X}\right)^{-1}$, onde $\mathrm{X}$ representa a matriz de observações, tem-se que os elementos da diagonal, Cjj são iguais a $\left(1-R^{2} j\right)^{-1}$, onde $R^{2} \mathrm{j}$ é o coeficiente de determinação obtido quando a j-ésima variável, xj, é regredida contra as demais. Sabe-se que se xj é (quase) ortogonal às demais variáveis, então CJJ deve ser aproximadamente igual a 1 , pois $\mathrm{R}^{2} \mathrm{j}$ deve ser próximo de zero. Sendo assim, define-se o Fator de Inaflação da Variância, ou VIF, como

$$
\operatorname{VIFj} \equiv\left(1-R^{2} j\right)^{-1}
$$

$>$ NVAR $<-$ ncol(NormDT)

$>$ NOBS $<-\operatorname{nrow}($ NormDT)

$>$ VIFMTRX <- data.frame (matrix (0,nrow=NVAR,ncol=2))

$>$ names(VIFMTRX) <- c("Variable","VIF")

$>$ for(IDX in 1:NVAR)\{

+ YTMP $<-$ NormDT[,IDX]

+ XTMP <- as.data.frame(NormDT[,-c(IDX)])

$+\mathrm{VIF}<-\operatorname{Im}(\mathrm{YTMP} \sim$., data $=\mathrm{XTMP})$

+ VIF $<-$ step (VIF, trace $=0)$

+ VIFSUMM <- summary(VIF)

+ VIF.R2 <- VIFSUMM\$r.squared

+ VIFMTRX[IDX,1]<- names(NormDT)[IDX]

+ VIFMTRX[IDX,2] $<-1 /(1-$ VIF.R2)

$+\}$

$>$ VIFMTRX

\begin{tabular}{lc}
\multicolumn{1}{c}{ Variable } & VIF \\
1 PARCEIRA & 2.862152 \\
2 GESCOMP & 3.779059 \\
3 GOVINF & 5.198533 \\
4 ESTRUT & 5.475684 \\
5 GERQUAL & 3.236694 \\
6 TECFERR & 3.257209 \\
7 APLICBI & 3.682668 \\
8 CONDESEMP & 4.811625 \\
9 CONSULTA & 8.959191 \\
10 RECOMENDA & 77.563255 \\
11 REUTILIZA & 24.470676 \\
12 QUALDEC & 32.813193 \\
13 TEMPDEC & 17.430926 \\
14 ESFODEC & 32.237159 \\
15 TEMPPRO & 25.279016 \\
16 MELHPRO & 27.725111 \\
17 GESREC & 24.914081
\end{tabular}




$\begin{array}{ll}\text { 18 SERVCLI } & 57.600130 \\ \text { 19 SATICLI } & 50.466885 \\ \text { 20 NECECLI } & 15.549325 \\ \text { 21 CREDIBIL } & 12.573041 \\ \text { 22 ACESSIBI } & 7.262299 \\ \text { 23 FACILIDADE } & 5.046999 \\ \text { 24 REPUTACAO } & 4.938875 \\ \text { 25 VALORADI } & 4.530428 \\ \text { 26 RELVISAO } & 13.075350 \\ \text { 27 ANALDADOS } & 9.182927 \\ \text { 28 RELAVANC } & 37.459960 \\ \text { 29 INFOCOMP } & 28.206081 \\ \text { 30 BASECONH } & 36.265315 \\ \text { 31 OBSOPORT } & 49.553078 \\ \text { 32 ALINHESTR } & 13.067687 \\ \text { 33 INFOESTRAT } & 18.326272 \\ \text { 34 INFRISCO } & 11.395033\end{array}$

Na prática, a experiência diz que a presença de valores de VIF muito superiores a 10 indica que as variáveis do modelo são excessivamente dependentes e que, portanto, o efeito de multicolinearidade é significativo.

\subsection{Análise de Autovalores}

Colineariedade significa tambéem que a matriz $X^{\prime} X$ é singular. Portanto, um outro modo de se checar se as variáaveis do modelo são linearmente dependentes é considerando-se os autovalores de $X^{\prime} X$.

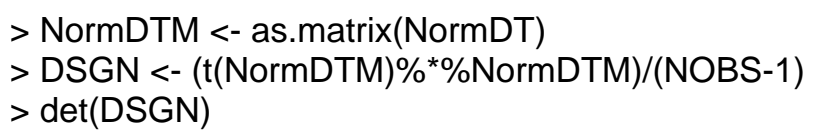

[1] $6.225001 \mathrm{e}-21$

$>$ XEIGEN <- eigen(DSGN)\$values

$>$ XEIGEN

[1] 9.6683326414 .4044833783 .6249484652 .8955991421 .8786268701 .743424809

[7] 1.6347054971 .1544403050 .9596776460 .8798537600 .7667606230 .674366255

[13] 0.5097505860 .4308089370 .3722638790 .3501703040 .3418609070 .279603001

[19] 0.2615836770 .2291289840 .1862986440 .1654252130 .1321418310 .107512278

[25] 0.0802815870 .0707243850 .0516581220 .0458344730 .0374854230 .020239554

[31] 0.0180958000 .0114206240 .0084642330 .004028166

$>$ CONDN $<-\max (X E I G E N) / \min (X E I G E N)$

$>$ CONDN

[1] 2400.182

$>$ CONDV $<-\operatorname{rep}(0, N V A R)$

$>$ for(IDX in 1:NVAR)\{

+ CONDV[IDX] <- $\max ($ XEIGEN)/XEIGEN[IDX]

+ +

$>$ CONDV

[1] 1.0000002 .1951122 .6671643 .3389755 .1464895 .545598

[7] 5.9144198 .37490910 .07456310 .98856812 .60932314 .336916

[13] 18.96679122 .44227525 .97171827 .61037328 .28148134 .578787

[19] 36.96076442 .19602651 .89695758 .44533973 .16632989 .927707 
[25] 120.430263136 .704371187 .159972210 .940193257 .922463477 .694948

[31] 534.285988846 .5678081142 .2573452400 .182280

$\mathrm{O}$ determinante igual a 6,22e-21 indica que a matriz de planejamento $\mathrm{X}$ ' $\mathrm{X}$ é essencialmente singular o que reforça a ideia de que há forte multicolineariedade nos dados. Mais ainda, o "valor característico" de X'X definido por

$$
\mathrm{k}=\frac{\lambda \max }{\lambda \min }
$$

onde $\lambda$ representa um autovalor de $X^{\prime} X$, é igual a 2.400. Normalmente, valores acima de 1.000 são considerados como uma indicacação severa de multicolineariedade. $O$ vetor de valores característicos possui dois termos maiores do que 1.000 e um igual a 846 , indicando a presença de duas ou três dependências lineares entre as variáveis do modelo.

Analisando os valores de VIF, chega-se à conclusão de que os dois candidatos mais prováveis de estar causando multicolineariedade são SERVCLI e RECOMENDA. Abaixo, estão o resultados das análises de regressão linear para ambas as variáveis.

\section{SERVCLI}

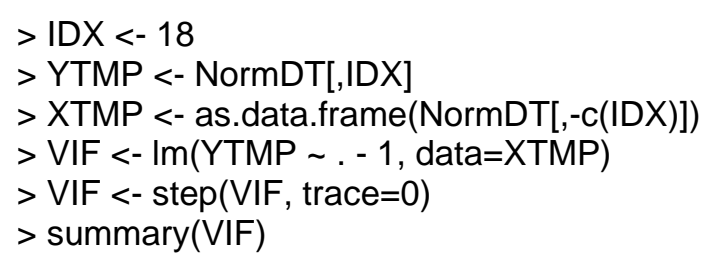

Call:

Im (formula $=$ YTMP $\sim$ PARCEIRA + GESCOMP + GOVINF + TECFERR + CONDESEMP +

RECOMENDA + REUTILIZA + QUALDEC + TEMPDEC + TEMPPRO + MELHPRO +

GESREC + SATICLI + CREDIBIL + ACESSIBI + FACILIDADE + REPUTACAO +

ANALDADOS + INFOCOMP + BASECONH + OBSOPORT + INFOESTRAT +

INFRISCO -1 , data $=$ XTMP)

Residuals:

Min 1Q Median 3Q Max

$-0.36514-0.081840 .018940 .055520 .35776$

Coefficients:

$\begin{array}{lrlcl} & \text { Estimate } & \text { Std. Error } & \mathrm{t} \text { value } & \operatorname{Pr}(>|\mathrm{t}|) \\ \text { PARCEIRA } & -0.05225 & 0.02096 & -2.493 & 0.014442^{*} \\ \text { GESCOMP } & -0.03553 & 0.02410 & -1.474 & 0.143798 \\ \text { GOVINF } & 0.06862 & 0.02559 & 2.681 & 0.008699^{* *} \\ \text { TECFERR } & -0.05292 & 0.02233 & -2.370 & 0.019872^{*} \\ \text { CONDESEMP } & 0.12392 & 0.02119 & 5.849 & 7.50 \mathrm{e}-08^{* * *} \\ \text { RECOMENDA } & 0.44231 & 0.04183 & 10.575 & <2 \mathrm{e}-16^{* * *} \\ \text { REUTILIZA } & -0.13919 & 0.03973 & -3.504 & 0.000710^{* * *} \\ \text { QUALDEC } & 0.16141 & 0.03394 & 4.756 & 7.29 \mathrm{e}-06^{* * *} \\ \text { TEMPDEC } & -0.32431 & 0.03003 & -10.798 & <2 \mathrm{e}-16^{* * *} \\ \text { TEMPPRO } & -0.11150 & 0.04979 & -2.239 & 0.027536^{*} \\ \text { MELHPRO } & 0.19292 & 0.04750 & 4.061 & 0.000103^{* * *} \\ \text { GESREC } & 0.15870 & 0.03999 & 3.968 & 0.000143^{* * *} \\ \text { SATICLI } & 0.73542 & 0.03656 & 20.114 & <2 \mathrm{e}-16^{* * *} \\ \text { CREDIBIL } & -0.11861 & 0.02981 & -3.978 & 0.000138^{* * *} \\ \text { ACESSIBI } & 0.06912 & 0.02548 & 2.713 & 0.007956^{* *}\end{array}$




$\begin{array}{lrrrl}\text { FACILIDADE } & -0.14631 & 0.02228 & -6.566 & 3.02 \mathrm{e}-09^{* * *} \\ \text { REPUTACAO } & 0.10639 & 0.02030 & 5.240 & 1.01 \mathrm{e}-06^{* * *} \\ \text { ANALDADOS } & 0.12207 & 0.02982 & 4.094 & 9.11 \mathrm{e}-05^{* * *} \\ \text { INFOCOMP } & 0.29638 & 0.04601 & 6.442 & 5.30 \mathrm{e}-09^{* * *} \\ \text { BASECONH } & -0.28174 & 0.05394 & -5.223 & 1.09 \mathrm{e}-06^{* * *} \\ \text { OBSOPORT } & -0.21850 & 0.06372 & -3.429 & 0.000908^{* * *} \\ \text { INFOESTRAT } & 0.10217 & 0.03882 & 2.632 & 0.009948^{* *} \\ \text { INFRISCO } & -0.05071 & 0.03534 & -1.435 & 0.154669\end{array}$

Signif. codes: $0{ }^{\prime * * * 1} 0.001^{* * * 1} 0.01^{* * 1} 0.05$ '.' $0.1^{\prime \prime} 1$

Residual standard error: 0.1467 on 92 degrees of freedom Multiple R-squared: 0.9826, Adjusted R-squared: 0.9783

F-statistic: 226.4 on 23 and 92 DF, p-value: $<2.2 \mathrm{e}-16$

\section{RECOMENDA}

$>$ IDX $<-10$

$>$ YTMP $<-$ NormDT[,IDX]

$>$ XTMP <- as.data.frame(NormDT[,-c(IDX)])

$>$ VIF $<-\operatorname{Im}($ YTMP . - 1, data $=X T M P)$

$>\mathrm{VIF}<-$ step $(\mathrm{VIF}$, trace $=0)$

$>$ summary $(\mathrm{VIF})$

Call:

Im (formula $=$ YTMP $\sim$ PARCEIRA + ESTRUT + GERQUAL + APLICBI + CONDESEMP + CONSULTA + REUTILIZA + QUALDEC + TEMPDEC + ESFODEC + TEMPPRO +

MELHPRO + SERVCLI + SATICLI + NECECLI + CREDIBIL + FACILIDADE +

REPUTACAO + VALORADI + ANALDADOS + RELAVANC + INFOCOMP +

BASECONH + OBSOPORT + ALINHESTR + INFOESTRAT -1 , data = XTMP)

Residuals:

Min 1Q Median 3Q Max

$-0.28994-0.06577-0.000420 .068300 .34324$

Coefficients:

$\begin{array}{lrlcl} & \text { Estimate } & \text { Std. Error } & \text { t value } & \operatorname{Pr}(>|\mathrm{t}|) \\ \text { PARCEIRA } & 0.05451 & 0.01901 & 2.867 & 0.005174^{* *} \\ \text { ESTRUT } & 0.08437 & 0.02180 & 3.871 & 0.000206^{* * *} \\ \text { GERQUAL } & -0.02957 & 0.02034 & -1.454 & 0.149490 \\ \text { APLICBI } & 0.04280 & 0.02210 & 1.937 & 0.055919^{* * *} \\ \text { CONDESEMP } & -0.09054 & 0.02187 & -4.140 & 7.88 \mathrm{e}-05^{* * *} \\ \text { CONSULTA } & 0.05820 & 0.02744 & 2.121 & 0.036732^{*} \\ \text { REUTILIZA } & 0.44766 & 0.03056 & 14.650 & <2 \mathrm{e}-16^{* * *} \\ \text { QUALDEC } & -0.49651 & 0.03875 & -12.814 & <2 \mathrm{e}-16^{* * *} \\ \text { TEMPDEC } & 0.27184 & 0.03791 & 7.171 & 2.10 \mathrm{e}-10^{* * *} \\ \text { ESFODEC } & 0.45689 & 0.03628 & 12.593 & <2 \mathrm{e}-16^{* * *} \\ \text { TEMPPRO } & 0.11230 & 0.05536 & 2.029 & 0.045498^{*} \\ \text { MELHPRO } & 0.29237 & 0.04618 & 6.331 & 9.64 \mathrm{e}-09^{* * *} \\ \text { SERVCLI } & 0.32773 & 0.07088 & 4.624 & 1.27 \mathrm{e}-05^{* * *} \\ \text { SATICLI } & -0.45684 & 0.05919 & -7.718 & 1.64 \mathrm{e}-11^{* * *} \\ \text { NECECLI } & 0.15546 & 0.04546 & 3.420 & 0.000948^{* * *} \\ \text { CREDIBIL } & 0.15289 & 0.02084 & 7.338 & 9.70 \mathrm{e}-11^{* * *} \\ \text { FACILIDADE } & 0.07100 & 0.02220 & 3.198 & 0.001917^{* *} \\ \text { REPUTACAO } & -0.05004 & 0.02255 & -2.219 & 0.029053^{*} \\ \text { VALORADI } & -0.10517 & 0.02141 & -4.911 & 4.08 \mathrm{e}-06^{* * *} \\ \text { ANALDADOS } & -0.12541 & 0.03330 & -3.766 & 0.000297^{* * *} \\ \text { RELAVANC } & 0.22203 & 0.05009 & 4.433 & 2.65 \mathrm{e}-05^{* * *} \\ \text { INFOCOMP } & -0.39698 & 0.04743 & -8.370 & 7.52 \mathrm{e}-13^{* * *} \\ \text { BASECONH } & 0.45266 & 0.04719 & 9.592 & 2.23 \mathrm{e}-15^{* * *} \\ \text { OBSOPORT } & -0.50245 & 0.04876 & -10.304 & <2 \mathrm{e}-16^{* * *}\end{array}$


ALINHESTR $\quad-0.16866 \quad 0.03051 \quad-5.528 \quad 3.19 \mathrm{e}-07^{* * *}$

INFOESTRAT $0.14444 \quad 0.04323 \quad 3.341 \quad 0.001220$ **

Signif. codes: $0^{* * * \prime} 0.001^{\prime * * \prime} 0.01^{\prime * \prime} 0.05$ '.' $0.1^{\prime \prime} 1$

Residual standard error: 0.1285 on 89 degrees of freedom Multiple R-squared: 0.9871, Adjusted R-squared: 0.9833

F-statistic: 262.1 on 26 and 89 DF, p-value: $<2.2 \mathrm{e}-16$ 


\subsection{Apêndice IV - Análise da Validade Discriminante do modelo conceitual}

\begin{tabular}{|c|c|c|c|c|c|c|c|c|c|c|c|c|}
\hline $\begin{array}{l}\text { Indicadores / } \\
\text { ariáveis Latentes }\end{array}$ & 岗 & 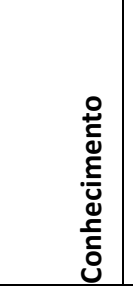 & 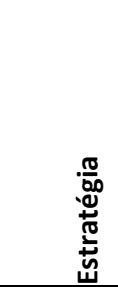 & 气્u & 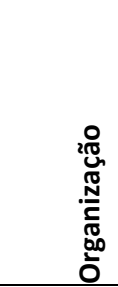 & 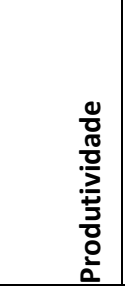 & 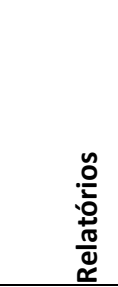 & 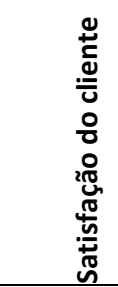 & 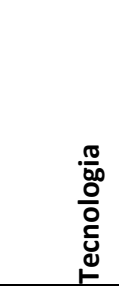 & 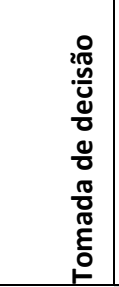 & $\begin{array}{l}\frac{8}{8} \\
\frac{\pi}{0} \\
\frac{0}{0} \\
\frac{0}{\pi} \\
\end{array}$ & $\stackrel{\circ}{n}$ \\
\hline ACESSIBI & 0,4073 & 0,2846 & 0,1148 & 0,1289 & 0,0104 & 0,0662 &, 2783 & 0,4444 & 1542 & ,1693 & 0,726 & 0,2529 \\
\hline CREDIBIL & 0,4459 & 0,4117 & 0,3432 & 0,0644 & 0,0708 & $-0,0431$ & 0,0679 & 0,4922 & 0393 & ,1817 & 0,7639 & 0,4528 \\
\hline FACILIDADE & 0,6145 & 0,3659 & 0,2994 & 0,2046 & 0,2698 & 0,4605 & 0,6443 & 0,3414 & 1215 & ,3192 & 0,7087 & 0,2028 \\
\hline REPUTACAO & 0,2982 & $-0,0467$ & 0,0188 & 0,071 & $-0,0809$ & 0,3004 & 0,4515 & 0,1981 & 0,1295 & 0,0776 & 0,5511 & 0,1356 \\
\hline VALORADI & 0,4073 & 0,5537 & 0,4071 & 0,1283 & 0,0491 & 0,2394 & 0,0011 & 0,2478 & 0,1378 & 0,345 & 0,4292 & 0,2563 \\
\hline CONSULTA & 0,5287 & 0,4632 & 0,3101 & 0,1006 & 0,129 & 0,3379 & 0,2575 & 0,5737 & 0,0534 & 0,4764 & 0,3712 & 0,9369 \\
\hline ECOMENDA & 0,3518 & 0,2347 & $-0,0288$ & 0,1834 & 0,0064 & 0,1192 & 0,1293 & 0,5561 & 0,2232 & 3986 & 0,4199 & 0,7793 \\
\hline REUTILIZA & 0,4426 & 0,4352 & 0,3999 & 0,0608 & 0,0917 & 0,2773 & 0,1904 & 0,3609 & 0,023 & 0,4392 & 0,2729 & 0,8434 \\
\hline ESFODEC & 0,4893 & 0,5004 & 0,3986 & 0,3486 & 0,3191 & 0,2132 & $-0,0278$ & 0,5058 & 0,2737 & ,7997 & 0,2463 & 0,5503 \\
\hline QUALDEC & 0,7057 & 0,6772 & 0,5896 & 0,295 & 0,2722 & 0,5479 & 0,2638 & 0,5681 & 0,2319 & 0,8782 & 0,3178 & 0,3876 \\
\hline TEMPDEC & 0,6124 & 0,4596 & 0,2791 & 0,3544 & 0,1281 & 0,7622 & 0,7129 & 0,1625 & 0,3881 & 0,6972 & 0,2855 & 0,3188 \\
\hline LICBI & 0,0579 & 0,0308 & $-0,1604$ & 0,5428 & 0,1193 & 0,0174 & 0,0078 & 0,046 & 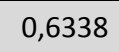 & 2142 & 0,2102 & 0,3262 \\
\hline CONDESEMP & 0,2548 & 0,0945 & 0,0956 & 0,8284 & 0,4141 & 0,3455 & 0,2784 & 0,0585 & 0,8451 & 0,3757 & 0,1533 & $-0,0028$ \\
\hline ESTRUT & 0,3989 & 0,2919 & 0,0119 & 0,6133 & 0,1401 & 0,4756 & 0,3974 & 0,2794 & 7088 &, 524 & 0,2319 & 0,0932 \\
\hline GERQUAL & $-0,0163$ & 0,0783 & $-0,0236$ & 0,5664 & 0,2455 & $-0,1921$ & $-0,2769$ & 0,1088 & 0,5953 & 0,1453 & 0,1019 & 0,215 \\
\hline TECFERR & $-0,0509$ & $-0,1688$ & $-0,2813$ & 0,715 & 0,3052 & 0,2386 & 0,1546 & $-0,1885$ & 0,7653 & 0,0678 & $-0,0319$ & $-0,1551$ \\
\hline NECECLI & 0,672 & 0,5212 & 0,46 & 0,0663 & 0,0821 & 0,256 & 0,2947 & 0,9263 & 0319 & 4969 & 0,5394 & 4803 \\
\hline SATICLI & 0,7293 & 0,6314 & 0,4532 & 0,0682 & 0,0471 & 0,357 & 0,3695 & 0,9604 & 0,0518 & 0,5158 & 0,5476 & 0,6126 \\
\hline SERVCLI & 0,5832 & 0,4173 & 0,1575 & 0,0821 & $-0,0751$ & 0,3511 & 0,3436 & 0,9393 & 0,1315 & 0,4507 & 0,4451 & 0,5307 \\
\hline ANALDADOS & 0,5398 & 0,3489 & 0,2843 & 0,0751 & $-0,0441$ & 0,6734 & 0,8425 & 0,1623 & 0,1192 & 0,3428 & 0,2751 & $-0,0338$ \\
\hline RELAVANC & 0,6403 & 0,3244 & 0,3043 & 0,1093 & 0,0093 & 0,789 & 0,8875 & 0,3812 & 0,1322 & ,2828 & 0,4285 & 0,2182 \\
\hline RELVISAO & 0,7752 & 0,5944 & 0,4533 & 0,1714 & $-0,0056$ & 0,7682 & 0,932 & 0,3761 & 0,2196 & 0,4816 &, 5312 & 0,3669 \\
\hline SREC & 0,4896 & 0,1945 & 0,258 & & & 0,7825 & 7704 & 0,1649 & & 0,301 & 732 & 1896 \\
\hline MELHPRO & 0,8173 & 0,7127 & 0,54 & 0,2549 & 0,0545 & 0,8878 & 0,65 & 0,4453 & 0,2963 & 0,7772 & 0,4375 & 0,3088 \\
\hline TEMPPRO & 0,6115 & 0,4602 & 0,2403 & 0,2371 & 0,078 & 0,9214 & 0,808 & 0,2043 & 0,2639 & 0,5415 & 0,2025 & 0,256 \\
\hline GESCOMP & 0,1552 & 0,092 & 731 & 0,5227 & 0,7957 & 026 & $-0,1839$ & 0,28 & 88 & 2894 & 05 & 1951 \\
\hline GOVINF & $-0,0647$ & $-0,2197$ & $-0,0706$ & 0,3029 & 0,6108 & $-0,0691$ & 0,0044 & 0,013 & 0,0676 & $-0,1383$ & 0,0492 & 0,2623 \\
\hline PARCEIRA & 0,1658 & 0,1346 & 0,1703 & 0,5841 & 0,7369 & 0,2324 & 0,1399 & $-0,2142$ & 0,3764 & 3365 & 0959 & $-0,1395$ \\
\hline ALINHESTR & 0,7115 & 0,6479 & 0,844 & $-0,0205$ & 0,1488 & 0,5081 & 524 & 0,4016 & $-0,1068$ & 3791 & 0,3532 & 0,223 \\
\hline INFOESTRAT & 0,5799 & 0,6826 & 0,8564 & $-0,1157$ & 0,0395 & 0,1629 & 0,1327 & 0,4405 & $-0,1729$ & 0,4714 & 0,304 & 0,1574 \\
\hline INFRISCO & 0,5368 & 0,6662 & 0,8558 & $-0,0377$ & 0,1185 & 0,0408 & 0,0581 & 0,3692 & $-0,1145$ & 0,4018 & 0,382 & 0,3587 \\
\hline OBSOPORT & 0,678 & 0,6343 & 0,8401 & 0,1438 & 0,2287 & 0,6352 & 0,5073 & 0,1356 & 0,0651 & 0,5862 & 0,3009 & 0,2524 \\
\hline ASECONH & 0,7917 & 0,9187 & 0,792 & נ, 0, & 0,0131 & 0,3617 & $0,315 /$ & 0,6244 & 0,0313 & 0,6035 & 0,56 & 0,5321 \\
\hline INFOCOMP & 0,7951 & 0,9194 & 0,6301 & 0,111 & 0,0343 & 0,692 & 0,5859 & 0,4118 & 0,1222 & 0,68 & 0,3992 & 0,3043 \\
\hline
\end{tabular}




\subsection{Apêndice V - Análise da Validade Discriminante do modelo ajustado}

\begin{tabular}{|c|c|c|c|c|c|c|c|c|c|c|c|}
\hline $\begin{array}{c}\text { Indicadores / } \\
\text { Variáveis Latentes }\end{array}$ & 岗 & 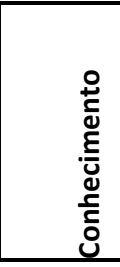 & 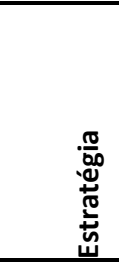 & 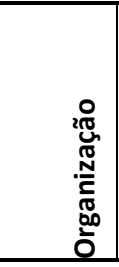 & 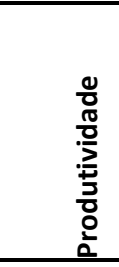 & 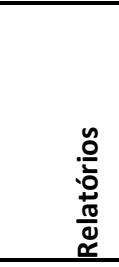 & 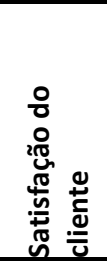 & 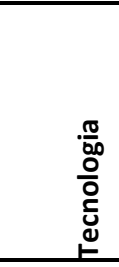 & 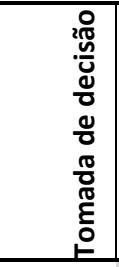 & $\begin{array}{l}\frac{0}{0} \\
\frac{\pi}{0} \\
\frac{0}{0} \\
\frac{0}{0} \\
\\
\end{array}$ & ڤ̆ \\
\hline ACESSIBI & 0,4052 & 0,2846 & 0,1152 & 0,0142 & 0,0664 & 0,2784 & 0,4384 & 0,1521 & 0,1694 & 0,7258 & 0,1947 \\
\hline CREDIBIL & 0,4482 & 0,4121 & 0,3438 & 0,1063 & $-0,0424$ & 0,068 & 0,5357 & 0,1949 & 0,1825 & 0,7662 & 0,3924 \\
\hline FACILIDADE & 0,6102 & 0,3659 & 0,2987 & 0,1616 & 0,4604 & 0,6444 & 0,3653 & $-0,0877$ & 0,318 & 0,7057 & 0,1507 \\
\hline REPUTACAO & 0,2932 & $-0,0466$ & 0,0183 & 0,0264 & 0,3003 & 0,4514 & 0,1733 & 0,0841 & 0,0768 & 0,5479 & 0,0938 \\
\hline VALORADI & 0,4115 & 0,5538 & 0,4075 & $-0,0516$ & 0,2403 & 0,0012 & 0,2694 & 0,3341 & 0,3458 & 0,4335 & 0,3031 \\
\hline CONSULTA & 0,5280 & 0,4635 & 0,3100 & 0,3052 & 0,3380 & 0,2576 & 0,5828 & 0,2323 & 0,4765 & 0,3722 & 0,9352 \\
\hline REUTILIZA & 0,4443 & 0,4353 & 0,4001 & 0,2194 & 0,2773 & 0,1906 & 0,3780 & 0,2537 & 0,4396 & 0,2746 & 0,9091 \\
\hline ESFODEC & 0,4905 & 0,5007 & 0,3991 & 0,1606 & 0,214 & $-0,0276$ & 0,5158 & 0,2647 & 0,801 & 0,2482 & 0,4746 \\
\hline QUALDEC & 0,7075 & 0,6772 & 0,5897 & 0,0374 & 0,5488 & 0,2639 & 0,5955 & 0,1584 & 0,8794 & 0,3195 & 0,4267 \\
\hline TEMPDEC & 0,6074 & 0,4592 & 0,2783 & $-0,0845$ & 0,7622 & 0,713 & 0,1479 & 0,0863 & 0,6949 & 0,2838 & 0,2975 \\
\hline APLICBI & 0,0553 & 0,0310 & $-0,1602$ & 0,0169 & 0,0176 & 0,0079 & 0,0274 & 0,9300 & 0,2140 & 0,2108 & 0,2664 \\
\hline GERQUAL & $-0,0148$ & 0,0786 & $-0,0230$ & 0,2255 & $-0,1916$ & $-0,2768$ & 0,1194 & 0,8684 & 0,1461 & 0,1043 & 0,1974 \\
\hline NECECLI & 0,6725 & 0,5216 & 0,4603 & 0,138 & 0,2566 & 0,2948 & 0,9509 & 0,0626 & 0,4982 & 0,5398 & 0,4238 \\
\hline SATICLI & 0,7292 & 0,6317 & 0,4535 & 0,1506 & 0,3575 & 0,3696 & 0,9584 & 0,0774 & 0,5164 & 0,5486 & 0,5807 \\
\hline ANALDADOS & 0,536 & 0,3483 & 0,2834 & $-0,1991$ & 0,6729 & 0,8425 & 0,1542 & $-0,1656$ & 0,3412 & 0,2725 & 0,0012 \\
\hline RELAVANC & 0,6353 & 0,3242 & 0,303 & 0,0571 & 0,7886 & 0,8873 & 0,3607 & $-0,1747$ & 0,2811 & 0,4257 & 0,2191 \\
\hline RELVISAO & 0,7719 & 0,5941 & 0,4524 & $-0,0921$ & 0,7681 & 0,9322 & 0,3816 & $-0,023$ & 0,4798 & 0,5294 & 0,3711 \\
\hline GESREC & 0,4848 & 0,1941 & 0,2565 & 0,1563 & 0,7816 & 0,7702 & 0,1405 & $-0,2222$ & 0,2994 & 0,1705 & 0,2383 \\
\hline MELHPRO & 0,8158 & 0,7125 & 0,5394 & $-0,1534$ & 0,8885 & 0,6501 & 0,4393 & 0,0261 & 0,7766 & 0,4381 & 0,3153 \\
\hline TEMPPRO & 0,6066 & 0,4596 & 0,2390 & $-0,0841$ & 0,9210 & 0,8080 & 0,1840 & $-0,0743$ & 0,5400 & 0,2011 & 0,3060 \\
\hline GESCOMP & 0,1566 & 0,0923 & 0,1733 & 0,793 & $-0,0257$ & $-0,1839$ & 0,3131 & 0,2085 & 0,2908 & 0,1417 & 0,1908 \\
\hline GOVINF & $-0,0664$ & $-0,2196$ & $-0,0709$ & 0,9151 & $-0,0699$ & 0,0043 & 0,0108 & 0,0304 & $-0,1385$ & 0,048 & 0,2882 \\
\hline ALINHESTR & 0,7157 & 0,648 & 0,8433 & 0,0824 & 0,5082 & 0,5624 & 0,4709 & $-0,2606$ & 0,3788 & 0,3535 & 0,2779 \\
\hline INFOESTRAT & 0,5876 & 0,6829 & 0,857 & $-0,0609$ & 0,1639 & 0,1328 & 0,5092 & $-0,0596$ & 0,4727 & 0,306 & 0,2095 \\
\hline INFRISCO & 0,5455 & 0,6666 & 0,8566 & 0,0362 & 0,0416 & 0,0584 & 0,463 & 0,0475 & 0,4029 & 0,385 & 0,4264 \\
\hline OBSOPORT & 0,6824 & 0,6342 & 0,8396 & 0,0328 & 0,6354 & 0,5073 & 0,2029 & $-0,0676$ & 0,5861 & 0,3017 & 0,3851 \\
\hline BASECONH & 0,7969 & 0,9191 & 0,7923 & $-0,0194$ & 0,3626 & 0,3159 & 0,6836 & 0,1408 & 0,6043 & 0,5627 & 0,5335 \\
\hline INFOCOMP & 0,7965 & 0,919 & 0,6298 & $-0,183$ & 0,6925 & 0,5861 & 0,4308 & $-0,0367$ & 0,6794 & 0,4007 & 0,3636 \\
\hline
\end{tabular}


9.6 Apêndice VI - Análise de Multicolinearidade do modelo ajustado

\begin{tabular}{|l|r|}
\hline \multicolumn{1}{|c|}{ Variável } & \multicolumn{1}{c|}{ *VIF } \\
\hline GESCOMP & 3,57 \\
GOVINF & 3,44 \\
GERQUAL & 2,41 \\
APLICBI & 3,36 \\
CONSULTA & 7,06 \\
REUTILIZA & 7,86 \\
QUALDEC & 12,67 \\
TEMPDEC & 7,63 \\
ESFODEC & 8,34 \\
TEMPPRO & 22,4 \\
MELHPRO & 14,89 \\
GESREC & 22,34 \\
SATICLI & 11,47 \\
NECECLI & 13,99 \\
CREDIBIL & 9,16 \\
ACESSIBI & 6,02 \\
FACILIDADE & 2,52 \\
REPUTACAO & 3,51 \\
VALORADI & 3,69 \\
RELVISAO & 12,77 \\
ANALDADOS & 7,15 \\
RELAVANC & 27,02 \\
INFOCOMP & 15,62 \\
BASECONH & 21,94 \\
OBSOPORT & 16,91 \\
ALINHESTRAT & 10,66 \\
INFOESTRAT & 13,29 \\
INFRISCO & 10,54 \\
\hline FatOI de Inflaça & $d a$ \\
\hline
\end{tabular}

*VIF - Fator de inflação da variância 
9.7 Apêndice VII - Scores fatoriais dos indicadores das VL do modelo ajustado

\begin{tabular}{|c|c|c|c|}
\hline & $\begin{array}{l}\text { VL } \\
\end{array}$ & Indicador & \\
\hline \multirow{22}{*}{$\begin{array}{l}\text { Benefícios } \\
\text { Esperados } \\
\text { (BE) }\end{array}$} & \multirow[t]{3}{*}{ Tomada de decisão } & ESFODEC & 0,801 \\
\hline & & QUALDEC & 0,8794 \\
\hline & & TEMPDEC & 0,6949 \\
\hline & \multirow[t]{3}{*}{ Produtividade } & GESREC & 0,7816 \\
\hline & & MELHPRO & 0,8885 \\
\hline & & TEMPPRO & 0,921 \\
\hline & \multirow[t]{2}{*}{$\begin{array}{l}\text { Satisfação do } \\
\text { cliente }\end{array}$} & NECECLI & 0,9509 \\
\hline & & SATICLI & 0,9584 \\
\hline & \multirow[t]{4}{*}{ Estratégia } & ALINHESTR & 0,8433 \\
\hline & & INFOESTRAT & 0,857 \\
\hline & & INFRISCO & 0,8566 \\
\hline & & OBSOPORT & 0,8396 \\
\hline & \multirow[t]{2}{*}{ Conhecimento } & BASECONH & 0,9191 \\
\hline & & INFOCOMP & 0,919 \\
\hline & \multirow[t]{3}{*}{ Relatórios } & ANALDADOS & 0,8425 \\
\hline & & RELAVANC & 0,8873 \\
\hline & & RELVISAO & 0,9322 \\
\hline & \multirow[t]{5}{*}{ Usabilidade } & ACESSIBI & 0,7258 \\
\hline & & CREDIBIL & 0,7662 \\
\hline & & FACILIDADE & 0,7057 \\
\hline & & REPUTACAO & 0,5479 \\
\hline & & VALORADI & 0,4335 \\
\hline \multirow{6}{*}{$\begin{array}{l}\text { Fatores } \\
\text { Críticos de } \\
\text { Sucesso } \\
\text { (FCS) }\end{array}$} & \multirow[t]{2}{*}{ Tecnologia } & APLICBI & 0,93 \\
\hline & & GERQUAL & 0,8684 \\
\hline & \multirow[t]{2}{*}{ Organização } & GESCOMP & 0,793 \\
\hline & & GOVINF & 0,9151 \\
\hline & \multirow[t]{2}{*}{ Uso } & CONSULTA & 0,9352 \\
\hline & & REUTILIZA & 0,9091 \\
\hline
\end{tabular}


9.8 Apêndice VIII - Scores fatoriais dos indicadores das VL do modelo alternativo

\begin{tabular}{|c|c|c|c|}
\hline & VL & Indicador & \\
\hline $\begin{array}{l}\text { Benefícios } \\
\text { Esperados } \\
\text { (BE) }\end{array}$ & $\begin{array}{l}\text { Tomada de decisão } \\
\text { Produtividade } \\
\text { Satisfação do cliente } \\
\text { Estratégia } \\
\text { Conhecimento } \\
\text { Relatórios } \\
\text { Usabilidade }\end{array}$ & $\begin{array}{r}\text { ESFODEC } \\
\text { QUALDEC } \\
\text { TEMPDEC } \\
\text { GESREC } \\
\text { MELHPRO } \\
\text { TEMPPRO } \\
\text { NECECLI } \\
\text { SATICLI } \\
\text { ALINHESTR } \\
\text { INFOESTRAT } \\
\text { INFRISCO } \\
\text { OBSOPORT } \\
\text { BASECONH } \\
\text { INFOCOMP } \\
\text { ANALDADOS } \\
\text { RELAVANC } \\
\text { RELVISAO } \\
\text { ACESSIBI } \\
\text { CREDIBIL } \\
\text { FACILIDADE } \\
\text { REPUTACAO } \\
\text { VALORADI }\end{array}$ & $\begin{array}{l}0,8773 \\
0,8851 \\
0,6007 \\
0,8056 \\
0,8621 \\
0,9332 \\
0,9392 \\
0,9680 \\
0,8054 \\
0,8415 \\
0,8921 \\
0,8498 \\
0,9491 \\
0,8840 \\
0,7085 \\
0,8952 \\
0,9642 \\
0,6808 \\
0,8830 \\
0,3436 \\
0,3376 \\
0,6741\end{array}$ \\
\hline $\begin{array}{l}\text { Fatores } \\
\text { Críticos de } \\
\text { Sucesso } \\
\text { (FCS) }\end{array}$ & $\begin{array}{l}\text { Tecnologia } \\
\text { Organização } \\
\text { Uso }\end{array}$ & $\begin{array}{r}\text { APLICBI } \\
\text { GERQUAL } \\
\text { GESCOMP } \\
\text { GOVINF } \\
\text { CONSULTA } \\
\text { REUTILIZA }\end{array}$ & $\begin{array}{l}0,8795 \\
0,9214 \\
0,8856 \\
0,8326 \\
0,9373 \\
0,9066\end{array}$ \\
\hline
\end{tabular}




\subsection{Apêndice IX - Análise da Validade Discriminante do modelo alternativo}

\begin{tabular}{|c|c|c|c|c|c|c|c|c|c|c|}
\hline $\begin{array}{c}\text { Indicadores / } \\
\text { Variáveis Latentes }\end{array}$ & 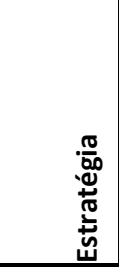 & ড & 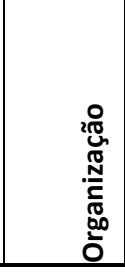 & 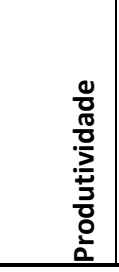 & 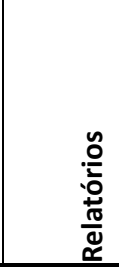 & 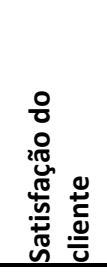 & 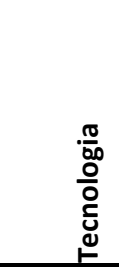 & 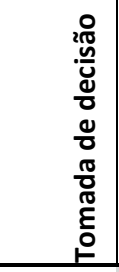 & $\begin{array}{l}\frac{0}{0} \\
\frac{\pi}{0} \\
\frac{0}{0} \\
\frac{0}{\pi} \\
\\
\end{array}$ & $\stackrel{\circ}{\stackrel{M}{S}}$ \\
\hline ACESSIBI & 0,1328 & 0,2873 & 0,0101 & 0,0591 & 0,2951 & 0,4396 & 0,1467 & 0,1695 & 0,6808 & 0,1948 \\
\hline CREDIBIL & 0,3685 & 0,448 & 0,1444 & $-0,0651$ & 0,143 & 0,5328 & 0,2089 & 0,2224 & 0,883 & 0,3929 \\
\hline FACILIDADE & 0,2695 & 0,3627 & 0,1508 & 0,4632 & 0,6554 & 0,3639 & $-0,1186$ & 0,2686 & 0,3436 & 0,1525 \\
\hline REPUTACAO & 0,0074 & $-0,0409$ & 0,0006 & 0,3004 & 0,4584 & 0,1685 & 0,0507 & 0,0308 & 0,3376 & 0,0939 \\
\hline VALORADI & 0,4295 & 0,564 & 0,0015 & 0,2086 & 0,0426 & 0,2765 & 0,3444 & 0,361 & 0,6741 & 0,3021 \\
\hline CONSULTA & 0,3171 & 0,4844 & 0,3001 & 0,3338 & 0,3443 & 0,5907 & 0,224 & 0,4835 & 0,3848 & 0,9373 \\
\hline REUTILIZA & 0,4451 & 0,4427 & 0,1956 & 0,2772 & 0,2672 & 0,3865 & 0,2451 & 0,4552 & 0,3741 & 0,9066 \\
\hline ESFODEC & 0,4178 & 0,5187 & 0,2395 & 0,189 & $-0,0019$ & 0,5113 & 0,2728 & 0,8773 & 0,3295 & 0,4746 \\
\hline QUALDEC & 0,5871 & 0,6769 & 0,135 & 0,5209 & 0,2673 & 0,5912 & 0,1663 & 0,8851 & 0,3708 & 0,4264 \\
\hline TEMPDEC & 0,2638 & 0,4211 & $-0,0897$ & 0,7608 & 0,7131 & 0,1577 & 0,049 & 0,6007 & 0,0915 & 0,2982 \\
\hline APLICBI & $-0,1347$ & 0,0432 & 0,0316 & 0,0123 & 0,0377 & 0,029 & 0,8795 & 0,2166 & 0,257 & 0,2662 \\
\hline GERQUAL & 0,0072 & 0,1005 & 0,2711 & $-0,2076$ & $-0,2314$ & 0,1189 & 0,9214 & 0,1854 & 0,283 & 0,1973 \\
\hline NECECLI & 0,4392 & 0,5497 & 0,1989 & 0,2386 & 0,3142 & 0,9392 & 0,0772 & 0,5364 & 0,5124 & 0,4253 \\
\hline SATICLI & 0,4455 & 0,6499 & 0,1899 & 0,3394 & 0,4408 & 0,968 & 0,0875 & 0,5293 & 0,5491 & 0,5821 \\
\hline ANALDADOS & 0,2479 & 0,3047 & $-0,2329$ & 0,6894 & 0,7085 & 0,1499 & $-0,2026$ & 0,2552 & 0,0391 & 0,001 \\
\hline RELAVANC & 0,2551 & 0,3103 & 0,0224 & 0,7981 & 0,8952 & 0,367 & $-0,2071$ & 0,1867 & 0,1629 & 0,2207 \\
\hline RELVISAO & 0,4391 & 0,5695 & $-0,1126$ & 0,771 & 0,9642 & 0,3887 & $-0,0596$ & 0,3901 & 0,3138 & 0,3709 \\
\hline GESREC & 0,2221 & 0,1645 & 0,0988 & 0,8056 & 0,7411 & 0,1482 & $-0,2553$ & 0,2193 & $-0,0739$ & 0,2385 \\
\hline MELHPRO & 0,5183 & 0,6939 & $-0,0966$ & 0,8621 & 0,6735 & 0,4441 & 0,0131 & 0,7168 & 0,3924 & 0,3159 \\
\hline TEMPPRO & 0,2096 & 0,4097 & $-0,0951$ & 0,9332 & 0,7677 & 0,1872 & $-0,1099$ & 0,4464 & 0,0322 & 0,3061 \\
\hline GESCOMP & 0,1755 & 0,1169 & 0,8856 & $-0,0374$ & $-0,1311$ & 0,3088 & 0,2485 & 0,3417 & 0,1801 & 0,1918 \\
\hline GOVINF & $-0,0665$ & $-0,211$ & 0,8326 & $-0,0461$ & 0,0304 & 0,0145 & 0,0457 & $-0,1271$ & $-0,0498$ & 0,2884 \\
\hline ALINHESTR & 0,8054 & 0,6519 & 0,0987 & 0,5034 & 0,5758 & 0,4681 & $-0,2495$ & 0,3498 & 0,2712 & 0,2784 \\
\hline INFOESTRAT & 0,8415 & 0,709 & 0,005 & 0,1322 & 0,1374 & 0,5045 & $-0,0323$ & 0,4946 & 0,3797 & 0,2093 \\
\hline INFRISCO & 0,8921 & 0,6952 & 0,082 & 0,0153 & 0,1181 & 0,4637 & 0,0774 & 0,4426 & 0,5318 & 0,4246 \\
\hline OBSOPORT & 0,8498 & 0,6295 & 0,0528 & 0,6243 & 0,5133 & 0,2064 & $-0,0674$ & 0,5478 & 0,2861 & 0,3836 \\
\hline BASECONH & 0,7929 & 0,9481 & 0,043 & 0,3316 & 0,3851 & 0,6862 & 0,1536 & 0,6231 & 0,6436 & 0,5341 \\
\hline INFOCOMP & 0,6203 & 0,884 & $-0,1495$ & 0,6782 & 0,5813 & 0,4392 & $-0,0372$ & 0,6301 & 0,3966 & 0,3632 \\
\hline
\end{tabular}




\subsection{Apêndice $X$ - Avaliação do modelo alternativo}

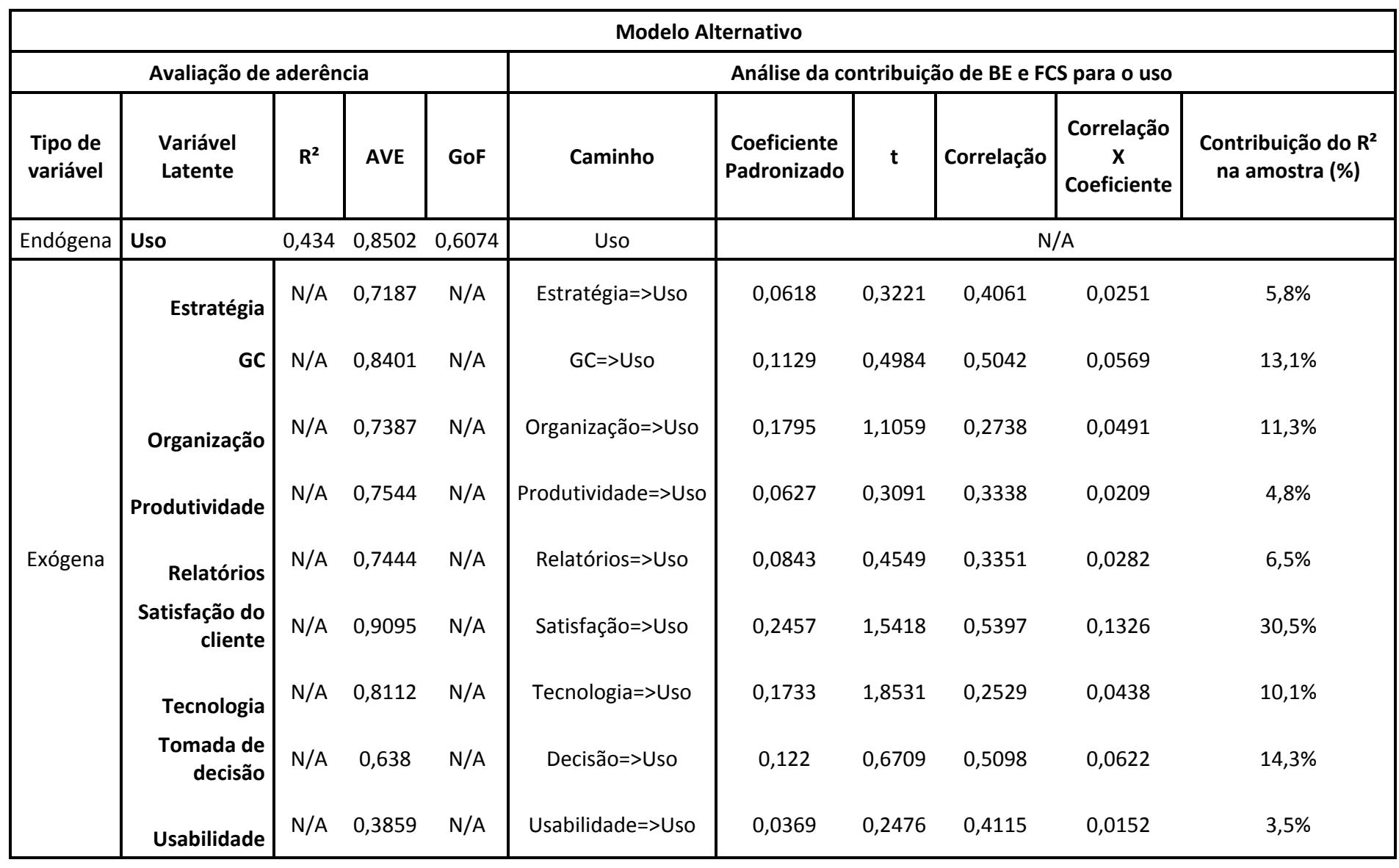

